UNIVERSIDADE DE SÃO PAULO

CENTRO DE ENERGIA NUCLEAR NA AGRICULTURA

MARIA ALICE PENNA FIRME DOS SANTOS

Avaliação da qualidade da água e sedimento da sub-bacia do rio Corumbataí (SP) por meio de testes ecotoxicológicos 
MARIA ALICE PENNA FIRME DOS SANTOS

\section{Avaliação da qualidade da água e sedimento da sub-bacia do rio Corumbataí (SP) por meio de testes ecotoxicológicos}

Tese apresentada ao Centro de Energia Nuclear na Agricultura da Universidade de São Paulo para obtenção do título de doutor em Ciências

Área de concentração: Química na Agricultura e no Ambiente Orientadora: Profa. Dra. Regina Teresa Rosim Monteiro 
AUTORIZO A REPRODUÇÃO TOTAL OU PARCIAL DESTE TRABALHO, POR QUALQUER MEIO CONVENCIONAL OU ELETRÔNICO, PARA FINS DE ESTUDO E PESQUISA, DESDE QUE CITADA A FONTE

Dados Internacionais de Catalogação na Publicação (CIP)

Seção Técnica de Biblioteca - CENA/USP

Santos, Maria Alice Penna Firme dos

Avaliação da qualidade da água e sedimento da sub-bacia do Rio Corumbataí (SP) por meio de testes ecotoxicológicos / Maria Alice Penna Firme dos Santos; orientadora Regina Teresa Rosim Monteiro. - Piracicaba, 2008.

186 f. : fig.

Tese (Doutorado - Programa de Pós-Graduação em Ciências. Área de Concentração: Química na Agricultura e no Ambiente) Centro de Energia Nuclear na Agricultura da Universidade de São Paulo.

1. Bacia hidrográfica 2. Ecotoxicologia 3. Sedimentologia fluvial I. Título

CDU 556.51:628.16 
DEDICATÓRIA

A todos os Mestres da Senda. 


\section{AGRADECIMENTOS}

Aos meus pais e à minha irmã que fornecem todos os alicerces para minha vida.

À professora Dra. Regina Teresa Rosim Monteiro, pela orientação e pelos ensinamentos sobre Ecologia e Ecotoxicologia.

Aos professores Dr. Plínio Camargo, Dra. Odete Rocha e Dra. Maria Aparecida Marin Morales, pelas excelentes sugestões e contribuições quando do Exame de Qualificação.

Aos funcionários do CENA, pela colaboração em meu trabalho.

Ao PPG em Ciências do CENA, pelo suporte e colaboração no desenvolvimento deste trabalho.

À Profa. Dra. Maria Aparecida Marin Morales, e à MSc. Daniela Morais Leme, ambas do Laboratório de Mutagênese da UNESP de Rio Claro, pelo auxílio com os testes de genotoxicidade.

Ao pessoal do Laboratório de Parasitologia da Unicamp, pelo auxílio nas leituras em microscópio óptico.

À colega Milena Falqueto, por gentilmente ceder as determinações dos elementos químicos para análise e complementação estatística.

Ao Prof. Dr. Plínio Camargo, pelas análises de DBO e pelo auxílio nas coletas.

Ao SEMAE, pelas análises das amostras de água coletadas.

À FAPESP, pelo financiamento do projeto de Políticas Públicas, ao qual está inserido o presente projeto.

Ao CNPq e CT-Hidro, pela concessão da bolsa de doutorado.

À CAPES, pela concessão da bolsa-sanduíche, que me permitiu desenvolver uma parte do doutorado em Montréal, Canadá.

Ao Dr. Christian Blaise, responsável pelo Laboratório de Ecossistemas Fluviais, do Saint Lawrence Centre, e aos funcionários do Environment Canada, do Saint Lawrence Centre: Kimberly Bull, Mélanie Douville, François Gagné, Sophie Trepanier, Bertrand Bourchard, por toda orientação dada durante meu período de estágio.

Ao prof. Dr. Christian Blaise, François Gagné, e Fernanda Massaro, pelo auxílio nas análises estatísticas.

Aos colegas de laboratório Jussara, Priscila Dellamatrice, Eduardo, Paula, Priscila Favoretto, Maria Júlia, Tâmara, Vivian, Luís Fernando, Laíse, Milena, Gláucia, Mário, que sempre que possível me ajudaram.

Aos amigos Danilo, Satya, Kil, Anand, Nando, Mário, Lilian, Milena, João e Carolina. 
"Vosso caminhar deve ser cada vez mais suave, de modo que vossas pegadas não mais fiquem marcadas na terra; somente assim podereis um dia chegar a viajar nas alturas. Enquanto quiserdes deixar vossos passos impressos no solo, não ingressareis na vida imaterial."

As Chaves de Ouro 


\section{SUMÁRIO}

Resumo 11

Abstract 12

1 Introdução 13

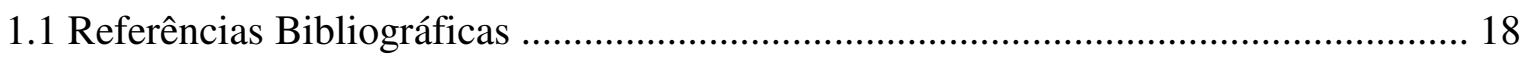

2 Avaliação da qualidade da água e sedimento da sub-bacia do rio Corumbataí (SP) por

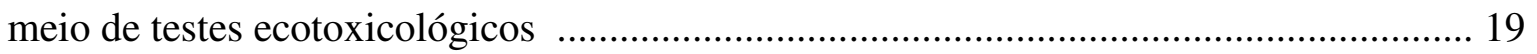

Resumo 19

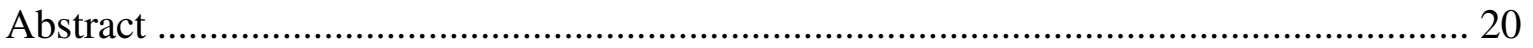

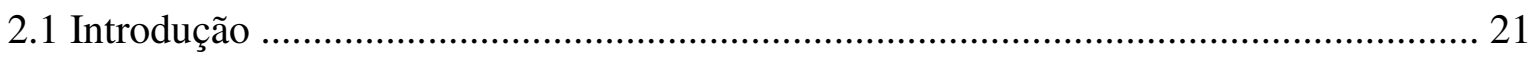

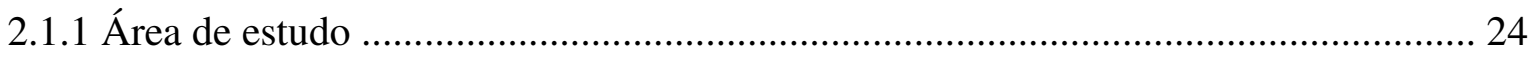

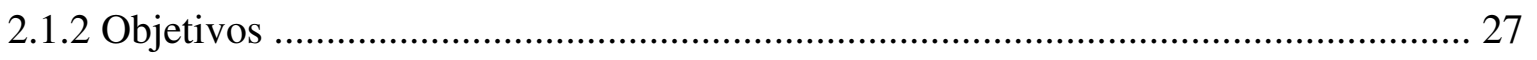

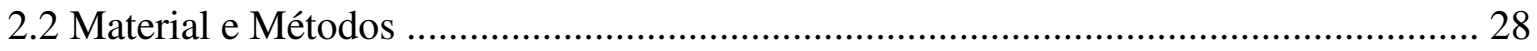

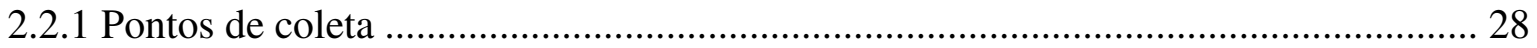

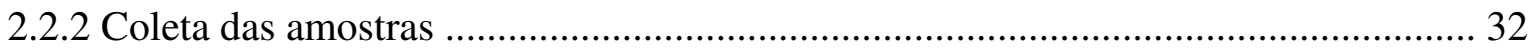

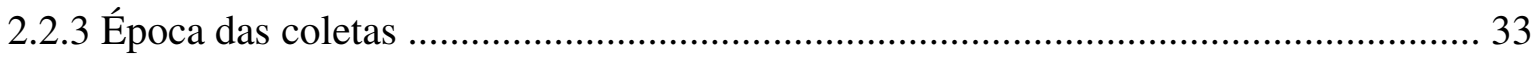

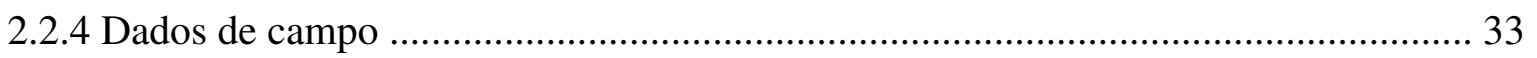

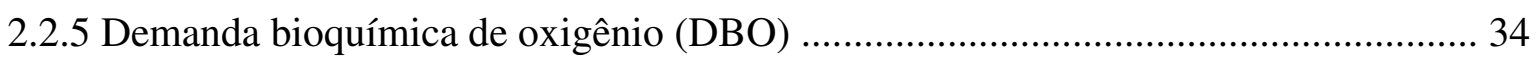

2.2.6 Determinação de nutrientes, clorofila-a, sólidos totais, turbidez e fluoretos ............. 34

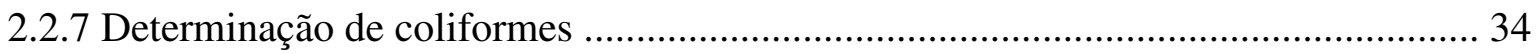

2.2.8 Manutenção das culturas dos organismos-teste ........................................................ 35

2.2.8.1 Água reconstituída para cultivo e teste de Chironomus xanthus ........................... 35

2.2.8.2 Água reconstituída para cultivo e teste de Daphnia magna ................................... 36

2.2.8.3 Água reconstituída para cultivo e teste de Hydra attenuata .................................. 37

2.2.8.4 Meio de cultivo para Pseudokirchneriella subcapitata .......................................... 37

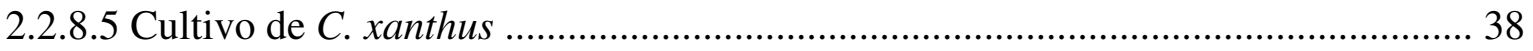

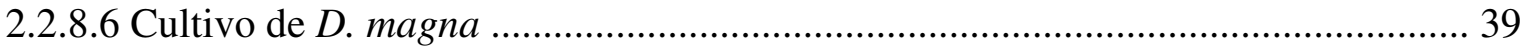

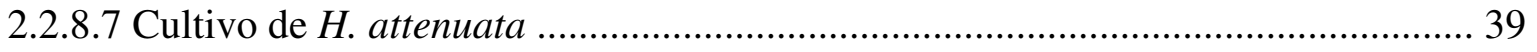

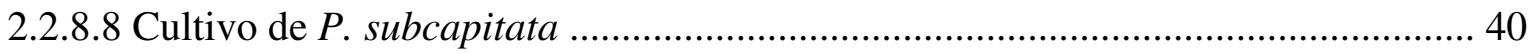

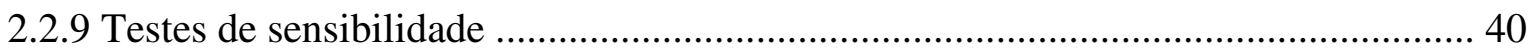

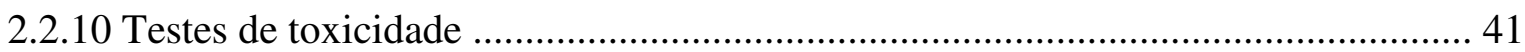

2.2.10.1 Testes de toxicidade aguda com Chironomus xanthus ........................................ 42

2.2.10.2 Testes de toxicidade aguda com Daphnia magna ............................................ 43 
2.2.10.3 Testes de toxicidade com Hydra attenuata ........................................................ 43

2.2.10.4 Testes de toxicidade com Lactuca sativa .......................................................... 45

2.2.10.5 Testes de toxicidade com Pseudokirchneriella subcapitata .............................. 46

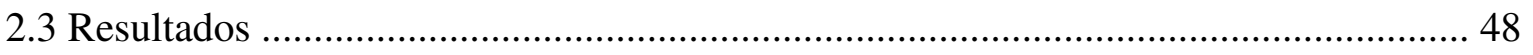

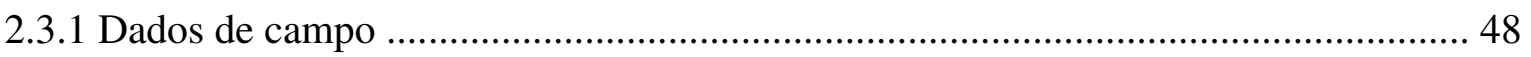

2.3.2 Demanda Bioquímica de Oxigênio (DBO) ........................................................... 49

2.3.3 Determinações de nutrientes, clorofila-a, sólidos totais, turbidez e fluoretos ........... 49

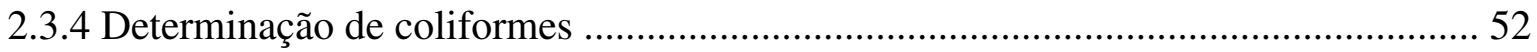

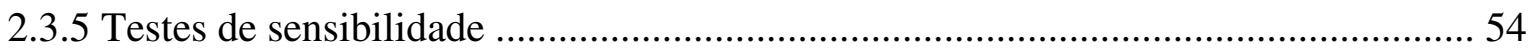

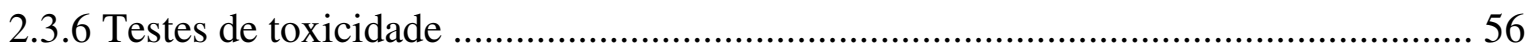

2.3.6.1 Testes de toxicidade com Chironomus xanthus .................................................... 56

2.3.6.2 Testes de toxicidade aguda com Daphnia magna ............................................... 57

2.3.6.3 Testes de toxicidade com Hydra attenuata ......................................................... 58

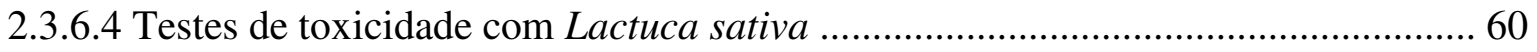

2.3.6.5 Testes de toxicidade com Pseudokirchneriella subcapitata ................................. 61

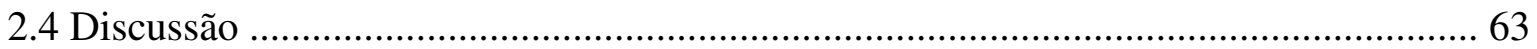

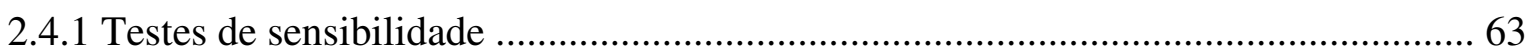

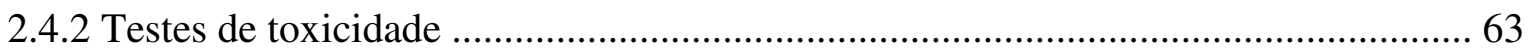

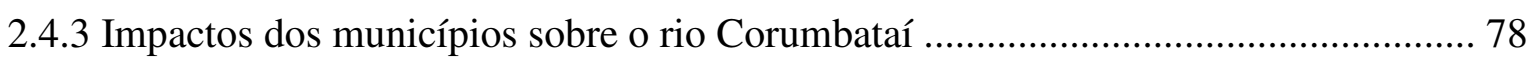

2.4.4 Sensibilidade e respostas dos organismos-teste utilizados ...................................... 82

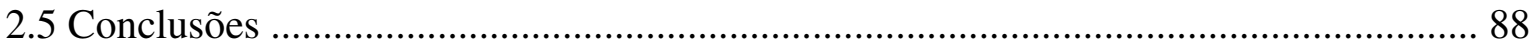

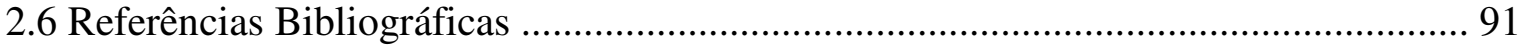

3 Bioensaios complementares para avaliação da qualidade da água e sedimento da sub-

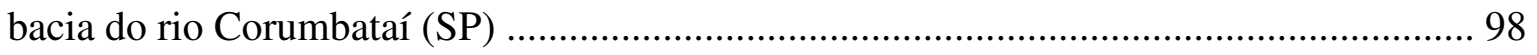

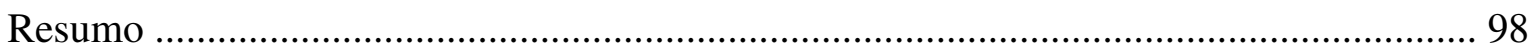

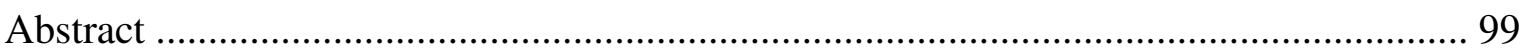

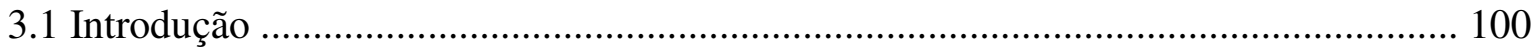

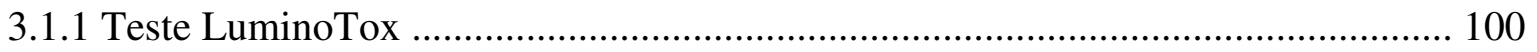

3.1.2 Teste de genotoxicidade com Allium cepa .......................................................... 100

3.1.3 Teste de toxicidade crônica com Daphnia magna .................................................. 102

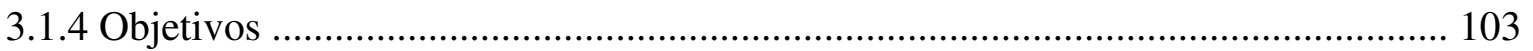

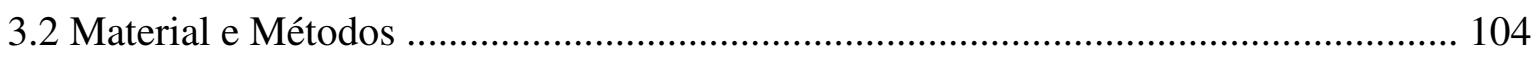

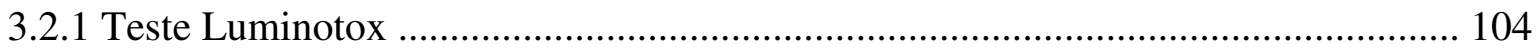

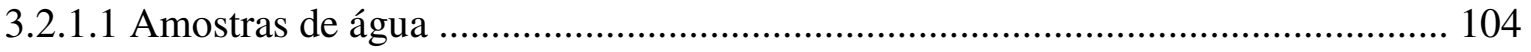




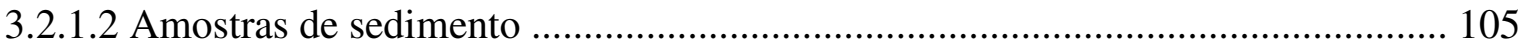

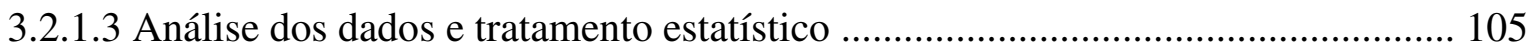

3.2.2 Teste de genotoxicidade com Allium cepa ................................................................ 105

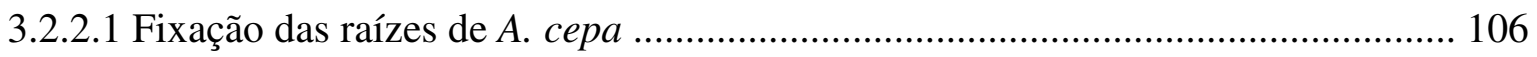

3.2.2.2 Preparação das lâminas permanentes .................................................................. 106

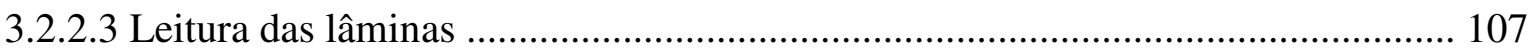

3.2.2.4 Análise dos dados e tratamento estatístico .......................................................... 108

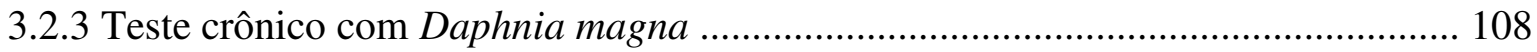

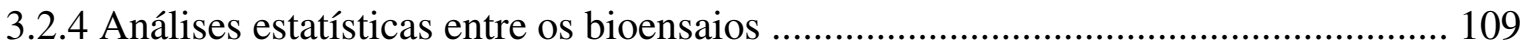

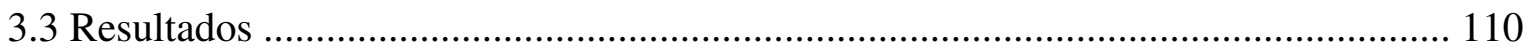

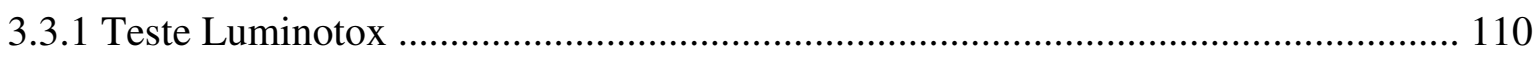

3.3.2 Teste de genotoxicidade com Allium cepa ........................................................... 111

3.3.3 Teste crônico com Daphnia magna ……................................................................ 113

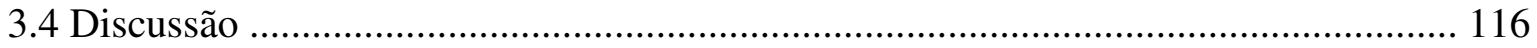

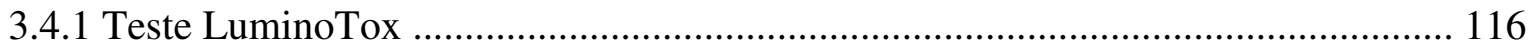

3.4.2 Teste de genotoxicidade com Allium cepa ............................................................. 118

3.4.3 Teste crônico com Daphnia magna ......................................................................... 119

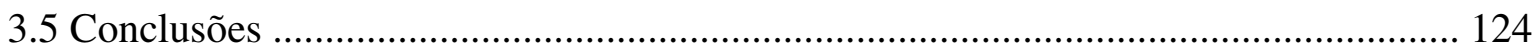

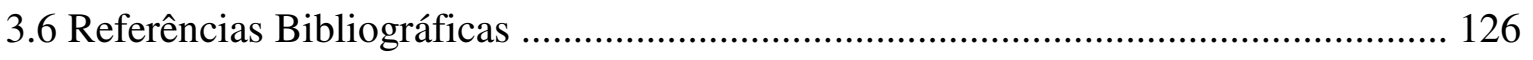

4 Avaliação de amostras fluviais (Saint Lawrence River, Montréal, Canada), efluentes tratados e de nanomateriais utilizando o bioensaio MARA (Microbial Array for Risk

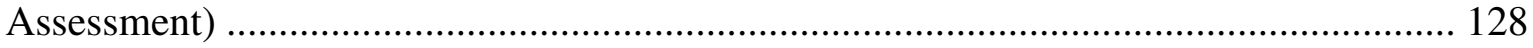

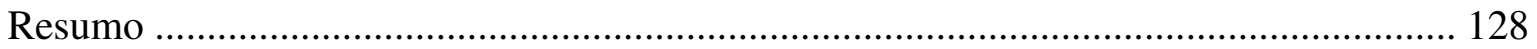

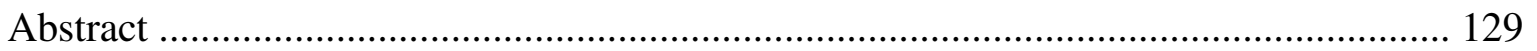

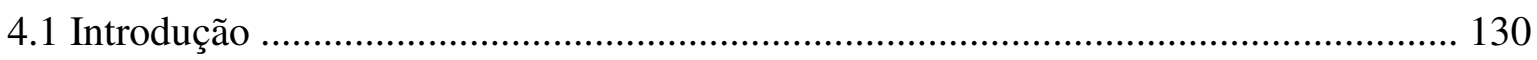

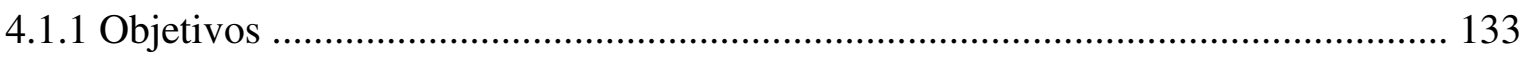

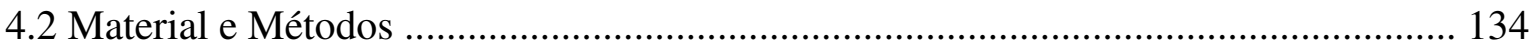

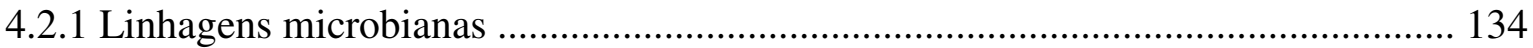

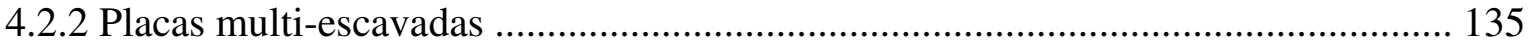

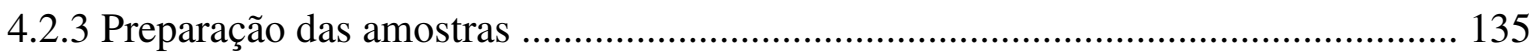

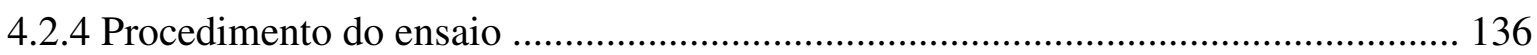

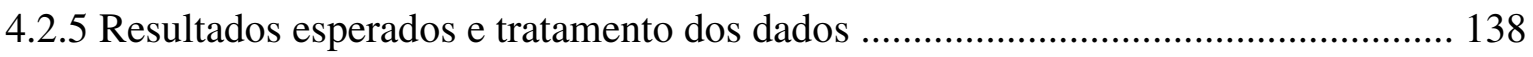

4.2.6 Monitoramento dos resultados do controle negativo ............................................ 140

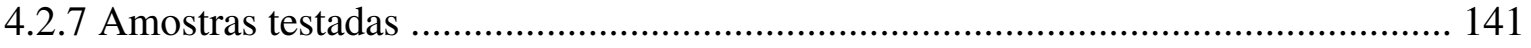


4.2.7.1 Sedimentos do rio Saint Lawrence, Montreal, Canadá ....................................... 141

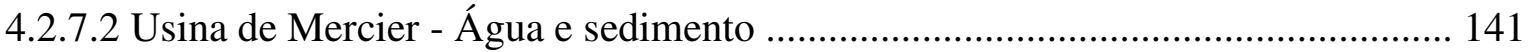

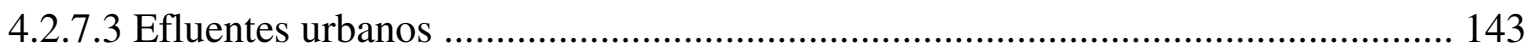

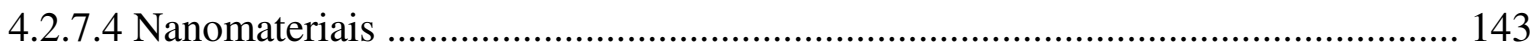

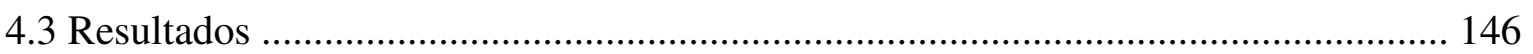

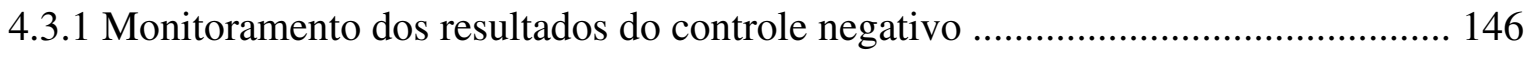

4.3.2 Sedimentos do rio Saint Lawrence, Montreal, Canadá ........................................... 146

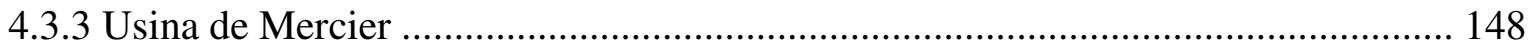

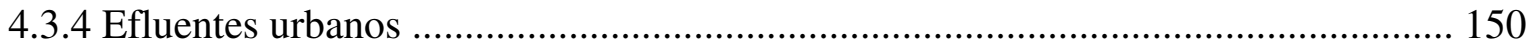

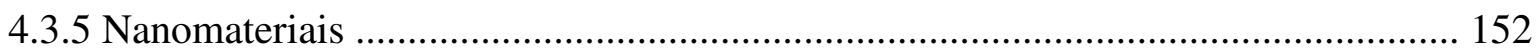

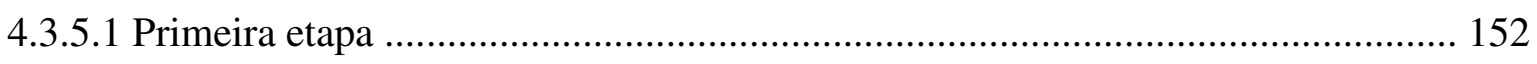

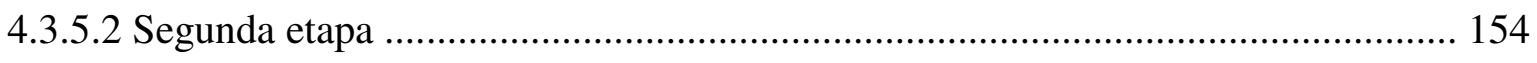

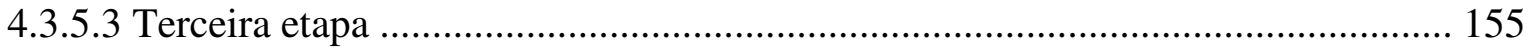

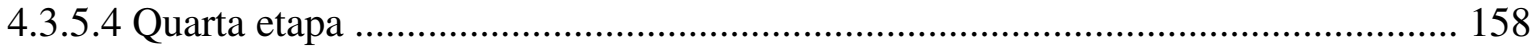

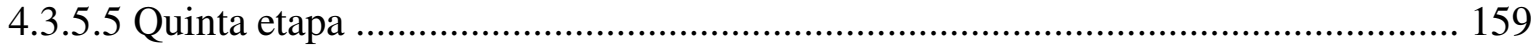

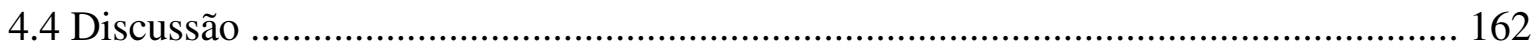

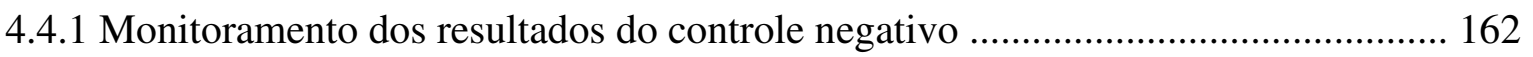

4.4.2 Sedimentos do rio Saint Lawrence, Montreal, Canadá .......................................... 162

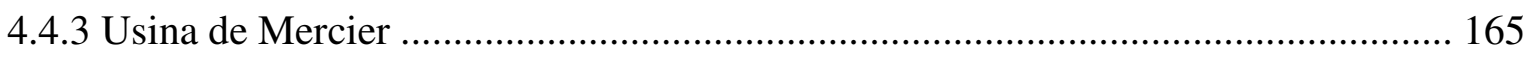

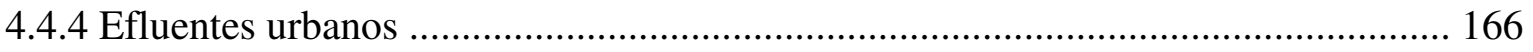

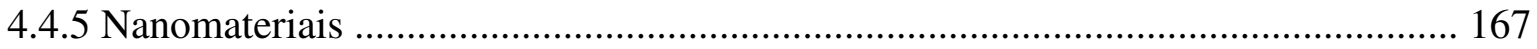

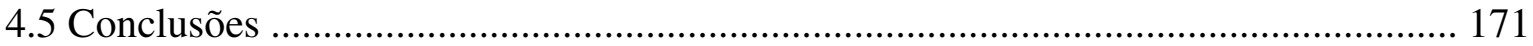

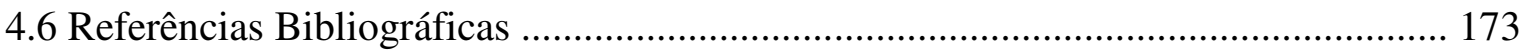

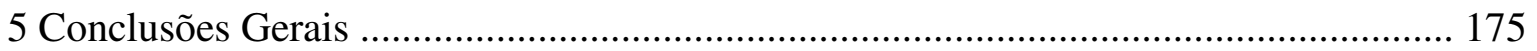

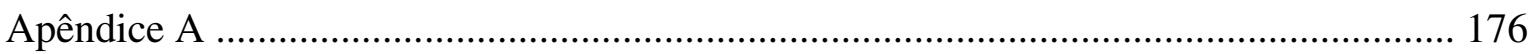




\section{RESUMO}

SANTOS, M.A.P.F. Avaliação da qualidade da água e sedimento da sub-bacia do rio Corumbataí (SP) por meio de testes ecotoxicológicos. 2008. 186p. Tese (doutorado) Centro de Energia Nuclear na Agricultura, Universidade de São Paulo, Piracicaba, 2008.

Foram realizados testes de toxicidade ao longo de dois anos, com amostras de água e sedimento do rio Corumbataí, entre Novembro de 2004 e Setembro de 2006, com o objetivo de avaliar a qualidade da água e do sedimento. Os testes de toxicidade aguda realizados com os organismos Chironomus xanthus, Daphnia magna, Hydra attenuata, Lactuca sativa e Pseudokirchneriella subcapitata indicaram variados graus de toxicidade nos diferentes pontos de coleta do rio Corumbataí, com maior ocorrência de toxicidade nos pontos de coleta mais próximos à foz do rio, principalmente devido à afluência do Ribeirão Claro. Todas as amostras de sedimento se mostraram mais tóxicas do que as amostras de água dos mesmos locais, para todos os organismos utilizados, em todas as coletas realizadas. Para todos os organismos, foram realizados testes de sensibilidade, com substância de referência $(\mathrm{NaCl})$, mensalmente, a fim de garantir a qualidade dos cultivos em laboratório e dos bioensaios realizados, com resultados regulares e satisfatórios. Os efeitos produzidos pelas amostras ambientais sobre as sementes de alface (Lactuca sativa) foram bastante variáveis e irregulares, não possibilitando os cálculos de $\mathrm{CI}_{50}$. Decidiu-se por bem suspender a realização deste teste após um ano. Dentre todos os endpoints avaliados, os dos testes de Hydra attenuata e Pseudokirchneriella subcapitata se mostraram mais sensíveis, e o de Daphnia magna o menos sensível às amostras testadas. A avaliação da toxicidade através de efeitos subletais em $H$. attenuata se mostrou um bom parâmetro de avaliação das condições ambientais do rio Corumbataí, sendo um dos endpoints mais sensíveis utilizados. Outros testes de toxicidade foram realizados em algumas das oito coletas realizadas neste estudo, em caráter complementar: teste de toxicidade crônica com D. magna, teste de toxicidade LuminoTox, que utiliza sistemas enzimáticos vegetais, e o teste de genotoxicidade com Allium cepa, com o objetivo de avaliar suas sensibilidades e contribuições ao estudo. Estes bioensaios adicionaram informações a respeito dos níveis de poluição e toxicidade do rio Corumbataí, contribuindo com os bioensaios principais. Informações como parâmetros físicos e químicos, quantificação de elementos químicos e herbicidas ofereceram subsídios para a interpretação dos resultados obtidos com os testes de toxicidade. São apresentados também resultados das atividades referentes ao estágio de doutorado realizado no exterior (doutorado-sanduíche), no período de Setembro a Dezembro de 2007, na agência de proteção ambiental Environment Canada, no qual foi aplicado um teste de toxicidade com linhagens microbianas (MARA assay) em amostras de água e sedimento, juntamente com nanomateriais.

Palavras-Chave: Bioensaios; rio Corumbataí, Daphnia magna; Hydra attenuata; Chironomus xanthus; Lactuca sativa; Pseudokirchneriella subcapitata; Allium cepa; genotoxicidade; LuminoTox; MARA assay; nanomateriais. 


\begin{abstract}
SANTOS, M.A.P.F. Water and sediment quality assessment of Corumbataí River (SP) using bioassays. 2008. 186p. Tese (doutorado) - Centro de Energia Nuclear na Agricultura, Universidade de São Paulo, Piracicaba, 2008.

Toxicity tests were conducted for two years with water and sediment samples from Corumbataí River, between November 2004 and September 2006, in order to assess the water and sediment quality. Acute toxicity tests conducted with Chironomus xanthus, Daphnia magna, Hydra attenuata, Lactuca sativa and Pseudokirchneriella subcapitata showed varying degrees of toxicity along the river course, with more toxic results in the sampling sites near the river mouth, due mainly to the inflow of Ribeirão Claro. All sediment samples were more toxic than the water samples (from the corresponding sites), for all test organisms, and for all samplings. Sensitivity tests were performed monthly, with $\mathrm{NaCl}$ as the reference toxicant, in order to guarantee both the laboratory culture quality and the bioassays conducted with these organisms. Results with $\mathrm{NaCl}$ were regular and satisfactory. The effects of the samples on lettuce seeds ( $L$. sativa) were irregular, thus not allowing the estimative of $\mathrm{IC}_{50}$. It was decided to suspend the performance of this bioassay after one year of testing. Among all studied tests and endpoints, the tests with $H$. attenuata and $P$. subcapitata had the most sensitive endpoints, and the acute toxicity test with $D$. magna had the less sensitive one. Toxicity assessment of Corumbataí River based on Hydra sub-lethality endpoint was one of the most sensitive among the tested ones. Other bioassays were conducted at least once as part of this study, as a complementary assessment: the 21-day chronic toxicity test with D. magna, the LuminoTox bioassay, and the genotoxicity test with Allium cepa, in order to assess their sensitivity and contribution to the present study. These bioassays added information about the contamination levels and toxicity of Corumbataí River, contributing with the main bioassays performed. Data such as physical and chemical parameters, metals and herbicides determinations had a contribution to bioassay results interpretation. Results from a research project developed during a four-month stay (from September 2007 to December 2007) at Environment Canada Protection Agency are further described, regarding the application of the MARA bioassay, (conducted with 11 microbial strains), testing water and sediment samples, along with nanomaterials.
\end{abstract}

Keywords: Bioassays; Corumbataí River; Daphnia magna; Hydra attenuata; Chironomus xanthus; Lactuca sativa; Pseudokirchneriella subcapitata; Allium cepa; genotoxicity; LuminoTox; MARA assay; nanomaterials. 


\section{Introdução}

À medida que o homem aumenta sua capacidade tecnológica de manipular os elementos da natureza para satisfazer suas necessidades e desejos, surgem conflitos diversos, e, dentre eles, podemos destacar a disposição de resíduos no ambiente. Desde o século XIX, um novo modelo de civilização se impôs, tendo como base a industrialização. Esta nova ordem teve como uma de suas consequiências a disponibilidade de uma enorme diversidade de novos produtos químicos potencialmente tóxicos, e a geração de resíduos suficiente para prejudicar o funcionamento do ambiente. No entanto, somente na década de 60 a poluição se tornou um fato reconhecido, devido aos problemas causados ao homem e ao próprio ambiente (ZAGATTO e BERTOLETTI, 2006).

$\mathrm{O}$ interesse do homem pelas questões ambientais começou a surgir devido às ocorrências de acidentes com produtos químicos, com repercussão mundial. Podemos citar diversos exemplos: o uso indiscriminado de DDT na década de 40; a doença de Minamata, ocorrida no Japão em 1956, por contaminação da população humana por mercúrio; a doença "Itai-Itai", causada por cádmio, em 1947, também no Japão. Neste país, houve também uma grande intoxicação por PCB presente no arroz consumido pela população. (ZAGATTO e BERTOLETTI, 2006).

Dentre as maiores fontes de poluição do ambiente aquático encontram-se os lançamentos de efluentes líquidos domésticos e industriais sem o devido tratamento. Os rios são um dos ecossistemas mais explorados pelo homem. A idéia de constante renovação da água, dada pelo escoamento unidirecional levou a humanidade a utilizar os rios como destino final de efluentes, esgotos, e despejos líquidos de diversos tipos (BOON, 1992). Muitos efluentes são extremamente complexos, e seus efeitos sobre a biota não podem ser caracterizados simplesmente por análises tradicionais. Assim, para a 
caracterização adequada e controle destes efluentes, a estratégia mais eficiente é o uso integrado de análises físicas, químicas e ecotoxicológicas.

Tendo em mente estes fatos, é possível perceber que o ambiente aquático não é um compartimento de diluição infinita da poluição recebida. Muitas vezes, esses ecossistemas aquáticos são capazes de assimilar e neutralizar substâncias tóxicas, através de mecanismos físicos, químicos e biológicos. Entretanto, quando os contaminantes excedem a capacidade de depuração dos corpos d'água, os organismos que lá vivem podem sofrer efeitos em sua sobrevivência, crescimento, desenvolvimento, reprodução, ou mesmo em seu comportamento (COONEY, 1995).

Os efeitos tóxicos de uma dada substância (ou de um conjunto de substâncias presentes em um corpo d'água) podem ser de dois tipos: o primeiro, denominado efeito agudo, são aqueles causados por uma exposição a uma substância (ou conjunto delas) por um curto período de tempo (horas, dias, e até algumas semanas). Geralmente, os efeitos medidos são: a morte ou a imobilidade dos organismos. O segundo, o efeito crônico ou subletal, são os que prejudicam a reprodução, o desenvolvimento, o crescimento e o comportamento do organismo dentro de seu ecossistema. O efeito crônico é causado por baixas concentrações, que são incapazes de matar ou causar efeitos agudos, mas que ao longo do ciclo de vida do organismo causa os efeitos deletérios supra-citados (RAND et al., 1995).

A metodologia empregada para fornecer dados qualitativos e quantitativos dos efeitos tóxicos (agudos e crônicos) citados tem sido desenvolvida e aprimorada há muitos anos, em todo o mundo, para uma grande quantidade de organismos - peixes, invertebrados de água doce, algas, vegetais superiores, etc. (RAND et al., 1995; VIGANÒ, 1996; TROTTIER et al., 1997; VERSTEEG et al., 1997; BLAISE et al., 2000; USEPA, 2000, 2002; FONSECA, 1997). Os testes ecotoxicológicos mais baratos e mais aplicados 
são os testes agudos - ou de curta duração - em que geralmente apenas um estágio de desenvolvimento do organismo-teste é avaliado quanto ao potencial tóxico da substância testada (ou da água de um corpo receptor). Os efeitos mais freqüentemente medidos nestes testes são a mortalidade e a imobilidade dos organismos.

Entretanto, para se obter informações mais precisas e acuradas sobre o potencial tóxico de uma substância (ou da água de um corpo receptor), é preciso avaliar os efeitos sobre todo um período reprodutivo do organismo testado (ovo, embrião, neonato, jovem, adulto), pois o fato de uma substância química (ou mistura de várias delas) não exercer efeitos tóxicos agudos sobre certo organismo, não necessariamente indica que esta amostra não é tóxica para ele. Os testes crônicos permitem avaliar possíveis efeitos adversos sob exposições prolongadas a concentrações subletais (RAND et al., 1995). Os efeitos medidos neste tipo de teste geralmente são: sobrevivência ao longo do tempo de exposição, taxa de crescimento, e efeitos sobre a fecundidade.

Contudo, a coluna d'água não é a única fonte tóxica em potencial para os organismos aquáticos: os sedimentos presentes no fundo de corpos d'água podem representar grande ameaça à sobrevivência dos organismos, principalmente os bentônicos, que vivem em contato direto com este compartimento (USEPA, 2000). Segundo Viganò (2000), a adsorção de substâncias químicas às partículas de sedimento é um importante processo, através do qual muitos contaminantes podem atingir concentrações muito mais altas no sedimento do que na coluna d'água. O sedimento pode ser um repositório destas substâncias, mas a longo prazo se tornar uma fonte de contaminantes tóxicos à biota aquática. As atividades de dragagem de lodo e sedimento freqüentemente executadas em rios e reservatórios acabam por revolver o sedimento e biodisponibilizar substâncias potencialmente tóxicas que estavam sequiestradas pelas partículas de sedimento (INGERSOLL, 1995). Os testes de toxicidade de sedimentos feitos com elutriatos 
(amostras de sedimento misturadas à água de diluição e agitadas) avaliam os efeitos tóxicos potenciais destas atividades de dragagem.

Portanto, a fim de se avaliar os riscos de impactos antropogênicos sobre a biota de um determinado ecossistema aquático, dois tipos de testes de toxicidade são freqüentemente executados: testes com água, e testes com sedimento. No primeiro tipo, é possível avaliar a toxicidade de efluentes domésticos, agrícolas e industriais, de substâncias solúveis em água (e.g., metais, pesticidas, xenobióticos), e também da qualidade da água de rios, lagos e reservatórios. Nestes casos, a(s) substância(s) causadora(s) de toxicidade deve(m) ser solúvel(is) em água, para que se obtenham resultados válidos. Já através de testes com sedimento, é possível avaliar: (1) se o mesmo é nocivo aos organismos bentônicos, (2) uma possível relação entre toxicidade e biodisponibilidade, (3) o risco de atividades de dragagem de lodo e sedimentos, e (4) a eficiência de remediação de áreas poluídas, dentre outros (INGERSOLL, 1995).

Devido ao comprometimento das águas do rio Piracicaba, 100\% da água fornecida para a cidade de Piracicaba vem do rio Corumbataí, e a previsão do plano diretor é de que este seja o único manancial por pelo menos mais 20 anos. A sub-bacia do rio Corumbataí abrange os municípios de Analândia, Itirapina, Corumbataí, Rio Claro, Santa Gertrudes, Ipeúna, Charqueada e Piracicaba, drenando uma área de $1690 \mathrm{Km}^{2}$, e servindo como corpo receptor de esgotos de origem doméstica e industrial ao longo de seu curso. Por conta disso, a carga orgânica, assim como a presença de metais e pesticidas vêm aumentando gradativamente, aumentando também os custos para o tratamento de água para o abastecimento humano, assim como piorando os seus índices de IQA (Índice de qualidade das águas), IVA (Índice de proteção da Vida Aquática), IET (Índice do estado trófico), e IAP (Índices de qualidade de água bruta para fins de abastecimento público), quando se comparam os dados a partir de 2002 (CETESB, 2007). 
Neste contexto, o presente trabalho se propôs a utilizar testes ecotoxicológicos como ferramentas para a avaliação do grau de toxicidade de diversos pontos na bacia do rio Corumbataí, responsável pelo abastecimento de água para as cidades de Analândia, Rio Claro e Piracicaba (SP). Amostras de água e sedimento foram avaliadas quanto à toxicidade para várias espécies, de diferentes níveis tróficos, tais como: Hydra attenuata (celenterado de água doce), Daphnia magna (microcrustáceo de água doce), Lactuca sativa (sementes de alface), Pseudokirchneriella subcapitata (micro-alga de água doce, antiga Selenastrum capricornutum), e Chironomus xanthus (inseto da ordem Diptera). Além destes, foram utilizados outros testes, em caráter complementar: o teste de genotoxicidade com Allium cepa (raízes de sementes de cebola) seguindo protocolo de Grant (1982); o teste LuminoTox, que avalia a toxicidade da amostra testada sobre sistemas enzimáticos vegetais; e o teste crônico (21 dias) com o cladócero Daphnia magna.

Os resultados de toxicidade obtidos por este estudo foram correlacionados com análises de elementos químicos e herbicidas realizados por outros autores envolvidos no mesmo projeto (Políticas Públicas, FAPESP, Proc. 01/02954-4). O SEMAE de Piracicaba (Serviço Municipal de Água e Esgoto) atuou como instituição parceira neste projeto, colaborando com a realização deste trabalho, através de apoio técnico e de infra-estrutura. Todos os testes de toxicidade foram realizados nos laboratórios de Ecologia Aplicada do CENA. 


\subsection{Referências Bibliográficas}

BLAISE, C.; FORGET, G.; TROTTIER, S. Toxicity screening of aqueous samples using a costeffective 72-h exposure Selenastrum capricornutum assay. Environmental Toxicology, New York, v. 15, special issue, p. 352-359, 2000.

BOON, P.J. Essential elements in the case for the river conservation. In: BOON, P.; CALOW, P.; PETTS, G.E. (Ed.). River conservation and management. London: John Wiley and Sons, 1992. $484 \mathrm{p}$.

COMPANHIA DE TECNOLOGIA DE SANEAMENTO AMBIENTAL. Plano das Bacias Hidrográficas dos rios Piracicaba, Capivari e Jundiaí - 2004-2007 - Síntese do Relatório Final. São Paulo: CETESB, 2007. 47 p.

COONEY, J.D. Freshwater tests. In: RAND, G.M. (Ed.). Fundamentals of aquatic toxicology: effects, environmental fate, and risk assessment. London: Taylor \& Francis, 1995. p. 71-102.

FONSECA, A.L. Avaliação da qualidade da água do rio Piracicaba / SP através de testes de toxicidade com invertebrados. 1997. 211 f. Tese (Doutorado em Hidráulica e Saneamento) Escola de Engenharia de São Carlos, Universidade de São Paulo, São Carlos, 1997.

INGERSOLL, C.G. Sediment tests. In: RAND, G.M. (Ed.). Fundamentals of aquatic toxicology: effects, environmental fate, and risk assessment. London: Taylor \& Francis, 1995. p. 231-256.

RAND, G.M.; WELLS, P.G.; MCCARTY, L.S. Introduction to aquatic toxicology. In: RAND, G.M. (Ed.). Fundamentals of aquatic toxicology: effects, environmental fate, and risk assessment. London: Taylor \& Francis, 1995. p. 3-70.

TROTTIER, S.; BLAISE, C.; KUSUI, T.; JOHNSON, E.M. Acute toxicity assessment of aqueous samples using a microplate-based Hydra attenuata assay. Environmental Toxicology and Water Quality, New York, v. 12, p. 265-271, 1997.

U.S. ENVIRONMENTAL PROTECTION AGENCY. EPA-600/R-99/064: Methods for measuring the toxicity and bioaccumulation of sediment-associated contaminants with freshwater invertebrates. 2. ed. Washington: USEPA, 2000. 192 p.

U.S. ENVIRONMENTAL PROTECTION AGENCY. EPA-821-R-02-012: Methods for measuring the acute toxicity of effluents and receiving waters to freshwater and marine organisms. 5. ed. Washington: USEPA, 2002. 266 p.

VERSTEEG, D.J.; STALMANS, M.; DYER, S.D.; JANSSEN, C. Ceriodaphnia and Daphnia: a comparison of their sensitivity to xenobiotics and utility as a test species. Chemosphere, Amsterdam, v. 34, p. 869-892, 1997.

VIGANÒ, L. Metodo per la valutazione della tossicità acuta con Ceriodaphnia dubia. Biologia Ambientale, Reggio Emilia v. 6, p. 11-22, 1996.

VIGANÒ, L. Assessment of the toxicity of River Po sediments with Ceriodaphnia dubia. Aquatic Toxicology, Amsterdam, v. 47, p. 191-202, 2000.

ZAGATTO, P.A.; BERTOLETTI, E. Ecotoxicologia aquática - Princípios e aplicações. São Carlos: Rima, 2006. 464 p. 


\section{Avaliação da qualidade da água e sedimento da sub-bacia do rio Corumbataí (SP) por meio de testes ecotoxicológicos}

\section{Resumo}

Foram realizados testes de toxicidade ao longo de dois anos, com amostras de água e sedimento do rio Corumbataí, entre Novembro de 2004 e Setembro de 2006. Os testes de toxicidade agudos realizados com os organismos Chironomus xanthus, Daphnia magna, Hydra attenuata, Lactuca sativa e Pseudokirchneriella subcapitata indicaram variados graus de toxicidade nos diferentes pontos de coleta do rio Corumbataí, com maior ocorrência de toxicidade nos pontos de coleta mais próximos à foz do rio, principalmente devido à afluência do Ribeirão Claro. Todas as amostras de sedimento se mostraram mais tóxicas do que as amostras de água dos mesmos locais, para todos os organismos utilizados, em todas as coletas realizadas. Para todos os organismos, foram realizados testes de sensibilidade, com substância de referência $(\mathrm{NaCl})$, mensalmente, a fim de garantir a qualidade dos cultivos em laboratório e dos bioensaios realizados, com resultados regulares e satisfatórios. Os efeitos produzidos pelas amostras ambientais sobre as sementes de alface (Lactuca sativa) foram bastante variáveis e irregulares, não possibilitando os cálculos de $\mathrm{CI}_{50}$. Decidiu-se por bem suspender a realização deste teste após um ano. Dentre todos os endpoints avaliados, os dos testes de Hydra attenuata e Pseudokirchneriella subcapitata se mostraram os mais sensíveis, e o de Daphnia magna o menos sensível às amostras testadas. A avaliação da toxicidade através de efeitos subletais em $H$. attenuata se mostrou um bom parâmetro de avaliação das condições ambientais do rio Corumbataí, sendo um dos endpoints mais sensíveis dentre os utilizados. Informações como parâmetros físicos e químicos, quantificação de elementos químicos e herbicidas ofereceram subsídios para a interpretação dos resultados obtidos com os testes de toxicidade, e corroboraram os resultados obtidos pelos bioensaios. Índices de qualidade de água utilizados pela CETESB (como IVA, IAP, IET, e IQA) também corroboraram estes resultados, indicando que bioensaios são boas ferramentas na avaliação da qualidade de corpos d'água e a proteção à vida aquática.

Palavras-Chave: Bioensaios; rio Corumbataí, Daphnia magna; Hydra attenuata; Chironomus xanthus; Lactuca sativa; Pseudokirchneriella subcapitata. 


\begin{abstract}
Toxicity tests were conducted for two years with water and sediment samples from Corumbataí River, between November 2004 and September 2006. Acute toxicity tests conducted with Chironomus xanthus, Daphnia magna, Hydra attenuata, Lactuca sativa and Pseudokirchneriella subcapitata showed varying degrees of toxicity along the river course, with more toxic results in the sampling sites near the river mouth, due mainly to inflow of the Ribeirão Claro. All sediment samples were more toxic than the water samples (from the corresponding sites), for all test organisms, and for all samplings. Sensitivity tests were performed monthly, with $\mathrm{NaCl}$ as the reference toxicant, in order to guarantee both the laboratory culture quality and the bioassays conducted with these organisms. Results with $\mathrm{NaCl}$ were regular and satisfactory. The effects of the samples on lettuce seeds (L. sativa) were irregular, thus not allowing the estimative of $\mathrm{IC}_{50}$. It was decided to suspend the performance of this bioassay after one year of testing. Among all studied tests and endpoints, the tests with $H$. attenuata and $P$. subcapitata had the most sensitive endpoints, and the acute toxicity test with $D$. magna had the less sensitive one. Toxicity assessment of Corumbataí River based on Hydra sub-lethality endpoint was one of the most sensitive among the tested ones. Data such as physical and chemical parameters, metals and herbicides determination had a contribution to bioassay results interpretation, and agreed with bioassay results. Water quality indexes used by CETESB (such as IVA, IAP, IET and IQA) also agreed with bioassay results, indicating them as good tools for river quality assessment and aquatic life protection.
\end{abstract}

Keywords: Bioassays; Corumbataí River; Daphnia magna; Hydra attenuata; Chironomus xanthus; Lactuca sativa; Pseudokirchneriella subcapitata. 


\subsection{Introdução}

Os ensaios ecotoxicológicos surgiram em grande escala a partir da década de 60 , década esta que é considerada um marco na preocupação do homem por toda a poluição gerada por seus processos tecnológicos e industriais. A Ecotoxicologia surgiu para suprir as necessidades de respostas quanto aos efeitos da poluição ambiental sobre os seres vivos em geral. Até a década de 60, era mais habitual realizarem-se análises físicas e químicas de efluentes e corpos d'água, o que não garantia e nem levava em consideração a proteção da biota aquática (ZAGATTO e BERTOLETTI, 2006).

Com os primeiros bioensaios realizados na década de 60, utilizando peixes, foi-se tendo um conhecimento mais preciso sobre o impacto exercido pelos poluentes sobre a biota. Foi apenas em 1973 que o Scientific Committee On the Problems of the Environment cunhou o termo Ecotoxicologia, definindo-o como "o ramo da toxicologia preocupada com o estudo dos efeitos tóxicos, causados por poluentes naturais ou sintéticos a elementos constituintes dos ecossistemas, sejam eles animais (incluindo humanos), vegetais, ou microbianos, em um contexto integrado" (TRUHAUT, 1977).

A partir da década de 70, as agências ambientais regulatórias norte-americanas, européias e canadenses começaram a utilizar ensaios ecotoxicológicos como ferramentas regulatórias de emissão de efluentes e poluentes. A utilização destes bioensaios veio para preencher a lacuna existente na interpretação das análises físicas e químicas, que não tem como, isoladamente, dizer se um dado efluente ou amostra ambiental são nocivos aos organismos aquáticos. Análises químicas, isoladamente, não são capazes de levar em conta, por exemplo, a biodisponibilidade, a persistência e a interação dos poluentes. Elas também não são capazes de fornecer informações sobre a toxicidade (seja aguda ou crônica) destes poluentes despejados no ambiente, nem se serão capazes de causar efeitos 
genotóxicos, carcinogênicos, ou teratogênicos nos ambientes em que serão lançados (BLAISE e FÉRARD, 2005).

Ensaios ecotoxicológicos podem ser ferramentas mais eficientes e com melhor relação custo-benefício para se detectar e quantificar estes efeitos deletérios já citados à biota aquática. O ideal é se demonstrar a presença de efeitos adversos através de bioensaios, que são capazes de integrar em suas respostas efeitos interativos de fatores físicos, químicos e biológicos, e a partir daí proceder com análises químicas para estabelecer relações mais diretas entre os efeitos detectados e contaminantes específicos (BLAISE e FÉRARD, 2005).

Avaliações ambientais de ecossistemas aquáticos, como rios, lagos e reservatórios, através de ensaios ecotoxicológicos têm sido utilizadas com sucesso e amplamente publicadas na literatura, mostrando que é possível detectar contaminação por poluentes através dos organismos expostos à amostras de: água de rios (VIGANÒ, 2000; ESPÍNDOLA et al., 2003; KOUKAL et at., 2004; CHRISTENSEN et al., 2006), lagos e reservatórios (BRIDGES et al., 1996; GREGOR e MUNAWAR, 1989), sedimentos (BRIDGES et al., 1996; BETTINETTI et al., 2003; HSU et al., 2007), e despejo de efluentes industriais (BLAISE e KUSUI, 1997; RA et al., 2006).

Os organismos-teste utilizados pela Ecotoxicologia são selecionados, através de extensos estudos por apresentar características adequadas aos testes, como: padronização por agências ambientais, boa reprodutibilidade, reprodução intensa, ciclo de vida curto, fácil manejo, relevância ecológica, interesse econômico, vasta distribuição geográfica, baixos custos, mas principalmente de acordo com sua sensibilidade a poluentes que acabam funcionando acidentalmente como agentes tóxicos a estes organismos (CALOW, 1994; RAND et al., 1995). Há um amplo registro na literatura mostrando que organismos como os utilizados no presente estudo: Chironomus xanthus, Daphnia magna, Hydra 
attenuata e Pseudokirchneriella subcapitata (e outras espécies dos mesmos gêneros) são bastante sensíveis a metais (KHANGAROT e RAY, 1987; ROJICKOVAÁ-PADRTOVÁ e MARSÁLEK, 1999; KARNTANUT e PASCOE, 2002), herbicidas e inseticidas (KALAFATICACUTE et al., 1991; FAIRCHILD et al., 1997; BAUN et al., 1998; FARIA et al., 2007), medicamentos farmacêuticos (BLAISE et al., 2006; FENT et al., 2006; QUINN et al., 2008), corantes têxteis (DELLAMATRICE, 2005), sais (UTZ e BOHRER, 2001; DUMCKE et al., 2005; GONÇALVES et al., 2007) e diversas outras fontes de contaminação ambiental (SIBLEY et al., 1997; WARNE e SCHIFKO, 1999; ANTUNES et al., 2007).

Quando do uso de testes de toxicidade, seja para avaliação de substâncias puras ou amostras ambientais, se apenas uma única espécie é utilizada, apenas uma resposta será obtida, e a toxicidade estimada irá refletir apenas a sensibilidade deste teste, e se poderá correr o risco de estar subestimando a toxicidade da amostra testada. Nenhum bioensaio é capaz de responder à vasta quantidade de agentes tóxicos existentes (CASTILLO et al., 2000). Nestes casos, o ideal é a utilização de uma bateria de testes que levam em conta o nível trófico e o compartimento do ecossistema de cada organismo escolhido para formar esta bateria. Realizando os testes desta maneira, reduz-se este risco, pois não se terá apenas uma única resposta, de um único organismo, e, portanto, uma única faixa de sensibilidade. O desejável é ter uma espécie de cada nível trófico, como por exemplo, um decompositor, um produtor primário, um consumidor primário, e um consumidor secundário. Tendo-se espécies representativas de cada nível trófico, tem-se uma boa bateria de bioensaios. Se possível, é igualmente desejável contemplar os diferentes compartimentos do ecossistema estudado, como o sedimento e a coluna d'água. (ROJICKOVAÁ-PADRTOVÁ et al., 1998; DAVOREN e FOGARTY, 2004). 
Por estes motivos foram escolhidos os organismos-teste utilizados na avaliação da água e sedimento do rio Corumbataí, a fim de formar a bateria de bioensaios: C. xanthus como organismo bentônico, para se avaliar o sedimento; $P$. subcapitata como produtor primário; D. magna como consumidor primário; e $H$. attenuata como consumidor secundário. Os resultados dos bioensaios, complementados pelas análises de elementos químicos, herbicidas e parâmetros físicos e químicos feitas por outros colegas, serviram como ferramenta para avaliar a qualidade da sub-bacia do rio Corumbataí, durante os anos de 2004 a 2006, e auxiliar na identificação dos efeitos dos principais impactos de origem humana sofridos por seus corpos d'água.

\subsection{1 Área de estudo}

O rio Corumbataí nasce em Analândia e passa pelos municípios de Corumbataí, Rio Claro, Charqueada e Piracicaba, drenando uma área de $1690 \mathrm{Km}^{2}$, e servindo como corpo receptor de esgotos de origem doméstica e industrial ao longo de seu curso. Juntamente com seus tributários: Ribeirão Claro, Ribeirão Passa Cinco e Ribeirão da Cabeça, o rio Corumbataí alimenta o rio Piracicaba, onde tem sua foz, a $136 \mathrm{~km}$ de sua nascente. As pastagens ocupam cerca de $46 \%$ da área da sub-bacia, e as culturas de cana-de-açúcar ocupam cerca de 26\% (IPEF, 2001). O rio Corumbataí tem grande importância na região, servindo como fonte de água para abastecimento público para as cidades de Analândia, Rio Claro e Piracicaba. Segundo dados da CETESB (2007a), a sub-bacia do rio Corumbataí conta com 597.727 habitantes, e de todo o esgoto doméstico coletado, apenas cerca de $43 \%$ recebe algum tratamento. Em praticamente todo o seu curso é possível notar a precariedade da conservação da vegetação ripária do rio Corumbataí, que segundo Lima e Zakia (2001) tem importante papel na redução de entrada por escoamento de nutrientes terrestres, 
estabilização de margens, manutenção do equilíbrio térmico e aporte de matéria orgânica, além de reter herbicidas e sedimentos gerados por atividades agrícolas.

O rio Corumbataí serve como corpo receptor de esgotos de origem doméstica e industrial ao longo de seu curso. Fischer (2003) fez um levantamento das fontes pontuais de despejo de efluentes domiciliares e industriais dos anos 1999-2002 de toda a sub-bacia. No rio Corumbataí, há algumas dezenas de indústrias despejando seus efluentes no rio, sejam eles in natura, ou após receber algum tipo de tratamento. Na Figura 1 constam os valores de carga poluidora remanescente (em $\mathrm{kg}$ DBO $\left.\mathrm{dia}^{-1}\right)$ destas fontes de efluentes, inventariadas pelo autor, bem como a localização aproximada dos pontos de coleta do presente estudo. A Tabela 1 mostra a carga poluidora domiciliar, com dados de 2004-2006, segundo relatórios da CETESB (2005; 2006; 2007b). Por estas informações, é possível notar um gradual aumento na carga poluidora despejada no rio Corumbataí ao longo deste período de tempo.

Tabela 1. Carga poluidora domiciliar $\left(\mathrm{kg} \mathrm{DBO} \mathrm{dia}^{-1}\right)$ dos municípios da sub-bacia do rio Corumbataí, nos anos de 2004-2006.

\begin{tabular}{|c|c|c|c|}
\hline \multirow[b]{2}{*}{ Município } & \multicolumn{3}{|c|}{ Carga Remanescente (kg DBO dia $\left.{ }^{-1}\right)$} \\
\hline & 2004 & 2005 & 2006 \\
\hline Analândia & 143 & 167 & 169 \\
\hline Charqueada & 310 & 321 & 326 \\
\hline Corumbataí & 19 & 22 & 22 \\
\hline Ipeúna & 43 & 56 & 59 \\
\hline Piracicaba & 12.670 & 13.854 & 13.753 \\
\hline Rio Claro & 6.999 & 7.446 & 7.565 \\
\hline Santa Gertrudes & 838 & 1.011 & 1.043 \\
\hline Total & 21.022 & 22.877 & 22.937 \\
\hline
\end{tabular}




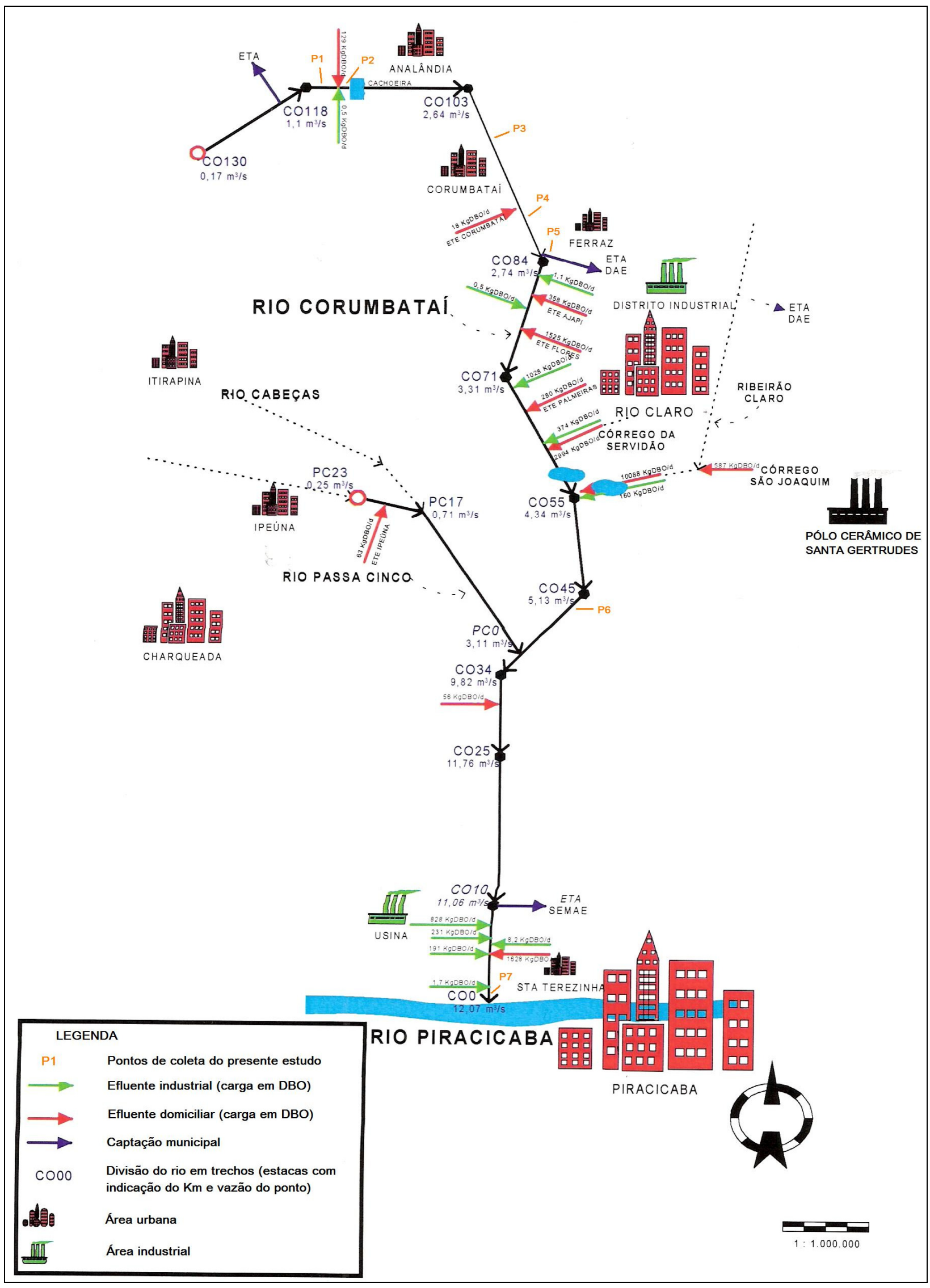

Figura 1. Diagrama da carga poluidora (domiciliar e industrial) da sub-bacia do rio Corumbataí, nos anos de 1999-2002 (adaptado de Fischer, 2003). 


\subsubsection{Objetivos}

- Propor a utilização de testes ecotoxicológicos como ferramentas para a avaliação do grau de toxicidade de diversos pontos na bacia do rio Corumbataí por meio de avaliação de amostras de água e sedimento quanto à toxicidade para várias espécies, de diferentes níveis tróficos, tais como: Hydra attenuata (celenterado de água doce), Daphnia magna (microcrustáceo de água doce), Lactuca sativa (sementes de alface), Pseudokirchneriella subcapitata (micro-alga de água doce, antiga Selenastrum capricornutum), e Chironomus xanthus (inseto da ordem Diptera);

- Correlacionar a presença de elementos químicos e resíduos de herbicidas das mesmas amostras com os resultados dos testes ecotoxicológicos;

- Avaliar a contribuição de cada organismo-teste dentro da bateria de bioensaios;

- Avaliar a utilização do $\mathrm{NaCl}$ como substância de referência em testes de sensibilidade para C. xanthus, D. magna, H. attenuata, e P. subcapitata. 


\subsection{Material e Métodos}

\subsubsection{Pontos de coleta}

Os pontos de coleta selecionados para os estudos de toxicidade estão localizados na sub-bacia do rio Corumbataí, dentro dos municípios de Analândia, Corumbataí, Rio Claro e Piracicaba (Figura 2). Os sete pontos foram georreferenciados através de uma unidade receptora de GPS (Global Position System), e marcaram os locais de coleta de água e sedimento para a realização de testes de toxicidade, a montante da captação de água dos principais municípios, e a jusante, após a emissão de esgotos, considerando-se uma amostra por ponto de coleta:

Ponto 1 - Município de Analândia, 500 m a montante da emissão do esgoto municipal (S $22^{\circ} 07^{\prime} 44,9^{\prime \prime}, \mathrm{W} 47^{\circ} 40^{\prime} 4,8^{\prime \prime}, 649 \mathrm{~m}$ de altitude). Local a jusante das nascentes do rio Corumbataí, e de pastagens (Figura 2).

Ponto 2 - Município de Analândia, $10 \mathrm{~m}$ a jusante da emissão de esgoto da cidade (S $22^{\circ}$ $07^{\prime}$ 54,9", W 47 39' 42,1", $648 \mathrm{~m}$ de altitude). Localiza-se logo antes da cachoeira de Analândia (Figura 2).

Ponto 3 - Município de Corumbataí, $1 \mathrm{~km}$ a montante da emissão do esgoto ( $\mathrm{S} 22^{\circ} 12^{\prime}$ 52,5", W 47 37' 30,21", 629 m de altitude). Local a jusante de áreas rurais (Figura 2).

Ponto 4 - Município de Corumbataí, $2 \mathrm{~km}$ a jusante da cidade, após a Mineração

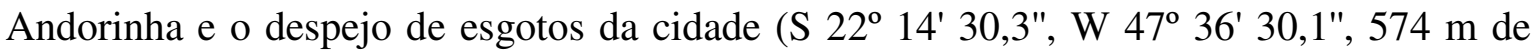
altitude) (Figura 2).

Ponto 5 - Município de Rio Claro, 1 km a montante da cidade (S 22 19' 28,6", W 47 33' 30,4", $561 \mathrm{~m}$ de altitude). Local de captação de água para tratamento e abastecimento público para a população de Rio Claro (Figuras 2 e 3). 
Ponto 6 - Município de Rio Claro, 2 km a jusante da cidade, no distrito de Assistência (S $22^{\circ} 30^{\prime} 54,1^{\prime \prime}, \mathrm{W} 47^{\circ} 37^{\prime} 26,4^{\prime \prime}, 508$ m de altitude). Neste ponto, o rio já recebeu o despejo de esgotos da população que mora no distrito de Assistência, assim como todo o esgoto doméstico e industrial do pólo cerâmico de Santa Gertrudes e de Rio Claro (despejados no Ribeirão Claro, afluente do rio Corumbataí) (Figuras 2 e 4).

Ponto 7 - Município de Piracicaba, $1 \mathrm{~km}$ a montante da foz do rio Corumbataí no rio Piracicaba (S 22 41' 04,5", W 47 40' 37,2", $495 \mathrm{~m}$ de altitude) (Figura 2). Neste Ponto (Figura 5), o rio Corumbataí já recebeu todo o esgoto de Santa Teresinha, e efluentes de indústrias localizadas a montante, como a Usina Costa Pinto (Figura 6). A captação de água para tratamento e abastecimento público para a cidade de Piracicaba localiza-se entre os pontos 6 e 7 do presente estudo, a montante da Usina Costa Pinto.

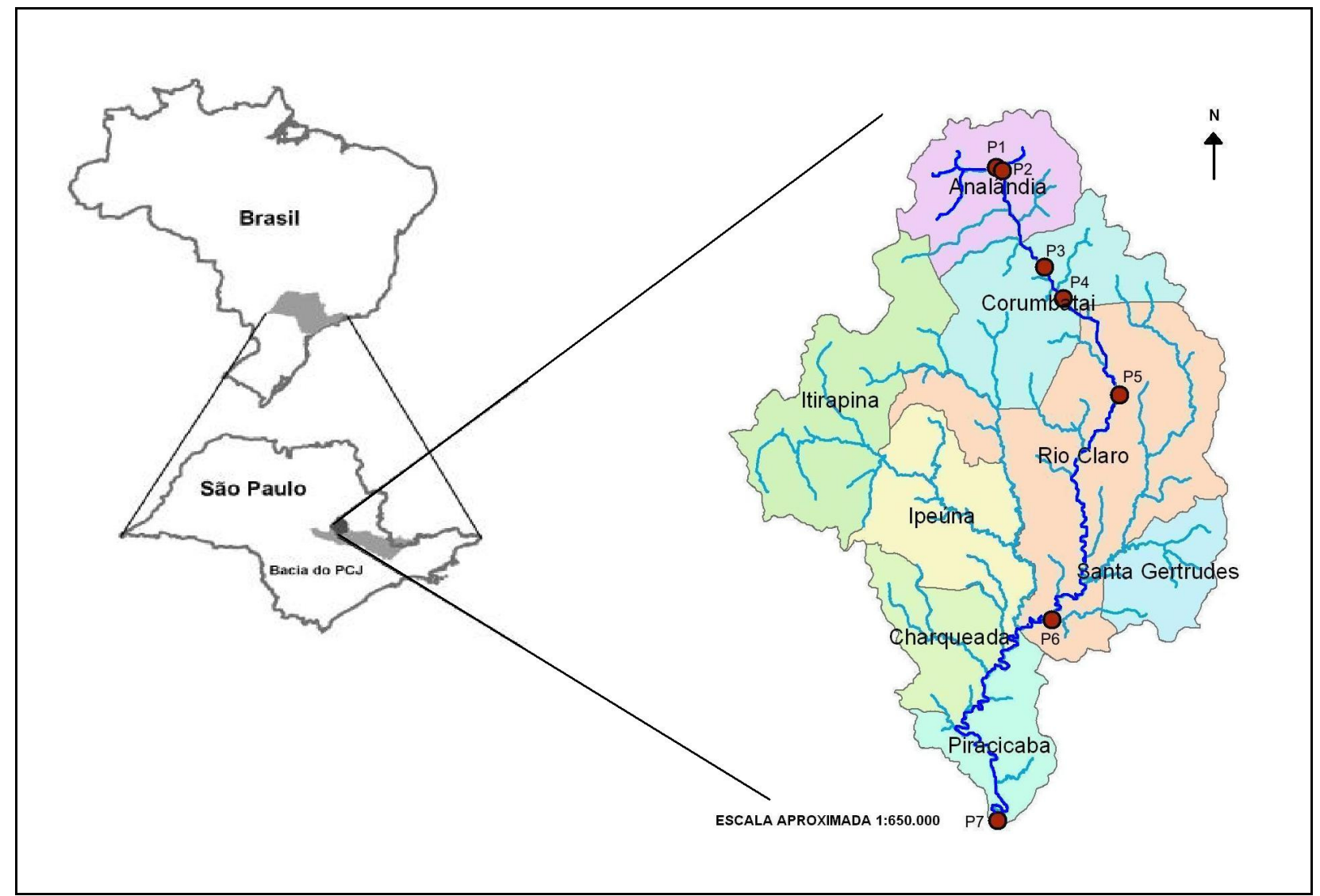

Figura 2. Mapa da sub-bacia do rio Corumbataí, onde estão localizados os sete pontos de coleta (P1 a P7) do presente estudo. 


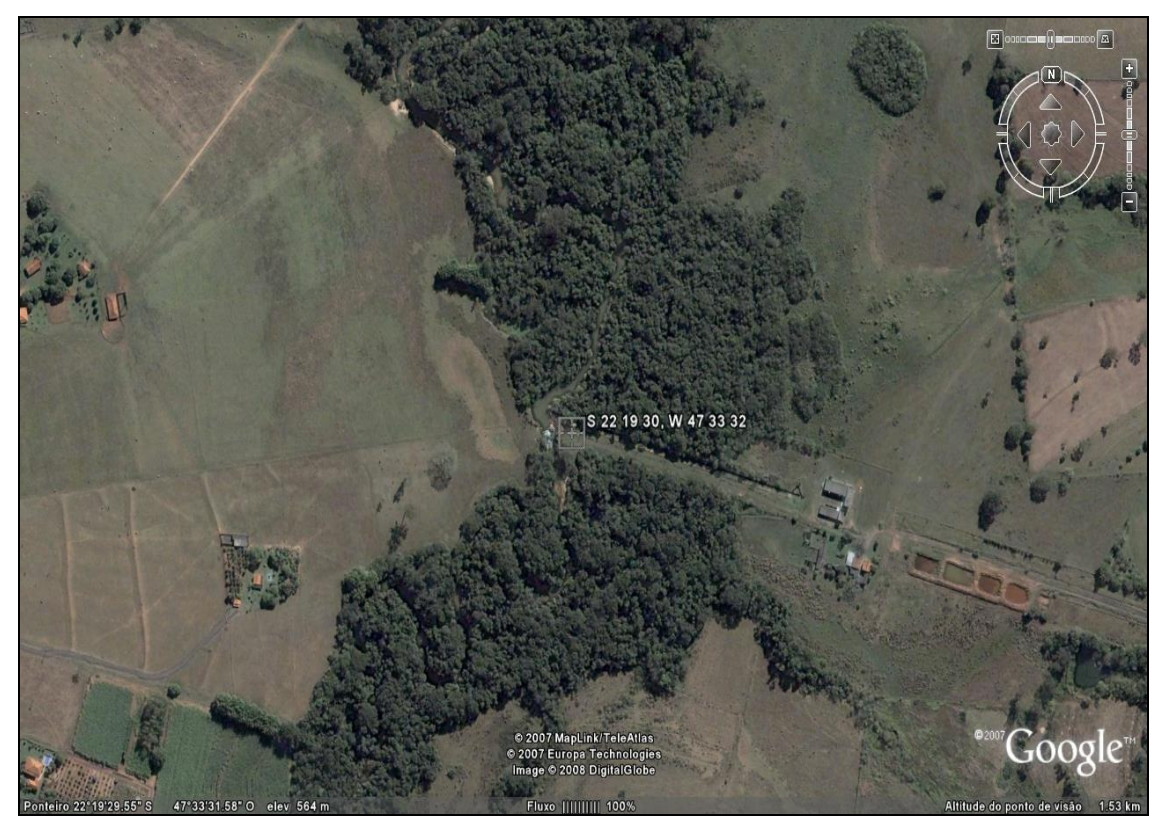

Figura 3. Foto tirada por satélite da área de entorno do Ponto de coleta 5 , no rio Corumbataí (no centro), município de Rio Claro. Este é o local do ponto de captação de água para tratamento e abastecimento da cidade de Rio Claro.

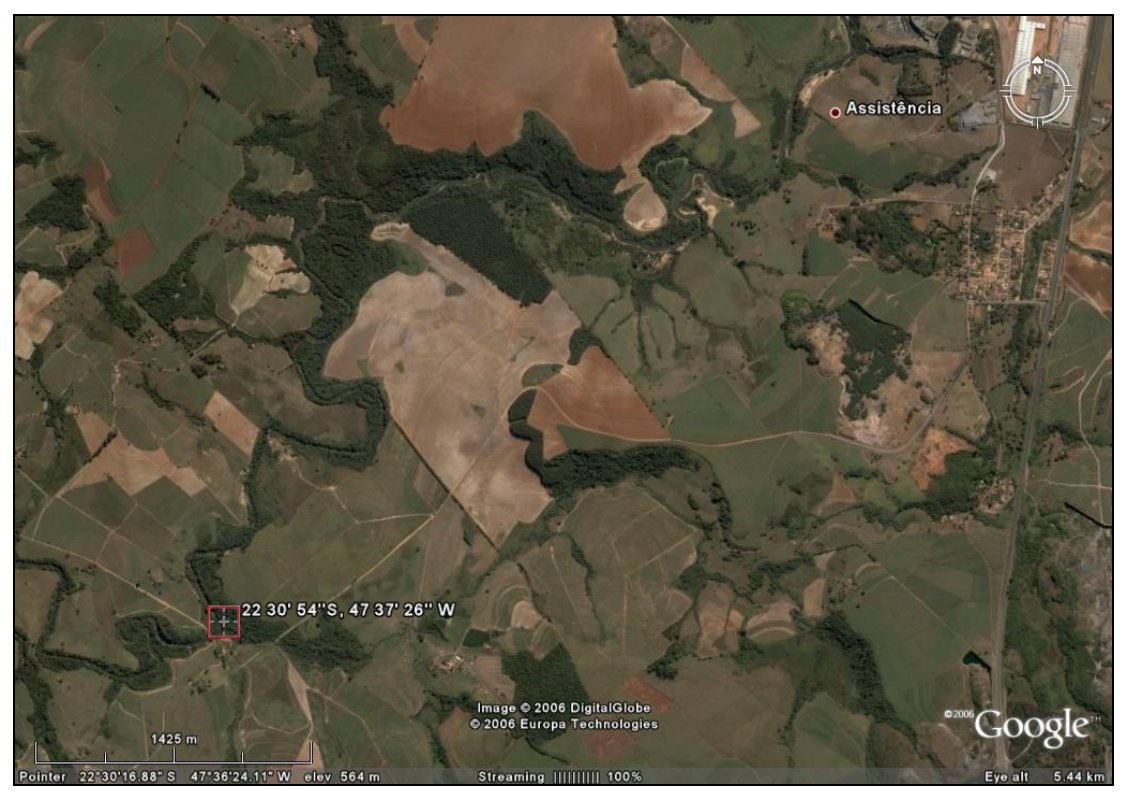

Figura 4. Foto tirada por satélite da área de entorno do Ponto de coleta 6, no rio Corumbataí (abaixo, à esquerda). No alto à direita, está localizado o distrito de Assistência, e à direita a rodovia Piracicaba-Rio Claro. 


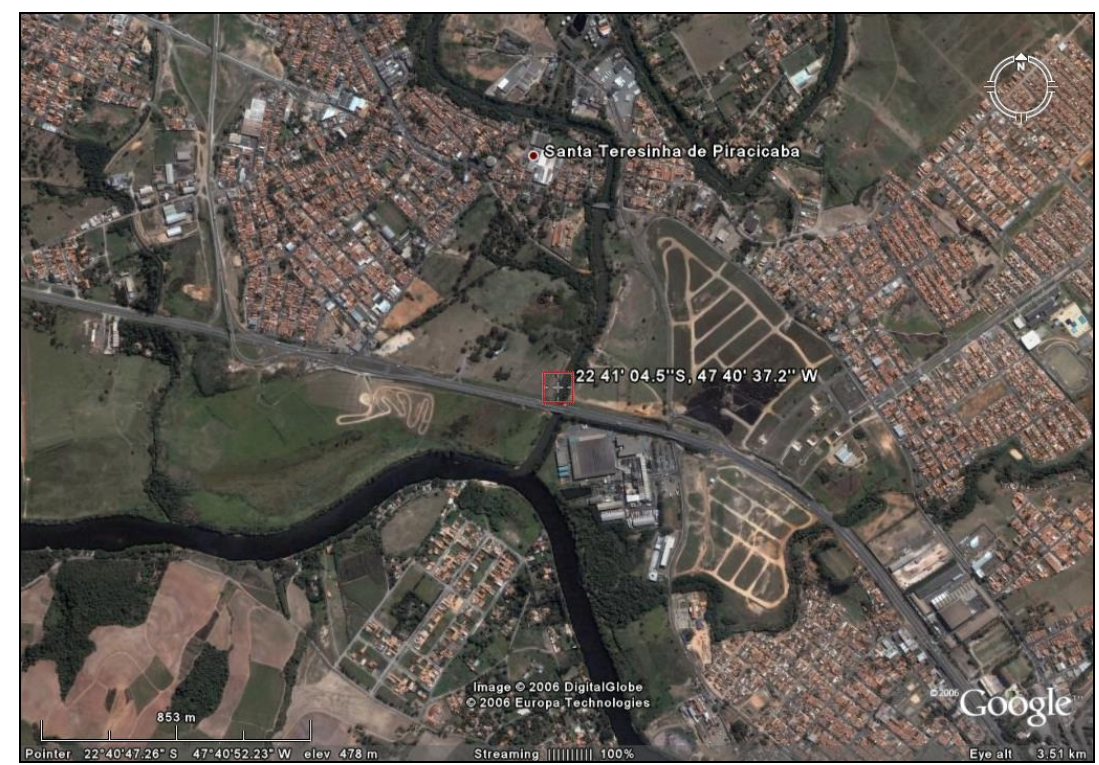

Figura 5. Foto tirada por satélite da área de entorno do Ponto de coleta 7 , no rio Corumbataí (centro da foto), localizado no Bairro de Santa Teresinha. O Ponto 7 localizase a alguns metros da foz do rio Corumbataí, no rio Piracicaba (abaixo), onde é possível observar a diferença entre a coloração da água dos dois rios.

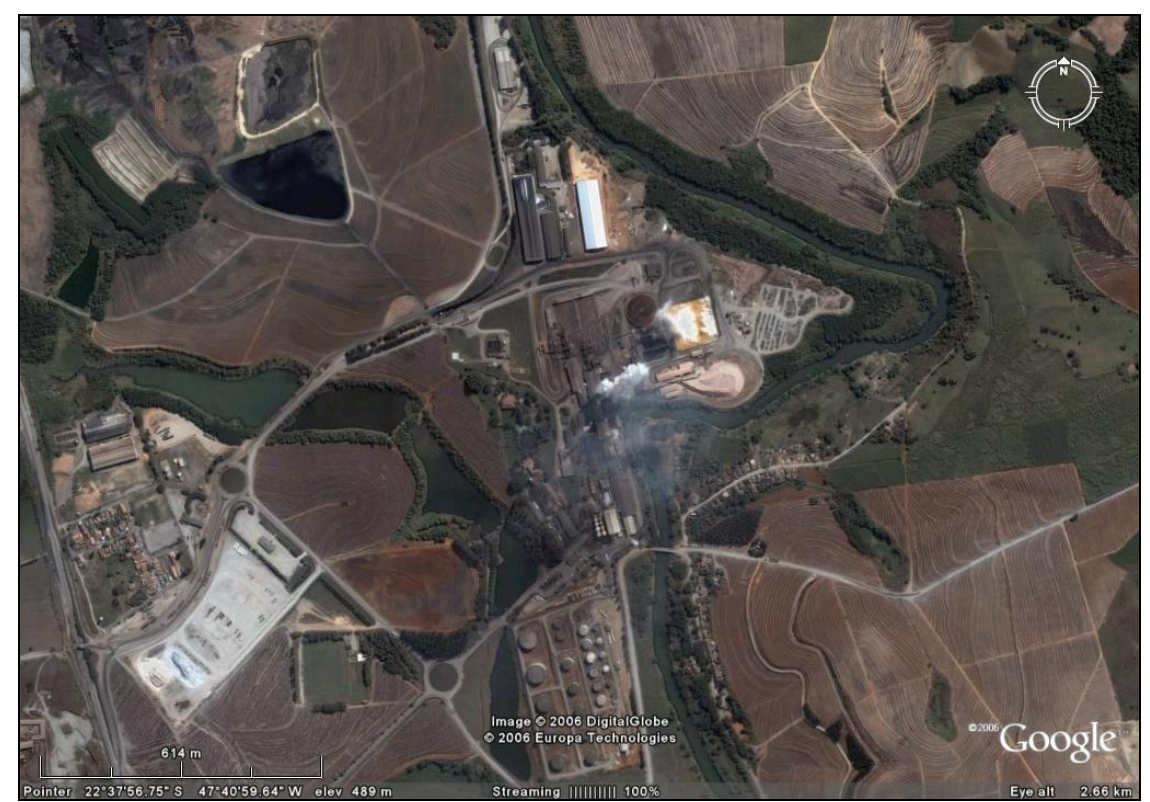

Figura 6. Foto tirada por satélite da área onde se localiza a Usina Costa Pinto, às margens do rio Corumbataí, entre os Pontos de coleta 6 e 7, e a jusante da captação de água para tratamento e abastecimento público de Piracicaba. 


\subsubsection{Coleta de amostras}

As amostras de água de cada ponto foram coletadas com auxílio de um balde de 10 L de capacidade, e armazenadas em frascos de polietileno (1 L de capacidade), devidamente identificados e mantidos em caixa de isopor, com gelo, para o transporte até o laboratório, onde permaneceram refrigeradas a $4^{\circ} \mathrm{C}$ até o momento da execução dos testes de toxicidade (não ultrapassando três dias de armazenagem), segundo norma da USEPA (2000). Os frascos de polietileno foram previamente lavados, mantidos em solução de ácido nítrico $10 \%$ por 24 h, enxaguados com água destilada e após secar em estufa, mantidos fechados para evitar contaminação.

As amostras de sedimento foram coletadas no meio da calha do rio, com auxílio de um aparato de aço-inox (Figura 7). Cada amostra de sedimento foi colocada em sacos plásticos duplos previamente identificados, e mantida em uma caixa de isopor, com gelo, para o transporte até o laboratório. Estas amostras permaneceram refrigeradas a $4^{\circ} \mathrm{C}$, e mantidas no escuro até o momento da execução dos testes de toxicidade (não ultrapassando seis semanas de armazenagem), segundo Burton (1992).

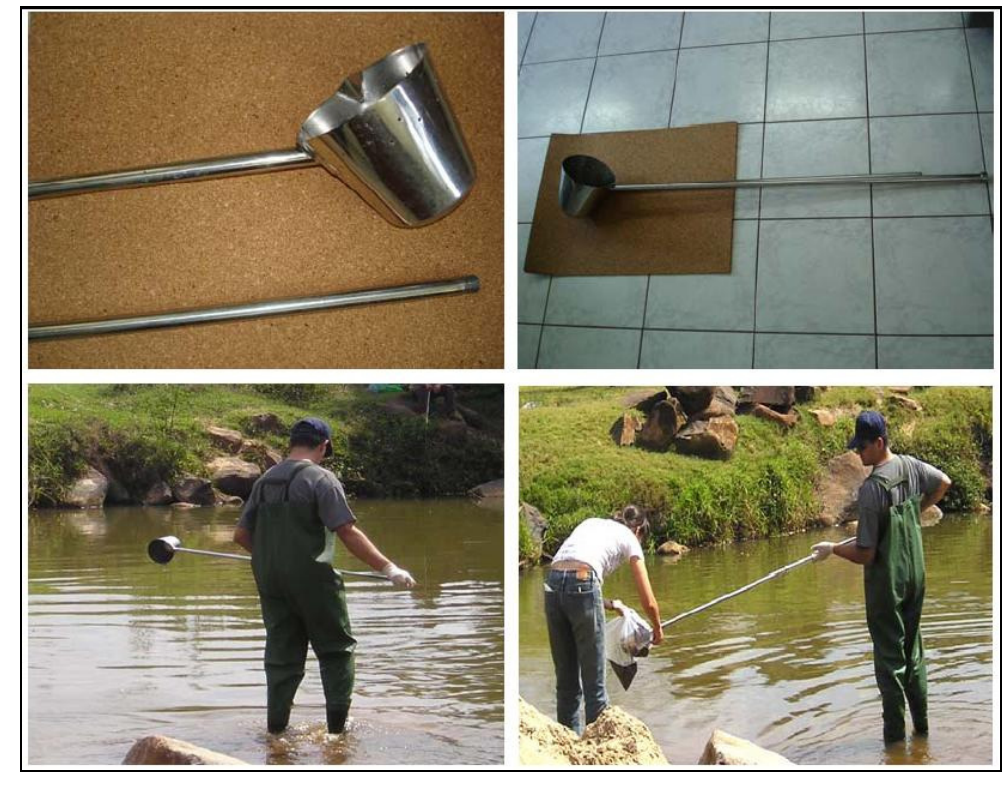

Figura 7. Aparato coletor de sedimentos e procedimento de coleta. 


\subsection{3 Época das coletas}

As coletas de amostras de água e sedimentos foram realizadas aproximadamente a cada três meses (uma para cada estação do ano), totalizando oito coletas no decorrer do período de Novembro de 2004 a Setembro de 2006. A Tabela 2 mostra os dias em que cada coleta foi realizada, a estação do ano, a época (de chuva ou de seca) e o volume de chuva acumulado dos 5 dias anteriores ao dia de cada coleta, segundo a estação meteorológica da ESALQ (ESALQ, 2008).

Tabela 2. Data das coletas realizadas no rio Corumbataí, e dados de pluviosidade.

\begin{tabular}{cccc}
\hline Datas das coletas & Estação & Época & Chuva nos últimos 5 dias (mm) \\
\hline 18 / NOV / 2004 & Primavera & Chuva & 62,3 \\
14 / FEV / 2005 & Verão & Chuva & 3,6 \\
31 / MAI / 2005 & Outono & Seca & 0,0 \\
23 / SET / 2005 & Primavera & Seca & 0,2 \\
5 / DEZ / 2005 & Primavera & Chuva & 44,1 \\
6 / MAR / 2006 & Verão & Chuva & 29,5 \\
12 / JUN / 2006 & Outono & Seca & 0,0 \\
18 / SET / 2006 & Inverno & Chuva & 25,5 \\
\hline
\end{tabular}

\subsubsection{Dados de campo}

Em campo, foram medidos parâmetros físicos e químicos das amostras recém coletadas, com auxílio de um balde de aço-inox de 20 L de capacidade. Foram medidos os seguintes parâmetros:

- $\mathrm{pH}$, e temperatura da água $\left(\mathrm{em}^{\circ} \mathrm{C}\right)$, com auxílio de $\mathrm{pH}$-metro de campo, marca Thermo Oriom, modelo 210A+.

- Oxigênio dissolvido (em $\mathrm{mg} \mathrm{L}^{-1}$ ), com auxílio de oxímetro de campo, marca YSI, modelo 95.

- Condutividade (em $\mu \mathrm{S} \mathrm{cm}^{-1}$ ), com auxílio de condutivímetro de campo, marca Digimed, modelo DM-3. 


\subsubsection{Demanda Bioquímica de Oxigênio (DBO)}

Para as determinações de DBO (em $\mathrm{mg} \mathrm{L}^{-1}$ ) foram coletadas amostras, que foram devidamente preservadas para as análises em laboratório, realizadas pelo Laboratório de Ecologia Isotópica, do Centro de Energia Nuclear na Agricultura (ESALQ-USP). As determinações de DBO seguiram protocolo de APHA (1992).

\subsubsection{Determinações de nutrientes, clorofila-a, sólidos totais, turbidez e fluoretos}

As determinações dos seguintes nutrientes foram realizadas nos laboratórios do SEMAE-Piracicaba: N-total (CETESB, 1978d), Amônia (CETESB, 1978b), Nitrato (CETESB, 1978c), P-total, P-solúvel, e $\mathrm{PO}_{4}{ }^{3-}$ (CETESB, 1978a), turbidez (NTU) e sólidos totais (CETESB, 1978e). As medições de fluoretos $\left(\mathrm{em} \mathrm{mg} \mathrm{L}^{-1}\right)$ foram feitas com auxílio de um fluorímetro, marca Thermo Orion, modelo 96-09.

As determinações de clorofila-a também foram realizadas nos laboratórios do SEMAE-Piracicaba, segundo metodologia de NEN 6520 (1981), e expressas em $\mu \mathrm{g} \mathrm{L}^{-1}$.

\subsubsection{Determinação de coliformes}

As amostras de água para determinação de coliformes foram coletadas em campo e imediatamente armazenadas em "Bag-Nasco" (estéril), de $100 \mathrm{~mL}$ de capacidade, contendo tiossulfato de sódio, e mantidas em um caixa de isopor com gelo até as análises em laboratório. As determinações de coliformes totais e coliformes fecais foram realizadas pela empresa BioAgri Ambiental, segundo Moed e Hallegraeff (1978) e APHA (2005), e apresentadas na forma de NMP $100 \mathrm{~mL}^{-1}$. 


\subsubsection{Manutenção das culturas dos organismos-teste}

As culturas de C. xanthus foram iniciadas em Julho de 2004, a partir de desovas cedidas pelo Laboratório de Ecotoxicologia do CRHEA (Centro de Recursos Hídricos e Ecologia Aplicada), da EESC - Escola de Engenharia de São Carlos/USP São Carlos.

As culturas de D. magna foram iniciadas em Julho de 2004, a partir de fêmeas cedidas pelo Laboratório de Ecotoxicologia do CENA.

As culturas de $H$. attenuata foram iniciadas a partir de indivíduos adultos cedidos pelo Laboratório de Ecossistemas Fluviais do Saint Lawrence Centre, Montreal, Canadá.

As culturas de $P$. subcapitata foram iniciadas a partir de inóculos cedidos pelo Laboratório de Ecossistemas Fluviais do Saint Lawrence Centre, Montreal, Canadá, provenientes da Coleção de Culturas Americanas (ATCC No 22662).

\subsubsection{1 Água reconstituída para cultivo e teste de Chironomus xanthus}

A água reconstituída utilizada no cultivo e nos testes de toxicidade para C. xanthus segue metodologia de Fonseca (1997) e Fonseca e Rocha (2004), e recomendações da USEPA (2000) para Chironomus tentans, apresentando a composição detalhada na Tabela 3. A água preparada com esta composição apresenta dureza total de $12-16 \mathrm{mg} \mathrm{CaCO}_{3} \mathrm{~L}^{-1}$ (água mole), e pH na faixa de 7,2 a 7,6, e passa por aeração nas primeiras 24 horas após o preparo.

Tabela 3. Composição do meio de cultivo para C. xanthus.

\begin{tabular}{lc}
\hline Reagentes & $\mathbf{m g ~ \mathbf { L } ^ { - 1 }}$ \\
\hline $\mathrm{CaSO}_{4}$ & 10,50 \\
$\mathrm{MgSO}_{4}$ & 21,35 \\
$\mathrm{NaHCO}_{3}$ & 16,80 \\
$\mathrm{KCl}$ & 0,70 \\
\hline
\end{tabular}




\subsubsection{2 Água reconstituída para cultivo e teste de Daphnia magna}

A água reconstituída utilizada no cultivo e nos testes de toxicidade para $D$. magna (Meio Elendt M4) segue normas da OECD (1987), apresentando dureza total de $250 \pm 25$ mg L ${ }^{-1} \mathrm{CaCO}_{3}$ e pH entre 7,0 e 8,0, e passa por aeração nas primeiras 24 horas após o preparo. Deve ser preparada a partir das soluções mostradas na Tabela 4, e estas soluções mantidas a $4^{\circ} \mathrm{C}$

Tabela 4. Composição do meio de cultivo (Elendt M4) para D. magna.

\begin{tabular}{|c|c|c|c|}
\hline $\begin{array}{l}\text { Solução } \\
\text { Estoque }\end{array}$ & Reagente & Quantidade $\mathrm{g} \mathrm{L}^{-1}$ & $\begin{array}{c}\begin{array}{c}\text { Sol-estoque mL } \mathrm{L}^{-1} \text { de } \\
\text { meio }\end{array} \\
\end{array}$ \\
\hline 1 & $\mathrm{CaCl}_{2} \cdot 2 \mathrm{H}_{2} \mathrm{O}$ & 73,52 & 4 \\
\hline 2 & $\mathrm{MgSO}_{4} \cdot 7 \mathrm{H}_{2} \mathrm{O}$ & 123,3 & 1 \\
\hline 3 & $\mathrm{KCl}$ & 5,8 & 1 \\
\hline 4 & $\mathrm{NaHCO}_{3}$ & 64,8 & 1 \\
\hline \multirow{7}{*}{5} & $\mathrm{MnCl}_{2} \cdot 4 \mathrm{H}_{2} \mathrm{O}$ & 3,605 & \multirow{7}{*}{0,1} \\
\hline & $\mathrm{LiCl}$ & 3,06 & \\
\hline & $\mathrm{RbCl}$ & 0,71 & \\
\hline & $\mathrm{SrCl}_{2} \cdot 6 \mathrm{H}_{2} \mathrm{O}$ & 1,52 & \\
\hline & $\mathrm{CuCl}_{2} \cdot 2 \mathrm{H}_{2} \mathrm{O}$ & 0,1675 & \\
\hline & $\mathrm{ZnCl}_{2}$ & 0,13 & \\
\hline & $\mathrm{CoCl}_{2} \cdot 6 \mathrm{H}_{2} \mathrm{O}$ & 0,1 & \\
\hline \multirow{7}{*}{6} & $\mathrm{H}_{3} \mathrm{BO}_{3}$ & 5,719 & \multirow{7}{*}{0,5} \\
\hline & $\mathrm{NaBr}$ & 0,032 & \\
\hline & $\mathrm{Na}_{2} \mathrm{MoO}_{4} \cdot 2 \mathrm{H}_{2} \mathrm{O}$ & 0,126 & \\
\hline & KI & 0,0065 & \\
\hline & $\mathrm{Na}_{2} \mathrm{SeO}_{3}$ & 0,00438 & \\
\hline & $\mathrm{NH}_{4} \mathrm{VO}_{3}$ & 0,00115 & \\
\hline & $\mathrm{NaNO}_{3}$ & 0,548 & \\
\hline 7 & $\mathrm{Na}_{2} \mathrm{SiO}_{3}$ & 0,021 & 0,2 \\
\hline 8* $^{*}$ & $\mathrm{FeSO}_{4} \cdot 7 \mathrm{H}_{2} \mathrm{O}$ & 0,1991 & 5 \\
\hline \multirow{2}{*}{9} & $\mathrm{KH}_{2} \mathrm{PO}_{4}$ & 0,286 & \multirow{2}{*}{0,5} \\
\hline & $\mathrm{K}_{2} \mathrm{HPO}_{4}$ & 0,368 & \\
\hline \multirow{3}{*}{10} & Hidrocloreto de tiamina & 0,75 & \multirow{3}{*}{0,1} \\
\hline & Cianocobalamina $\left(\mathrm{B}_{12}\right)$ & 0,010 & \\
\hline & Biotina & 0,0075 & \\
\hline
\end{tabular}




\subsubsection{3 Água reconstituída para cultivo e teste de Hydra attenuata}

A água reconstituída utilizada no cultivo e nos testes de toxicidade para $H$. attenuata segue a metodologia descrita em Trottier et al. (1997), apresentando a composição detalhada na Tabela 5. Após o preparo do meio de cultivo, o pH é ajustado para 7,0 utilizando-se soluções de $\mathrm{NaOH}$ ou $\mathrm{HCl} 1 \mathrm{M}$.

Tabela 5. Composição do meio de cultivo para $H$. attenuata.

\begin{tabular}{lc}
\hline Reagentes & $\mathbf{g ~ L}^{-1}$ \\
\hline $\mathrm{CaCl}_{2} \cdot 2 \mathrm{H}_{2} \mathrm{O}$ & 0,147 \\
$\mathrm{~N}$-tris [hidroximetil] ácido metil 1-2-aminoetanesulfonico (Tampão TES) & 0,11 \\
\hline
\end{tabular}

\subsubsection{Meio de cultivo para Pseudokirchneriella subcapitata}

O meio de cultivo para manutenção e testes com $P$. subcapitata segue metodologia descrita em Blaise et al. (2000), contendo em sua composição macro e micro-nutrientes necessários ao desenvolvimento desta micro-alga de água doce. A composição do meio utilizado no cultivo de $P$. subcapitata está detalhada na Tabela 6 . O meio é preparado, seu pH ajustado para 7,0 \pm 0,5 com auxílio de $\mathrm{NaOH}$ ou $\mathrm{HCl} 0,1 \mathrm{M}$, e imediatamente autoclavado a $121^{\circ} \mathrm{C}$ por 30 minutos. 
Tabela 6. Composição do meio de cultivo para $P$. subcapitata.

\begin{tabular}{|c|c|c|c|}
\hline Solução-estoque & Reagentes & Quantidade mg $\mathrm{L}^{-1}$ & Sol-estoque $m L L^{-1}$ de meio \\
\hline \multirow{9}{*}{1} & $\mathrm{MgCl}_{2} 6 \mathrm{H}_{2} \mathrm{O}$ & 12160 & \multirow{9}{*}{18} \\
\hline & $\mathrm{CaCl}_{2} \cdot 2 \mathrm{H}_{2} \mathrm{O}$ & 4400 & \\
\hline & $\left(\mathrm{H}_{3} \mathrm{BO}_{3}\right)_{3}$ & 185,6 & \\
\hline & $\mathrm{MnCl}_{2} \cdot 4 \mathrm{H}_{2} \mathrm{O}$ & 416 & \\
\hline & $\mathrm{ZnCl}_{2}$ & 3,28 & \\
\hline & $\mathrm{FeCl}_{3} \cdot 6 \mathrm{H}_{2} \mathrm{O}$ & 159,8 & \\
\hline & $\mathrm{CoCl}_{2} \cdot 6 \mathrm{H}_{2} \mathrm{O}$ & 1,428 & \\
\hline & $\mathrm{NaMoO}_{4} \cdot 2 \mathrm{H}_{2} \mathrm{O}$ & 7,26 & \\
\hline & $\mathrm{CuCl}_{2} \cdot \mathrm{H}_{2} \mathrm{O}$ & 0,012 & \\
\hline Solução-estoque & Reagentes & Quantidade g $\mathrm{L}^{-1}$ & Sol-estoque $m L L^{-1}$ de meio \\
\hline 2 & $\mathrm{NaNO}_{3}$ & 25,5 & 18 \\
\hline 3 & $\mathrm{MgSO}_{4} \cdot 7 \mathrm{H}_{2} \mathrm{O}$ & 14,7 & 18 \\
\hline 4 & $\mathrm{~K}_{2} \mathrm{HPO}_{4}$ & 1,044 & 18 \\
\hline 5 & $\mathrm{NaHCO}_{3}$ & 15 & 18 \\
\hline
\end{tabular}

\subsubsection{Cultivo de $C$. xanthus}

Os cultivos seguiram metodologia de Fonseca e Rocha (2004). Para as culturasestoque, assim como para os controles, foi usado um sedimento de referência, livre de contaminantes, que foi coletado próximo ao local do Ponto 1, e preparado segundo recomendações da USEPA (2000): lavado em água destilada, seco em estufa a $70^{\circ} \mathrm{C}$ por 24 horas, peneirado em peneira de $0,5 \mathrm{~mm}$ de abertura, e queimado em mufla a $500^{\circ} \mathrm{C}$ por 2 horas, para a retirada de matéria orgânica e contaminantes voláteis.

Cada cultura era iniciada a partir de três a cinco desovas (200 a 400 ovos em média), retiradas de bandejas com cultivos já formados, em bandejas plásticas cobertas por uma gaiola de tecido fino (para evitar a fuga dos mosquitos adultos), com uma camada de aproximadamente $2 \mathrm{~cm}$ de sedimento de referência, mais 4 litros de água reconstituída (item 2.2.8.1). As larvas eram alimentadas no primeiro dia com uma solução da alga $P$. subcapitata na concentração final de $10^{5}$ células $\mathrm{mL}^{-1}$, e nos dias subseqüentes três vezes por semana com uma suspensão de ração para peixes Alcon Basic® $\left(10 \mathrm{~g} \mathrm{~L}^{-1}\right)$. A partir do 
$10^{\circ}$ dia após a eclosão das desovas, as larvas já podiam ser retiradas para a montagem dos bioensaios. As culturas foram mantidas a $25 \pm 1{ }^{\circ} \mathrm{C}$, e sob fotoperíodo de $12 \mathrm{~h}$, no Laboratório de Ecologia Aplicada do CENA-USP.

\subsubsection{Cultivo de D. magna}

Fêmeas de D. magna foram cultivadas em água reconstituída (Meio Elendt M4), e alimentadas três vezes por semana com uma suspensão algal de $P$. subcapitata $\left(5 \times 10^{5}\right.$ células $\left.\mathrm{mL}^{-1}\right)$, mais uma solução de fermento biológico $\left(5 \mathrm{~g} \mathrm{~L}^{-1}\right)$ e ração para trutas $\left(5 \mathrm{~g} \mathrm{~L}^{-1}\right)$. Antes da alimentação, os neonatos nascidos eram retirados das culturas, e o meio trocado. Cada cultura era mantida por cerca de um mês, e após este período descartada. Neonatos nascidos na primeira e na segunda crias eram descartados, e não usados nos bioensaios. As culturas-estoque de D. magna foram mantidas a $22 \pm 1{ }^{\circ} \mathrm{C}$, e sob fotoperíodo de $12 \mathrm{~h}$, no Laboratório de Ecologia Aplicada do CENA-USP.

\subsubsection{Cultivo de H. attenuata}

A metodologia para os testes com Hydra foi baseada em Trottier et al. (1997). Os indivíduos da cultura-estoque foram cultivados em água reconstituída, em cristalizador de 1 litro, e alimentados com artêmias de água salgada (Artemia salina), eclodidas no dia, três vezes por semana, no Laboratório de Ecologia Aplicada do CENA-USP. A troca de meio cultivo era realizado três vezes por semana, duas horas após a alimentação dos indivíduos. As culturas-estoque de $H$. attenuata foram mantidas a $22 \pm 1{ }^{\circ} \mathrm{C}$, e sob fotoperíodo de $12 \mathrm{~h}$. 


\subsubsection{Cultivo de $P$. subcapitata}

A alga P. subcapitata obtida da Coleção de Culturas Americana (ATCC nº 22662), foi mantida em meio de cultura previamente autoclavado a $120^{\circ} \mathrm{C}$ por 30 minutos (preparado adicionando-se $18 \mathrm{~mL}$ de cada uma das soluções-estoque para $1 \mathrm{~L}$ de água destilada). As culturas, mantidas em frascos Erlenmeyers de $250 \mathrm{~mL}$, com $50 \mathrm{~mL}$ de meio, foram incubadas sob iluminação contínua com lâmpadas frias fluorescentes $(4.000 \pm 10 \%$ lux) à $25 \pm 2^{\circ} \mathrm{C}$ e agitadas manualmente por alguns segundos, três vezes ao dia. Entre 5 a 7 dias após a repicagem, as culturas estavam no ponto ideal para a montagem dos bioensaios. Novas culturas eram repicadas semanalmente, mantendo-as sempre prontas para a montagem dos bioensaios. As culturas-estoque de $P$. subcapitata foram mantidas, seguindo metodologia de Blaise et al. (2000), no próprio laboratório de Ecologia Aplicada do CENA-USP.

\subsubsection{Testes de sensibilidade}

A partir de Abril de 2005 foi implementada a realização dos testes de sensibilidade, a fim de avaliar a qualidade das culturas mantidas em laboratório, para a realização dos testes de toxicidade. Para todos os organismos, foi adotada como substância de referência o $\mathrm{NaCl}$ P.A., dissolvido no meio de cultivo de cada organismo-teste. Decidiu-se pela utilização do $\mathrm{NaCl}$ como substância de referência, ao invés de um metal, com o objetivo de minimizar o manuseio e o contato com substâncias nocivas à saúde humana, bem como visando a redução de resíduos perigosos produzidos pelos próprios bioensaios.

Os testes de sensibilidade foram repetidos mensalmente, expondo os organismos à substância de referência nas mesmas condições dos testes de toxicidade - como temperatura, fotoperíodo, número de repetições, tempo de exposição, recipientes 
experimentais utilizados, e endpoints avaliados ao final do tempo de exposição. Inicialmente, fez-se um teste preliminar com diluições da substância de referência em escala logarítmica, para encontrar, posteriormente, uma faixa adequada de concentrações para a realização do teste de sensibilidade definitivo.

Os resultados foram expressos na forma de $\mathrm{CL}_{50}(96 \mathrm{~h})$ para C. xanthus, $\mathrm{CL}_{50}(48 \mathrm{~h})$ para D. magna, $\mathrm{CE}_{50}(96 \mathrm{~h})$ e $\mathrm{CL}_{50}(96 \mathrm{~h})$ para $H$. attenuata, e $\mathrm{CI}_{50}(72 \mathrm{~h})$ para $P$. subcapitata. Os cálculos de todos os parâmetros de toxicidade foram determinado pelo método Trimmed Spearman-Karber (HAMILTON et al., 1977). Com todos os resultados obtidos ao longo do período em que os testes de sensibilidade foram realizados, foi feita uma carta controle para cada espécie, para comparação e análise dos resultados.

\subsubsection{Testes de toxicidade}

Para os testes de toxicidade, foi incluído controle negativo, que visa confirmar que o método, os materiais e reagentes empregados não contêm materiais tóxicos que possam interferir na análise das amostras.

Para os testes com sedimento, as amostras provenientes das estações de coleta do rio Corumbataí foram pesadas e distribuídas em recipientes mantendo-se a proporção de 4:1 (peso) de água destilada e sedimentos, respectivamente. Após sedimentar por 24 horas, foi retirado o líquido sobrenadante (elutriato). Essa solução foi utilizada a 100\% e diluída com meio de cultivo (próprio para cada espécie) para 75\%, 50\%, 25\%, e 12,5\% (e 6,25\% em alguns casos), para exposição dos organismos-teste. Nos testes com água, foram utilizadas as mesmas concentrações citadas acima, e as diluições feitas da mesma forma supracitada. 
Trabalhos desenvolvidos em paralelo com o presente estudo tiveram como objetivo determinar concentrações de elementos químicos (FALQUETO ${ }^{1}$, em fase de elaboração; ZAMBETTA, 2006) e herbicidas (MONTEIRO et al., 2008; ARMAS, 2006) nas mesmas amostras de água e sedimento. Quando disponíveis, estes dados foram utilizados para auxiliar na interpretação dos resultados obtidos com os testes de toxicidade, assim como os dados dos parâmetros físicos e químicos. Para isso, os valores de toxicidade foram transformados em Unidades Tóxicas (e.g., UT $=100 \% / \mathrm{CL}_{50}$ ), e correlacionados com as determinações de elementos químicos, herbicidas e outros parâmetros através do método estatístico paramétrico de correlação linear de Pearson ( $<$ <,05), segundo ZAR (1999). Para os cálculos, foi utilizado o software Graphpad Instat® (versão 3.00).

\subsubsection{Testes de toxicidade aguda com Chironomus xanthus}

A metodologia para cultivo de $C$. xanthus foi baseada em Fonseca e Rocha (2004) e para os testes em Fonseca (1997). O teste de toxicidade de sedimentos avaliou a sobrevivência de larvas de C. xanthus à amostras após 96 horas de exposição. Seis larvas de 10 dias de idade $\left(2^{\circ}\right.$ ou $3^{\circ}$ ínstar) foram usadas por réplica, num total de três réplicas para cada ponto de coleta. Para este teste, colocou-se $40 \mathrm{~g}$ de sedimento em $160 \mathrm{~mL}$ de meio de cultivo (proporção de 1:4), de maneira a ressuspender o sedimento em um frasco de polipropileno de $300 \mathrm{~mL}$ de capacidade. Após 24 horas, as larvas foram colocadas nos frascos e alimentadas com $1 \mathrm{~mL}$ de uma solução preparada com ração em flocos para peixes, Alcon ${ }^{\circledR}\left(10 \mathrm{~g} \mathrm{~L}^{-1}\right)$. Os testes foram realizados a $25 \pm 1^{\circ} \mathrm{C}$. Para os controles, foi utilizado o mesmo sedimento de referência utilizado nos cultivos.

\footnotetext{
${ }^{1}$ FALQUETO, M. Elementos químicos na água e sedimento do rio Corumbataí por ICP-MS. Dissertação (Mestrado em Ecologia Aplicada) - Interunidades - Centro de Energia Nuclear na Agricultura, Escola Superior de Agricultura Luiz de Queiroz, Universidade de São Paulo, Piracicaba, Em fase de elaboração.
} 


\subsubsection{Testes de toxicidade aguda com Daphnia magna}

Para os testes com D. magna (água bruta e elutriato), grupos de 5 neonatos com até 24 horas de idade foram separados e colocados em frascos de poliestireno contendo $30 \mathrm{~mL}$ do líquido testado (água bruta ou elutriato), e expostos durante um período de 48 horas. O controle negativo foi realizado com água reconstituída. Para todos os pontos de coleta, e em todas as diluições, foram feitas 4 réplicas, inclusive nos controles, totalizando 20 neonatos expostos por amostra. Os animais não foram alimentados no início e nem durante o teste. $\mathrm{O}$ efeito medido nestes testes foi a mortalidade, e a estimativa de $\mathrm{CL}_{50}$ determinada através do método Trimmed Spearman-Karber (HAMILTON et al., 1977), quando possível. A metodologia para os testes agudos foi baseada em OECD (1987), seguindo também recomendações de Jonczyk e Gilron (2005).

\subsubsection{Testes de toxicidade com Hydra attenuata}

Nos testes de toxicidade com $H$. attenuata, foram avaliados os efeitos das amostras de água e do elutriato (extraído das amostras de sedimento) sobre a morfologia e a mortalidade dos organismos. A duração destes testes é de 96 horas, e as leituras feitas com o auxílio de uma lupa (Leica, modelo Zoom 2000). Para todos os pontos de coleta, e em todas as diluições, foram feitas 3 réplicas, inclusive nos controles, com 3 organismos selecionados, sem brotos ou danos morfológicos (Figura 8). 


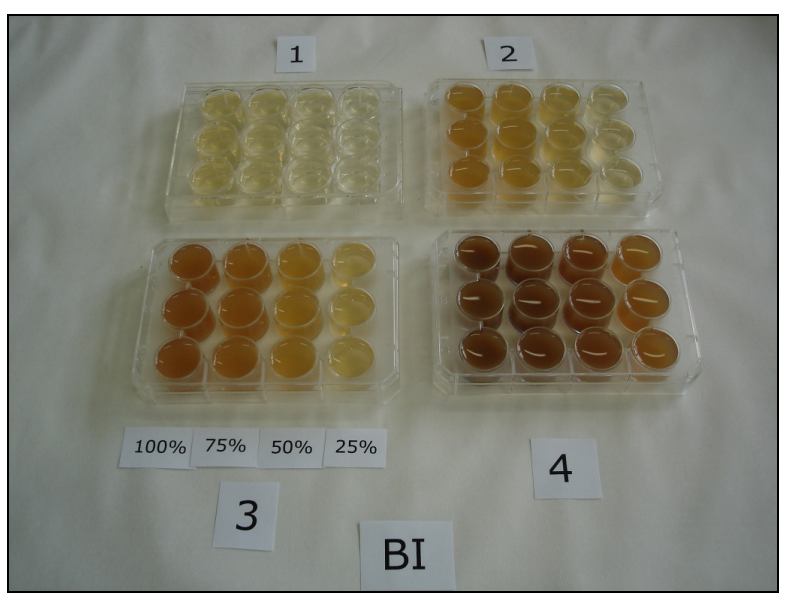

Figura 8. Foto demonstrativa de um teste de toxicidade com $H$. attenuata, em que foram testadas diferentes concentrações de elutriato extraído de amostras de sedimento.

O controle negativo foi realizado com meio de cultivo apropriado. Os efeitos medidos nestes testes são a mortalidade e o surgimento de danos morfológicos (efeitos subletais). Estes se apresentam em estágios progressivos (Figura 9): primeiramente, observa-se o aparecimento de bulbos nas extremidades dos tentáculos do animal (estágio "bulbo"). Posteriormente, tem-se o encurtamento dos tentáculos (estágio “curto”); segue-se a degeneração total dos tentáculos (estágio "tulipa"); e finalmente a morte do animal. Estimativas de $\mathrm{CL}_{50}$ e $\mathrm{CE}_{50}$ foram determinadas através do método Trimmed SpearmanKarber (HAMILTON et al., 1977) e cálculos descritos em Trottier et al. (1997), quando possível. As estimativas de $\mathrm{CL}_{50}$ foram calculadas baseadas no número de indivíduos mortos e no estágio "tulipa", em que os indivíduos não se regeneram mais se forem recolocados em meio de cultivo; enquanto que as de $\mathrm{CE}_{50}$ foram calculadas baseadas no aparecimento de quaisquer danos morfológicos, constituindo, portanto, um endpoint mais sensível. 


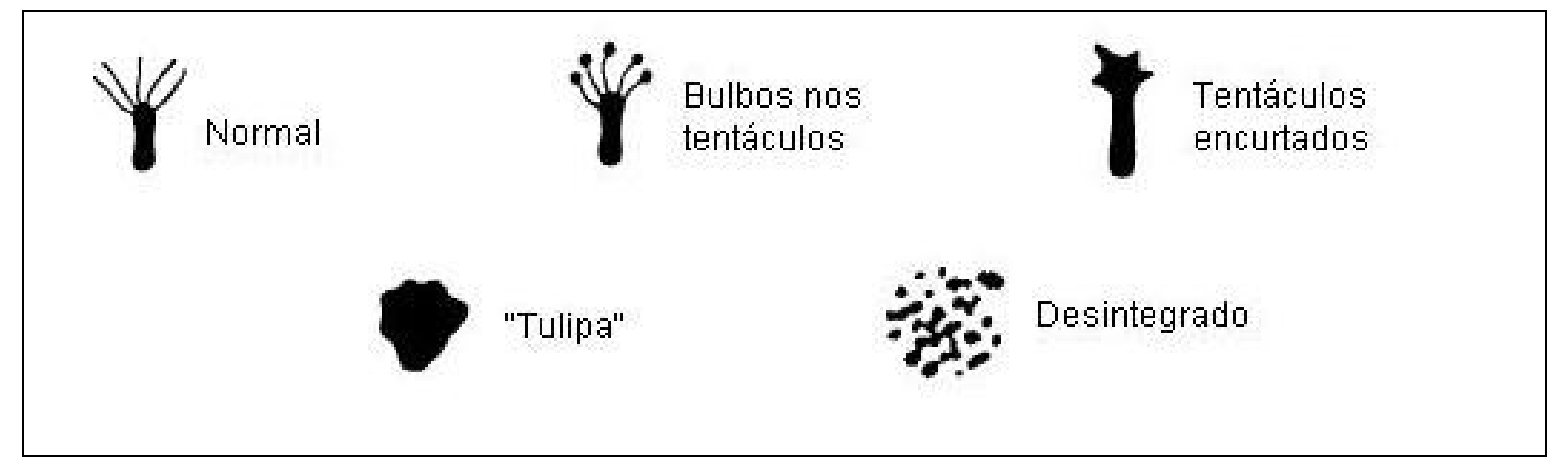

Figura 9. Estágios progressivos de intoxicação e degeneração de indivíduos de $H$. attenuata. Adaptado de Blaise e Kusui (1997).

\subsubsection{Testes de toxicidade com Lactuca sativa}

Para sementes de L. sativa (variedade comercial), foram feitos dois tipos de testes: com água e com sedimento (elutriato). Para ambos os tipos de amostras, e para cada ponto de coleta, placas de Petri ( $9 \mathrm{~cm}$ de diâmetro) contendo um disco de papel de filtro embebido com $2 \mathrm{~mL}$ do líquido testado receberam 20 sementes de L. sativa, uniformemente distribuídas. Para cada ponto de coleta foi testada a toxicidade da água sem diluição e diluída com água destilada para $75 \%, 50 \%$ e $25 \%$. As placas de Petri assim preparadas foram envoltas por papel alumínio e mantidas a $25^{\circ} \mathrm{C}$ por 72 horas, em ausência de luz. O efeito medido, ao final do período de exposição, foi a porcentagem de inibição de crescimento das raízes, em relação ao controle (água destilada).

A estimativa da toxicidade foi determinada pelo $\mathrm{CI}_{50}$ (\% de inibição do crescimento das raízes em relação ao controle) através do método Trimmed Spearman-Karber (HAMILTON et al., 1977), quando possível. Foi calculada também a porcentagem de inibição de crescimento das raízes, em relação ao controle, das amostras puras (sem diluição). A porcentagem de inibição foi calculada segundo a fórmula (1). A metodologia para os testes com sementes de L. sativa seguiu a de Dutka (1997). 


$$
\% \text { Inibição }=100-\left[\left(\frac{\bar{x} \text { amostra }}{\overline{\bar{x} \text { controle }}}\right) * 100\right] \text {, }
$$

\subsubsection{Testes de toxicidade com Pseudokirchneriella subcapitata}

O teste com $P$. subcapitata foi realizado baseado na metodologia descrita por Blaise et al. (2000), e nas recomendações de Staveley e Smrchek (2005). Este teste é recomendado para medir fitotoxicidade em águas, efluentes, águas intersticiais, dentre outros.

Neste bioensaio, certas condições de exposição devem ser satisfeitas para que os resultados sejam julgados como aceitáveis. A validade dos testes para o ensaio de fitotoxicidade é condicionada aos seguintes parâmetros: o coeficiente de variação de cinco amostras controle, com tempo de exposição igual a 72 horas, após a contagem em câmara de Neubauer, não pode exceder a 40\%; e a densidade celular nos frascos de controle deve aumentar por um fator de no mínimo 16.

Entre 5 a 7 dias após a repicagem, a cultura estava no ponto ideal para a montagem dos bioensaios, apresentando crescimento exponencial. A contagem do número de células por $\mathrm{mL}$ era feita, com auxílio de câmara de Neubauer e microscópio óptico. Tendo-se ajustado $2 \mathrm{~mL}$ de água tamponada (que contém $15 \mathrm{mg} \mathrm{L}^{-1}$ de $\mathrm{NaHCO}_{3}$ ) para ter a concentração de $2,6 \times 10^{6}$ células $\mathrm{mL}^{-1}$, adiciona-se $18 \mathrm{~mL}$ de meio de cultivo, obtendo-se, portanto, $20 \mathrm{~mL}$ de solução com concentração final de $2,6 \times 10^{5}$ células $\mathrm{mL}^{-1}$. Esta solução é utilizada como inóculo para as amostras ambientais (água bruta e elutriato), obtendo-se uma concentração de células no início do teste igual a $10^{4}$ células $\mathrm{mL}^{-1}$. Este inóculo contém uma concentração adequada de nutrientes para que a alga cresça durante o ensaio, 
garantindo que seu crescimento seja inibido somente por agentes tóxicos presentes nas amostras ambientais, e não por falta de nutrientes (BLAISE et al., 2000).

Para os testes com as amostras de água e elutriato, populações de $P$. subcapitata foram expostas ao líquido testado, sem diluição, e diluída em frascos contendo meio de cultivo apropriado nas concentrações de $75 \%, 50 \%, 25 \%, 12,5 \%$, e 6,25\%. Estes frascos permaneceram vedados com filme plástico transparente e incubados sob a luz contínua $(4.000 \pm 10 \% \operatorname{lux})$, a $25 \pm 1^{\circ} \mathrm{C}$, por 72 horas, sendo realizada agitação manual três vezes ao dia. Foram feitas 5 réplicas para o controle e três para cada diluição. Após este período, fez-se a avaliação de fitotoxicidade, realizando a contagem das células, com auxílio câmara de Neubauer e microscópio óptico.

As contagens de células de cada amostra foram, posteriormente, transformadas em porcentagem de inibição, em relação à média das amostras-controle, através da seguinte fórmula (2):

$$
\% \text { Inibição }=100-\left[\left(\frac{\text { amostra }}{\overline{\text { xcontrole }}}\right) * 100\right] \text {, }
$$

e estes valores, transformados desta forma, utilizados para os cálculos de $\mathrm{CI}_{50}(72 \mathrm{~h})$, através do método Trimmed-Spearman Karber (HAMILTON et al., 1977), quando possível. 


\subsection{Resultados}

\subsubsection{Dados de campo}

Os dados de campo: $\mathrm{pH}$, temperatura da água $\left(\mathrm{em}{ }^{\circ} \mathrm{C}\right)$, oxigênio dissolvido (O.D., em $\mathrm{mg} \mathrm{L}^{-1}$ ), e condutividade elétrica (em $\mu \mathrm{S} \mathrm{cm}^{-1}$ ) estão mostrados na Figura 10 e na Tabela 48 (Apêndice A). Os valores de pH parecem sofrer certa alteração ao longo do rio, em geral variando entre 6,0 e 7,5, assim como os valores de temperatura seguem as variações diárias, já que as amostras foram coletadas na seqüência da nascente em direção à foz, ao longo do dia. Os valores de O.D. sofrem uma acentuada queda a partir do Ponto 6, enquanto que os valores de condutividade sofrem uma acentuada elevação a partir deste mesmo ponto.

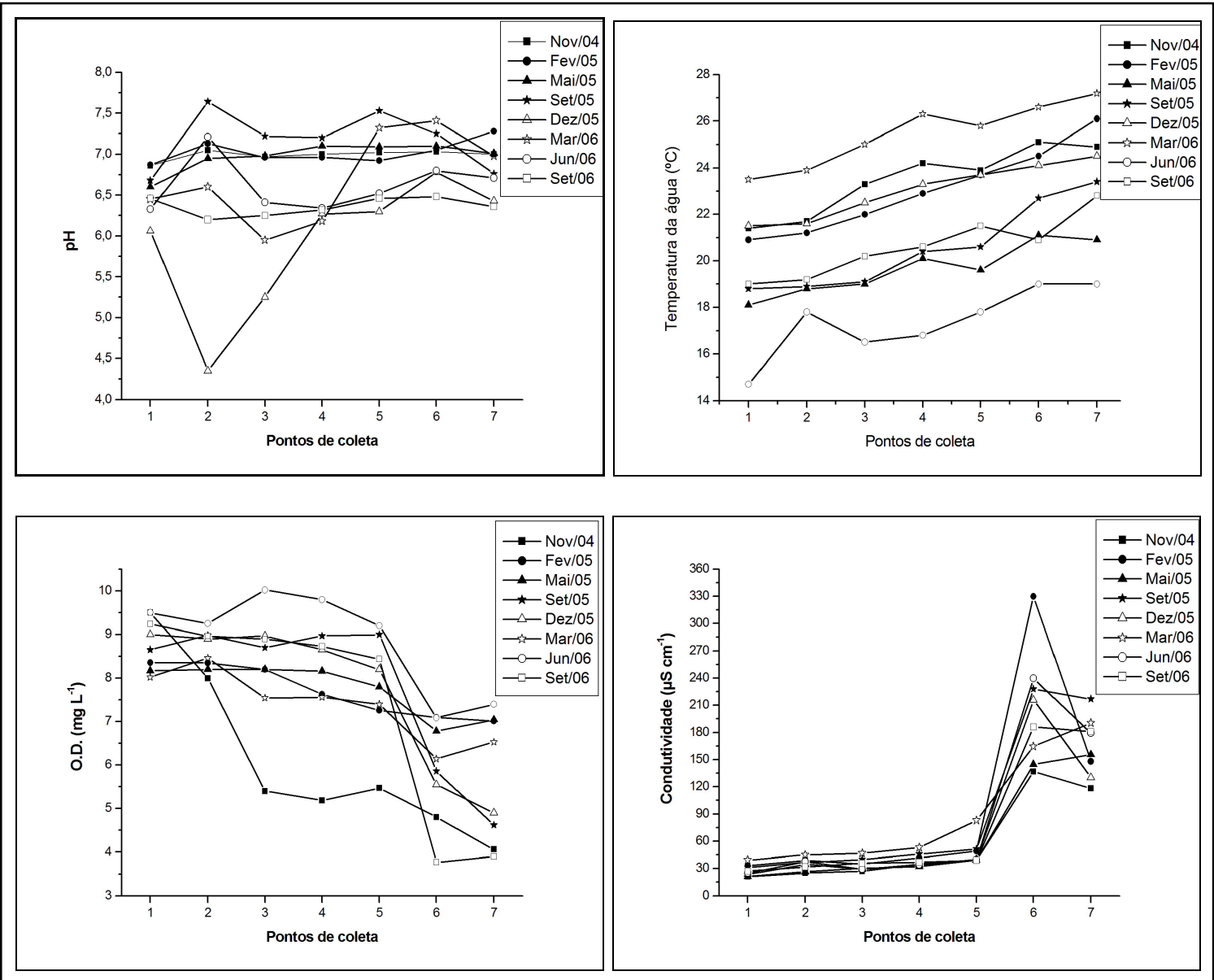

Figura 10. Gráficos com valores de $\mathrm{pH}$, temperatura da água, oxigênio dissolvido e condutividade elétrica das amostras de água coletadas no rio Corumbataí. 


\subsubsection{Demanda Bioquímica de Oxigênio (DBO)}

Os valores obtidos de DBO (em mg L ${ }^{-1}$ ) estão dispostos na Figura 11 e na Tabela 49 (Apêndice A). Com exceção da coleta de Maio/2005, todas as amostras dos Pontos 6 e 7 sofreram um significativo aumento na demanda bioquímica de oxigênio, quando comparadas com as amostras dos pontos precedentes.

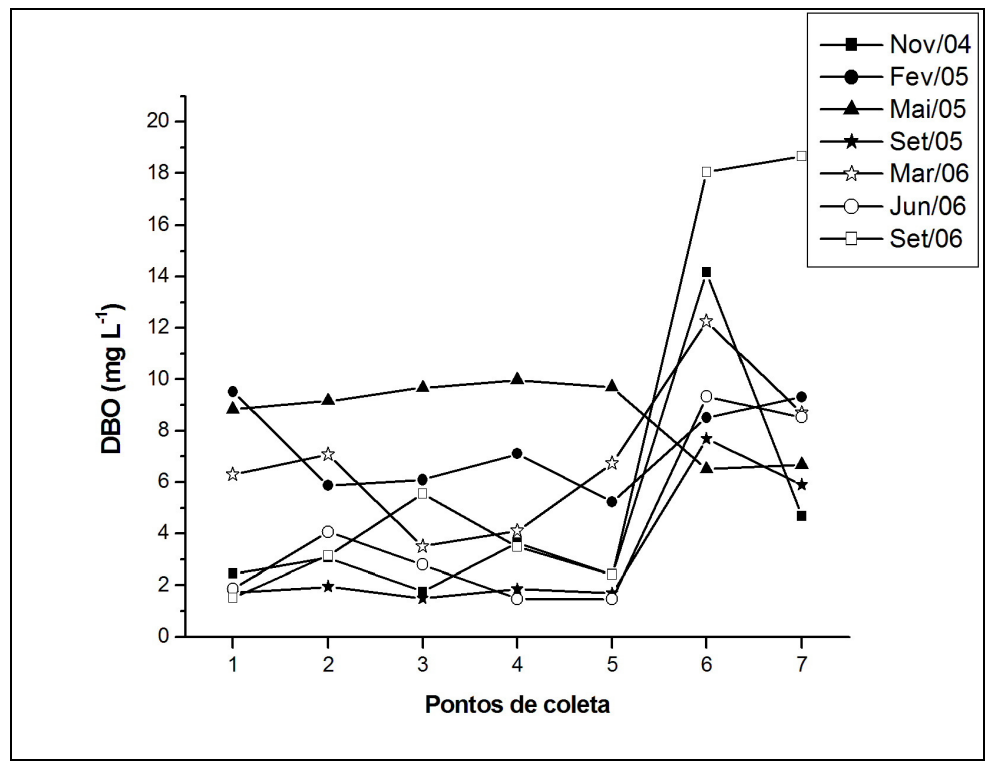

Figura 11. Gráfico com dados de $\mathrm{DBO}\left(\mathrm{mg} \mathrm{L}^{-1}\right)$ das amostras de água coletadas no rio Corumbataí.

\subsubsection{Determinações de nutrientes, clorofila-a, sólidos totais, turbidez e fluoretos}

Os valores de nitrogênio (N-total, Amônia, e Nitrato) estão dispostos na Figura 12, e na Tabela 50 (Apêndice A); enquanto que os valores de fósforo (P-total, P-solúvel, e $\mathrm{PO}_{4}{ }^{3-}$ ) estão na Figura 13 e na Tabela 51 (Apêndice A). Os valores de sólidos totais (mg L'

${ }^{1}$ ), turbidez (NTU), fluoretos $\left(\mathrm{mg} \mathrm{L}^{-1}\right)$, e de clorofila-a encontram-se dispostos na Figura 14 e nas Tabelas 52 e 53 (Apêndice A). 

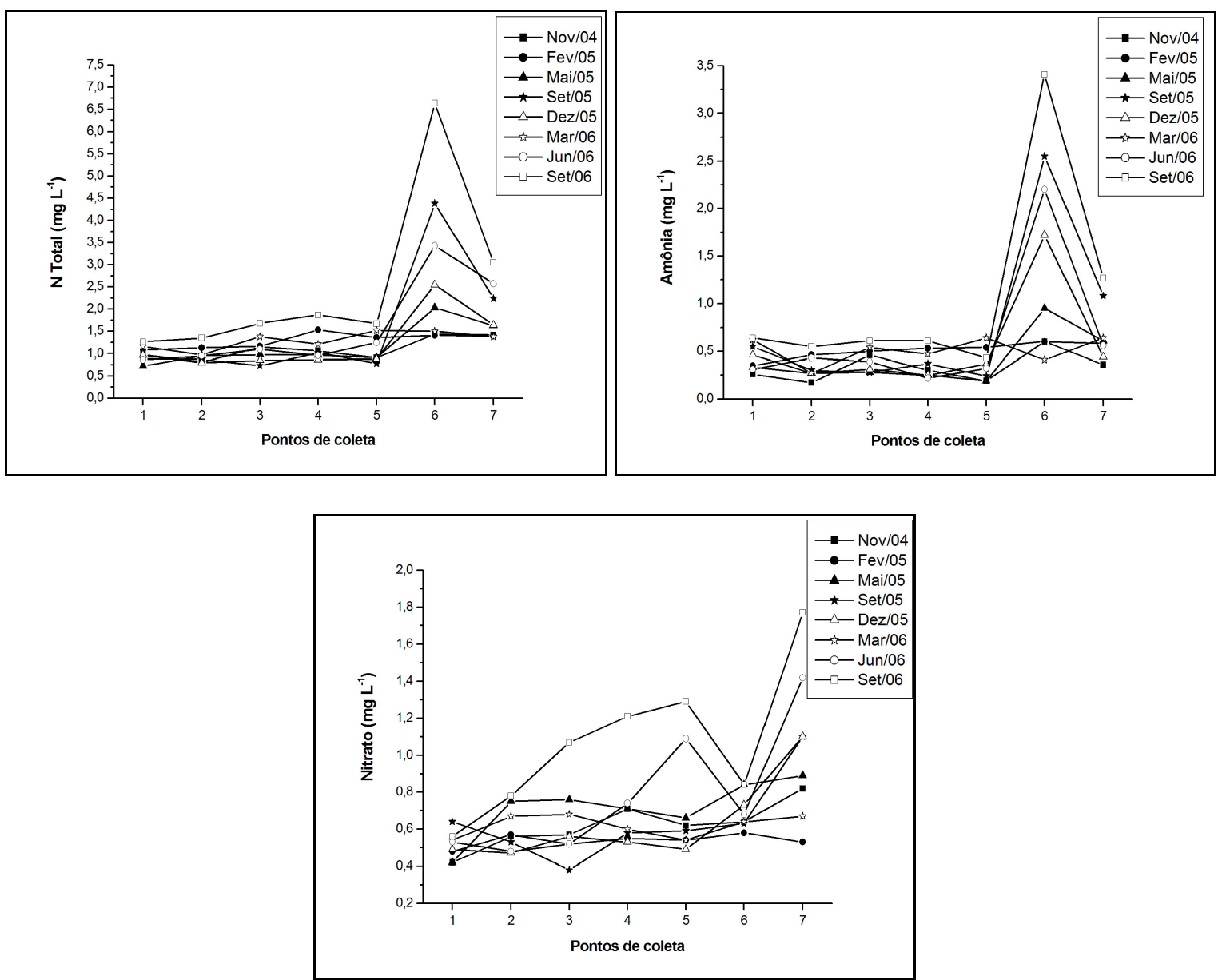

Figura 12. Determinações de Nitrogênio total $\left(\mathrm{mg} \mathrm{L}^{-1}\right)$, amônia $\left(\mathrm{NH}_{3}, \mathrm{mg} \mathrm{L}^{-1}\right)$ e nitrato $\left(\mathrm{mg} \mathrm{L}^{-1}\right)$, das amostras de água coletadas no rio Corumbataí.

Os gráficos da Figura 12 mostram que até o Ponto 5 as medidas de nitrogênio total e de amônia se mantiveram estáveis, tendo aumentado significativamente no Ponto 6. Já no Ponto 7, há uma tendência destas concentrações diminuírem. Já o gráfico de nitrato demonstra concentrações maiores apenas no Ponto 7. Não parece haver influência das estações do ano nos valores medidos de nitrogênio. 

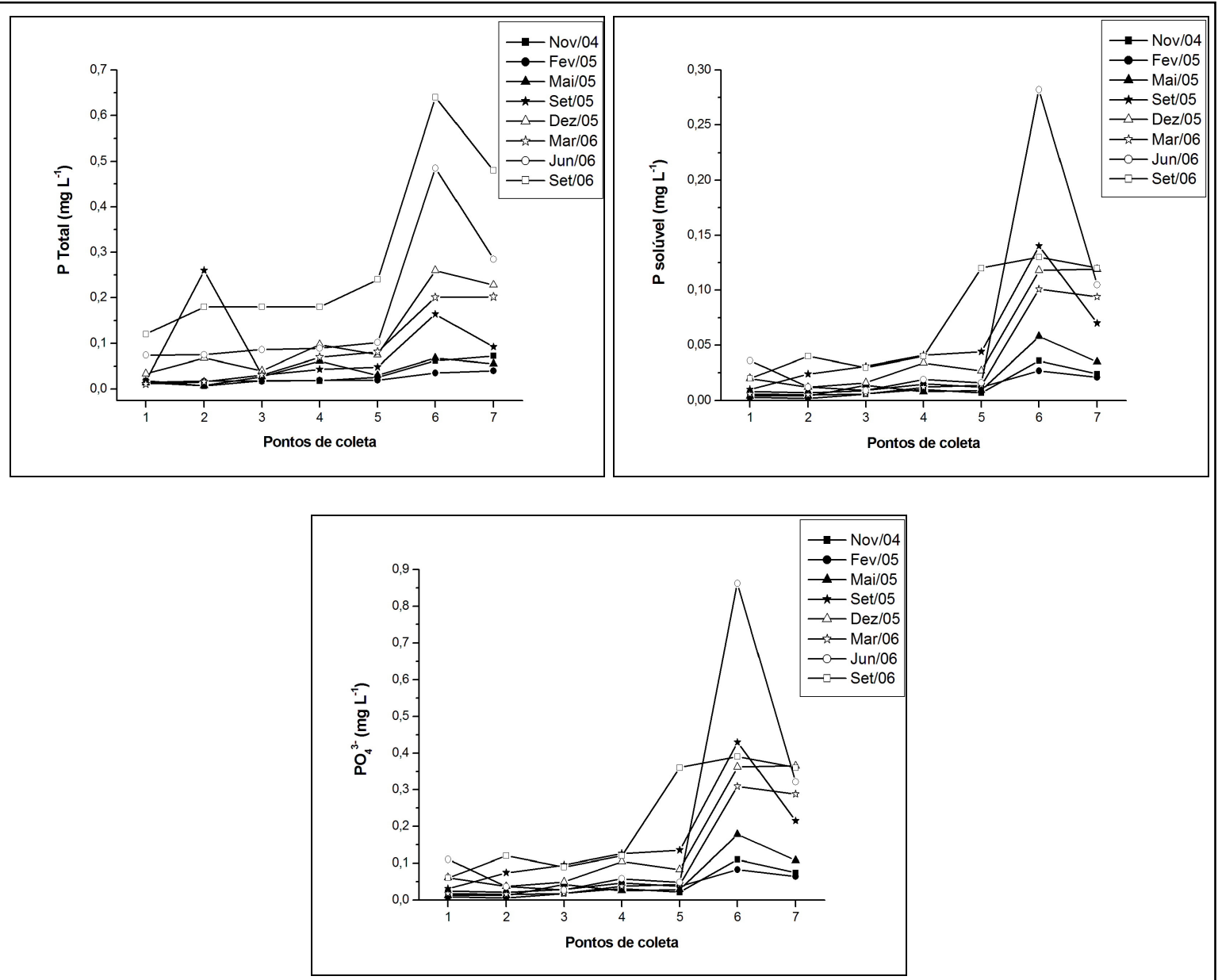

Figura 13. Determinações de fósforo total $\left(\mathrm{mg} \mathrm{L}^{-1}\right)$, fósforo solúvel $\left(\mathrm{mg} \mathrm{L}^{-1}\right)$, e $\mathrm{PO}_{4}{ }^{3-}(\mathrm{mg}$ $\mathrm{L}^{-1}$ ), das amostras de água coletadas no rio Corumbataí.

Os gráficos da Figura 13 mostram que, em geral, até o Ponto 5 as concentrações de fósforo se mantiveram estáveis. No Ponto 6, houve registros de aumentos significativos na maioria das coletas. No Ponto 7, as concentrações das formas de fósforo medidas voltaram a diminuir, apresentando comportamento semelhante ao $\mathrm{N}$-total e à amônia $\left(\mathrm{NH}_{3}\right.$, Figura 12). 

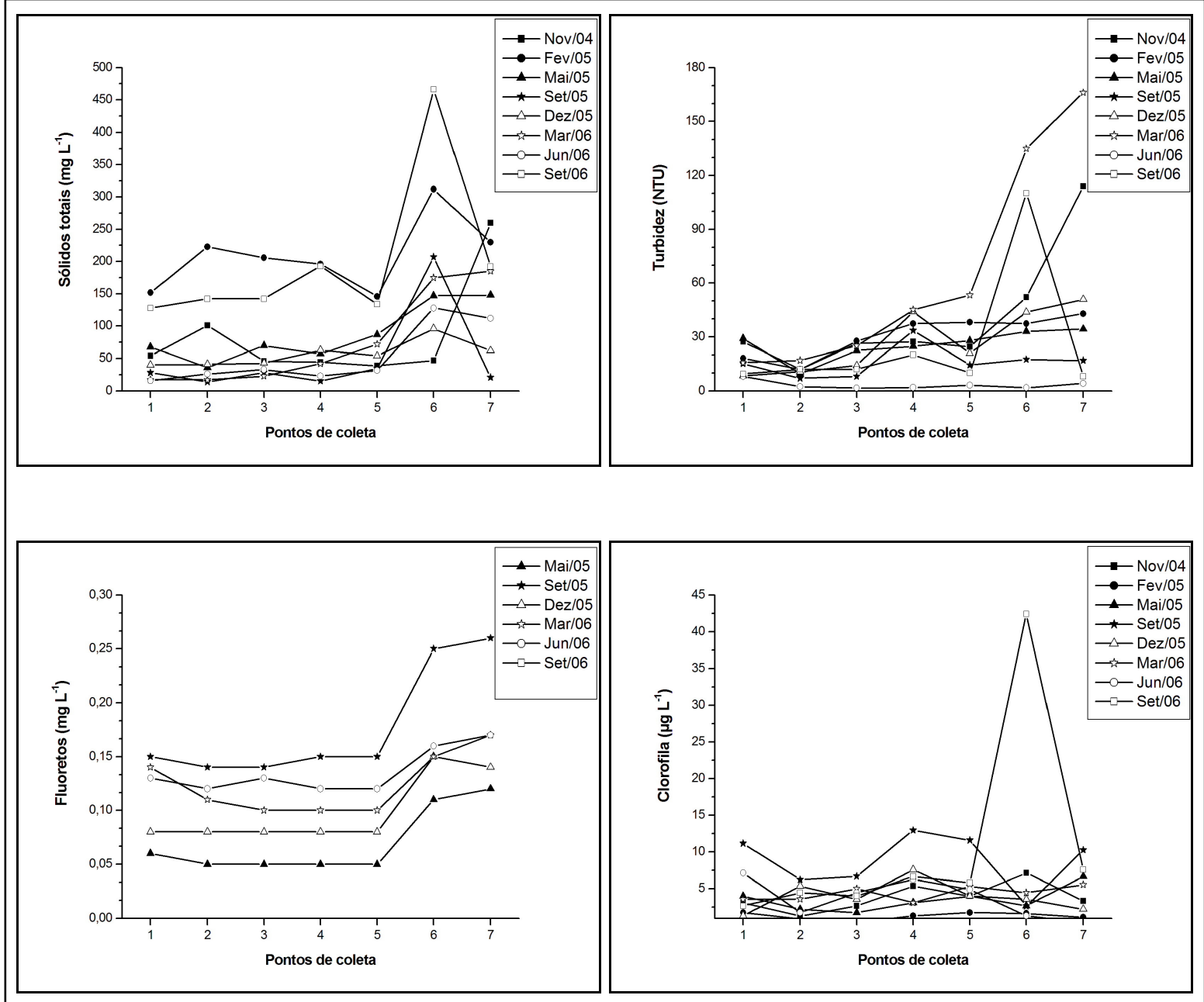

Figura 14. Determinações de sólidos totais $\left(\mathrm{mg} \mathrm{L}^{-1}\right)$, turbidez (NTU), fluoretos $\left(\mathrm{mg} \mathrm{L}^{-1}\right)$, e clorofila-a $\left(\mu \mathrm{g} \mathrm{L}^{-1}\right)$, das amostras de água coletadas no rio Corumbataí.

Assim como nos parâmetros anteriores, os gráficos da Figura 14 mostram alterações significativas nos teores de sólidos totais, turbidez e fluoretos nos Pontos 6 e 7 do rio Corumbataí. Os valores de clorofila permaneceram entre 0 e $15 \mu \mathrm{g} \mathrm{L}^{-1}$ (exceto em uma ocasião, no Ponto 6, quando atingiu valor mais alto).

\subsubsection{Determinação de coliformes}

As determinações de coliformes fecais e totais (em NMP $100 \mathrm{~mL}^{-1}$ ) de todas as coletas estão dispostas na Tabela 7. Através destas determinações é possível observar o 
impacto dos efluentes domiciliares sobre as águas do rio Corumbataí. Nota-se um aumento de coliformes do Ponto 1 para o Ponto 2 (Pontos antes e depois de Analândia), assim como do Ponto 3 para o Ponto 4 (antes e depois de Corumbataí). Já entre os Pontos 2 e 3, onde não há despejos de efluentes domiciliares, os valores de coliformes diminuem. Nos Pontos de coleta mais próximos à foz, os valores são bastante altos, sendo que em várias ocasiões ultrapassam o valor máximo detectável pela técnica utilizada.

Tabela 7. Valores de coliformes fecais e totais (em NMP $100 \mathrm{~mL}^{-1}$ ), encontrados nas amostras de água coletadas no rio Corumbataí.

\begin{tabular}{|c|c|c|c|c|c|c|c|c|}
\hline \multirow{2}{*}{$\begin{array}{c}\text { Pontos de } \\
\text { Coleta }\end{array}$} & \multicolumn{2}{|c|}{ Novembro / 2004} & \multicolumn{2}{|c|}{ Fevereiro / 2005} & \multicolumn{2}{|c|}{ Maio / 2005} & \multicolumn{2}{|c|}{ Setembro / 2005} \\
\hline & Fecais & Totais & Fecais & Totais & Fecais & Totais & Fecais & Totais \\
\hline 1 & $2,0 \times 10^{2}$ & $9,6 \times 10^{2}$ & $1,7 \times 10^{2}$ & $1,7 \times 10^{2}$ & $7,8 \times 10^{1}$ & $1,3 \times 10^{2}$ & $1,1 \times 10^{3}$ & $4,9 \times 10^{3}$ \\
\hline 2 & $9,1 \times 10^{2}$ & $3,2 \times 10^{3}$ & $1,6 \times 10^{4} \quad 1$ & $1,6 \times 10^{4}$ & $9,2 \times 10^{3}$ & $1,6 \times 10^{4}$ & $<1 \times 10^{2}$ & $1,4 \times 10^{4}$ \\
\hline 3 & $7,0 \times 10^{2}$ & $6,1 \times 10^{3}$ & $1,1 \times 10^{3} 3$ & $3,5 \times 10^{3}$ & $1,3 \times 10^{3}$ & $2,4 \times 10^{3}$ & $9,2 \times 10^{2}$ & $1,0 \times 10^{4}$ \\
\hline 4 & $4,9 \times 10^{3}$ & $1,5 \times 10^{4}$ & $2,1 \times 10^{3} 1$ & $1,3 \times 10^{4}$ & $3,5 \times 10^{3}$ & $5,4 \times 10^{3}$ & $1,4 \times 10^{3}$ & $1,6 \times 10^{4}$ \\
\hline 5 & $4,1 \times 10^{3}$ & $3,0 \times 10^{4}$ & $2,2 \times 10^{3} 2$ & $2,2 \times 10^{3}$ & $5,4 \times 10^{3}$ & $5,4 \times 10^{3}$ & $4,5 \times 10^{3}$ & $2,8 \times 10^{4}$ \\
\hline 6 & $1,7 \times 10^{4}$ & $1,2 \times 10^{5}$ & $2,2 \times 10^{3} 2$ & $2,7 \times 10^{3}$ & $4,8 \times 10^{4}$ & $7,2 \times 10^{4}$ & $1,1 \times 10^{5}=$ & $>2,42 \times 10^{5}$ \\
\hline 7 & $1,9 \times 10^{4}$ & $3,0 \times 10^{4}$ & $7,9 \times 10^{3} 1$ & $1,1 \times 10^{4}$ & $8,1 \times 10^{4}$ & $9,2 \times 10^{4}$ & $5,2 \times 10^{4}>$ & $>2,42 \times 10^{5}$ \\
\hline \multicolumn{9}{|c|}{ (Continuação) } \\
\hline \multirow{2}{*}{$\begin{array}{c}\text { Pontos de } \\
\text { Coleta } \\
\end{array}$} & \multicolumn{2}{|c|}{ Dezembro / 2005} & \multicolumn{2}{|c|}{ Março / 2006} & \multicolumn{2}{|c|}{ Junho / 2006} & \multicolumn{2}{|c|}{ Setembro / 2006} \\
\hline & Fecais & Totais & Fecais & Totais & Fecais & Totais & Fecais & Totais \\
\hline 1 & $2,3 \times 10^{3}$ & $5,8 \times 10^{4}$ & $2,5 \times 10^{2}$ & $9,8 \times 10^{2}$ & $1,0 \times 10^{2}$ & )$^{2} 1,5 \times 10^{3}$ & $9,7 \times 10^{2}$ & $9,6 \times 10^{3}$ \\
\hline 2 & $2,4 \times 10^{3}$ & $3,1 \times 10^{4}$ & $6,2 \times 10^{3}$ & $4,6 \times 10^{4}$ & $1,2 \times 10^{3}$ & $1^{3} 9,3 \times 10^{3}$ & $2,8 \times 10^{3}$ & $1,7 \times 10^{4}$ \\
\hline 3 & $1,5 \times 10^{3}$ & $2,9 \times 10^{4}$ & $6,1 \times 10^{2}$ & $7,6 \times 10^{3}$ & $1,8 \times 10^{3}$ & $3,1 \times 10^{3}$ & $1,5 \times 10^{4}$ & $2,4 \times 10^{5}$ \\
\hline 4 & $2,2 \times 10^{3}$ & $5,2 \times 10^{4}$ & $1,2 \times 10^{3}$ & $7,1 \times 10^{3}$ & $6,3 \times 10^{2}$ & )$^{2} 8,4 \times 10^{3}$ & $3,8 \times 10^{3}$ & $2,9 \times 10^{4}$ \\
\hline 5 & $5,9 \times 10^{3}$ & $4,1 \times 10^{4}$ & $2,4 \times 10^{3}$ & $5,2 \times 10^{3}$ & $3,5 \times 10^{3}$ & )$^{3} 1,2 \times 10^{4}$ & $2,5 \times 10^{3}$ & $1,8 \times 10^{4}$ \\
\hline 6 & $1,6 \times 10^{4}$ & $6,9 \times 10^{4}$ & $2,0 \times 10^{5}$ & $>2,42 \times 10^{5}$ & $7,5 \times 10^{3}$ & )$^{3} 8,2 \times 10^{4}$ & $1,7 \times 10^{5}$ & $>2,42 \times 10^{5}$ \\
\hline 7 & $5,5 \times 10^{4}$ & $>2,42 \times 10^{5}$ & $3,3 \times 10^{4}$ & $1,1 \times 10^{5}$ & $3,6 \times 10^{4}$ & $4^{4} 1,5 \times 10^{5}$ & $4,1 \times 10^{4}$ & $>2,42 \times 10^{5}$ \\
\hline
\end{tabular}




\subsubsection{Testes de sensibilidade}

Os resultados de todos os testes de sensibilidade estão dispostos nas cartas-controle, para C. xanthus (Figura 15), D. magna (Figura 16), H. attenuata (Figura 17), e $P$. subcapitata (Figura 18), onde estão representados em cada gráfico: os valores de $\mathrm{CL}_{50}$, $\mathrm{CE}_{50}$ ou $\mathrm{CI}_{50}$ de cada mês, a média dos valores obtidos (linha contínua), o desvio padrão ( \pm 1x desvio padrão, linhas pontilhadas), e o coeficiente de variação $(\mathrm{CV}(\%))$. Os valores brutos estão dispostos na Tabela 54 (Apêndice A).

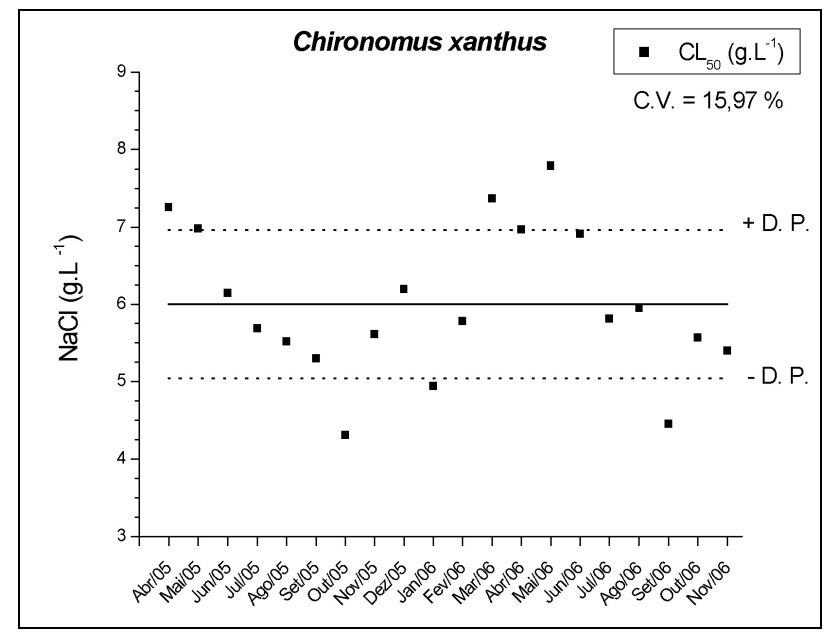

Figura 15. Carta-controle do organismo-teste Chironomus xanthus, utilizando $\mathrm{NaCl}$ como substância de referência.

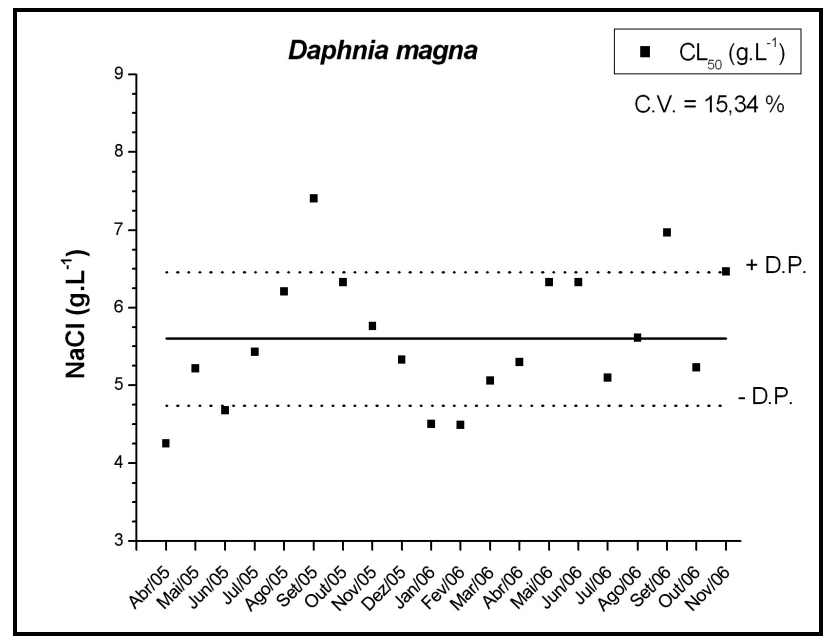

Figura 16. Carta-controle do organismo-teste Daphnia magna, utilizando $\mathrm{NaCl}$ como substância de referência. 

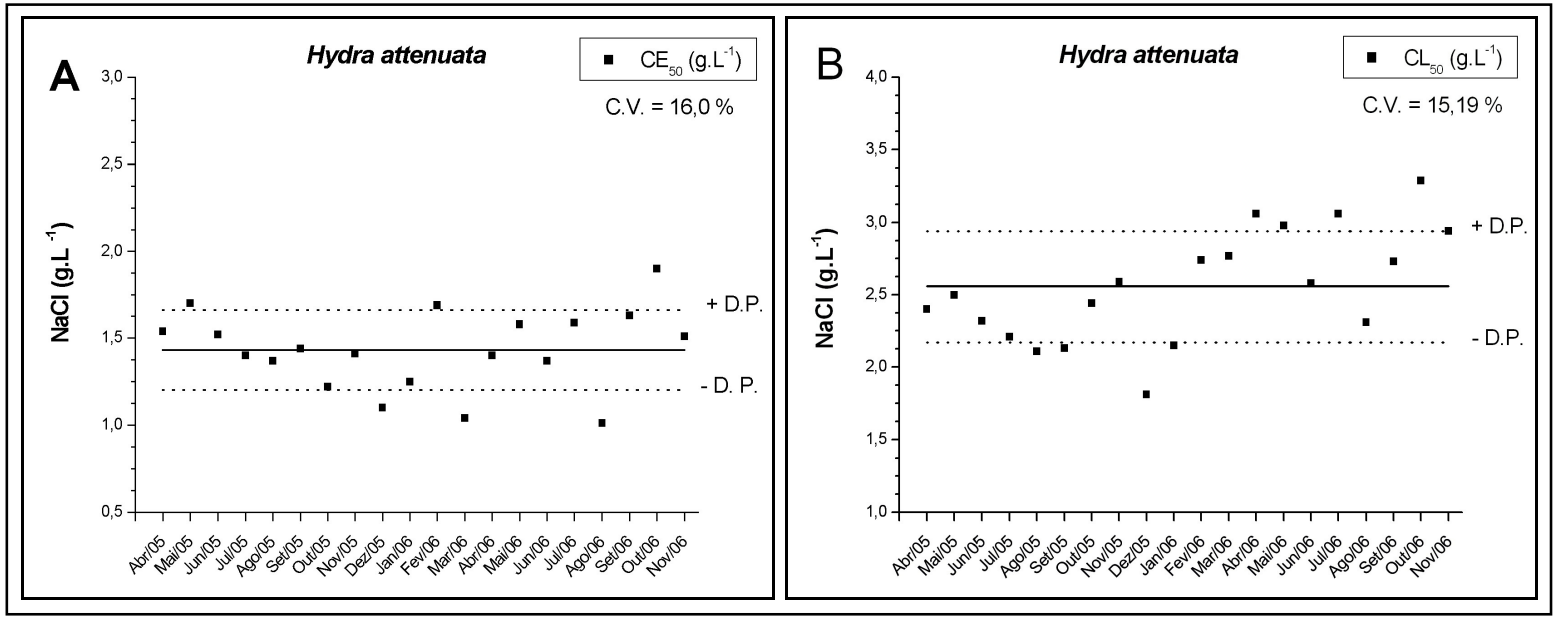

Figura 17. Cartas-controle do organismo-teste Hydra attenuata, utilizando $\mathrm{NaCl}$ como substância de referência: (A) Endpoint avaliado: $\mathrm{CE}_{50}(96 \mathrm{~h})$, e (B) Endpoint avaliado: $\mathrm{CL}_{50}(96 \mathrm{~h})$.

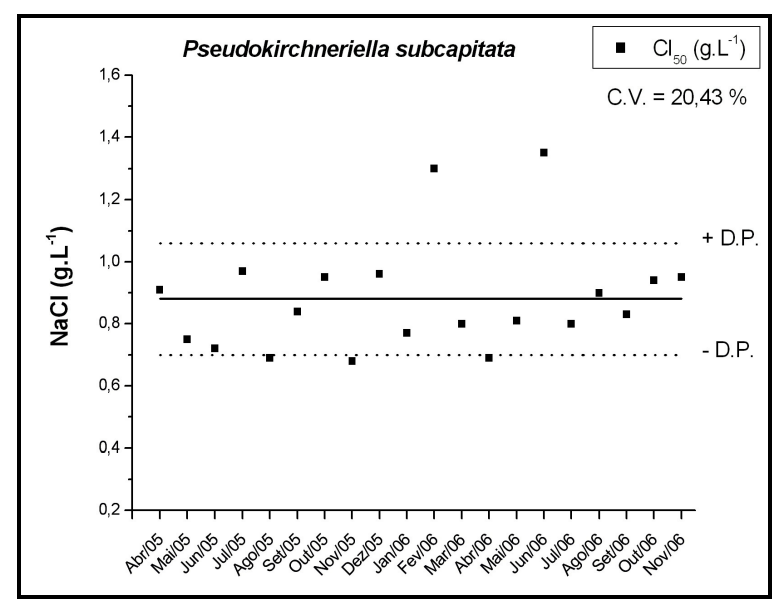

Figura 18. Carta-controle do organismo-teste Pseudokirchneriella subcapitata, utilizando $\mathrm{NaCl}$ como substância de referência.

Os valores obtidos através dos testes de sensibilidade para todos os organismos utilizados foram considerados satisfatórios, como se pode observar nos gráficos das Figuras 15 a 18. Para todos os organismos, a maioria dos pontos ficaram dentro da faixa de $\pm 1 \mathrm{x}$ desvio padrão, e todos (com exceção de $P$. subcapitata) ficaram dentro da faixa de $\pm 2 \mathrm{x}$ desvio padrão (i.e., dentro do intervalo de confiança, 95\% - Tabela 54 (Apêndice A)).Os valores do coeficiente de variação para cada organismo também se apresentaram em uma faixa dentro do aceitável, permanecendo entre $15,19 \%$ e $20,43 \%$. 


\subsubsection{Testes de toxicidade}

\subsubsection{Testes de toxicidade com Chironomus xanthus}

A Tabela 8 mostra os resultados dos testes de toxicidade com larvas de C. xanthus. Até a coleta realizada em Maio/2005 foram observadas poucas ocorrências de alta mortalidade. Entretanto, a partir da coleta de Setembro/2005, foram registradas altas taxas de mortalidade dos indivíduos expostos às amostras de sedimento do rio Corumbataí, em todos os pontos, com exceção do Ponto 1. Pela classificação de toxicidade adotada segundo Barbosa (2000), é possível notar uma tendência das amostras tornarem-se mais tóxicas ao longo do tempo, dentro de cada ponto de coleta, e mais tóxicas ao longo do curso do rio, ao invés de uma variação sazonal da toxicidade a este organismo. A análise pelo teste de Fischer indicou diferença significativa em relação ao controle de cada amostra testada, sugerindo que ao longo das coletas realizadas houve uma crescente mortalidade dos indivíduos expostos às amostras do sedimento. A classificação usada por Barbosa (2000) difere notadamente da análise pelo teste de Fischer: enquanto que para a primeira a morte de dois indivíduos já caracteriza "indício de toxicidade", para o teste de Fischer apenas mortalidades maiores que cinco indivíduos caracterizam-se como diferentes do controle. 
Tabela 8. Classificação do grau de toxicidade (§) para larvas de Chironomus xanthus expostas $(96 \mathrm{~h})$ a amostras de sedimento coletadas no rio Corumbataí. Os números entre parênteses mostram o número de indivíduos mortos, dentre 18 expostos. Valores marcados com * mostram diferença significativa em relação ao controle (Fischer's Exact Test, $\mathrm{p}<0,05)$.

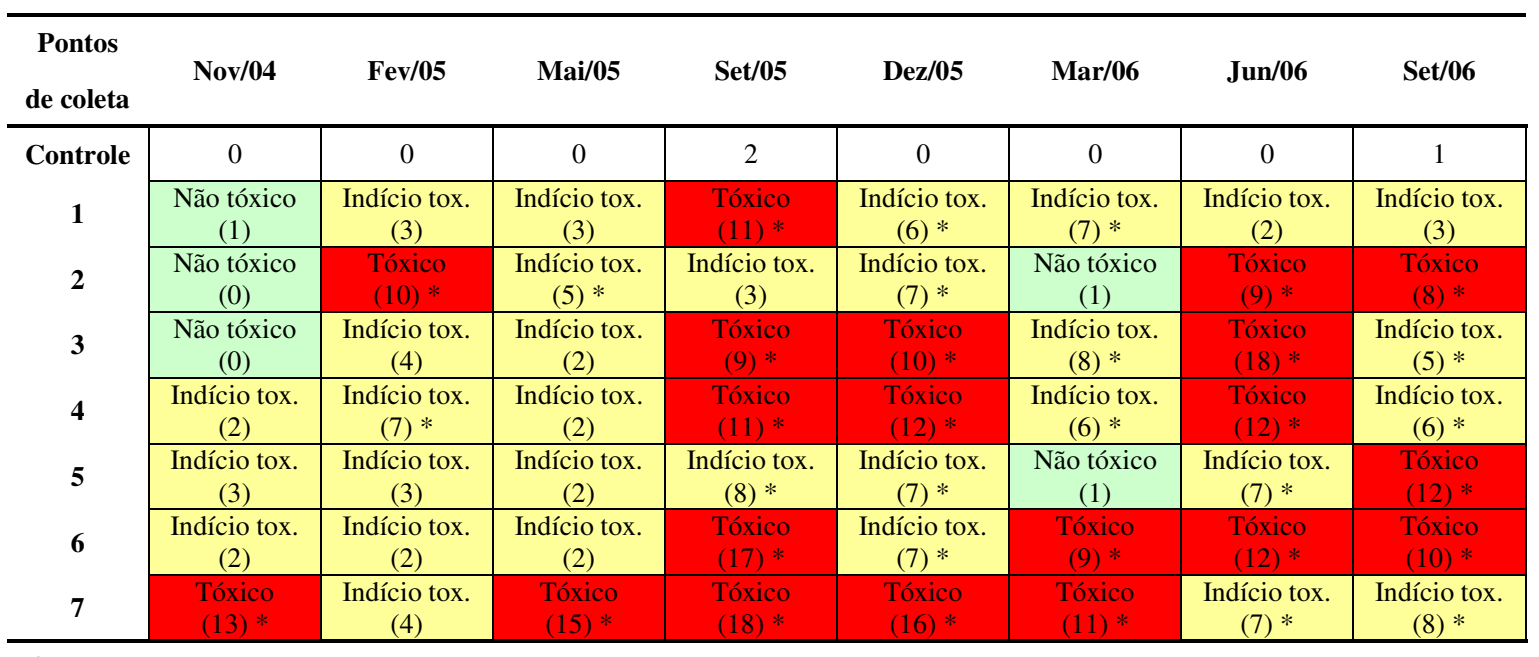

(§) Não tóxico: 0 a 10\% de mortalidade; Indício de toxicidade: 11\% a 49\% de mortalidade; Tóxico: > 50\%, segundo Barbosa (2000).

\subsubsection{Testes de toxicidade aguda com Daphnia magna}

A Tabela 9 mostra os resultados (valores de $\mathrm{CL}_{50}(48 \mathrm{~h})$ ) dos testes de toxicidade aguda para D. magna, expostas às amostras de água do rio Corumbataí. No Ponto 2, houve indício de toxicidade em três das oito coletas. Entretanto, nos testes realizados com elutriato das amostras de sedimento (Tabela 10$)$, os valores de $\mathrm{CL}_{50}(48 \mathrm{~h})$ apresentaram-se menores, indicando maior toxicidade em alguns pontos, com destaque para a coleta de Fevereiro/2005. Apenas no Ponto 7 não houve indícios de toxicidade alguma, em nenhuma coleta. É possível observar uma tendência de maior toxicidade para D. magna nos pontos mais próximos à nascente. 
Tabela 9. Valores de $\mathrm{CL}_{50}(48 \mathrm{~h})$ para amostras de água, coletadas no rio Corumbataí, para Daphnia magna.

\begin{tabular}{ccccccccc}
\hline $\begin{array}{c}\text { Pontos } \\
\text { de coleta }\end{array}$ & Nov/04 & Fev/05 & Mai/05 & Set/05 & Dez/05 & Mar/06 & Jun/06 & Set/06 \\
\hline $\mathbf{1}$ & $100 \%$ & N.T. & N.T. & N.T. & N.T. & N.T. & N.T. & N.T. \\
$\mathbf{2}$ & $100 \%$ & N.T. & N.T. & N.T. & $86,6 \%$ & N.T. & $97,10 \%$ & N.T. \\
$\mathbf{3}$ & N.T. & N.T. & N.T. & N.T. & N.T. & N.T. & N.T. & N.T. \\
$\mathbf{4}$ & N.T. & N.T. & N.T. & N.T. & N.T. & N.T. & N.T. & N.T. \\
$\mathbf{5}$ & N.T. & N.T. & $90,9 \%$ & N.T. & N.T. & N.T. & N.T. & N.T. \\
$\mathbf{6}$ & N.T. & N.T. & N.T. & N.T. & N.T. & $88,7 \%$ & N.T. & N.T. \\
$\mathbf{7}$ & N.T. & N.T. & N.T. & N.T. & N.T. & N.T. & N.T. & N.T. \\
\hline
\end{tabular}

N.T.: amostras não tóxicas.

Tabela 10. Valores de $\mathrm{CL}_{50}(48 \mathrm{~h})$ para elutriatos de sedimento, coletados no rio Corumbataí, para Daphnia magna.

\begin{tabular}{ccccccccc}
\hline $\begin{array}{c}\text { Pontos } \\
\text { de coleta }\end{array}$ & Nov/04 & Fev/05 & Mai/05 & Set/05 & Dez/05 & Mar/06 & Jun/06 & Set/06 \\
\hline $\mathbf{1}$ & $86,5 \%$ & $77,3 \%$ & $97,5 \%$ & $89,8 \%$ & $97,5 \%$ & $80,8 \%$ & $86,6 \%$ & $99,5 \%$ \\
$\mathbf{2}$ & $93,6 \%$ & $78,7 \%$ & N.T. & $83,9 \%$ & N.T. & $78,6 \%$ & $84,3 \%$ & $99,5 \%$ \\
$\mathbf{3}$ & $85,1 \%$ & $68,5 \%$ & $98,7 \%$ & N.T. & $97,2 \%$ & $86,6 \%$ & $77,8 \%$ & N.T. \\
$\mathbf{4}$ & $86,6 \%$ & $72,1 \%$ & N.T. & N.T. & N.T. & N.T. & $87,4 \%$ & N.T. \\
$\mathbf{5}$ & N.T. & $72,6 \%$ & N.T. & N.T. & $98,1 \%$ & N.T. & $90,9 \%$ & $96,7 \%$ \\
$\mathbf{6}$ & N.T. & $100,0 \%$ & N.T. & N.T. & N.T. & N.T. & N.T. & N.T. \\
$\mathbf{7}$ & N.T. & N.T. & N.T. & N.T. & N.T. & N.T. & N.T. & N.T. \\
\hline
\end{tabular}

N.T.: amostras não tóxicas.

\subsubsection{Testes de toxicidade com Hydra attenuata}

Nos testes realizados com $H$. attenuata foram obtidos valores de $\mathrm{CE}_{50}(96 \mathrm{~h})$, em que foi registrada e considerada para este cálculo a presença de qualquer sinal deletério nos organismos, tais como: o aparecimento de bulbos nas extremidades dos tentáculos, o encurtamento dos mesmos, sua degeneração, e morte (Figura 9). Estes valores de $\mathrm{CE}_{50}$ obtidos para amostras de água bruta e elutriato dos sedimentos estão mostrados nas Tabelas 11 e 12, respectivamente. Pode-se observar maior toxicidade causada pelo sedimento do que pelas amostras de água, sendo que os valores que indicam maior 
toxicidade foram registrados nos testes com elutriato dos meses de Novembro/2004, Setembro/2005, e Março/2006 (Tabela 12). Não se observou uma mortalidade significativa em nenhum teste realizado, que permitisse o cálculo de valores de $\mathrm{CL}_{50}(96$ h). É possível observar, para ambas as amostras que os pontos mais próximos à foz do rio apresentam maior toxicidade à $H$. attenuata.

Tabela 11. Valores de $\mathrm{CE}_{50}(96 \mathrm{~h})$ para amostras de água, coletadas no rio Corumbataí, para Hydra attenuata.

\begin{tabular}{ccccccccc}
\hline $\begin{array}{c}\text { Pontos } \\
\text { de coleta }\end{array}$ & Nov/04 & Fev/05 & Mai/05 & Set/05 & Dez/05 & Mar/06 & Jun/06 & Set/06 \\
\hline $\mathbf{1}$ & N.T. & $*$ & N.T. & N.T. & N.T. & N.T. & N.T. & N.T. \\
$\mathbf{2}$ & $86,6 \%$ & $*$ & N.T. & N.T. & N.T. & N.T. & $95,30 \%$ & N.T. \\
$\mathbf{3}$ & N.T. & $*$ & N.T. & $86,6 \%$ & $95,3 \%$ & N.T. & N.T. & N.T. \\
$\mathbf{4}$ & N.T. & $*$ & N.T. & N.T. & N.T. & N.T. & N.T. & N.T. \\
$\mathbf{5}$ & N.T. & $*$ & N.T. & N.T. & $95,3 \%$ & N.T. & N.T. & N.T. \\
$\mathbf{6}$ & N.T. & $*$ & N.T. & $68,7 \%$ & $80,7 \%$ & $29,7 \%$ & $86,6 \%$ & $69,9 \%$ \\
$\mathbf{7}$ & $68,7 \%$ & $*$ & N.T. & N.T. & $96,5 \%$ & $93,1 \%$ & N.T. & $96,4 \%$ \\
\hline (*) Testes não realizados, devido à inadequação da cultura às condições mínimas necessárias. N.T.: amostras não tóxicas. &
\end{tabular}

Tabela 12. Valores de $\mathrm{CE}_{50}(96 \mathrm{~h})$ para elutriatos de sedimento, coletados no rio Corumbataí, para Hydra attenuata.

\begin{tabular}{ccccccccc}
\hline $\begin{array}{c}\text { Pontos } \\
\text { de coleta }\end{array}$ & Nov/04 & Fev/05 & Mai/05 & Set/05 & Dez/05 & Mar/06 & Jun/06 & Set/06 \\
\hline $\mathbf{1}$ & N.T. & N.T. & N.T. & N.T. & N.T. & N.T. & N.T. & N.T. \\
$\mathbf{2}$ & $26,0 \%$ & N.T. & N.T. & N.T. & N.T. & N.T. & N.T. & N.T. \\
$\mathbf{3}$ & $14,3 \%$ & N.T. & N.T. & $96,9 \%$ & N.T. & $86,6 \%$ & N.T. & N.T. \\
$\mathbf{4}$ & $23,6 \%$ & N.T. & N.T. & $95,3 \%$ & N.T. & $80,7 \%$ & N.T. & $96,4 \%$ \\
$\mathbf{5}$ & $43,7 \%$ & N.T. & N.T. & $96,5 \%$ & $93,1 \%$ & $77,1 \%$ & N.T. & N.T. \\
$\mathbf{6}$ & $22,6 \%$ & N.T. & N.T. & $26,0 \%$ & $96,5 \%$ & $62,5 \%$ & $75,8 \%$ & N.T. \\
$\mathbf{7}$ & $17,1 \%$ & N.T. & $70,1 \%$ & $22,3 \%$ & $57,7 \%$ & $38,7 \%$ & N.T. & $86,6 \%$ \\
\hline
\end{tabular}

N.T.: amostras não tóxicas. 


\subsubsection{Testes de toxicidade com Lactuca sativa}

Os testes com sementes de alface não produziram resultados que permitissem o cálculo de $\mathrm{CI}_{50}(72 \mathrm{~h})$. Assim como nos testes com outros organismos, foram feitas diluições do material testado (água e elutriato) para determinação dos valores de inibição de crescimento das raízes. Entretanto, nestes testes as respostas de toxicidade (inibição do crescimento das raízes) quase nunca foram maiores quanto maior a concentração das amostras. Frente a estes resultados, este bioensaio foi suspenso após a coleta de Setembro/2005. Nas Tabelas 13 e 14, estão dispostos os valores de porcentagem de inibição (em relação ao controle) das sementes expostas às amostras puras (a 100\%). Valores negativos indicam a porcentagem de estímulo de crescimento causado pelas amostras de água e sedimento. Pelos valores obtidos, é possível notar na maioria dos casos um estímulo de crescimento, ao invés de efeito tóxico. Em poucos casos houve inibição de crescimento, e quando houve, não foi significativa (15\% para água e $17 \%$ para sedimento). Não houve um padrão de resposta claro das sementes em relação à pluviosidade, ou em relação aos impactos de cada cidade, a montante e a jusante de cada uma delas. Em geral, as amostras de sedimento causaram um leve estímulo de crescimento nos Pontos 1 e 2, enquanto que os Pontos 6 e 7 causaram uma tendência à inibição.

Tabela 13. Porcentagem de inibição de crescimento de raízes de Lactuca sativa, para amostras de água coletadas no rio Corumbataí.

\begin{tabular}{ccccc}
\hline $\begin{array}{c}\text { Pontos } \\
\text { de coleta }\end{array}$ & Nov/04 & Fev/05 & Mai/05 & Set/05 \\
\hline $\mathbf{1}$ & 8 & -24 & -6 & 2 \\
$\mathbf{2}$ & 0 & -12 & -4 & -47 \\
$\mathbf{3}$ & -8 & -2 & -14 & 4 \\
$\mathbf{4}$ & -2 & -15 & 7 & 15 \\
$\mathbf{5}$ & -9 & -8 & -2 & 2 \\
$\mathbf{6}$ & 3 & -18 & -12 & -9 \\
$\mathbf{7}$ & 2 & -19 & -13 & 1 \\
\hline
\end{tabular}


Tabela 14. Porcentagem de inibição de crescimento de raízes de Lactuca sativa, para amostras de sedimento coletadas no rio Corumbataí.

\begin{tabular}{ccccc}
\hline $\begin{array}{c}\text { Pontos } \\
\text { de coleta }\end{array}$ & Nov/04 & Fev/05 & Mai/05 & Set/05 \\
\hline $\mathbf{1}$ & -18 & -8 & 0 & -15 \\
$\mathbf{2}$ & -16 & -33 & -5 & -1 \\
$\mathbf{3}$ & -11 & 5 & 17 & -12 \\
$\mathbf{4}$ & -14 & 0 & 7 & -6 \\
$\mathbf{5}$ & -3 & -4 & -6 & -32 \\
$\mathbf{6}$ & 0 & -6 & 14 & -1 \\
$\mathbf{7}$ & 7 & -20 & 2 & 1 \\
\hline
\end{tabular}

\subsubsection{Testes de toxicidade com Pseudokirchneriella subcapitata}

Os resultados obtidos nos testes realizados com a alga unicelular $P$. subcapitata estão mostrados nas Tabelas 15 e 16. Estes resultados são os que mais demonstraram toxicidade tanto das amostras de água quanto de sedimentos de todos os pontos de coletas do rio Corumbataí. Para as amostras de água, em quase todas foi observada toxicidade para P. subcapitata. De maneira geral, observa-se também que as amostras de sedimento apresentaram-se ainda mais tóxicas que as de água, para cada ponto de coleta.

Tabela 15. Valores de $\mathrm{CI}_{50}(72 \mathrm{~h})$ para amostras de água, coletadas no rio Corumbataí, para Pseudokirchneriella subcapitata.

\begin{tabular}{ccccccccc}
\hline $\begin{array}{c}\text { Pontos } \\
\text { de coleta }\end{array}$ & Nov/04 & Fev/05 & Mai/05 & Set/05 & Dez/05 & Mar/06 & Jun/06 & Set/06 \\
\hline $\mathbf{1}$ & N.T. & N.T. & N.T. & $89,5 \%$ & $47,5 \%$ & $33,0 \%$ & $60,4 \%$ & $95,5 \%$ \\
$\mathbf{2}$ & N.T. & $<25 \%$ & N.T. & $50,0 \%$ & N.T. & $71,4 \%$ & N.T. & N.T. \\
$\mathbf{3}$ & $25,0 \%$ & $56,9 \%$ & $96,0 \%$ & N.T. & $85,5 \%$ & $56,9 \%$ & N.T. & $75,0 \%$ \\
$\mathbf{4}$ & $22,0 \%$ & $25 \%$ & N.T. & $88,2 \%$ & $74,1 \%$ & $7,0 \%$ & $85,3 \%$ & $68,6 \%$ \\
$\mathbf{5}$ & $15,3 \%$ & N.T. & $76,1 \%$ & $54,9 \%$ & $64,9 \%$ & $38,7 \%$ & $79,5 \%$ & $60,5 \%$ \\
$\mathbf{6}$ & N.T. & $37,4 \%$ & $89,8 \%$ & N.T. & $52,9 \%$ & $13,3 \%$ & N.T. & $61,6 \%$ \\
$\mathbf{7}$ & N.T. & $25 \%$ & $81,7 \%$ & N.T. & $92,6 \%$ & $8,5 \%$ & $45,6 \%$ & $50,0 \%$ \\
\hline
\end{tabular}

N.T.: amostras não tóxicas. 
Tabela 16. Valores de $\mathrm{CI}_{50}(72 \mathrm{~h})$ para elutriatos de sedimento, coletados no rio Corumbataí, para Pseudokirchneriella subcapitata.

\begin{tabular}{ccccccccc}
\hline $\begin{array}{c}\text { Pontos } \\
\text { de coleta }\end{array}$ & Nov/04 & Fev/05 & Mai/05 & Set/05 & Dez/05 & Mar/06 & Jun/06 & Set/06 \\
\hline $\mathbf{1}$ & $89,8 \%$ & N.T. & $73,2 \%$ & $30,8 \%$ & N.T. & $35,5 \%$ & $53,1 \%$ & $62,4 \%$ \\
$\mathbf{2}$ & $95,1 \%$ & $30,9 \%$ & $84,3 \%$ & $30,8 \%$ & $40,7 \%$ & $47,5 \%$ & $34,5 \%$ & $79,9 \%$ \\
$\mathbf{3}$ & N.T. & $29,3 \%$ & N.T. & $20,6 \%$ & $78,4 \%$ & $35,2 \%$ & $87,8 \%$ & $94,1 \%$ \\
$\mathbf{4}$ & $98,1 \%$ & $91,4 \%$ & $89,9 \%$ & $30,4 \%$ & $23,7 \%$ & $76,2 \%$ & $23,9 \%$ & $48,2 \%$ \\
$\mathbf{5}$ & N.T. & $98,2 \%$ & $88,8 \%$ & $14,2 \%$ & $6,6 \%$ & $94,3 \%$ & $24,7 \%$ & $92,8 \%$ \\
$\mathbf{6}$ & $94,2 \%$ & $88,0 \%$ & $75,0 \%$ & $28,2 \%$ & $21,5 \%$ & $52,8 \%$ & $24,2 \%$ & $68,1 \%$ \\
$\mathbf{7}$ & $61,6 \%$ & $92,1 \%$ & $12,1 \%$ & $8,3 \%$ & $17,2 \%$ & $53,6 \%$ & $8,6 \%$ & $37,6 \%$ \\
\hline N.T. amostras não tóxicas. & & & & & &
\end{tabular}

N.T.: amostras não tóxicas. 


\subsection{Discussão}

\subsubsection{Testes de sensibilidade}

Os resultados obtidos nos testes de sensibilidade, utilizando $\mathrm{NaCl}$ como substância de referência foram considerados bastante satisfatórios, sendo indicado o uso desta substância para monitoramento da qualidade das culturas mantidas em laboratórios dos organismos-teste do presente estudo. Os valores do C.V.(\%) ficaram por volta de $20 \%$, indicando boa reprodutibilidade em todos os bioensaios, além de a maioria dos pontos estar dentro da faixa de $\pm 1 \mathrm{x}$ desvio padrão, e de todos os pontos estarem dentro da faixa de $\pm 2 \mathrm{x}$ desvio padrão (exceto para $P$. subcapitata). Resultados comparáveis obtidos por outros autores são encontrados na literatura para D. magna e $P$. subcapitata. Geis et al. (2000) obtiveram valor de $\mathrm{CI}_{50}(96 \mathrm{~h})$ igual a $2,5 \mathrm{~g} \mathrm{~L}^{-1}$ para $P$. subcapitata. Os resultados para $D$. magna são mais comuns na literatura, para $\mathrm{NaCl}$ : $\mathrm{CL}_{50}(48 \mathrm{~h})$ de $6,03 \mathrm{~g} \mathrm{~L}^{-1}$ encontrado por Cowgill e Millazo (1990); 7,7 $\mathrm{g} \mathrm{L}^{-1}$ encontrado por Cowgill e Millazo (1991); 7,3 g L ${ }^{-1}$ encontrado por Hong et al. (2004); 4,77 $\mathrm{g} \mathrm{L}^{-1}$ encontrado por Mount et al. (1997), e 5,9 g $\mathrm{L}^{-1}$ encontrado por Gonçalves et al. (2007). Valores para os outros organismos testados não foram encontrados na literatura.

\subsubsection{Testes de toxicidade}

Nas Tabelas 17 e 18, os resultados obtidos (classificação de toxicidade para $C$. xanthus, valores de $\mathrm{CL}_{50}, \mathrm{CE}_{50}, \mathrm{CI}_{50}$, e \% inibição) estão dispostos de modo a comparar os endpoints avaliados das diferentes espécies de organismos-teste, assim como permitir uma comparação entre resultados dos mesmos pontos de coleta. 
Tabela 17. Valores estimados dos parâmetros para os quatro organismos-teste utilizados nos testes de toxicidade com amostras de água, coletadas no rio Corumbataí.

\begin{tabular}{|c|c|c|c|c|c|}
\hline $\begin{array}{c}\text { Pontos } \\
\text { de coleta }\end{array}$ & $\begin{array}{c}\text { Data da } \\
\text { coleta }\end{array}$ & $\begin{array}{l}\text { D. magna } \\
\mathrm{CL}_{50}(48 \mathrm{~h})\end{array}$ & $\begin{array}{l}\text { H. attenuata } \\
\mathrm{CE}_{50}(96 \mathrm{~h})\end{array}$ & $\begin{array}{l}\text { L. sativa } \\
\text { \% inibição }\end{array}$ & $\begin{array}{c}P \text { P subcapitata } \\
\mathrm{CI}_{50}(72 \mathrm{~h})\end{array}$ \\
\hline \multirow{8}{*}{1} & Nov/04 & $100 \%$ & N.T. & 8 & N.T. \\
\hline & $\mathrm{Fev} / 05$ & N.T. & $*$ & -24 & N.T. \\
\hline & Mai/05 & N.T. & N.T. & -6 & N.T. \\
\hline & Set/05 & N.T. & N.T. & 2 & $89,5 \%$ \\
\hline & Dez/05 & N.T. & N.T. & $\ddagger$ & $47,5 \%$ \\
\hline & Mar/06 & N.T. & N.T. & $\neq$ & $33,0 \%$ \\
\hline & Jun/06 & N.T. & N.T. & $\ddagger$ & $60,4 \%$ \\
\hline & Set/06 & N.T. & N.T. & $\ddagger$ & $95,5 \%$ \\
\hline \multirow{8}{*}{2} & Nov/04 & $100 \%$ & $86,6 \%$ & 0 & N.T. \\
\hline & $\mathrm{Fev} / 05$ & N.T. & $*$ & -12 & $<25 \%$ \\
\hline & Mai/05 & N.T. & N.T. & -4 & N.T. \\
\hline & Set/05 & N.T. & N.T. & -47 & $50,0 \%$ \\
\hline & Dez/05 & $86,6 \%$ & N.T. & $\neq$ & N.T. \\
\hline & Mar/06 & N.T. & N.T. & $\ddagger$ & $71,4 \%$ \\
\hline & Jun/06 & $97,10 \%$ & $95,30 \%$ & $\ddagger$ & N.T. \\
\hline & Set/06 & N.T. & N.T. & + & N.T. \\
\hline \multirow{8}{*}{3} & Nov/04 & N.T. & N.T. & -8 & $25,0 \%$ \\
\hline & Fev/05 & N.T. & $*$ & -2 & $56,9 \%$ \\
\hline & Mai/05 & N.T. & N.T. & -14 & $96,0 \%$ \\
\hline & Set/05 & N.T. & $86,6 \%$ & 4 & N.T. \\
\hline & Dez/05 & N.T. & $95,3 \%$ & $\ddagger$ & $85,5 \%$ \\
\hline & Mar/06 & N.T. & N.T. & $\neq$ & $56,9 \%$ \\
\hline & Jun/06 & N.T. & N.T. & $\ddagger$ & N.T. \\
\hline & Set/06 & N.T. & N.T. & $\ddagger$ & $75,0 \%$ \\
\hline \multirow{8}{*}{4} & Nov/04 & N.T. & N.T. & -2 & $22,0 \%$ \\
\hline & Fev/05 & N.T. & $*$ & -15 & $25 \%$ \\
\hline & Mai/05 & N.T. & N.T. & 7 & N.T. \\
\hline & Set/05 & N.T. & N.T. & 15 & $88,2 \%$ \\
\hline & Dez/05 & N.T. & N.T. & $\ddagger$ & $74,1 \%$ \\
\hline & Mar/06 & N.T. & N.T. & $\neq$ & $7,0 \%$ \\
\hline & Jun/06 & N.T. & N.T. & $\neq$ & $85,3 \%$ \\
\hline & Set/06 & N.T. & N.T. & $\ddagger$ & $68,6 \%$ \\
\hline (continua. & & & & & \\
\hline
\end{tabular}




\begin{tabular}{|c|c|c|c|c|c|}
\hline $\begin{array}{c}\text { Pontos } \\
\text { de coleta }\end{array}$ & $\begin{array}{c}\text { Data da } \\
\text { coleta }\end{array}$ & $\begin{array}{l}\text { D. magna } \\
\mathrm{CL}_{50}(48 \mathrm{~h})\end{array}$ & $\begin{array}{c}\text { H. attenuata } \\
\mathrm{CE}_{50}(96 \mathrm{~h})\end{array}$ & $\begin{array}{c}\text { L. sativa } \\
\text { \% inibição }\end{array}$ & $\begin{array}{c}P \text {. subcapitata } \\
\mathrm{CI}_{50}(72 \mathrm{~h})\end{array}$ \\
\hline \multirow{8}{*}{5} & Nov/04 & N.T. & N.T. & -9 & $15,3 \%$ \\
\hline & Fev/05 & N.T. & $*$ & -8 & N.T. \\
\hline & Mai/05 & $90,9 \%$ & N.T. & -2 & $76,1 \%$ \\
\hline & Set/05 & N.T. & N.T. & 2 & $54,9 \%$ \\
\hline & Dez/05 & N.T. & $95,3 \%$ & $\ddagger$ & $64,9 \%$ \\
\hline & Mar/06 & N.T. & N.T. & $\ddagger$ & $38,7 \%$ \\
\hline & Jun/06 & N.T. & N.T. & $\ddagger$ & $79,5 \%$ \\
\hline & Set/06 & N.T. & N.T. & $\ddagger$ & $60,5 \%$ \\
\hline \multirow{8}{*}{6} & Nov/04 & N.T. & N.T. & 3 & N.T. \\
\hline & Fev/05 & N.T. & $*$ & -18 & $37,4 \%$ \\
\hline & Mai/05 & N.T. & N.T. & -12 & $89,8 \%$ \\
\hline & Set/05 & N.T. & $68,7 \%$ & -9 & N.T. \\
\hline & Dez/05 & N.T. & $80,7 \%$ & $\ddagger$ & $52,9 \%$ \\
\hline & Mar/06 & $88,7 \%$ & $29,7 \%$ & $\ddagger$ & $13,3 \%$ \\
\hline & Jun/06 & N.T. & $86,6 \%$ & $\ddagger$ & N.T. \\
\hline & Set/06 & N.T. & $69,9 \%$ & $\ddagger$ & $61,6 \%$ \\
\hline \multirow{8}{*}{7} & Nov/04 & N.T. & $68,7 \%$ & 2 & N.T. \\
\hline & Fev/05 & N.T. & $*$ & -19 & $25 \%$ \\
\hline & Mai/05 & N.T. & N.T. & -13 & $81,7 \%$ \\
\hline & Set/05 & N.T. & N.T. & 1 & N.T. \\
\hline & Dez/05 & N.T. & $96,5 \%$ & $\ddagger$ & $92,6 \%$ \\
\hline & Mar/06 & N.T. & $93,1 \%$ & $\ddagger$ & $8,5 \%$ \\
\hline & Jun/06 & N.T. & N.T. & $\ddagger$ & $45,6 \%$ \\
\hline & Set/06 & N.T. & $96,4 \%$ & $\ddagger$ & $50,0 \%$ \\
\hline
\end{tabular}

Pelos endpoints avaliados, mostrados na Tabela 17, podemos observar que o endpoint mais sensível às amostras de água foi o da alga $P$. subcapitata, que apresentou os valores mais baixos de seu respectivo endpoint $\left(\mathrm{CI}_{50}\right)$. Apesar de o celenterado $H$. attenuata ser considerado bastante sensível, sua sensibilidade não foi tão alta quanto à de P. subcapitata. Para estas amostras de água, observou-se que D. magna não indicou qualquer toxicidade, tendo o endpoint menos sensível dentre os utilizados no presente estudo. Em poucos casos L. sativa demonstrou efeitos tóxicos, tendo na maior parte um 
leve estímulo de crescimento. Não houve um padrão claro de respostas em relação à pluviosidade, ou um padrão dentro de cada Ponto de coleta.

Geralmente, dois dos principais tipos de agentes tóxicos freqüentemente presentes em rios são metais e agrotóxicos (BRIGANTE e ESPÍNDOLA, 2003). Existem vastos registros na literatura sobre a toxicidade destas substâncias a organismos aquáticos (BARATA et al., 2006; BORGMANN e NORWOOD, 2002; FAIRCHILD et al., 1997). Estes tipos de substâncias estão presentes na sub-bacia do rio Corumbataí, sendo introduzidos por ações humanas de diversos tipos, e certamente desempenham papéis significativos neste ecossistema. Elementos químicos (como os metais) atingem os corpos d'água principalmente via despejos de efluentes industriais, enquanto que o potencial de contaminação de um produto utilizado na agricultura está diretamente associado às suas propriedades de solubilidade em água, mobilidade no solo e sua persistência. Está também associado às propriedades do solo e relevo e bastante associado à freqüência e quantidade utilizada. Na sub-bacia do rio Corumbataí, o solo predominante é do tipo arenoso, o relevo é acidentado, e a cultura de cana-de-açúcar é predominante há vários anos, sendo empregados vários produtos que podem alcançar os corpos hídricos (MONTEIRO et al., 2008). Falqueto $^{1}$ (em fase de elaboração) e Monteiro et al. (2008) realizaram determinações de elementos químicos e herbicidas, respectivamente, nas mesmas amostras de água do presente estudo, em algumas coletas (Tabela 55/Apêndice A). Análises de correlação linear (Pearson) realizadas com os dados de toxicidade e com estas determinações estão dispostas nas Tabelas 18 e 19.

Analisando-se as correlações da Tabela 18, é possível observar que todos os elementos químicos foram correlacionados pelo menos uma vez aos resultados do bioensaios, para pelo menos um dos organismos-teste, ou seja, os organismos utilizados demonstraram sensibilidade a todos os elementos determinados nestas coletas. Dentre estes 
organismos, $H$. attenuata mostrou-se o mais sensível aos elementos presentes nas amostras de água, mostrando altas correlações com diversos deles (Tabela 18). L. sativa não apresentou nenhuma correlação, na coleta de Setembro/2005.

Tabela 18. Análise de correlação linear (Pearson) entre os bioensaios com amostras de água e determinações de elementos químicos de quatro coletas realizadas por Falqueto ${ }^{1}$ (em fase de elaboração).

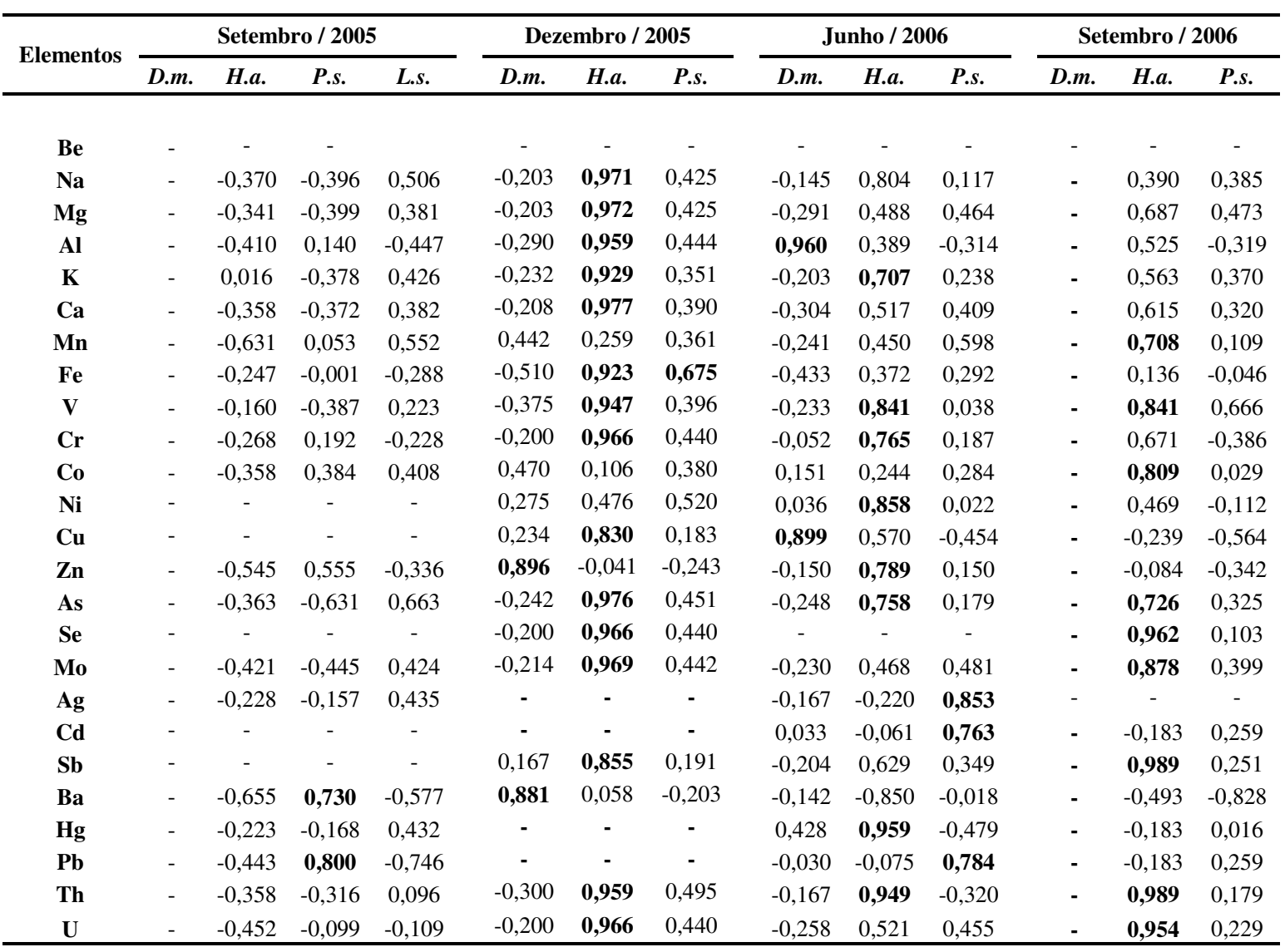

D.m.: D. magna; H.a.: H.attenuta; P.s.: P. subcapitata; L.s.: L. sativa (-) Análises não realizadas por ausência de toxicidade e/ou do elemento.

D. magna não mostrou respostas correlacionadas com os elementos químicos, por (1) não ter sofrido nenhuma toxicidade em várias coletas (e.g., em Setembro/2005 e Setembro/2006), e (2) por ter tido maior mortalidade nos Pontos de coleta mais próximos à nascente, e baixa mortalidade nos pontos mais contaminados do rio (vide discussão no item 2.4.4), tendo a mortalidade inversamente proporcional à concentração da maioria dos 
elementos químicos determinados. Apesar de $P$. subcapitata ter apresentado o endpoint mais sensível dentre os avaliados, a maior parte dos seus resultados não puderam ser explicados pelos elementos químicos presentes nas amostras de água (Tabela 18). Ainda assim, existem efeitos aditivos e/ou sinérgicos que ocorrem com agentes tóxicos (ZAGATTO e BERTOLETTI, 2006), mas que não são demonstrados por análises de correlação como esta, e que poderiam explicar as respostas de $P$. subcapitata às amostras testadas. Os elementos químicos analisados por Falqueto ${ }^{1}$ (em fase de elaboração) e correlacionados com os bioensaios mostram uma presença significativa de metais principalmente, nas águas do rio Corumbataí, e que os organismos-teste utilizados tiveram sensibilidade suficiente para acusar a presença destas substâncias. Portanto, estes elementos estão presentes em concentrações suficientes para comprometer a sobrevivência e a manutenção de populações de organismos aquáticos semelhantes a estes. Podem estar ocorrendo, também, efeitos sobre a cadeia alimentar, como a biomagnificação, pois sabe-se que vários destes elementos - como chumbo e cromo - podem ser bioacumulados no zooplâncton, em peixes e em aves (ZAGATTO e BERTOLETTI, 2006). Os resultados de toxicidade são explicados pela ocorrência de elementos diferentes em cada caso, em cada coleta, não havendo um padrão que se repita ou que explique a toxicidade em todas as coletas. Provavelmente, isto se deve à alta dinâmica dos rios, que carregam materiais ao longo de seu curso rápida e unidirecionalmente (BRIGANTE e ESPÍNDOLA, 2003). Logo, cada coleta reflete um instante desta dinâmica, e dificilmente encontram-se resultados similares ao longo do tempo.

Resultados similares foram também observados pelas análises de correlação linear entre os bioensaios e os herbicidas detectados nas amostras de água por Monteiro et al. (2008) (Tabela 19). Para os herbicidas determinados por estes autores (Tabela 55/Apêndice A), em pelo menos uma vez houve concentrações suficientes para atingir um (ou mais) dos 
organismos testados. Por estas correlações, foi possível observar que D. magna sofreu efeitos tóxicos de dois herbicidas: ametrina e picloran, na coleta de Maio/2005. L. sativa teve respostas correlacionadas com ametrina na coleta de Novembro/2004 apenas. $H$. attenuata mostrou respostas na toxicidade correlacionadas com a presença de diversos herbicidas nas coletas de Setembro/2005 e Dezembro/2005, com ênfase para glifosato e AMPA. Os resultados de toxicidade de $P$. subcapitata puderam ser explicados apenas pelos herbicidas da coleta de Maio/2005 (ametrina, clomazona e picloran), que têm seu modo de ação focado na inibição da fotossíntese (NICOLAI e CHRISTOFFOLETI, 2008). Provavelmente por isso e por estarem em concentrações suficientes foram capazes de causar efeitos tóxicos a $P$. subcapitata. Efeitos aditivos e/ou sinérgicos podem explicar a toxicidade sofrida por $P$. subcapitata nas outras coletas. Também não deve-se descartar a possibilidade de que outros herbicidas ou grupos de agroquímicos estivessem presentes nas amostras, e que não tenham sido investigados. A presença destes herbicidas - normalmente aplicados na agricultura - mostra que a sub-bacia do rio Corumbataí é susceptível de contaminação pelas atividades agrícolas da região; sugere também que há uma contaminação em larga escala desta sub-bacia, que pode estar atingindo organismos nãoalvo à longas distâncias (campo-rio), e que existe uma ameaça à biota aquática, servindo como um alerta para entidades que visam à proteção da vida aquática. 
Tabela 19. Análise de correlação linear (Pearson) entre os bioensaios com amostras de água e determinações de herbicidas realizadas por Monteiro et al. (2008).

\begin{tabular}{|c|c|c|c|c|c|c|c|c|}
\hline & \multicolumn{4}{|c|}{ Novembro / 2004} & \multicolumn{4}{|c|}{ Maio / 2005} \\
\hline & D.m. & H.a. & P.s. & L.s. & D.m. & H.a. & P.s. & L.s. \\
\hline Glifosato & 0,2928 & 0,4082 & 0,0154 & $-0,3739$ & $-0,4082$ & - & $-0,1138$ & $-0,6669$ \\
\hline AMPA & - & - & - & - & $-0,3750$ & - & 0,1214 & $-0,7324$ \\
\hline Ametrina & 0,2945 & $-0,2259$ & $-0,3979$ & 0,7094 & 0,9954 & - & 0,7345 & 0,1912 \\
\hline Atrazina & 0,2899 & $-0,2628$ & $-0,2905$ & 0,6132 & 0,2624 & - & $-0,2423$ & 0,2651 \\
\hline Simazina & 0,2196 & $-0,4023$ & $-0,0781$ & 0,4416 & $-0,2998$ & - & $-0,1560$ & $-0,4425$ \\
\hline Metribuzin & - & - & - & - & 0,2500 & - & 0,5259 & $-0,8351$ \\
\hline Tebuthiuron & - & - & - & - & $-0,4082$ & - & 0,1668 & $-0,5676$ \\
\hline Clomazona & 0,2291 & $-0,3950$ & $-0,0404$ & 0,3949 & 0,6864 & - & 0,7298 & $-0,3866$ \\
\hline Picloran & - & - & - & - & $\mathbf{0 , 7 0 3 3}$ & - & 0,8886 & $-0,0894$ \\
\hline Propanil & - & - & - & - & - & - & - & - \\
\hline Hexazinona & - & - & - & - & $-0,6124$ & - & $-0,1759$ & $-0,8607$ \\
\hline Sulfentrazona & - & - & - & - & - & - & - & - \\
\hline
\end{tabular}

\begin{tabular}{|c|c|c|c|c|c|c|c|}
\hline & \multicolumn{4}{|c|}{ Setembro / 2005} & \multicolumn{3}{|c|}{ Dezembro / 2005} \\
\hline & D.m. & H.a. & P.s. & L.s. & D.m. & H.a. & P.s. \\
\hline Glifosato & - & 0,8729 & $-0,5995$ & $-0,8413$ & - & 0,9757 & 0,4041 \\
\hline AMPA & - & 0,8126 & $-0,5438$ & $-0,7546$ & - & 0,8044 & $-0,1496$ \\
\hline Ametrina & - & 0,3668 & $-0,5673$ & $-0,4362$ & - & $-0,1515$ & $-0,5295$ \\
\hline Atrazina & - & 0,7984 & $-0,7121$ & $-0,7017$ & - & $-0,4319$ & $-0,2412$ \\
\hline Simazina & - & 0,7845 & $-0,7945$ & $-0,6018$ & - & $-0,4416$ & $-0,6312$ \\
\hline Metribuzin & - & 1,0000 & $-0,3475$ & $-0,7343$ & - & - & - \\
\hline Tebuthiuron & - & 0,9854 & $-0,4192$ & $-0,6360$ & - & 0,6301 & $-0,5292$ \\
\hline Clomazona & - & 0,7717 & $-0,6408$ & $-0,5217$ & - & $-0,8191$ & $-0,2533$ \\
\hline Picloran & - & 0,3687 & $-0,5319$ & $-0,5275$ & - & 0,6304 & $-0,2474$ \\
\hline Propanil & - & 0,8792 & $-0,5393$ & $-0,8617$ & - & $-0,7683$ & $-0,5561$ \\
\hline Hexazinona & - & - & - & - & - & 0,9732 & 0,2728 \\
\hline Sulfentrazona & - & - & - & - & - & $-0,1606$ & $-0,6979$ \\
\hline
\end{tabular}

Nota: D.m.: D. magna; H.a.: H. attenuata; P.s.: P. subcapitata; L.s.: L. sativa. (-): Valores não determinados por ausência de toxicidade e/ou do herbicida.

Ao observar-se a Tabela 20, nota-se a maior toxicidade do elutriato (extraído das amostras de sedimento) quando comparado às amostras de água dos mesmos Pontos de coleta. Os testes realizados com C. xanthus, organismo bentônico, indicaram toxicidade crescente ao longo do curso do rio Corumbataí, onde os pontos mais próximos da nascente causaram menor mortalidade, enquanto que os pontos mais próximos à foz causaram maior mortalidade deste organismo. Observa-se também um aumento de indivíduos mortos ao longo do tempo das amostragens, indicando uma degradação ambiental gradativa do 
sedimento ao longo do período amostrado. Não foi observada correlação da mortalidade de C. xanthus com a pluviosidade, nem com as estações do ano. Os níveis de contaminação no sedimento parecem se sobressair às variações sazonais que ocorrem naturalmente.

Zambetta (2006) e Armas (2006) realizaram determinações de elementos químicos e herbicidas, respectivamente, nas amostras de sedimento do rio Corumbataí, e suas determinações coincidem com as duas primeiras coletas do presente estudo (Tabelas 56 e 57/Apêndice A). Pela análise de correlação linear (Pearson) entre os resultados de $C$. xanthus e estas determinações (Tabela 21), os resultados de C. xanthus de Novembro/2004 podem ser explicados pelas concentrações de ametrina, e de todos os elementos determinados por Zambetta (2006), com uma alta correlação.

D. magna respondeu mais nos testes com sedimento do que nos testes realizados com amostras de água. Entretanto, este organismo não sofreu efeitos tóxicos em nenhuma das coletas das amostras dos Pontos 6 e 7 (com exceção de uma ocasião para o Ponto 6). Estes resultados podem ser explicados (1) por uma presença maior de nutrientes para $D$. magna do que de agentes tóxicos, ou (2) pela presença de agentes tóxicos abaixo da sensibilidade de D. magna, ou ainda (3) porque é sabido que cladóceros também se alimentam de detritos orgânicos e bactérias, e, portanto, uma grande carga de efluentes domiciliares pode funcionar como alimento para D. magna (SALONEN e HAMMAR, 1986; OJALA et al., 1995; VIJVERBERG, 1989). Neste caso, estes resultados estariam mascarando a presença de efeitos tóxicos de amostras sabidamente contaminadas, e a posse de parâmetros físicos, químicos, e também de uma bateria de bioensaios auxiliam na interpretação correta de resultados como estes. Para D. magna também não houve relação da ocorrência de toxicidade com a pluviosidade, nem com as estações do ano. Os valores da Tabela 21 que mostram correlação entre elementos químicos e toxicidade à $D$. magna 
Tabela 20. Valores estimados dos parâmetros para os cinco organismos-teste utilizados nos testes de toxicidade com amostras de elutriatos, coletadas no rio Corumbataí.

\begin{tabular}{|c|c|c|c|c|c|c|}
\hline $\begin{array}{c}\text { Pontos } \\
\text { de coleta }\end{array}$ & $\begin{array}{c}\text { Data da } \\
\text { coleta }\end{array}$ & $\begin{array}{l}\text { C. xanthus } \\
\mathrm{CL}_{50}(96 \mathrm{~h})\end{array}$ & $\begin{array}{c}\text { D. magna } \\
\mathrm{CL}_{50}(48 \mathrm{~h})\end{array}$ & $\begin{array}{c}\text { H. attenuata } \\
\mathrm{CE}_{50}(96 \mathrm{~h})\end{array}$ & $\begin{array}{c}\text { L. sativa } \\
\text { \% inibição }\end{array}$ & $\begin{array}{c}\text { P. subcapitata } \\
\mathrm{CI}_{50}(72 \mathrm{~h})\end{array}$ \\
\hline \multirow{8}{*}{1} & Nov/04 & Não tóxico & $86,5 \%$ & N.T. & -18 & $89,8 \%$ \\
\hline & Fev/05 & Indício tox. & $77,3 \%$ & N.T. & -8 & N.T. \\
\hline & Mai/05 & Indício tox. & $97,5 \%$ & N.T. & 0 & $73,2 \%$ \\
\hline & Set/05 & Tóxico & $89,8 \%$ & N.T. & -15 & $30,8 \%$ \\
\hline & Dez/05 & Indício tox. & $97,5 \%$ & N.T. & $\ddagger$ & N.T. \\
\hline & Mar/06 & Indício tox. & $80,8 \%$ & N.T. & $\ddagger$ & $35,5 \%$ \\
\hline & Jun/06 & Indício tox. & $86,6 \%$ & N.T. & $\ddagger$ & $53,1 \%$ \\
\hline & Set/06 & Indício tox. & $99,5 \%$ & N.T. & $\ddagger$ & $62,4 \%$ \\
\hline \multirow{8}{*}{2} & Nov/04 & Não tóxico & $93,6 \%$ & $26,0 \%$ & -16 & $95,1 \%$ \\
\hline & Fev/05 & Tóxico & $78,7 \%$ & N.T. & -33 & $30,9 \%$ \\
\hline & Mai/05 & Indício tox. & N.T. & N.T. & -5 & $84,3 \%$ \\
\hline & Set/05 & Indício tox. & $83,9 \%$ & N.T. & -1 & $30,8 \%$ \\
\hline & Dez/05 & Indício tox. & N.T. & N.T. & $\ddagger$ & $40,7 \%$ \\
\hline & Mar/06 & Não tóxico & $78,6 \%$ & N.T. & $\ddagger$ & $47,5 \%$ \\
\hline & Jun/06 & Tóxico & $84,3 \%$ & N.T. & $\ddagger$ & $34,5 \%$ \\
\hline & Set/06 & Tóxico & $99,5 \%$ & N.T. & $\ddagger$ & $79,9 \%$ \\
\hline \multirow{8}{*}{3} & Nov/04 & Não tóxico & $85,1 \%$ & $14,3 \%$ & -11 & N.T. \\
\hline & Fev/05 & Indício tox. & $68,5 \%$ & N.T. & 5 & $29,3 \%$ \\
\hline & Mai/05 & Indício tox. & $98,7 \%$ & N.T. & 17 & N.T. \\
\hline & Set/05 & Tóxico & N.T. & $96,9 \%$ & -12 & $20,6 \%$ \\
\hline & Dez/05 & Tóxico & $97,2 \%$ & N.T. & $\ddagger$ & $78,4 \%$ \\
\hline & Mar/06 & Indício tox. & $86,6 \%$ & $86,6 \%$ & $\ddagger$ & $35,2 \%$ \\
\hline & Jun/06 & Tóxico & $77,8 \%$ & N.T. & $\ddagger$ & $87,8 \%$ \\
\hline & Set/06 & Indício tox. & N.T. & N.T. & $\ddagger$ & $94,1 \%$ \\
\hline \multirow{8}{*}{4} & Nov/04 & Indício tox. & $86,6 \%$ & $23,6 \%$ & -14 & $98,1 \%$ \\
\hline & Fev/05 & Indício tox. & $72,1 \%$ & N.T. & 0 & $91,4 \%$ \\
\hline & Mai/05 & Indício tox. & N.T. & N.T. & 7 & $89,9 \%$ \\
\hline & Set/05 & Tóxico & N.T. & $95,3 \%$ & -6 & $30,4 \%$ \\
\hline & Dez/05 & Tóxico & N.T. & N.T. & $\ddagger$ & $23,7 \%$ \\
\hline & Mar/06 & Indício tox. & N.T. & $80,7 \%$ & $\ddagger$ & $76,2 \%$ \\
\hline & Jun/06 & Tóxico & $87,4 \%$ & N.T. & $\ddagger$ & $23,9 \%$ \\
\hline & Set/06 & Indício tox. & N.T. & $96,4 \%$ & $\ddagger$ & $48,2 \%$ \\
\hline \multirow{8}{*}{5} & Nov/04 & Indício tox. & N.T. & $43,7 \%$ & -3 & N.T. \\
\hline & Fev/05 & Indício tox. & $72,6 \%$ & N.T. & -4 & $98,2 \%$ \\
\hline & Mai/05 & Indício tox. & N.T. & N.T. & -6 & $88,8 \%$ \\
\hline & Set/05 & Indício tox. & N.T. & $96,5 \%$ & -32 & $14,2 \%$ \\
\hline & Dez/05 & Indício tox. & $98,1 \%$ & $93,1 \%$ & $\ddagger$ & $6,6 \%$ \\
\hline & Mar/06 & Não tóxico & N.T. & $77,1 \%$ & $\ddagger$ & $94,3 \%$ \\
\hline & Jun/06 & Indício tox. & $90,9 \%$ & N.T. & $\ddagger$ & $24,7 \%$ \\
\hline & Set/06 & Tóxico & $96,7 \%$ & N.T. & $\ddagger$ & $92,8 \%$ \\
\hline (Con & 1а...) & & & & & \\
\hline
\end{tabular}




\begin{tabular}{|c|c|c|c|c|c|c|}
\hline \multicolumn{7}{|c|}{ (Continuação) } \\
\hline $\begin{array}{c}\text { Pontos } \\
\text { de coleta }\end{array}$ & $\begin{array}{c}\text { Data da } \\
\text { coleta }\end{array}$ & $\begin{array}{l}\text { C. xanthus } \\
\mathrm{CL}_{50}(96 \mathrm{~h})\end{array}$ & $\begin{array}{c}\text { D. magna } \\
\mathrm{CL}_{50}(48 \mathrm{~h})\end{array}$ & $\begin{array}{c}\text { H. attenuata } \\
\mathrm{CE}_{50}(96 \mathrm{~h})\end{array}$ & $\begin{array}{c}\text { L. sativa } \\
\text { \% inibição }\end{array}$ & $\begin{array}{c}P \text {. subcapitata } \\
\mathrm{CI}_{50}(72 \mathrm{~h})\end{array}$ \\
\hline \multirow{8}{*}{6} & Nov/04 & Indício tox. & N.T. & $22,6 \%$ & 0 & $94,2 \%$ \\
\hline & Fev/05 & Indício tox. & $100,0 \%$ & N.T. & -6 & $88,0 \%$ \\
\hline & Mai/05 & Indício tox. & N.T. & N.T. & 14 & $75,0 \%$ \\
\hline & Set/05 & Tóxico & N.T. & $26,0 \%$ & -1 & $28,2 \%$ \\
\hline & Dez/05 & Indício tox. & N.T. & $96,5 \%$ & $\ddagger$ & $21,5 \%$ \\
\hline & Mar/06 & Tóxico & N.T. & $62,5 \%$ & $\ddagger$ & $52,8 \%$ \\
\hline & Jun/06 & Tóxico & N.T. & $75,8 \%$ & $\ddagger$ & $24,2 \%$ \\
\hline & Set/06 & Tóxico & N.T. & N.T. & $\ddagger$ & $68,1 \%$ \\
\hline \multirow{8}{*}{7} & Nov/04 & Tóxico & N.T. & $17,1 \%$ & 7 & $61,6 \%$ \\
\hline & Fev/05 & Indício tox. & N.T. & N.T. & -20 & $92,1 \%$ \\
\hline & Mai/05 & Tóxico & N.T. & $70,1 \%$ & 2 & $12,1 \%$ \\
\hline & Set/05 & Tóxico & N.T. & $22,3 \%$ & 1 & $8,3 \%$ \\
\hline & Dez/05 & Tóxico & N.T. & $57,7 \%$ & $\ddagger$ & $17,2 \%$ \\
\hline & Mar/06 & Tóxico & N.T. & $38,7 \%$ & $\ddagger$ & $53,6 \%$ \\
\hline & Jun/06 & Indício tox. & N.T. & N.T. & $\ddagger$ & $8,6 \%$ \\
\hline & Set/06 & Indício tox. & N.T. & $86,6 \%$ & $\ddagger$ & $37,6 \%$ \\
\hline
\end{tabular}

Tabela 21. Análise de correlação linear (Pearson) entre os resultados de toxicidade com amostras de sedimento e herbicidas e metais determinados por Armas (2006) e Zambetta (2006), respectivamente, e outros parâmetros.

\begin{tabular}{|c|c|c|c|c|c|c|c|c|c|c|}
\hline & \multicolumn{5}{|c|}{ Novembro / 2004} & \multicolumn{5}{|c|}{ Fevereiro / 2005} \\
\hline & C.x. & D. $m$. & H. $a$. & P. s. & L.s. & C.x. & D. $m$. & H. $a$. & P. s. & L.s. \\
\hline Glifosato & 0,463 & 0,468 & 0,506 & $-0,041$ & 0,258 & 0,112 & $-0,214$ & 0,218 & $-0,187$ & $-0,223$ \\
\hline Ametrina & 0,969 & 0,488 & $-0,120$ & $-0,288$ & $0,6864 *$ & 0,112 & $-0,214$ & 0,218 & $-0,187$ & $-0,223$ \\
\hline Al & 0,976 & 0,518 & $-0,134$ & $-0,264$ & $\mathbf{0 , 7 0 3}$ & 0,189 & $0,637 *$ & 0,592 & $-0,224$ & $-0,289$ \\
\hline Cd & 0,969 & 0,476 & $-0,022$ & $-0,300$ & $0,6319 *$ & $-0,215$ & 0,258 & $0,6455 *$ & 0,736 & $-0,215$ \\
\hline $\mathrm{Cr}$ & 0,950 & $0,6079 *$ & $-0,139$ & $-0,172$ & $\mathbf{0 , 7 7 0}$ & $-0,057$ & 0,339 & 0,492 & $-0,027$ & $-0,116$ \\
\hline $\mathrm{Cu}$ & $\mathbf{0 , 9 7 0}$ & 0,501 & $-0,123$ & $-0,277$ & $0,6957 *$ & 0,128 & 0,849 & 0,329 & $-0,239$ & $-0,286$ \\
\hline $\mathbf{F e}$ & 0,971 & 0,494 & $-0,031$ & $-0,282$ & $0,6497 *$ & $-0,219$ & 0,159 & $0,6685 *$ & 0,744 & $-0,216$ \\
\hline Mn & $\mathbf{0 , 9 7 7}$ & 0,501 & $-0,093$ & $-0,267$ & $0,6775 *$ & 0,266 & 0,085 & 0,595 & $-0,134$ & 0,188 \\
\hline $\mathbf{N i}$ & 0,969 & 0,500 & $-0,127$ & $-0,279$ & $0,6975 *$ & $-0,107$ & $0,6168 *$ & 0,317 & $-0,077$ & $-0,204$ \\
\hline $\mathbf{P b}$ & 0,973 & 0,500 & $-0,085$ & $-0,282$ & $0,6675 *$ & 0,042 & $0,6239 *$ & 0,447 & $-0,173$ & $-0,311$ \\
\hline $\mathbf{S r}$ & 0,979 & 0,570 & $-0,161$ & $-0,208$ & 0,738 & 0,262 & 0,754 & $0,6079 *$ & $-0,169$ & $-0,234$ \\
\hline pH & 0,093 & 0,397 & $-0,925$ & 0,256 & $0,6864 *$ & 0,135 & 0,796 & 0,000 & $-0,481$ & $-0,674$ \\
\hline O.D. & $-0,512$ & $-0,617$ & 0,770 & $-0,408$ & $-0,790$ & $-0,181$ & $-0,509$ & 0,000 & 0,509 & $-0,107$ \\
\hline Condut. & 0,541 & 0,784 & $-0,326$ & 0,227 & 0,824 & $-0,254$ & 0,201 & 0,000 & $-0,264$ & $-0,015$ \\
\hline
\end{tabular}

C.x.: C. xanthus; D.m.: D. magna; H.a.: H. attenuata; P.s.: P. subcapitata; L.s.: L. sativa.

Significância à $0,05:>0,7$. (*) Valores com significância marginal. 
correspondem aos elementos que apresentaram maior concentração nos pontos mais próximos da nascente. A correlação com a condutividade registrada na coleta de Novembro/2004 poderia ser explicada como uma soma dos efeitos dos elementos, que tiveram cada um uma correlação em torno de 0,5 para $D$. magna.

O organismo $H$. attenuata demonstrou sofrer mais efeitos tóxicos dos Pontos de coleta mais próximos à foz do rio (Pontos 6 e 7), com menos indícios de toxicidade nos outros pontos (Tabela 20). A análise de correlação linear indicou apenas uma correlação marginal $(0,6<\mathrm{r}<0,7)$ com alguns elementos químicos, para a coleta de Fevereiro/2005, e correlação com O.D. na coleta de Novembro/2004 (Tabela 21). Na Tabela 22 é mostrada a análise de correlação linear (Pearson) entre os valores de toxicidade e os de pluviosidade destas duas coletas, e estes dados parecem explicar bem a resposta de $H$. attenuata às amostras de sedimento. Todos estes dados sugerem que o organismo $H$. attenuata pareceu sofrer efeitos tóxicos principalmente devido a dois fatores: (1) os efeitos da pluviosidade sobre o rio (chuvas carreando substâncias para o rio, e as depositando no sedimento) e a contaminação do rio como um todo. Nos Pontos 2, 3, 4, e 5 (pontos menos poluídos) a toxicidade esteve estreitamente relacionada com a pluviosidade (valores de $\mathrm{r}$ superiores a 0,7), mas não nos Pontos 6 e 7, que estão localizados no trecho mais poluído do rio (com altos valores de $\mathrm{DBO}$, coliformes, condutividade, e baixos de oxigênio dissolvido), e aqui a poluição se sobressairia aos efeitos da pluviosidade, que estaria influenciando menos as respostas de $H$. attenuata. A análise de Pearson indicou boas correlações para L. sativa em Novembro/2004, mas não em Fevereiro/2005 (Tabela 21). 
Tabela 22. Análise de correlação linear (Pearson) entre os valores de toxicidade do sedimento à $H$. attenuata e pluviosidade (dos dias precedentes às coletas de Nov/2004 e Fev/2005).

\begin{tabular}{cc}
\hline Pontos de coleta & r (Pearson) \\
1 & - \\
2 & 0,7086 \\
3 & 0,7136 \\
4 & 0,7240 \\
5 & 0,7718 \\
6 & 0,3603 \\
7 & 0,5090 \\
\hline
\end{tabular}

Os resultados obtidos nos bioensaios com a alga $P$. subcapitata indicam um aumento gradual na toxicidade em direção à foz do rio Corumbataí. A Tabela 21 indica correlação positiva apenas com os metais cádmio e ferro, na coleta de Fevereiro/2005. Também não foi encontrada relação da toxicidade sofrida por $P$. subcapitata com a pluviosidade. A toxicidade sofrida por $P$. subcapitata poderia ser explicada por efeitos aditivos e/ou sinérgicos existentes entre os elementos e herbicidas determinados nas amostras de sedimento. Mesmo assim, foram diversos os registros de toxicidade a este organismo, que apresentou o endpoint mais sensível dentre os principais testes realizados. O teste com $H$. attenuata entraria como o segundo mais sensível, seguido por $C$. xanthus e D. magna.

Determinações de elementos químicos no sedimento foram também realizadas em cinco das oito coletas por Falqueto $^{1}$ (em fase de elaboração). Correlações lineares (Pearson) entre estes elementos e os bioensaios estão dispostas na Tabela 23. As correlações obtidas explicam a maioria das respostas apresentadas pelos organismos-teste. Em todas as coletas, a toxicidade sobre $H$. attenuata pôde ser explicada pelos elementos analisados, e também para C. xanthus, com exceção da última coleta (de Setembro/2006). Para $P$. subcapitata, as correlações explicaram a toxicidade em três destas cinco coletas. Não houve boa correlação dos elementos químicos com a mortalidade de D. magna, 
provavelmente pelos fatos já supracitados. Também na foram observadas boas correlações para L. sativa. A condutividade também esteve bem correlacionada com a toxicidade em diversas ocasiões. Por estes resultados, em que se observa uma alternância de correlação com os elementos entre os organismos, é preciso ressaltar a importância da utilização de uma bateria de bioensaios, que respondam de maneiras diferentes quando expostos às mesmas amostras. Utilizando uma bateria de bioensaios, aumenta-se a sensibilidade da avaliação, por haver uma "intersecção" de faixas de sensibilidade; elimina-se a chance de interpretações equivocadas, e torna-se capaz de identificar efeitos deletérios de uma maior quantidade de agentes tóxicos passíveis de estarem presentes no ambiente estudado.

Tabela 23. Análise de correlação linear (Pearson) entre resultados de bioensaios e determinações de elementos químicos em amostras de sedimento do rio Corumbataí. Determinações realizadas por Falqueto ${ }^{1}$ (em fase de elaboração).

\begin{tabular}{|c|c|c|c|c|c|c|c|c|c|}
\hline \multirow{2}{*}{ Elementos } & \multicolumn{5}{|c|}{ Setembro / 2005} & \multicolumn{4}{|c|}{ Dezembro / 2005} \\
\hline & C.x. & D. $m$. & H. $a$. & P.s. & L.s. & C.x. & D. $m$. & H. $a$. & P.s. \\
\hline $\mathrm{Be}$ & 0,4551 & $-0,4211$ & 0,5899 & 0,9987 & $-0,0075$ & 0,7905 & $-0,3086$ & 0,9981 & 0,1795 \\
\hline $\mathrm{Na}$ & $-0,0407$ & $-0,3167$ & 0,1199 & 0,7034 & 0,0266 & 0,8022 & $-0,4767$ & 0,8930 & $-0,2197$ \\
\hline Mg & 0,4587 & $-0,3612$ & 0,5800 & 0,8999 & 0,2618 & 0,8004 & $-0,3718$ & 0,9959 & 0,0945 \\
\hline Al & 0,4420 & $-0,4067$ & 0,5940 & 0,9558 & 0,1405 & 0,7942 & $-0,3470$ & 0,9970 & 0,1420 \\
\hline $\mathbf{K}$ & 0,3670 & $-0,4905$ & 0,3831 & 0,8043 & 0,0239 & 0,8189 & $-0,3590$ & 0,9950 & 0,1908 \\
\hline $\mathbf{C a}$ & 0,4173 & $-0,3606$ & 0,5789 & 0,9733 & 0,1478 & 0,8056 & $-0,3632$ & 0,9970 & 0,1131 \\
\hline $\mathbf{V}$ & 0,4829 & $-0,3923$ & 0,6341 & 0,9960 & 0,0337 & $\mathbf{0 , 7 7 3 0}$ & $-0,2871$ & 0,9945 & 0,1628 \\
\hline $\mathrm{Cr}$ & $-0,0297$ & $-0,1557$ & $-0,0617$ & $-0,4798$ & 0,3549 & $-0,3502$ & $-0,1153$ & $-0,1878$ & $-0,2675$ \\
\hline Mn & 0,2331 & $-0,3074$ & 0,4101 & 0,9140 & $-0,2011$ & $\mathbf{0 , 7 8 3 7}$ & $-0,3294$ & 0,9950 & 0,1745 \\
\hline $\mathbf{F e}$ & 0,5019 & $-0,3453$ & 0,6489 & 0,9930 & 0,1016 & 0,7812 & $-0,3077$ & 0,9960 & 0,1341 \\
\hline Co & 0,3026 & $-0,2817$ & 0,4852 & 0,9607 & $-0,0725$ & 0,7195 & $-0,2888$ & 0,9796 & 0,1987 \\
\hline $\mathbf{N i}$ & 0,6939 & $-0,3880$ & 0,6689 & 0,7210 & 0,5273 & 0,7017 & $-0,3892$ & 0,9416 & $-0,0089$ \\
\hline $\mathrm{Cu}$ & 0,5583 & $-0,3227$ & 0,6921 & 0,9429 & 0,3163 & 0,8036 & $-0,3601$ & 0,9971 & 0,1049 \\
\hline $\mathbf{Z n}$ & 0,4896 & $-0,3467$ & 0,6142 & 0,9068 & 0,2930 & 0,7917 & $-0,3755$ & 0,9941 & 0,0783 \\
\hline As & 0,5044 & $-0,4529$ & 0,6240 & 0,9758 & 0,1471 & 0,8031 & $-0,3126$ & 0,9976 & 0,1500 \\
\hline Se & 0,5940 & $-0,2471$ & 0,7322 & 0,9050 & 0,3959 & 0,8137 & $-0,3459$ & 0,9946 & 0,0803 \\
\hline Mo & $-0,0160$ & $-0,1925$ & $-0,1955$ & $-0,3771$ & 0,2542 & $-0,4741$ & $-0,0778$ & $-0,5067$ & $-0,5289$ \\
\hline Ag & 0,5022 & $-0,3504$ & 0,5991 & 0,8522 & 0,3415 & 0,8116 & $-0,3517$ & 0,9949 & 0,0801 \\
\hline Cd & 0,5594 & $-0,3030$ & 0,6944 & 0,9387 & 0,3254 & 0,8089 & $-0,3499$ & 0,9961 & 0,0942 \\
\hline Sb & $-0,5470$ & 0,6466 & $-0,1968$ & $-0,0641$ & 0,5016 & 0,6810 & $-0,4437$ & 0,9628 & 0,0457 \\
\hline Ba & 0,3735 & $-0,4278$ & 0,5238 & 0,9784 & $-0,1151$ & 0,7957 & $-0,3217$ & 0,9976 & 0,1734 \\
\hline $\mathrm{Hg}$ & 0,5940 & $-0,2471$ & 0,7322 & 0,9050 & 0,2241 & 0,8137 & $-0,3459$ & 0,9946 & 0,0803 \\
\hline Tl & 0,5278 & $-0,3830$ & 0,6697 & 0,9803 & 0,1819 & 0,7903 & $-0,3396$ & 0,9996 & 0,1655 \\
\hline $\mathbf{P b}$ & 0,5084 & $-0,3974$ & 0,6304 & 0,9432 & 0,2261 & 0,8018 & $-0,3508$ & 0,9978 & 0,1129 \\
\hline Th & 0,5364 & $-0,3310$ & 0,6639 & 0,9579 & 0,0511 & 0,8110 & $-0,2629$ & 0,9925 & 0,1308 \\
\hline $\mathbf{U}$ & 0,5186 & $-0,3796$ & 0,6420 & 0,9777 & 0,1785 & 0,7992 & $-0,3420$ & 0,9991 & 0,1369 \\
\hline Condut. & 0,8519 & $-0,4281$ & 0,9859 & 0,7793 & 0,5191 & 0,1528 & $-0,5302$ & 0,3768 & 0,0706 \\
\hline
\end{tabular}


(Continuação)

\begin{tabular}{|c|c|c|c|c|c|c|c|c|c|c|c|c|}
\hline \multirow{2}{*}{ Elementos } & \multicolumn{4}{|c|}{ Março / 2006} & \multicolumn{4}{|c|}{ Junho / 2006} & \multicolumn{4}{|c|}{ Setembro / 2006} \\
\hline & C.x. & D. $m$. & H. $a$. & P. s. & C.x. & D. $m$. & H. $a$. & P.s. & C.x. & D. $m$. & H. $a$. & P.s. \\
\hline $\mathbf{B e}$ & 0,8000 & $-0,5073$ & 0,7887 & 0,0780 & 0,6507 & $-0,8597$ & 0,7186 & 0,6643 & $-0,0632$ & $-0,4543$ & 0,7145 & 0,5378 \\
\hline $\mathbf{N a}$ & $-0,4614$ & 0,4658 & $-0,6550$ & 0,1652 & 0,3629 & $-0,5471$ & 0,9904 & $-0,0263$ & 0,0371 & $-0,0661$ & 0,1300 & 0,0097 \\
\hline Mg & 0,7169 & $-0,5139$ & $\mathbf{0 , 8 2 5 7}$ & $-0,0553$ & 0,6450 & $-0,8255$ & 0,7360 & 0,6334 & 0,2306 & $-0,4036$ & $\mathbf{0 , 7 8 1 1}$ & 0,6711 \\
\hline Al & 0,7579 & $-0,4842$ & 0,8074 & 0,0439 & 0,6387 & $-0,8365$ & 0,7089 & 0,6694 & 0,1082 & $-0,4369$ & 0,8012 & 0,6383 \\
\hline $\mathbf{K}$ & 0,6805 & $-0,6127$ & $\mathbf{0 , 8 3 3 8}$ & $-0,1622$ & 0,6256 & $-0,7244$ & 0,2293 & 0,9271 & 0,2347 & $-0,3120$ & 0,8763 & 0,7287 \\
\hline $\mathbf{C a}$ & 0,7274 & $-0,5388$ & 0,8051 & $-0,0482$ & 0,6639 & $-0,8455$ & 0,5967 & 0,7667 & 0,1741 & $-0,4248$ & 0,8224 & 0,6962 \\
\hline $\mathbf{V}$ & 0,8816 & $-0,3694$ & 0,6814 & 0,2938 & 0,6856 & $-0,8427$ & 0,7358 & 0,6297 & $-0,2151$ & $-0,4981$ & 0,7111 & 0,5387 \\
\hline $\mathrm{Cr}$ & 0,7494 & $-0,4811$ & 0,8062 & 0,0118 & $-0,3755$ & 0,9053 & $-0,4152$ & $-0,7672$ & $-0,2245$ & 0,2879 & $-0,2882$ & $-0,2195$ \\
\hline Mn & 0,7694 & $-0,4866$ & 0,8153 & 0,0487 & 0,5969 & $-0,8316$ & 0,5303 & 0,7679 & $-0,4779$ & $-0,5383$ & 0,6091 & 0,5009 \\
\hline $\mathbf{F e}$ & 0,8875 & $-0,3686$ & 0,7211 & 0,2730 & 0,6668 & $-0,8471$ & 0,7015 & 0,6215 & $-0,1993$ & $-0,4912$ & 0,8913 & 0,8105 \\
\hline Co & 0,8446 & $-0,3355$ & 0,7216 & 0,2693 & 0,5235 & $-0,7616$ & 0,8108 & 0,3894 & $-0,4913$ & $-0,5647$ & 0,5044 & 0,3903 \\
\hline $\mathrm{Ni}$ & 0,7436 & $-0,5172$ & $\mathbf{0 , 8 2 3 6}$ & $-0,0226$ & 0,2617 & 0,4355 & $-0,1906$ & $-0,1686$ & 0,1229 & $-0,2732$ & 0,9516 & 0,7866 \\
\hline $\mathrm{Cu}$ & 0,7499 & $-0,5174$ & 0,8414 & $-0,0277$ & 0,6809 & $-0,8021$ & 0,7254 & 0,5991 & 0,2313 & $-0,3647$ & 0,8176 & 0,6935 \\
\hline Zn & 0,7115 & $-0,5099$ & 0,8009 & $-0,0509$ & 0,5964 & $-0,7945$ & 0,8498 & 0,4864 & 0,3177 & $-0,3844$ & 0,6025 & 0,5444 \\
\hline As & 0,7332 & $-0,6217$ & $\mathbf{0 , 8 5 0 3}$ & $-0,1284$ & 0,6360 & $-0,8605$ & 0,6778 & 0,6981 & 0,2233 & $-0,3693$ & 0,8415 & 0,7526 \\
\hline Se & 0,7638 & $-0,4950$ & 0,8567 & 0,0115 & 0,6512 & $-0,8437$ & 0,7267 & 0,6523 & 0,0519 & $-0,4684$ & 0,7531 & 0,5958 \\
\hline Mo & 0,6219 & $-0,6147$ & $\mathbf{0 , 8 3 3 5}$ & $-0,2412$ & $-0,2747$ & 0,8919 & $-0,3971$ & $-0,6927$ & 0,3630 & $-0,1437$ & $-0,1353$ & $-0,0658$ \\
\hline Ag & 0,6924 & $-0,5245$ & 0,8652 & $-0,1064$ & 0,5340 & $-0,7311$ & 0,9296 & 0,3331 & 0,3970 & $-0,3065$ & 0,1403 & 0,1879 \\
\hline Cd & 0,7002 & $-0,5181$ & $\mathbf{0 , 8 1 6 7}$ & $-0,0648$ & 0,6601 & $-0,8439$ & 0,6748 & 0,6958 & 0,2798 & $-0,3735$ & 0,7373 & 0,6462 \\
\hline Sb & 0,6574 & $-0,5326$ & 0,7489 & $-0,1161$ & 0,5745 & $-0,3275$ & 0,7599 & 0,1795 & 0,2890 & $-0,3569$ & 0,4923 & 0,4798 \\
\hline $\mathbf{B a}$ & 0,7960 & $-0,4676$ & 0,7481 & 0,1385 & 0,6252 & $-0,8570$ & 0,6432 & 0,7348 & $-0,0858$ & $-0,5185$ & 0,5559 & 0,4128 \\
\hline Hg & 0,7000 & $-0,5069$ & 0,9414 & $-0,1053$ & - & - & - & - & - & - & - & - \\
\hline $\mathbf{T l}$ & 0,7226 & $-0,5806$ & $\mathbf{0 , 8 3 8 8}$ & $-0,0738$ & 0,6116 & $-0,8583$ & 0,6219 & 0,7443 & 0,1307 & $-0,4290$ & 0,7306 & 0,5540 \\
\hline $\mathbf{P b}$ & 0,7195 & $-0,5343$ & $\mathbf{0 , 8 2 1 7}$ & $-0,0597$ & 0,6274 & $-0,8118$ & 0,8143 & 0,5427 & 0,2252 & $-0,4444$ & 0,6123 & 0,4935 \\
\hline Th & 0,8248 & $-0,5233$ & 0,7778 & 0,0793 & 0,8058 & $-0,7435$ & 0,3669 & 0,8364 & $-0,3854$ & $-0,4798$ & 0,7715 & 0,6120 \\
\hline $\mathbf{U}$ & 0,7192 & $-0,5661$ & 0,8540 & $-0,0929$ & 0,6271 & $-0,8293$ & 0,7916 & 0,5772 & 0,2513 & $-0,3392$ & $\mathbf{0 , 8 2 7 7}$ & 0,6940 \\
\hline Condut. & 0,5882 & $-0,6527$ & 0,9064 & $-0,2823$ & 0,6063 & $-0,8279$ & 0,7842 & 0,5859 & 0,3874 & $-0,3241$ & 0,5775 & 0,5252 \\
\hline
\end{tabular}

C.x.: C. xanthus; D.m.: D. magna; H.a.: H. attenuata; P.s.: P. subcapitata; L.s.: L. sativa. (-): Valores não calculados por ausência do elemento nas amostras.

Nenhum bioensaio é capaz de responder à vasta quantidade de agentes tóxicos potencialmente presentes em um ambiente aquático (CASTILLO et al., 2000). Se não há possibilidade de realizar determinações de todas as substâncias tóxicas potencialmente presentes num dado corpo d'água - e geralmente não há, por conta dos gastos financeiros e da dificuldade em se conhecer toda uma região necessários para tal- uma bateria de bioensaios bem composta pode sanar esta necessidade, respondendo bem a todos os tóxicos presentes (BLAISE e FÉRARD, 2005). 


\subsubsection{Impactos dos municípios sobre o rio Corumbataí}

O rio Corumbataí tem suas nascentes no município de Analândia. Os Pontos de coleta 1 e 2 ficam localizados neste município, sendo o primeiro a montante e o segundo a jusante do despejo de esgotos domiciliares, estando distantes entre eles cerca de 500 metros. Observando os valores de condutividade (Figura 10, e Tabela 48/Apêndice A), DBO (Figura 11, e Tabela 49/Apêndice A) coliformes (Tabela 7), é possível observar os efeitos deste despejo sobre os valores destes parâmetros. Segundo dados da CETESB (2007b), 94\% do esgoto domiciliar é coletado em Analândia, sendo despejado neste trecho do rio sem qualquer tratamento. Em 2006, a carga remanescente média deste esgoto foi de $169 \mathrm{~kg} \mathrm{DBO} \mathrm{dia}{ }^{-1}$ (Tabela 1). Não foram observados aumentos significativos de fósforo e nitrogênio no Ponto 2 em relação ao Ponto 1, nas coletas realizadas (Tabelas 50 e 51/Apêndice A). Observam-se apenas pequenos aumentos nos valores de $\mathrm{N}$ e $\mathrm{P}$, para algumas coletas. Os bioensaios de D. magna e $H$. attenuata realizados com amostras de água destes dois pontos, indicam apenas uma ligeira toxicidade no Ponto 2 em três e duas das oito coletas, respectivamente, e nenhuma toxicidade no Ponto 1 (Tabelas 9 e 11). Nos bioensaios realizados com sedimento, no teste com C. xanthus houve mais mortalidade no Ponto 2 em cinco das oito coletas (Tabela 8); no teste com D. magna, os valores de toxicidade dos dois pontos são equivalentes, não diferindo muito entre si (Tabela 10); no teste com $H$. attenuata, não houve registro de toxicidade em nenhum dos dois pontos (exceto em uma ocasião); no teste com $P$. subcapitata a toxicidade em geral ou é semelhante ou é menor no Ponto 2. Mesmo assim, foi o endpoint mais sensível. É possível notar um comprometimento maior da qualidade do sedimento do que na água, quando comparamos todos estes resultados, dos Pontos 1 e 2 do rio. Neste trecho, o principal impacto antropogênico é o despejo de esgotos domiciliares (Figura 1). Através destes resultados, é possível afirmar que este despejo, ainda existente, dado o aumento na 
contagem de coliformes, exerce um pequeno impacto negativo sobre a qualidade do rio neste trecho.

Entre os Pontos de coleta 2 e 3, distantes cerca de $10 \mathrm{~km}$ entre si, há uma tendência de manutenção ou aumento nos valores de N-total, P-total, sólidos totais, e turbidez, e manutenção ou diminuição de condutividade, DBO e coliformes. Entre estes pontos, o rio parece ter conseguido se recuperar um pouco dos impactos, pela diminuição dos valores dos três últimos parâmetros citados. Quanto aos resultados dos bioensaios com amostras de água destes Pontos, D. magna e $H$. attenuata demonstram uma leve redução da toxicidade. No teste com $P$. subcapitata, houve tendência de a toxicidade ser maior no Ponto 3 do que no Ponto 2 (Tabela 15). Nos bioensaios realizados com amostras de sedimento destes dois pontos de coleta, os testes com $C$. xanthus e $H$. attenuata mostraram um leve aumento na toxicidade do Ponto 2 para o Ponto 3; no teste com $P$. subcapitata, os resultados são bastante variáveis, havendo aumentos e diminuições de toxicidade, em ambos os Pontos (Tabela 16). Pelos parâmetros físicos e químicos, poder-se-ia dizer que o rio se recuperou através de auto-depuração, mas os bioensaios sugerem uma tendência contrária, que não pode ser ignorada, dado serem mais sensíveis na detecção de agentes tóxicos.

Entre os Pontos de coleta 3 e 4, há a cidade de Corumbataí, que segundo a CETESB (2007b) trata 100\% de seu esgoto domiciliar, lançando uma carga remanescente de $22 \mathrm{~kg}$ DBO $\operatorname{dia}^{-1}$ (Tabela 1), além de empresas mineradoras de areia. Comparando-se os resultados dos Pontos 3 e 4, observam-se aumentos de condutividade, coliformes (exceto nas duas últimas coletas, onde houve uma discreta diminuição na contagem), DBO (exceto nas duas últimas coletas também), clorofila-a, N-total, nitrato, e fósforo. Nos bioensaios realizados com amostras de água, os testes com D. magna e $H$. attenuata não indicam queda na qualidade da água (Tabelas 9 e 11), mas $P$. subcapitata $\operatorname{sim}$, em sete das oito coletas (Tabela 15). Nos bioensaios realizados com amostras de sedimento, os testes com 
C. xanthus e H. attenuata mostram uma uniformidade de resultados entre estes dois pontos de coleta (Tabelas 8 e 12); no teste com P. subcapitata há predominância de valores mais tóxicos no Ponto 4 (Tabela 16). Os impactos existentes nestes trechos parecem ser pequenos, e o rio Corumbataí parece ainda recebê-los sem grandes prejuízos para a qualidade de suas águas. Entretanto, seu sedimento já apresenta alguns indícios de contaminação, já que a mortalidade registrada nos bioensaios com $C$. xanthus não é desprezível, e é sabido que o sedimento tem a tendência de acumular agentes tóxicos ao longo do tempo.

Analisando-se os resultados dos Pontos 4 e 5, em geral os valores de DBO e coliformes diminuem, assim como os de clorofila-a, turbidez e nitrogênio total. Também após este trecho o rio Corumbataí parece se recuperar um pouco dos impactos sofridos. Nos bioensaios realizados com amostras de água, os testes com D. magna e H. attenuata não indicaram toxicidade em nenhuma coleta para estes dois pontos, com exceção de uma ocorrência em cada teste no Ponto 5 (Tabelas 9 e 11); já o teste com a alga $P$. subcapitata indicou aumento de toxicidade em seis das oito coletas (Tabela 15). Nos bioensaios realizados com amostras de sedimento, os testes com $C$. xanthus, $H$. attenuata e $P$. subcapitata indicaram menor toxicidade no Ponto 5.

Os Pontos 5 e 6 localizam-se a montante e a jusante de Rio Claro. A montante do Ponto 6 há a foz do Ribeirão Claro, que traz para o rio Corumbataí toda a poluição por esgotos domésticos e efluentes industriais de parte de Rio Claro e de Santa Gertrudes, onde há o pólo cerâmico. Na Figura 1, é possível notar a grande quantidade de efluentes despejados no rio Corumbataí, assim como as altas cargas poluidoras (em kg DBO dia ${ }^{-1}$ ). No ano de 2006, segundo dados da CETESB (2007b), Rio Claro foi responsável pelo despejo de mais de $7500 \mathrm{~kg}$ DBO dia ${ }^{-1}$ só com esgotos domiciliares, enquanto que Santa Gertrudes foi responsável por mais de $1000 \mathrm{~kg} \mathrm{DBO} \mathrm{dia}{ }^{-1}$ (Tabela 1). A partir deste trecho, 
a qualidade da água e do sedimento do rio cai muito, devido a todos estes impactos, e ainda mais por conta da mudança do terreno, em que a declividade cai para cerca de $0,9 \mathrm{~m} \mathrm{~km}^{-1}$, fazendo com o que rio tenha reduzida a sua capacidade de auto-depuração (Fischer, 2003). No Ponto 6, há significativos aumentos, em todas as coletas, nos valores de condutividade, DBO, N (N-total, Amônia e Nitrato), P (P-total, P-solúvel e fosfatos), sólidos totais, turbidez, fluoretos e coliformes; e há queda de oxigênio dissolvido e clorofila-a (Figuras 10 a 14, e Tabela 7). Com exceção dos testes com D. magna, todos os outros bioensaios corroboram estes dados, e tanto nos bioensaios com amostras de água quanto de sedimento, há uma maior toxicidade generalizada para todos os organismos amostrados, em todas as coletas. Os resultados de Vicensotti (2006) corroboram os resultados encontrados no presente estudo, mostrando que o Ribeirão Claro, ao desembocar no rio Corumbataí, contribui no aporte de nitrogênio e fósforo, na concentração de coliformes, e aumenta a toxicidade para $H$. attenuata e $P$. subcapitata a jusante da sua foz. Messias ${ }^{2}$ (em fase de elaboração) também mostra resultados que estão de acordo com os encontrados no presente estudo, concluindo que tanto o Ribeirão Claro quanto o rio São Joaquim são responsáveis por um grande aporte de poluentes para o rio Corumbataí, aumentando a toxicidade da água e do sedimento após a confluência dos dois rios. As mais altas concentrações de fluoretos no rio Corumbataí ocorrem apenas após a afluência do Ribeirão Claro (Pontos 6 e 7), que recebe despejos do pólo industrial de Rio Claro e do pólo cerâmico de Santa Gertrudes. Segundo Zimbre (2000), fluoretos podem estar presentes em corpos hídricos naturalmente, ou por conta de despejos por indústrias de fabricação de louças e esmaltados de vidro, dentre outras atividades.

\footnotetext{
${ }^{2}$ Messias, T.G. Toxicidade da água e do sedimento dos rios São Joaquim e Ribeirão Claro - Sub-bacia do rio Corumbataí. Dissertação (Mestrado em Química na Agricultura e no meio ambiente) - Centro de Energia Nuclear na Agricultura, Escola Superior de Agricultura Luiz de Queiroz, Universidade de São Paulo, Piracicaba, Em fase de elaboração.
} 
Comparando-se os últimos dois pontos (6 e 7), onde o rio já recebeu a maior carga de poluentes, tanto de Rio Claro quanto de Santa Gertrudes, os parâmetros físicos e químicos indicam uma leve melhora no Ponto 7 em relação ao Ponto 6, mas ainda apresentando uma péssima qualidade da água, refletida nos valores de condutividade, oxigênio dissolvido, clorofila-a, coliformes, DBO, nitrogênio, fósforo, sólidos totais, turbidez e fluoretos, quando comparados com os primeiros cinco pontos de coleta. Esta leve melhora parece ser causada pela afluência das águas do Ribeirão Passa Cinco entre os Pontos 6 e 7, afluente este relativamente despoluído do rio Corumbataí (ARMAS, 2006). Dentre os bioensaios com amostras de água, o teste com $H$. attenuata demonstra os efeitos biológicos destas condições, mas o teste com $P$. subcapitata indica uma piora do Ponto 6 para o Ponto 7. Entretanto, em todos os testes realizados com amostras de sedimento $(C$. xanthus, $H$. attenuata e $P$. subcapitata) o Ponto 7 se mostra mais tóxico, indicando o comportamento típico do sedimento de, ao longo do tempo, acumular poluentes e agentes tóxicos em grandes quantidades. A baixa declividade do terreno neste trecho do rio favorece uma maior sedimentação e conseqüente acumulação de poluentes e partículas no sedimento nesta porção final do rio Corumbataí, e isto pode explicar os maiores valores de toxicidade do sedimento de todo o rio.

\subsubsection{Sensibilidade e respostas dos organismos-teste utilizados}

Os resultados obtidos através dos testes com $C$. xanthus tiveram uma sensibilidade considerada muito boa para avaliação da toxicidade do sedimento do rio Corumbataí, tendo demonstrado ausência ou pequena toxicidade nos Pontos de coleta considerados menos contaminados, e alta mortalidade nos Pontos de coleta tidos como mais poluídos. Os bioensaios com C. xanthus indicaram (1) um gradiente de toxicidade ao longo do curso do 
rio, da nascente em direção à foz, (2) um gradiente de toxicidade ao longo do período de tempo amostrado, tendo apresentado menor toxicidade até a terceira coleta e maior toxicidade nas coletas subsequientes, e (3) altas correlações com as determinações tanto dos elementos químicos quanto de herbicidas. As correlações encontradas com os elementos e herbicidas demonstraram que $C$. xanthus é um excelente organismo-teste para avaliação da qualidade do sedimento, e que seu endpoint que mede a mortalidade dos indivíduos expostos é também sensível o suficiente para acusar os teores de contaminação encontrados no rio Corumbataí.

Os resultados dos testes com D. magna não indicaram valores significativos de toxicidade das amostras de água. Já nos testes com sedimento, pôde-se verificar toxicidade nos pontos mais próximos à nascente, e ausência nos mais próximos à foz. Este resultado, aparentemente contraditório ao esperado, parece ter sido causado pela concentração de poluentes abaixo da sensibilidade de D. magna e pela grande quantidade de bactérias (coliformes fecais e totais, Tabela 7) e sólidos totais (Figura 14, Tabela 52/Apêndice A) presentes nestes pontos. É possível observar de forma bastante clara a menor mortalidade dos organismos conforme a maior quantidade de coliformes e sólidos totais, quando se confrontam os dados das Tabelas 7, 10 e 52/Apêndice A. Já está bastante comprovado na literatura que daphnídeos são capazes de se alimentar tanto de bactérias quanto de detritos orgânicos (OJALA et al., 1995 e VIJVERBERG, 1989). Segundo CETESB (2005), os sólidos totais podem reter bactérias e resíduos orgânicos no fundo dos rios, e ambos podem servir de alimento a daphnídeos. Esta fonte de alimento disponível aos neonatos de $D$. magna presente nas amostras testadas parece ter conferido uma maior resistência e sobrevivência a estes animais, o que não é verdade para os outros organismos-teste, que não tem esta mesma capacidade de D. magna. 
Nos dois endpoints avaliados nos testes com $H$. attenuata (letalidade e subletalidade) não se registrou a morte de nenhum organismo exposto às amostras coletadas, mas pôde-se verificar a presença de efeitos subletais, em diversas coletas, de forma acentuada (Tabelas 11 e 12), e em quase todas as coletas nos Pontos 6 e 7. Avaliando a toxicidade por meio das mudanças morfológicas progressivas ao invés da avaliação apenas pela morte dos organismos torna este bioensaio mais sensível, por revelar mais detalhes do padrão de resposta de $H$. attenuata frente aos poluentes, além da determinação bem mais precisa e sensível de concentrações menores que já causam efeitos deletérios. Os resultados encontrados aqui estão de acordo com os de Karntanut e Pascoe (2000), quando recomendam esta mesma forma de detectar efeitos deletérios às populações de Hydra expostas a poluentes. Com o avanço das técnicas e tecnologias na área da Ecotoxicologia Aquática, é cada vez mais incentivada e destacada a detecção de poluentes com efeitos subletais (crônicos), que, a longo prazo, comprometem o equilíbrio e a sobrevivência das populações naturais. Nos últimos anos iniciou-se uma tendência das agências reguladoras, como a EPA e o Environment Canada de não considerar mais como satisfatória apenas a ausência de efeitos agudos para a proteção da vida aquática. Segundo Blaise (informação verbal) $)^{3}$, no Canadá não há mais efluentes industriais com toxicidade aguda sendo despejados nos rios canadenses. Como conseqüência da evolução das medidas protetoras ao meio ambiente, a tendência é atingir o ponto onde efluentes não apresentem mais nem toxicidade crônica. E para isso, testes que tenham a toxicidade crônica como endpoint são de grande valia como ferramentas para atingir esta meta.

As respostas das sementes de L. sativa, quanto ao crescimento das raízes, não apresentaram inibição de crescimento proporcional às concentrações das amostras a que

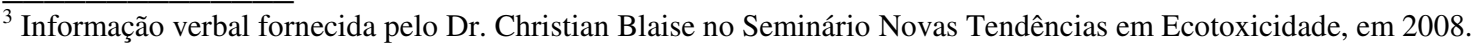


foram expostas, impossibilitando, dessa maneira, cálculos de parâmetros como $\mathrm{CI}_{50}$. Baseados nestes resultados, a sua realização foi suspensa após um ano (o equivalente a quatro coletas), já que este organismo não respondeu bem frente às concentrações ambientais de poluentes, apesar de apresentar boas respostas quando se testa apenas uma substância - como relatado na literatura (LIN e XING, 2007; D’ABROSCA et al., 2008). Quando se analisou a porcentagem de inibição de crescimento das raízes expostas às amostras puras, em geral houve uma maior tendência de estímulo do que de inibição de crescimento. Não houve um padrão de resposta claro das sementes em relação à pluviosidade, ou em relação aos impactos de cada cidade, a montante e a jusante de cada uma delas. Em geral, as amostras de sedimento dos Pontos 1 e 2 causaram um leve estímulo de crescimento, enquanto que o sedimento dos Pontos 6 e 7 causaram uma leve tendência à inibição (Tabela 20). Os resultados de L. sativa puderam ser correlacionados apenas uma vez com ametrina (Tabela 19) e uma vez com metais no sedimento (Nov/2004, Tabela 21). Pelos resultados obtidos, L. sativa não foi um organismo-teste dos mais sensíveis aos poluentes detectados na água e no sedimento do rio Corumbataí.

Os resultados obtidos através dos testes com a alga $P$. subcapitata demonstraram ser este o teste com o endpoint mais sensível dentre os utilizados no presente estudo, tanto para as amostras de água quanto para as de sedimento. Em várias comparações demonstrou efeitos tóxicos que os outros bioensaios não detectaram. Apesar disso, apresentou poucas correlações com as determinações de elementos químicos e herbicidas detectados na água e no sedimento. Esta baixa freqüência de correlações pode ser explicada pela alta sensibilidade deste organismo, que está em íntimo contato com o meio líquido, e por prováveis efeitos aditivos e/ou sinérgicos de todos os agentes tóxicos que não podem ser relacionados separadamente por uma análise de correlação linear, assim como pela presença de eventuais outras substâncias não investigadas. Este bioensaio também 
confirmou a maior toxicidade nas amostras de sedimento do que nas de água. $P$. subcapitata pôde ser considerado um bom organismo-teste a compor uma bateria de bioensaios, no papel de produtor primário.

Avaliando-se os bioensaios de forma mais ampla, é possível notar que eles respondem de formas diferentes a cada amostra testada, seja ela de água ou de sedimento. Cada organismo pertence a um nível trófico, fica exposto à amostra de uma maneira diferente, sofre influências deste meio de modos diferentes, tem estruturas e fisiologias diferentes, e conseqüentemente apresentam faixas de sensibilidade diferentes aos diversos agentes tóxicos presentes em amostras ambientais, de forma que na avaliação de ambientes naturais, como o rio Corumbataí, por meio de bioensaios, é de vital importância a utilização de uma bateria de bioensaios. Diversos estudos presentes na literatura enfatizam a importância da utilização de baterias de bioensaios. Blinova (2000) utilizou uma bateria composta por D. magna, Lemna minor, P. subcapitata, Tetrahymena thermophila, e Thamnocephalus platyurus, para avaliar amostras de água fluviais e efluentes tratados, obtendo bons resultados, e observando sensibilidades bem diferentes entre os organismos estudados. Dentre eles, $P$. subcapitata se mostrou mais sensível que D. magna, assim como no presente estudo. Arkhipchuk e Malinovskaya (2002) também encontraram resultados de sensibilidade similares aos estudos já citados, concluindo que $P$. subcapitata é mais sensível que $H$. attenuata e D. magna à amostras de águas fluviais. Um artigo publicado sobre o programa de calibração interlaboratorial do Projeto WaterTox também indica nesta direção (DIAZ-BAEZ et al., 2002).

De uma forma geral, houve um aumento visível em todos os parâmetros de toxicidade determinados nas últimas coletas, para todos os organismos utilizados. Observase que, além de uma variação sazonal esperada dentro de uma determinada faixa, está havendo uma deterioração gradual das condições ambientais do rio Corumbataí. Segundo 
relatórios da CETESB (2005; 2006; 2007a), o rio Corumbataí, no seu trecho final, recebeu em geral classificações como "regular", "ruim", e "péssima" para os índices IQA, IVA, IAP e IET no ano de 2006. Nos últimos anos não foram registradas implantações de estações de tratamento de esgotos domiciliares nos municípios da sub-bacia do rio Corumbataí (CETESB, 2005; 2006; 2007b), e na maioria das cidades o esgoto continua sendo lançado in natura nas águas do rio Corumbataí. Os valores de diversos índices, como o IVA, IAP, IET, e IQA também não mostram uma melhora na qualidade do rio Corumbataí ao longo dos últimos três anos. Os resultados obtidos no presente estudo, por meio dos bioensaios, mostram respostas plenamente de acordo com isso, refletindo a manutenção ou até mesmo a piora da qualidade do rio Corumbataí. Os bioensaios utilizados foram considerados adequados na determinação da presença de agentes tóxicos e na avaliação da qualidade da água e do sedimento do rio Corumbataí, tendo sido corroborados por diversas outras determinações, como elementos químicos, herbicidas, e parâmetros físicos e químicos.

Pode-se então concluir sobre a grande importância da utilização de baterias de testes ecotoxicológicos como ferramentas na avaliação (e monitoramento) da qualidade de corpos d'água. Foi demonstrado neste estudo que os bioensaios têm a capacidade de oferecer informações que análises tradicionais como determinações de metais, elementos químicos, agrotóxicos e parâmetros físicos e químicos não podem fornecer, sendo um bom complemento para os estudos de contaminação dos corpos hídricos. 


\subsection{Conclusões}

- Os testes de sensibilidade realizados com $\mathrm{NaCl}$ como substância de referência ao longo de um período de dois anos demonstraram ser esta substância adequada para o monitoramento da qualidade das culturas mantidas em laboratório para os organismos estudados;

- $\quad$ Em todos os pontos de coleta, desde o ponto mais próximo à nascente, até o ponto mais próximo à foz, houve registro de toxicidade para a maioria dos organismos utilizados no presente estudo;

- De maneira geral, as amostras de sedimento se mostraram mais tóxicas que as de água, para todos os pontos de coleta, e para todos os organismos;

- Através dos bioensaios realizados, pôde-se inferir que os municípios de Analândia e Corumbataí, apesar de lançarem seus esgotos domiciliares no rio Corumbataí, não causam um efeito severo sobre a qualidade da água e do sedimento do rio, por terem um volume relativamente baixo de efluentes, e carga remanescente relativamente baixa - cargas estas que o rio consegue depurar em parte, sem grandes aumentos na toxicidade;

- Os bioensaios mostraram que a qualidade do rio Corumbataí cai bastante a partir do Ponto de coleta 6, ponto este localizado a jusante da foz do Ribeirão Claro;

- Foram observados, através dos testes de toxicidade, impactos significativos nas amostras de sedimento do rio Corumbataí causados pelo despejo de esgotos domiciliares e efluentes industriais dos 
municípios de Corumbataí, Rio Claro e Santa Gertrudes, de maneira mais pronunciada que nas amostras de água analisadas, dos mesmos locais;

- Determinações de parâmetros físicos e químicos da água complementaram os resultados obtidos pelos bioensaios realizados, assim como as determinações de elementos químicos e resíduos de herbicidas;

- C. xanthus se mostrou um excelente organismo-teste para avaliação de amostras de sedimento, apresentando uma boa sensibilidade e boa correlação com a concentração de elementos químicos e resíduos de herbicidas investigados neste compartimento do rio Corumbataí;

- $\mathrm{O}$ teste agudo com D. magna mostrou pouca toxicidade aos contaminantes presentes, embora seja um bioindicador muito utilizado mundialmente;

- Os efeitos produzidos pelas amostras ambientais sobre as sementes de alface (Lactuca sativa) foram bastante variáveis e irregulares, não possibilitando os cálculos de $\mathrm{CI}_{50}$. L. sativa mostrou pouca sensibilidade e baixa correlação aos poluentes presentes no rio Corumbataí;

- Os testes com H. attenuata e $P$. subcapitata se mostraram, dentre os testes utilizados, os com os endpoints mais sensíveis;

- O bioensaio com $P$. subcapitata apresentou os maiores valores de toxicidade, sendo considerado o mais sensível. Entretanto, poucos foram os resultados que puderam ser correlacionados com os elementos químicos e resíduos de herbicidas. Atribui-se a isso uma alta sensibilidade deste organismo, ligada a possíveis efeitos aditivos e/ou sinérgicos dos agentes tóxicos presentes nas amostras, ou ainda à presença de outros poluentes não investigados; 
- Não foi observado um padrão nas respostas dos organismos quanto às estações do ano e/ou pluviosidade (exceto para sedimento $\mathrm{x} H$. attenuata). $\mathrm{O}$ que se observou foi a manutenção ou piora da toxicidade para os organismos, de maneira gradativa, ao longo do período estudado;

- Os resultados obtidos pelos bioensaios corroboram índices de qualidade utilizados pela CETESB, sendo aqueles considerados boas ferramentas na avaliação da qualidade de corpos d'água;

- A utilização de uma bateria de bioensaios foi fundamental para a avaliação da qualidade do rio Corumbataí, pois bioensaios diferentes se complementam, adicionam informações uns aos outros, aumentam a faixa de sensibilidade de uma avaliação ecotoxicológica, e dão indicações das respostas de cada nível trófico de um ambiente aquático;

- Os bioensaios utilizados se mostraram como boas ferramentas na avaliação da qualidade da água e do sedimento do rio Corumbataí, constituindo um bom complemento para análises tradicionais. 


\subsection{Referências Bibliográficas}

AMERICAN PUBLIC HEALTH ASSOCIATION. Standard methods for the examination of water and wastewater. Method 5210. 5-day BOD Test. 18 ed. Washington: APHA, AWWA, WEF, 1992. 22p.

AMERICAN PUBLIC HEALTH ASSOCIATION. Standard methods for the examination of water and wastewater. Method 9223 A- Introduction; 9223 B-Enzyme Substrate coliform Test. 21. ed. Washington: APHA, AWWA, WEF, 2005. 15 p.

ANTUNES S.C.; FIGUEIREDO D.R.; MARQUES, S.M.; CASTRO, B.B.; PEREIRA, R.; GONÇALVES, F. Evaluation of water column and sediment toxicity from an abandoned uranium mine using a battery of bioassays. Science of the Total Environment, Amsterdam, v. 374, p. $252-$ 259, 2007.

ARKHIPCHUK, V.V.; MALINOVSKAYA, M.V. Quality of water types in Ukraine evaluated by WaterTox bioassays. Environmental Toxicology, New York, v. 17, p. 250-257, 2002.

ARMAS, E.D. Biogeodinâmica de herbicidas utilizados em cana-de-açúcar (Saccharum spp.) na sub-bacia do rio Corumbataí. 2006. 187 f. Tese (Doutorado em Ecologia de Agroecossistemas) - Centro de Energia Nuclear na Agricultura, Universidade de São Paulo, Piracicaba, 2006.

BARATA, C.; BAIRD, D.J.; NOGUEIRA, A.J.A.; SOARES, A.M.V.M.; RIVA, M.C. Toxicity of binary mixtures of metals and pyrethroid insecticides to Daphnia magna Straus. Implications for multi-substance risks assessment. Aquatic Toxicology, Amsterdam, v. 78, p. 1-14, 2006.

BARBOSA, R. Avaliação do impacto de efluentes (lodos) de Estações de tratamento de água à biota aquática através de testes de toxicidade. 2000. 199 f. Tese (Doutorado em Hidráulica e Saneamento) - Escola de Engenharia de São Carlos, Universidade de São Paulo, São Carlos, 2000.

BAUN, A.; BUSSARAWIT, N.; NYHOLM, N. Screening of pesticide toxicity in surface water from an agricultural area at Phuket Island (Thailand). Environmental Pollution, London, v. 102, p. 185-190, 1998.

BETTINETTI, R.; GIAREI, C.; PROVINI, A. Chemical Analysis and Sediment Toxicity Bioassays to Assess the Contamination of the River Lambro (Northern Italy). Archives of Environmental Contamination and Toxicology, New York, v. 45, p. 72-78, 2003.

BLAISE, C.; FÉRARD, J.F. (Ed.). Small-scale freshwater toxicity investigations. v. 1. Toxicity test methods. Dordrecht: Springer Science, 2005. 551 p.

BLAISE, C.; FORGET, G.; TROTTIER, S. Toxicity screening of aqueous samples using a costeffective 72-h exposure Selenastrum capricornutum assay. Environmental Toxicology, New York, v. 15, special issue, p. 352-359, 2000.

BLAISE, C.; GAGNÉ, F.; EULLAFFROY, P.; FÉRARD, J.F. Ecotoxicity of selected pharmaceuticals of urban origin discharged to the Saint-Lawrence River (Québec, Canada): a review. Brazilian Journal of Aquatic Science and Technology, Itajaí, v. 10, n. 2, p. 29-51, 2006.

BLAISE, C.; KUSUI, T. Acute toxicity assessment of industrial effluents with a microplate-based Hydra attenuata assay. Environmental Toxicology and Water Quality, New York, v. 12, p. 5360, 1997. 
BLINOVA, I. The perspective of microbiotests application to surface water monitoring and effluent control in Estonia. Environmental Toxicology, New York, v. 15, p. 385-389, 2000.

BORGMANN, U.; NORWOOD W.P. Metal bioavailability and toxicity through a sediment core. Environmental Pollution, London, v. 116, p. 159-168, 2002.

BRIDGES, T.S.; WRIGHT, R.B.; GRAY, B.R.; GIBSON, A.B.; DILLON, T.M. Chronic toxicity of Great Lakes sediments to Daphnia magna: elutriate effects on survival, reproduction and population growth. Ecotoxicology, Berlin, v. 5, p. 83-102, 1996.

BRIGANTE, J.; ESPÍNDOLA, E.L.G. (Ed.). Limnologia fluvial - Um estudo no rio Mogi-Guaçu. São Carlos: Rima, 2003. 255 p.

BURTON, G.A. Sediment toxicity assessment. Chelsea: Lewis Publishers, 1992. 376 p.

CALOW, P. Handbook of ecotoxicology. Oxford: Blackwell Science, 1994. 885 p.

CASTILLO G.C.; VILA, I.C.; NIELD, E. Ecotoxicity of metals and wastewater using multitrophic bioassays. Environmental Toxicology, New York, v. 15, n. 5, p. 370-375, 2000.

COMPANHIA DE TECNOLOGIA DE SANEAMENTO AMBIENTAL. Norma Técnica L5.128: Determinação de fósforo em águas: método do ácido ascórbico. São Paulo: CETESB, 1978a. 17 p.

COMPANHIA DE TECNOLOGIA DE SANEAMENTO AMBIENTAL. Norma Técnica L5.136: Determinação de nitrogênio amoniacal em águas: método da nesslerização com destilação prévia: método de ensaio. São Paulo: CETESB, 1978b. 13 p.

COMPANHIA DE TECNOLOGIA DE SANEAMENTO AMBIENTAL. Norma Técnica L5.137: Determinação de nitrato em águas: método de ácido fenoldissulfônico: método de ensaio. São Paulo: CETESB, 1978c. 9 p.

COMPANHIA DE TECNOLOGIA DE SANEAMENTO AMBIENTAL. Norma Técnica L5.139: Determinação de nitrogênio orgânico e de nitrogênio total Kjeldahl em águas: método da determinação de nitrogênio na forma de amônia: método de ensaio. São Paulo: CETESB, 1978d. $12 \mathrm{p}$.

COMPANHIA DE TECNOLOGIA DE SANEAMENTO AMBIENTAL. Norma Técnica L5.149: Determinação de resíduos em águas: métodos gravimétricos. São Paulo: CETESB, 1978e. 14 p.

COMPANHIA DE TECNOLOGIA DE SANEAMENTO AMBIENTAL. Relatório de qualidade das águas interiores no estado de São Paulo - 2004. São Paulo: CETESB, 2005. 307 p.

COMPANHIA DE TECNOLOGIA DE SANEAMENTO AMBIENTAL. Relatório de qualidade das águas interiores no estado de São Paulo - 2005. São Paulo: CETESB, 2006. 488 p.

COMPANHIA DE TECNOLOGIA DE SANEAMENTO AMBIENTAL. Plano das Bacias Hidrográficas dos rios Piracicaba, Capivari e Jundiaí - 2004-2007 - Síntese do Relatório Final. São Paulo: CETESB, 2007a. 47 p.

COMPANHIA DE TECNOLOGIA DE SANEAMENTO AMBIENTAL. Relatório de qualidade das águas interiores no estado de São Paulo - 2006. São Paulo: CETESB, 2007b. 327 p. 
CHRISTENSEN, A. M.; NAKAJIMA, F.; BAUN, A. Toxicity of water and sediment in a small urban river. Environmental Pollution, London, v. 144, p. 621-625, 2006.

COWGILL, U.M.; MILLAZZO, D.P. The sensitivity of two cladocerans to water quality variables: salinity and hardness. Archiv fuer Hidrobiologie, Stuttgart, v. 120, n. 2, p. 185-196, 1990.

COWGILL, U.M.; MILAZZO, D.P. Demographic effects of salinity, water hardness and carbonate alkalinity on Daphnia magna and Ceriodaphnia dubia. Archiv fuer Hidrobiologie, Stuttgart, v. 122, p. 35-56, 1991.

DAVOREN, M.; FOGARTY, A.M. A test battery for the ecotoxicological evaluation of the agrichemical Environ. Ecotoxicology and Environmental Safety, New York, v. 59, p. 116-122, 2004.

D'ABROSCA, B.; FIORENTINO, A.; IZZO, A.; CEFARELLI, G.; PASCARELLA, M.T.; UZZO, P.; MONACO, P. Phytotoxicity evaluation of five pharmaceutical pollutants detected in surface water on germination and growth of cultivated and spontaneous plants. Journal of Environmental Science and Health. Part A, New York, v. 43, p. 285-294, 2008.

DELLAMATRICE, P. Biodegradação e toxicidade de corantes têxteis e efluentes da Estação de Tratamento de Águas Residuárias de Americana, SP. 2005. 137 f. Tese (Doutorado em Ecologia de Agroecossistemas) - Centro de Energia Nuclear na Agricultura, Universidade de São Paulo, Piracicaba, 2005.

DIAZ-BAEZ, M.C.; SÁNCHEZ, W.A.; DUTKA, B.J.; RONCO, A.; CASTILLO, G.; PICAGRANADOS, Y.; CASTILLO, L.E.; RIDAL, J.; ARKHIPCHUK, V.; SRIVASTAVA, R.C. Overview of results from the WaterTox intercalibration and environmental testing phase II program: Part 2. Ecotoxicological evaluation of drinking water supplies. Environmental Toxicology, New York, v. 17, p. 241-249, 2002.

DUMCKE, M.S.; LANZER, R.M.; RASERA, K. Avaliação da toxicidade do corante Remazol Brilliant Blue $\mathrm{R}$ sobre a reprodução e a sobrevivência de D. magna (Straus, 1820). In: ENCONTRO DE JOVENS PESQUISADORES DA UCS, 13., 2005, Caxias do Sul. Anais... Caxias do Sul: UCS, 2005. 1 CD-ROM.

DUTKA, B.J. Methods for microbiological and toxicological analysis of waters, wastewaters and sediments. Ottawa: National Water Research Institute (NWRI), Environmental Canada, 1997. $317 \mathrm{p}$.

ESCOLA SUPERIOR DE AGRONOMIA LUIZ DE QUEIROZ. Base de dados da estação meteorológica automatizada: Dados diários. Piracicaba, 2008. Disponível em: $<$ http://www.esalq.usp.br/departamentos/lce/automatica/pagina5.html>. Acesso em: 25 abr. 2008.

ESPÍNDOLA, E.L.G.; BRIGANTE, J.; DORNFELD, C. B. Estudos ecotoxicológicos no Rio Mogi-Guaçu. In: BRIGANTE, J.; ESPÍNDOLA, E.L.G. (Ed.) Limnologia Fluvial - Um estudo no rio Mogi-Guaçu. São Carlos: Rima Editora, 2003. p. 129-148.

FAIRCHILD, J.F.; RUESSLER, D.S.; HAVERLAND, P.S.; CARLSON, A.R. Comparative sensitivity of Selenastrum capricornutum and Lemna minor to sixteen herbicides. Archives of Environmental Contamination and Toxicology, New York, v. 32, p. 353-357, 1997.

FARIA, M.S.; NOGUEIRA, A.J.A.; SOARES, A.M.V.M. The use of Chironomus riparius larvae to assess effects of pesticides from rice fields in adjacent freshwater ecosystems. Ecotoxicology and Environmental Safety, New York, v. 67, p. 218-226, 2007. 
FENT, K.; WESTON, A.A.; CAMINADA, D. Ecotoxicology of human pharmaceuticals. Aquatic Toxicology, Amsterdam, v. 76, p. 122-159, 2006.

FISCHER, E. G. Proposição e aplicação de metodologia de gerenciamento integrado dos rios Corumbataí e Passa Cinco da bacia do Piracicaba por meio de banco de dados georreferenciado e modelagam matemática. 2003. 211 f. Tese (Doutorado em Ciências) - Centro de Energia Nuclear na Agricultura, Universidade de São Paulo, Piracicaba, 2003.

FONSECA, A.L. Avaliação da qualidade da água do rio Piracicaba / SP através de testes de toxicidade com invertebrados. 1997. 211 f. Tese (Doutorado em Hidráulica e Saneamento) Escola de Engenharia de São Carlos, Universidade de São Paulo, São Carlos, 1997.

FONSECA, A.L.; ROCHA, O. Laboratory cultures of the native species Chironomus xanthus Rempel (1939) (Diptera-Chironomidae). Acta Limnologica Brasiliensia, São Carlos, v. 16, n. 2, p. 153-161, 2004.

GEIS, S.W.; FLEMING, K.L.; KORTHALS, E.T.; SEARLE, G.; REYNOLDS, L.; KARNER, D.A. Modifications to the algal growth inhibition test for use as a regulatory assay. Environmental Toxicology and Chemistry, New York, v. 19, n. 1, p. 36-41, 2000.

GONÇALVES, A.M.M.; CASTRO, B.B.; PARDAL, M.A.; GONÇALVES, F. Salinity effects on survival and life history of two freshwater cladocerans (Daphnia magna and Daphnia longispina). Annales de Limnologie - International Journal of Limnology, Paris, v. 43, p. 13-20, 2007.

GREGOR, D.J.; MUNAWAR, M. Assessing toxicity of Lake Diefenbaker (Canada) sediments using algal and nematode bioassays. Hydrobiologia, Dordrecht, v. 188/189, p. 291-300, 1989.

HAMILTON, M.A.; RUSSO, R.C.; THURSTON, R.V. Trimmed Spearman-Karber method for estimating median lethal concentration in toxicity bioassays. Environmental Science and Technology, Easton, v. 11, p. 714-719, 1978; Correction v. 12, p. 417, 1977.

HONG, L.C.D.; VAN SLOOTEN, K.B.; TARRADELLAS, J. Tropical ecotoxicity testing with Ceriodaphnia cornuta. Environmental Toxicology, New York, v. 19, p. 497-504, 2004.

HSU, P.; MATTHÄI, A.; HEISE, S.; ALFH, W. Seasonal variation of sediment toxicity in the Rivers Dommel and Elbe. Environmental Pollution, London, v. 148, p. 817-823, 2007.

INSTITUTO DE PESQUISAS E ESTUDOS FLORETAIS. Plano diretor: conservação dos recursos hídricos por meio da recuperação e da conservação da cobertura florestal da bacia do rio Corumbataí. Piracicaba: IPEF, 2001. 343 p.

JONCZYK, E.; GILRON, G. Acute and chronic toxicity testing with Daphnia sp. In: BLAISE, C.; FÉRARD, J.F. (Ed.). Small-scale freshwater toxicity investigations. v. 1. Toxicity test methods. Dordrecht: Springer Science, 2005.

KALAFATICACUTE, M.; ZNIDARICACUTE, D.; LUI, A.; WRISCHER, M. Effect of insecticides (Dimiline WP 25, Torak EC 24 and Gamacide 20) on hydra (Hydra vulgaris Pallas). International Journal of Developmental Biology, Vizcaya, v. 35, n. 3, p. 335-340, 1991.

KARNTANUT, W.; PASCOE, D. A comparison of methods for measuring acute toxicity to Hydra vulgaris. Chemosphere, Amsterdam, v. 41, p. 1543-1548, 2000. 
KARNTANUT, W.; PASCOE, D. The toxicity of copper, cadmium and zinc to four different Hydra (Cnidaria: Hydrozoa). Chemosphere, Amsterdam, v. 47, p. 1059-1064, 2002.

KHANGAROT, B.S.; RAY, P.K. Correlation between heavy metal acute toxicity values in Daphnia magna and fish. Bulletin of Environmental Contamination and Toxicology, New York, v. 38, p. 722-726, 1987.

KOUKAL, B.; DOMINIK, J.; VIGNATI, D.; ARPAGAUS, P.; SANTIAGO, S.; OUDDANE, B.; BENAABIDATE, L. Assessment of water quality and toxicity of polluted Rivers Fez and Sebou in the region of Fez (Morocco). Environmental Pollution, London, v. 131, p. 163-172, 2004.

LIMA, W.P.L.; ZAKIA, M.J.B. Hidrologia de matas ciliares. In: RODRIGUES, R.R.; LEITÃOFILHO, H.F. Matas ciliares: conservação e recuperação. São Paulo: EDUSP, 2001. 320 p.

LIN, D.; XING, B. Phytotoxicity of nanoparticles: Inhibition of seed germination and root growth. Environmental Pollution, London, v. 150, p. 243-250, 2007.

MOED, J.R.; HALLEGRAEFF, G.M. Some problems in the estimation of chlorophyll-alpha and phaeopigments from pre-acidification and pos-acidification spectrophotometric measurements. Internationale Revue der Gasamten Hydrobiologie, Berlin, v. 63, n. 6, p. 787-800, 1978.

MONTEIRO, R.T.R.; ARMAS, E.D.; QUEIROZ, S.C.N. Lixiviação e contaminação das águas do rio Corumbataí por herbicidas. In: KARAM, D.; MASCARENHAS, M.H.T.; SILVA, J.B. A ciência das plantas daninhas na sustentabilidade dos sistemas agrícolas. Viçosa: SBCPD, 2008. $381 \mathrm{p}$.

MOUNT, D.R.; GULLEY, D.D.; HOCKETT, J.R.; GARRISON, T.D.; EVANS, J.M. Statistical models to predict the toxicity of major ions to Ceriodaphnia dubia, Daphnia magna and Pimephales promelas (Fathead minnows). Environmental Toxicology and Chemistry, New York, v. 16, n. 10, p. 2009-2019, 1997.

NEN 6520. Water: Spectrophotometric determination of chlorophyll a content. Nederlands Normalisatie instituut, Delft: NEN. 1981. 18p.

NICOLAI, M.; CHRISTOFFOLETI, P.J. Casos potenciais de resistências de plantas daninhas a herbicidas. In: CHRISTOFFOLETI, P.J. (Coord.) Aspectos de resistência de plantas daninhas a herbicidas. Ouro Preto: HRAC-BR, 2008, p. 97-108.

ORGANISATION FOR ECONOMIC CO-OPERATION AND DEVELOPMENT. OECD Test Guidelines: Daphnia sp. Acute Immobilization test and reproductive test. Paris: OECD, 1987. 20 p. (Test 202).

OJALA, A.; KANKAALA, P.; KAIRESALO, T.; SALONEN, K. Growth of Daphnia longispina $\mathrm{L}$. in a polyhumic lake under various availabilities of algal, bacterial and detrital food. Hydrobiologia, Dordrecht, v. 10, p. 891-900, 1995.

QUINN, B.; GAGNÉ, F.; BLAISE, C. An investigation into the acute and chronic toxicity of eleven pharmaceuticals (and their solvents) found in wastewater effluent on the cnidarians, Hydra attenuata. Science of the Total Environment, Amsterdam, v. 389, n. 2-3, p. 306-314, 2008.

RA, J.S.; KIM, H.K.; CHANG, N.I.; KIM, S.D. Whole effluent toxicity (WET) tests on wastewater treatment plant with Daphnia magna and Selenastrum capricornutum. Environmental Monitoring Assessment, Heidelberg, v. 129, n. 1-3, p. 107-113, 2007. doi 10.1007/s10661-006-9431-2. 2006. 
RAND, G.M.; WELLS, P.G.; MCCARTY, L.S. Introduction to aquatic toxicology. In: RAND, G.M. (Ed.). Fundamentals of aquatic toxicology: effects, environmental fate, and risk assessment. London: Taylor \& Francis, 1995. p. 3-70.

ROJICKOVAÁ-PADRTOVÁ, R.R.; MARSÁLEK, B. Selection and sensitivity comparisons of algal species for toxicity testing. Chemosphere, Amsterdam, v. 38, n. 14, p. 3329-3338, 1999.

ROJICKOVAÁ-PADRTOVÁ, R.R.; MARSÁLEK, B.; HOLOUBEK, I. Evaluation of alternative and standard toxicity assays for screening of environmental samples: selection of an optimal test battery. Chemosphere, Amsterdam, v. 37, n. 3, p. 495-507, 1998.

SALONEN, K.; HAMMAR, T. On the importance of dissolved organic matter in the nutrition of zooplankton in some lake waters. Oecologia, Berlin, v. 68, p. 264-253, 1986.

SIBLEY, P.K.; LEGLER, J.; DIXON, D.G.; BARTON, D.R. Environmental Health Assessment of the Benthic Habitat Adjacent to a Pulp Mill Discharge. I. Acute and Chronic Toxicity of Sediments to Benthic Macroinvertebrates. Archives of Environmental Contamination and Toxicology, New York, v. 32, p. 274-284, 1997.

STAVELEY, J.P.; SMRCHEK, J.C. Algal toxicity test. In: BLAISE, C.; FÉRARD, J.F. (Ed.). Small-scale freshwater toxicity investigations. v. 1. Toxicity test methods. Dordrecht: Springer Science, 2005.

TROTTIER, S.; BLAISE, C.; KUSUI, T.; JOHNSON, E.M. Acute toxicity assessment of aqueous samples using a microplate-based Hydra attenuata assay. Environmental Toxicology and Water Quality, New York, v. 12, p. 265-271, 1997.

TRUHAUT, R. Ecotoxicology: Objectives, Principles and Perspectives. Ecotoxicology and Environmental Safety, New York, v. 1, p. 151-173, 1977.

U.S. ENVIRONMENTAL PROTECTION AGENCY. EPA-600/R-99/064: Methods for measuring the toxicity and bioaccumulation of sediment-associated contaminants with freshwater invertebrates. 2. ed. Washington: USEPA, 2000. 192 p.

UTZ, L.R.P.; BOHRER, M.B.C. Acute and chronic toxicity of potassium chloride $(\mathrm{KCl})$ and potassium acetate $\left(\mathrm{KC}_{2} \mathrm{H}_{3} \mathrm{O}_{2}\right)$ to Daphnia similis and Ceriodaphnia dubia (Crustacea; Cladocera). Bulletin of Environmental Contamination and Toxicology, New York, v. 66, p. 379-385, 2001.

VICENSOTTI, J. Contribuição do Ribeirão Claro na qualidade da água e do sedimento da sub-bacia do rio Corumbataí. 2006. 30 f. Relatório final (Iniciação Científica) - Centro de Energia Nuclear na Agricultura, Universidade de São Paulo. Piracicaba, Piracicaba, 2006.

VIGANÒ, L. Assessment of the toxicity of River Po sediments with Ceriodaphnia dubia. Aquatic Toxicology, Amsterdam, v. 47, p. 191-202, 2000.

VIJVERBERG, J. Culture techniques for studies on the growth, development and reproduction of copepods and cladocerans under laboratory and in situ conditions: a review. Freshwater Biology, Oxford, v. 21, p. 317-373, 1989.

WARNE, M. St. J.; SCHIFKO, A. D. Toxicity of laundry detergent components to a freshwater cladoceran and their contribution to detergent toxicity. Ecotoxicology and Environmental Safety, New York, v. 44, p. 196-206, 1999. 
ZAGATTO, P.A.; BERTOLETTI, E. Ecotoxicologia aquática - Princípios e aplicações. São Carlos: Rima, 2006. 464 p.

ZAMBETTA, P.M.A. Espécies químicas inorgânicas (Al, As, Cd, Cr, Cu, Fe, $\mathrm{Hg}, \mathrm{Mn}, \mathrm{Ni}, \mathrm{Pb}$ e Sr) no sedimento e nos sólidos em suspensão do rio Corumbataí, SP. 2006. 74 f. Dissertação (Mestrado em Ecologia de Agroecossistemas) - Centro de Energia Nuclear na Agricultura, Universidade de São Paulo, Piracicaba, 2006.

ZAR, J. H. Biostatistical analysis. New Jersey: Prentice Hall, 1999. 663 p.

ZIMBRE, E. Guia avançado sobre água subterrânea. Disponível em: $<$ http://www.meioambiente.pro.br/agua/guia/aguasubterranea.htm>. Acesso em: 30 jun. 2008. 


\section{Bioensaios complementares para avaliação da qualidade da água e sedimento da sub-bacia do rio Corumbataí (SP)}

\section{Resumo}

Utilizando as mesmas amostras de água e sedimento coletadas no rio Corumbataí (descritas no capítulo anterior), foram realizados em caráter complementar três bioensaios: o teste LuminoTox, o teste de genotoxicidade com raízes de Allium cepa, e o teste crônico com Daphnia magna. O teste LuminoTox foi realizado com amostras de duas coletas (Março/2006 e Junho/2006); o teste com A. cepa com amostras de uma coleta (Setembro/2006), e o teste crônico com D. magna com elutriato de três coletas (Setembro/2005, Março/2006 e Setembro/2006). O bioensaio LuminoTox foi desenvolvido recentemente, e utiliza enzimas do sistema fotossintético extraídas de folhas de espinafre. Para quantificar a toxicidade de uma amostra, se baseia na redução da emissão de fluorescência emitida pelas enzimas dos fotossistemas I e II. O teste de genotoxicidade com A. cepa avalia a ocorrência de aberrações cromossômicas e de micronúcleos nas células meristemáticas das raízes. O teste crônico com $D$. magna avalia efeitos subletais, como redução na produção de ovos, neonatos, longevidade, número de crias, dentre outros parâmetros. Foram realizadas análises de correlação linear entre os bioensaios complementares e os principais, a fim de comparar resultados e sensibilidades. $\mathrm{O}$ LuminoTox foi o teste que indicou maior toxicidade nos pontos a jusante das cidades, e apresentou boa correlação com os resultados de $P$. subcapitata para amostras de sedimento. $\mathrm{O}$ teste de genotoxicidade com A. cepa indicou ocorrência significativa de aberrações cromossômicas nos pontos 5, 6, e 7, mas indicou também aumento quantitativo (mas não estatisticamente significativo) de aberrações em todos os Pontos de coleta. Não houve diferença significativa entre a freqüência de micronúcleos nos diferentes Pontos de coleta, em relação ao controle. Os parâmetros reprodutivos do teste crônico com D. magna foram bastante sensíveis na indicação de poluição no rio Corumbataí, e mostraram acentuada toxicidade crônica nos Pontos 6 e 7. A maioria das amostras causou redução no número de ovos e, conseqüentemente, de neonatos produzidos em relação ao controle. Várias amostras causaram um atraso na produção da primeira cria - o que pode causar efeitos severos na dinâmica de populações. Os três bioensaios se mostraram válidos para o monitoramento de ambientes naturais, e são sugeridos para compor baterias de bioensaios para monitoramento de ambientes fluviais. Os três bioensaios também indicaram a presença de agentes tóxicos, contribuindo com os outros bioensaios realizados com as mesmas amostras na avaliação da qualidade do rio Corumbataí.

Palavras-chave: bioensaios; LuminoTox; Allium cepa; genotoxicidade; Daphnia magna; teste crônico; rio Corumbataí. 


\section{Abstract}

Using the same water and sediment samples collected from Corumbataí River (as described in the previous chapter), three bioassays were conducted in order to complement the main toxicity tests: the LuminoTox bioassay, the genotoxicity assay with Allium cepa root tips, and the 21-day chronic toxicity test with Daphnia magna. The LuminoTox was performed with both water and sediment samples from two samplings (March 2006 and June 2006); the genotoxicity test with A. cepa with one sampling (September 2006); and the Daphnia magna 21-day chronic test with sediment elutriates from three samplings (September 2005, March 2006 and September 2006). The LuminoTox bioassay was recently developed. It uses stabilized photosynthetic enzyme complexes (PECs), isolated from spinach leaves. In order to assess the toxicity of a given sample, LuminoTox measures the decrease in fluorescence emission by PECs. The genotoxicity test with $A$. сера assesses the frequency of chromosomal aberrations and micronuclei in root tip meristematic cells. The chronic toxicity test with $D$. magna assesses sublethal effects, such as reduction in egg and neonate production, longevity, number of broods, among other parameters. Linear correlations between these complementary bioassays and the main ones were calculated in order to compare results and sensitivities. LuminoTox bioassay was the best one to show the toxic impacts in sampling sites downstream the cities. It also presented good correlations with algae $P$. subcapitata sediment results. The genotoxicity tests with A. cepa showed a statistically significant frequency of chromosomal aberrations in sampling sites 5, 6 and 7, but it also showed a chromosomal aberrations quantitative increase in all sampling sites (but without statistical confirmation). There was no statistical differences between micronuclei frequencies in sampling sites in relation to control frequencies. The reproductive endpoints of $D$. magna chronic test were sensitive in demonstrating pollution in Corumbataí River, showing more pronounced chronic toxicity in sites 6 and 7. Most samples caused a reduction in egg and neonate production by females, when compared to control results. Several samples caused a delay in the first reproduction, which can cause severe effects in population dynamics. The three complementary bioassays had been successful to the monitoring of natural environments, and they are suggested to be part of a test battery to assess fluvial environments. The three bioassays also indicated the presence of toxic agents, contributing with the other bioassays performed in this study, with the same samples in Corumbataí River quality assessment.

Keywords: bioassays; LuminoTox; Allium cepa; genotoxicity; Daphnia magna; chronic test; Corumbataí River. 


\subsection{Introdução}

A fim de complementar os principais bioensaios, realizados em todas as oito coletas programadas neste projeto, foram realizados também outros três bioensaios, em pelo menos uma das mesmas amostras de água e sedimento do rio Corumbataí (como descrito no capítulo anterior). Os resultados obtidos destes testes tanto foram comparados com os dos outros testes, quanto analisados em relação à sua própria eficiência e sensibilidade.

\subsubsection{Teste LuminoTox}

O teste LuminoTox avalia a toxicidade de amostras baseado no princípio de que agentes tóxicos são capazes de interferir nos sistemas enzimáticos da fotossíntese de plantas (PEC). Muitos herbicidas, inclusive, têm seu modo de ação baseados neste princípio (HUANG et al., 1997). Este princípio, aplicado a este bioensaio leva em consideração a ação de agentes tóxicos na fluorescência emitida por estas enzimas. Normalmente, a maior parte da energia luminosa absorvida pelas plantas é usada para reações fotoquímicas, e uma parte acaba sendo dissipada na forma de fluorescência e energia não-radioativa. Mas a presença de inibidores do transporte de elétrons pode modificar o balanço destes processos de dissipação luminosa. Baseado na emissão de fluorescência pelos sistemas enzimáticos da fotossíntese, a toxicidade da amostra é indicada pela modificação dos parâmetros de fluorescência (BOUCHER et al., 2005). No presente estudo, o LuminoTox foi aplicado em amostras de água e sedimento das coletas de Março e Junho de 2006.

\subsubsection{Teste de genotoxicidade com Allium cepa}

Para o teste de genotoxicidade com A. cepa foram utilizadas amostras de água e sedimento da coleta de Setembro/2006. Neste bioensaio é possível a identificação e a 
quantificação de aberrações cromossômicas (AC) e ocorrência de micronúcleos (MN) em células meristemáticas de radículas de A. cepa (cebola). Aberrações cromossômicas são caracterizadas por mudanças na estrutura normal de um cromossomo ou no número total de cromossomos, podendo ocorrer espontaneamente ou como resultado da exposição à agentes que atuam no material genético (RUSSEL, 2002). Alterações cromossômicas estruturais podem ser causadas por diversos fatores, como quebras no DNA, inibição da síntese de DNA e replicação de DNA alterado. Já as aberrações cromossômicas numéricas, como aneuploidia e poliploidia, são conseqüências de segregações anormais de cromossomos, podendo ocorrer tanto espontaneamente ou pela ação de um agente aneugênico (ALBERTINI et al., 2000). Shugart (1998) define aneuploidia como sendo a perda ou ganho de um ou mais cromossomos durante os eventos de meiose e/ou mitose; e poliploidia como sendo o ganho de um ou mais conjuntos inteiros de cromossomos. Devese ressaltar a importância de testes de genotoxicidade pelo fato de que análises tradicionais de poluentes funcionam bem para detectar e quantificar as concentrações de substâncias químicas tanto no ambiente quanto em tecidos de organismos vivos, mas eles não são capazes de detectar e identificar efeitos biológicos. A genotoxicologia ambiental oferece um meio prático, sensível e relativamente barato para monitorar a ocorrência de agentes genotóxicos no ambiente, e, assim, auxiliar em avaliações de risco e no delineamento dos efeitos de poluentes antropogênicos (SHUGART, 1998).

A espécie A. cepa tem sido indicada, não apenas pela sua alta eficiência e sensibilidade, mas também por outras vantagens, como baixo custo, fácil manuseio e, principalmente, por apresentar boas condições cromossômicas, como a presença de cromossomos grandes e em número reduzido $(2 \mathrm{n}=16)$, sendo este fator fundamental para estudos de avaliação de danos cromossômicos e/ou de distúrbios do ciclo de divisão celular, incluindo riscos de aneuploidia (FISKEJÖ, 1985; GRANT, 1982). 


\subsubsection{Teste de toxicidade crônica com Daphnia magna}

O teste de toxicidade crônica com Daphnia magna é um teste bastante difundido, e usado há muitos anos (BIESINGE et al., 1974). Por avaliar parâmetros subletais, é mais sensível que o teste agudo realizado com o mesmo organismo. Os testes agudos não são capazes de detectar níveis de poluição a fim de garantir uma proteção à biota quanto a efeitos deletérios sobre crescimento, reprodução e sobrevivência (MARTINEZJERÓNIMO et al., 1993). Segundo trabalho de Nebeker et al. (1988), bioensaios crônicos com D. magna são sensíveis o suficiente para detectar a presença de agentes tóxicos em amostras de sedimento. Testes crônicos com sedimentos são capazes de avaliar com maior sensibilidade e em condições mais semelhantes às de campo este compartimento dos ecossistemas aquáticos continentais, que agem como um repositório de contaminantes orgânicos e inorgânicos (Bridges et al., 1996). No presente estudo, este bioensaio foi realizado com elutriatos preparados a partir de amostras de sedimento, em três das oito coletas realizadas, como complemento aos testes agudos que não mostraram efeitos marcadamente severos sobre os neonatos expostos a estas amostras. Neste teste, a maioria dos endpoints avaliados focou-se nos efeitos deletérios sobre a reprodução dos organismos-teste, como redução na fecundidade e no número de neonatos nascidos por cria. Avaliou também parâmetros como a longevidade dos organismos, desenvolvimento embrionário, intervalo na produção de ovos, dentro do período de 21 dias do teste. 


\subsubsection{Objetivos}

- Avaliar os testes: LuminoTox, de genotoxicidade com A. cepa, e crônico com $D$. magna quanto às suas sensibilidades às amostras do rio Corumbataí;

- Comparar estes três bioensaios com os principais (apresentados no Capítulo 2);

- Avaliar a contribuição destes bioensaios: (1) na avaliação da qualidade da água e do sedimento do rio Corumbataí, e (2) como parte da bateria de bioensaios utilizados em todo o estudo. 


\subsection{Material e Métodos}

A área de estudo e o procedimento de coleta das amostras utilizadas nestes bioensaios são as mesmas dos bioensaios descritos no capítulo anterior, e estão descritas nos itens 2.2.1, e 2.2.2, respectivamente. Estes bioensaios foram aplicados nas amostras coletadas, como indicado na Tabela 24.

Tabela 24. Amostras avaliadas pelos bioensaios complementares: LuminoTox, Teste de genotoxicidade com A. cepa e teste crônico com D. magna.

\begin{tabular}{|c|c|c|c|c|c|c|c|c|}
\hline & Nov/04 & Fev/05 & Mai/05 & Set/05 & Dez/05 & Mar/06 & Jun/06 & Set/06 \\
\hline LuminoTox & & & & & & $\mathrm{X}$ & $\mathrm{X}$ & \\
\hline Genotoxicidade A. сера & & & & & & & & $\mathrm{X}$ \\
\hline Crônico D. magna & & & & $\mathrm{X}$ & & $\mathrm{X}$ & & $\mathrm{X}$ \\
\hline
\end{tabular}

\subsubsection{Teste LuminoTox}

Todos os procedimentos do teste LuminoTox seguem os protocolos de Boucher et al. (2005) e Dellamatrice et al. (2006). Na fase de pré-preparo dos bioensaios, procedeu-se com a reativação das enzimas (PEC), que são fornecidas pelo fabricante (Lab Bell) liofilizadas. Para isso, foram adicionados $5 \mathrm{~mL}$ de uma solução tampão (também fornecida pelo fabricante) às enzimas, que foram então incubadas no escuro por 15 minutos, com agitação periódica. As leituras foram realizadas pelo Aparelho LuminoTox da Lab Bell, que fornece os valores de porcentagem de inibição para cada réplica.

\subsubsection{Amostras de água}

Foram preparadas as diluições das amostras de água: 100\%, 50\%, 25\%, 12,5\% e 6,25\%. Para cada diluição, foram feitas três réplicas, em um volume de $2 \mathrm{~mL}$. A cada réplica, foram adicionados $100 \mu \mathrm{L}$ da solução com as enzimas (PEC), e todas foram 
incubadas por 15 minutos no escuro. Após este período, foram feitas as leituras de absorbância em aparelho LuminoTox (Lab Bell).

\subsubsection{Amostras de sedimento}

Foram preparadas as diluições de elutriato a partir das amostras de sedimento: 10\%, $5 \%, 2,5 \%, 1,25 \%$ e $0,625 \%$. Para cada diluição, foram feitas três réplicas, em um volume de $2 \mathrm{~mL}$. A cada réplica, foram adicionados $100 \mu \mathrm{L}$ da solução com as enzimas (PEC), e todas foram incubadas por 15 minutos no escuro. Após este período, foram feitas as leituras de absorbância em aparelho LuminoTox (Lab Bell).

\subsubsection{Análise dos dados e tratamento estatístico}

Com os dados de porcentagem de inibição em mãos, é utilizada uma planilha para o cálculo dos endpoints. Esta planilha - a RegTox - pode ser obtida pela Internet (http://eric.vindimian.9online.fr/), e é indicada para este uso (BOUCHER et al., 2005). Ela calcula as curvas dose-resposta, e os resultados são expressos na forma $\mathrm{CI}_{25}$ (15 min).

\subsubsection{Teste de genotoxicidade com Allium cepa}

Os testes de genotoxicidade foram realizados apenas com amostras de água e preparados de elutriato da última coleta (Setembro/2006). Para este experimento, foram seguidos os protocolos de Grant (1982). Cerca de 50 sementes de A. cepa, vendidas comercialmente, foram colocadas em placas de Petri, forradas com papel filtro, para cada ponto de coleta e também para o controle negativo (feito com água mineral). O papel de filtro foi embebido com a amostra a ser testada, que foi reposta diariamente, conforme 
evaporava. As placas de Petri, tampadas, foram mantidas em luz ambiente, a $25^{\circ} \mathrm{C}$, por cerca de 5 dias, até que as raízes atingissem entre 2 e $3 \mathrm{~cm}$ de comprimento.

\subsubsection{Fixação das raízes de $A$. cepa}

Após atingir este comprimento, as radículas foram retiradas da placa de Petri, e fixadas em solução de Carnoy (Álcool e ácido acético na proporção 3:1) por 24 horas, sendo que após este período o fixador foi trocado por um recém-preparado. As radículas ficaram então nesta solução, mantidas a $4^{\circ} \mathrm{C}$ até o momento da preparação das lâminas.

\subsubsection{Preparação das lâminas permanentes}

As raízes fixadas foram lavadas em três banhos de água destilada, por cerca de cinco minutos, sendo posteriormente submetidas à hidrólise ácida em $\mathrm{HCl} 1 \mathrm{~N}$ a $60^{\circ} \mathrm{C}$ durante 11 minutos, seguidas por novos banhos em água destilada. Após esta etapa, as raízes foram ligeiramente secas em papel de filtro e o material foi transferido para frascos escuros, para coloração em reativo de Schiff, por aproximadamente 2 horas. Após este período, as raízes foram lavadas em água destilada, até a retirada do excesso de corante. Para o preparo das lâminas, a extremidade do meristema foi cortada da radícula, suavemente esmagada em uma gota de carmim acético (2\%), e recoberta com uma lamínula. Nesta etapa, cada lâmina foi mantida em nitrogênio líquido por alguns segundos para a posterior retirada da lamínula. Após espera de 24 horas, até que as lâminas secassem, as lâminas permanentes foram montadas com resina sintética, para serem, posteriormente, analisadas em microscópio óptico. 


\subsubsection{Leitura das lâminas}

Para a análise das aberrações cromossômicas (AC), diferentes tipos de aberrações foram considerados (perdas, fragmentos, pontes, atrasos, aderências cromossômicas, entre outros) nas diferentes fases da divisão celular (prófase, metáfase, anáfase, telófase). No entanto, para a avaliação das $\mathrm{AC}$ como um único endpoint todas as diferentes aberrações foram reunidas em um só grupo. A contagem de micronúcleos, nestas células, foi considerada como outro parâmetro de avaliação, não sendo agrupada junto com as aberrações cromossômicas. O Índice mitótico (IM), que indica o número de células em 1.000 contadas que estejam em qualquer fase de divisão mitótica (ou seja, todas as células que estavam em prófase, metáfase, anáfase ou telófase), constituiu um terceiro parâmetro de avaliação.

Para cada tratamento (cada ponto de coleta e cada controle) procedeu-se com a contagem de 5.000 células por tratamento, sendo 1.000 células por lâmina para um total de 5 lâminas (o mesmo que 5 radículas).

\subsubsection{Análise dos dados e tratamento estatístico}

Os resultados de aberrações cromossômicas em um único grupo, de índice mitótico e de micronúcleos foram submetidos à análise estatística pelo teste de Kruskal-Wallis, o qual possibilita a comparação dos tratamentos com o controle negativo, bem como dos tratamentos entre si, a 0,05 de nível de significância (ZAR, 1999). Para os cálculos estatísticos foi utilizado o software GraphPad Instat (v. 3.00, 1997). 


\subsubsection{Teste crônico com Daphnia magna}

Os testes crônicos foram realizados seguindo normas da OECD (1987), e recomendações de Jonczyk e Gilron (2005). Neonatos com até 24 horas de idade foram retirados das culturas-estoque, e colocados em frascos plásticos de poliestireno individualmente, em $100 \mathrm{~mL}$ da amostra de elutriato testada. Foram feitas 10 réplicas para o controle (mantido com meio de cultivo M4) e para cada ponto de coleta. Os frascos foram mantidos a $22^{\circ} \mathrm{C}$ e fotoperíodo de 12 horas. Foram feitas as trocas de água, com fornecimento de alimento ( $P$. subcapitata, a $10^{6}$ células $\mathrm{mL}^{-1}$ ), três vezes por semana. Os testes foram iniciados no primeiro dia de vida dos neonatos e encerrados no $21^{\circ}$ dia. Diariamente, foram registrados dados sobre:

- Idade primípara (a primeira oviposição)

- Número médio de ovos/fêmea

- Número médio de neonatos/fêmea

- Desenvolvimento embrionário (dias)

- Intervalo na produção de ovos (dias)

- Número médio de crias no período estudado

- Longevidade média (dias)

Os dados obtidos foram computados e analisados pelos métodos estatísticos: ANOVA seguido pelo pós-teste de Dunnet, a fim de se determinar diferenças em relação ao controle (ZAR, 1999). Para os cálculos, foi utilizado o software GraphPad Instat (v. $3.00,1997)$. 


\subsubsection{Análises estatísticas entre os bioensaios}

Com o objetivo de avaliar os três bioensaios complementares em relação aos testes de toxicidade principais, foram realizadas análises de correlação linear (Pearson) entre seus resultados. Para isso, os valores de $\mathrm{CL}_{50}, \mathrm{CE}_{50}, \mathrm{CI}_{50}, \mathrm{CI}_{25}$, etc., foram transformados em unidades tóxicas $\left(\mathrm{UT}=100 / \mathrm{CL}_{50}\right)$ antes da comparação pelo teste de Pearson, por conta dos diferentes modos em que os resultados são expressos. Através destas análises, foi possível avaliar se os testes apresentam resultados redundantes ou diferentes entre si, permitindo uma melhor interpretação sobre as informações que eles produziram. 


\subsection{Resultados}

\subsubsection{Teste LuminoTox}

Os resultados obtidos dos testes realizados com o LuminoTox estão dispostos na Tabela 25, na forma de $\mathrm{CI}_{25}$ (15 min.). Foram realizados testes com amostras de água e elutriato de duas coletas - Março/2006 e Junho/2006. Os valores obtidos, tanto para amostras de água quanto de sedimento, mostraram toxicidade aos sistemas enzimáticos do LuminoTox para todas as amostras, exceto para o sedimento do Ponto 1. Para as amostras de sedimento do Ponto 6, o aparelho de leitura do LuminoTox não apresentou resultados coerentes, apresentando erro nas leituras. Estes resultados estão indicados com “*”. Os resultados indicados com "N.R." não foram realizados, por problemas técnicos com os reagentes. Em geral, os resultados indicaram maior toxicidade das amostras de sedimento do que das de água (como nos bioensaios principais); indicaram também mais efeitos tóxicos nos Pontos de coleta a jusante de Analândia (Ponto 2), Corumbataí (Ponto 4), e Rio Claro (Ponto 6) do que nos respectivos pontos a montante.

Tabela 25. Valores de toxicidade $\left(\mathrm{CI}_{25}(15 \mathrm{~min}\right.$.), em \%) de amostras de água e elutriato (sedimento) do rio Corumbataí, obtidas no teste LuminoTox. Coletas de Março/2006 e Junho/2006.

\begin{tabular}{|c|c|c|c|c|}
\hline \multirow{3}{*}{$\begin{array}{c}\text { Pontos } \\
\text { de coleta }\end{array}$} & \multicolumn{2}{|c|}{ ÁGUA } & \multicolumn{2}{|c|}{ SEDIMENTO } \\
\hline & Março / 2006 & Junho / 2006 & Março / 2006 & Junho / 2006 \\
\hline & $\mathrm{CI}_{25}$ & $\mathbf{C I}_{25}$ & $\mathrm{CI}_{25}$ & $\mathbf{C I}_{25}$ \\
\hline 1 & 99,9 & 20,4 & N.T. & N.R. \\
\hline 2 & 7,8 & 10,7 & 1,12 & N.R. \\
\hline 3 & 53,8 & 43,9 & 1,14 & N.R. \\
\hline 4 & 18,4 & 10,5 & N.R. & N.R. \\
\hline 5 & 25,9 & 70,7 & 4,47 & N.R. \\
\hline 6 & $*$ & $*$ & 2,15 & N.R. \\
\hline 7 & 34,8 & 18,5 & 4,92 & N.R. \\
\hline
\end{tabular}

(*) Amostras ilegíveis; N.R.: Não realizados; N.T.: Não tóxico. 


\subsubsection{Teste de genotoxicidade com Allium cepa}

Os testes de genotoxiciade com A. cepa indicaram a ocorrência significativamente maior de efeitos genotóxicos (na forma de aberrações cromossômicas) em diversos Pontos de coleta (principalmente nos Pontos 5, 6 e 7), tanto para água, quanto para sedimento, quando estes resultados foram comparados aos do controle (Tabela 26). Apesar dos valores médios de aberrações cromossômicas serem maiores que os do controle nos quatro primeiros pontos de coleta, não houve diferença estatística. Observou-se aumento na ocorrência de micronúcleos na maioria dos pontos de coleta, mas o teste de Kruskal-Wallis $(\mathrm{p}<0,05)$ não indicou diferença estatística entre eles. Quanto ao índice mitótico, apesar de as amostras de água terem causado uma redução neste parâmetro, e as de sedimento terem causado um aumento, em apenas alguns pontos houve diferença estatística entre eles e o controle (Tabela 26). Imagens das fases normais da mitose podem ser vistas na Figura 19, e ocorrências de aberrações cromossômicas e micronúcleos durante a mitose podem ser vistas na Figura 20. As fotos foram tiradas das lâminas preparadas no presente estudo, sob microscópio óptico, com aumento de 400x. 


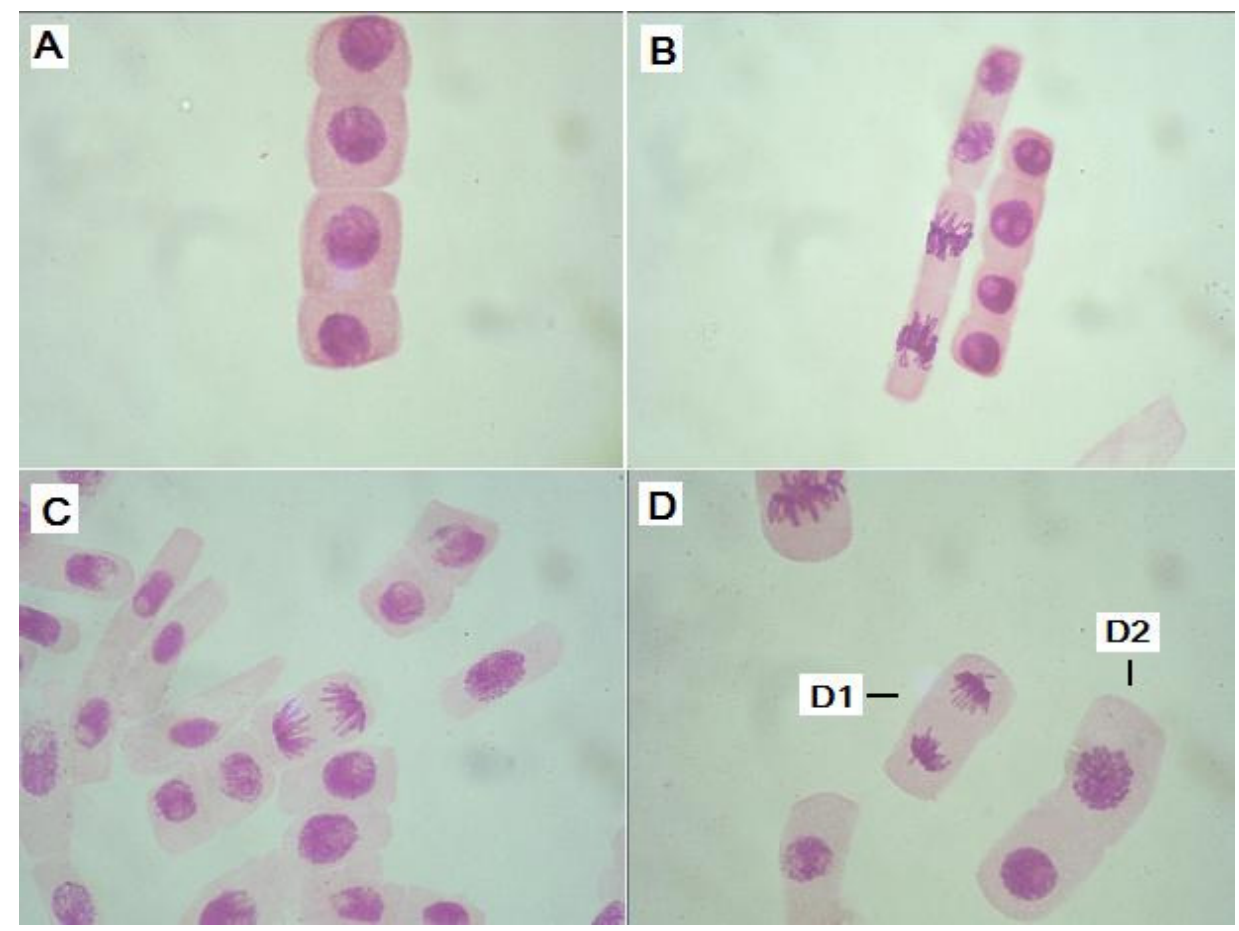

Figura 19. Fases normais da mitose em células meristemáticas de radículas de Allium cepa. (A) Intérfase; (B) Metáfase; (C) Anáfase; (D1) Telófase; (D2) Prófase. Fotos: microscópio óptico, aumento 400x.

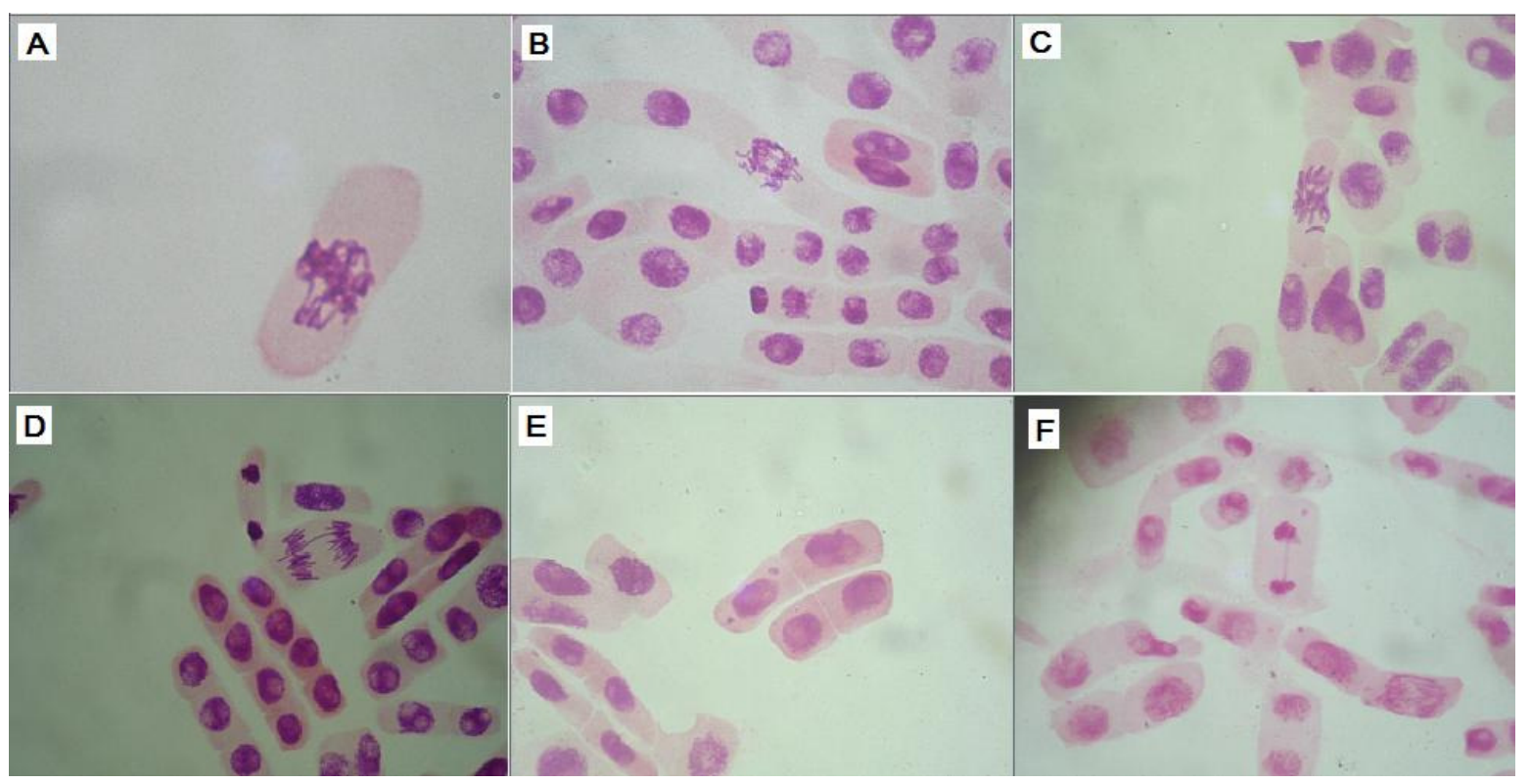

Figura 20. Aberrações cromossômicas e micronúcleos observados em células meristemáticas de radículas de Allium cepa exposta à amostras de água e sedimento do rio Corumbataí. (A) Metáfase com aderência cromossômica; (B) Anáfase com ponte cromossômica; (C) Metáfase com perda cromossômica; (D) Anáfase com ponte cromossômica; (E) Célula com dois micronúcleos; (F) Telófase com ponte cromossômica e micronúcleo. Fotos: microscópio óptico, aumento 400x. 
Tabela 26. Valores médios ( \pm desvio padrão) de índice mitótico, aberrações cromossômicas e ocorrência de micronúcleos em cada 1.000 células meristemáticas de Allium cepa, expostas a amostras de água e sedimento coletadas no rio Corumbataí, em Setembro/2006. Para cada controle e para cada ponto de coleta, foram analisadas 5.000 células. Os valores marcados com “*” indicam diferença estatisticamente significativa em relação ao controle. Foram aplicados os testes de Kruskal-Wallis e o pós-teste de Dunn $(\mathrm{p}<0,05)$.

\begin{tabular}{ccccc}
\hline Amostra & $\begin{array}{c}\text { Pontos de } \\
\text { coleta }\end{array}$ & Índice mitótico & $\begin{array}{c}\text { Aberraçóes } \\
\text { cromossômicas }\end{array}$ & Micronúcleos \\
\hline Controle & $112,6 \pm 14,3$ & $5,2 \pm 0,8$ & $0,2 \pm 0,4$ \\
ÁGUA & $\mathbf{1}$ & $99,4 \pm 6,7$ & $7,6 \pm 0,5$ & $0,2 \pm 0,4$ \\
& $\mathbf{2}$ & $107,6 \pm 9,9$ & $9,0 \pm 1,9$ & $0 \pm 0$ \\
& $\mathbf{3}$ & $105,2 \pm 14,2$ & $10,6 \pm 0,5$ & $2,6 \pm 2,5$ \\
& $\mathbf{4}$ & $73,0 \pm 8,0^{*}$ & $10,2 \pm 0,8$ & $1,2 \pm 1,3$ \\
& $\mathbf{5}$ & $102,6 \pm 7,1$ & $10,4 \pm 0,5$ & $1,4 \pm 1,7$ \\
SEDIMENTO & $\mathbf{6}$ & $85,6 \pm 9,9$ & $13,2 \pm 1,5^{*}$ & $1,6 \pm 1,3$ \\
& $\mathbf{7}$ & $86,4 \pm 11,9$ & $16,4 \pm 3,3^{*}$ & $1,2 \pm 0,8$ \\
\hline & $\mathbf{3}$ & $105,6 \pm 22,4$ & $9,2 \pm 1,6$ & $0 \pm 0$ \\
& $\mathbf{4}$ & $104,4 \pm 15,3$ & $10,0 \pm 1,6$ & $0,8 \pm 1,3$ \\
& $\mathbf{1}$ & $115,6 \pm 17,2$ & $12,0 \pm 1,8^{*}$ & $2,4 \pm 1,5$ \\
& $\mathbf{5}$ & $125,0 \pm 15,8^{*}$ & $15,8 \pm 2,3^{*}$ & $2,0 \pm 2,9$ \\
& $\mathbf{6}$ & $89,2 \pm 17,4$ & $10,4 \pm 2,9$ & $0,2 \pm 0,4$ \\
& $\mathbf{7}$ & $125,7 \pm 13,2^{*}$ & $15,4 \pm 2,7^{*}$ & $2,4 \pm 1,1$ \\
\hline
\end{tabular}

\subsubsection{Teste crônico com Daphnia magna}

Os testes crônicos com D. magna apresentaram uma maior sensibilidade que o teste agudo com este mesmo organismo. Os resultados obtidos nos testes realizados em três coletas estão dispostos nas Tabelas 26 a 28. Os resultados de todas as coletas indicaram que, dentre os parâmetros analisados, os mais sensíveis foram os parâmetros relacionados à reprodução de D. magna, como o número de ovos, o de neonatos, e o número médio de crias por fêmea, que sofreram reduções estatisticamente significativas quando comparados aos valores correspondentes do controle. Outros parâmetros foram menos afetados pelas amostras, tais como longevidade, desenvolvimento embrionário, e intervalo na produção 
de ovos. Na coleta de Setembro/2006 foram obtidos resultados inesperados com amostras do Ponto 6, onde as fêmeas tiveram desempenho equivalente ao do controle.

Tabela 26. Valores médios dos parâmetros avaliados no teste crônico com D. magna, das amostras coletadas em Setembro/2005. As letras após os valores indicam diferença estatística em relação ao controle (a letra "b" após o valor indica $p<0,05$. A letra "c" após o valor indica $\mathrm{p}<0,01)$. Análise estatística por ANOVA e pós-teste de Dunnet.

\begin{tabular}{lcccccccc}
\hline & \multicolumn{10}{c}{ Pontos de coleta } \\
\hline \multicolumn{1}{c}{ Parâmetros } & CONTROLE & $\mathbf{1}$ & $\mathbf{2}$ & $\mathbf{3}$ & $\mathbf{4}$ & $\mathbf{5}$ & $\mathbf{6}$ & $\mathbf{7}$ \\
\hline Idade da primípara (dias) & 6,0 & 6,2 & 5,6 & 6,8 & 6,5 & 6,2 & 5,0 & 5,6 \\
Longevidade média (dias) & 18,3 & 13,8 & 18,8 & $7,8^{\mathrm{c}}$ & 20,7 & $8,5^{\mathrm{c}}$ & $11,5^{\mathrm{b}}$ & $11,2^{\mathrm{b}}$ \\
$\mathrm{N}^{\mathrm{o}}$ médio ovos/fêmea & 58,1 & $12,2^{\mathrm{c}}$ & $8,6^{\mathrm{c}}$ & $5,4^{\mathrm{c}}$ & $10,4^{\mathrm{c}}$ & $6,6^{\mathrm{c}}$ & $8,2^{\mathrm{c}}$ & $23,8^{\mathrm{c}}$ \\
$\mathrm{N}^{\mathbf{c}}$ médio neonatos/fêmea & 57,6 & $11,6^{\mathrm{c}}$ & $8,6^{\mathrm{c}}$ & $5,2^{\mathrm{c}}$ & $9,7^{\mathrm{c}}$ & $6,6^{\mathrm{c}}$ & $8,1^{\mathrm{c}}$ & $17,2^{\mathrm{c}}$ \\
Desenvolv. Embrionário (dias) & 3,0 & 2,5 & 2,6 & 2,6 & 3,0 & 2,6 & $3,6^{\mathrm{b}}$ & 3,0 \\
Intervalo produção ovos (dias) & 3,0 & 3,3 & 2,8 & 3,0 & $3,9^{\mathrm{c}}$ & 3,0 & $5,3^{\mathrm{c}}$ & 2,8 \\
$\mathrm{~N}^{\mathrm{o}}$ médio de crias/fêmea & 4,0 & $1,0^{\mathrm{c}}$ & $0,5^{\mathrm{c}}$ & 3,3 & 3,3 & $0,7^{\mathrm{c}}$ & $1,2^{\mathrm{c}}$ & $1,6^{\mathrm{b}}$ \\
$\mathrm{N}$ & 10 & 10 & 10 & 10 & 10 & 10 & 10 & 10 \\
\hline
\end{tabular}

Tabela 27. Valores médios dos parâmetros avaliados no teste crônico com D. magna, das amostras coletadas em Março/2006. As letras após os valores indicam diferença estatística em relação ao controle (a letra "b" após o valor indica $\mathrm{p}<0,05$. A letra "c" após o valor indica $\mathrm{p}<0,01)$. Análise estatística por ANOVA e pós-teste de Dunnet.

\begin{tabular}{lcccccccc}
\hline & \multicolumn{10}{c}{ Pontos de coleta } \\
\hline \multicolumn{1}{c}{ Parâmetros } & CONTROLE & $\mathbf{1}$ & $\mathbf{2}$ & $\mathbf{3}$ & $\mathbf{4}$ & $\mathbf{5}$ & $\mathbf{6}$ & $\mathbf{7}$ \\
\hline Idade da primípara (dias) & 4,6 & 5,5 & 4,6 & $6,6^{\mathrm{b}}$ & 4,3 & 5,4 & $9,5^{\mathrm{c}}$ & 5,4 \\
Longevidade média (dias) & 21,0 & 20,1 & 21,0 & 18,0 & 18,4 & 16,7 & 19,0 & 21,0 \\
$\mathrm{~N}^{\mathrm{o}}$ médio ovos/fêmea & 59,4 & $18,1^{\mathrm{c}}$ & $21,6^{\mathrm{c}}$ & $10,4^{\mathrm{c}}$ & $20,7^{\mathrm{c}}$ & $20,8^{\mathrm{c}}$ & $1,5^{\mathrm{c}}$ & $14,2^{\mathrm{c}}$ \\
$\mathrm{N}^{\mathrm{o}}$ médio neonatos/fêmea & 59,4 & $16,1^{\mathrm{c}}$ & $19,5^{\mathrm{c}}$ & $10,0^{\mathrm{c}}$ & $19,7^{\mathrm{c}}$ & $18,1^{\mathrm{c}}$ & $0,7^{\mathrm{c}}$ & $10,8^{\mathrm{c}}$ \\
Desenvolv. Embrionário (dias) & 2,8 & 2,7 & 2,7 & 2,7 & 2,6 & 2,6 & $3,7^{\mathrm{c}}$ & 2,7 \\
Intervalo produção ovos (dias) & 2,8 & 2,9 & 2,8 & 2,7 & 2,9 & 2,6 & $6,0^{\mathrm{c}}$ & $3,7^{\mathrm{c}}$ \\
$\mathrm{N}^{\mathbf{o}}$ médio de crias/fêmea & 6,1 & $4,2^{\mathrm{b}}$ & 5,4 & $3,2^{\mathrm{c}}$ & 5,0 & $4,0^{\mathrm{c}}$ & $0,6^{\mathrm{c}}$ & $3,9^{\mathrm{c}}$ \\
$\mathrm{N}$ & 10 & 10 & 10 & 10 & 10 & 10 & 10 & 10 \\
\hline
\end{tabular}


Tabela 28. Valores médios dos parâmetros avaliados no teste crônico com D. magna, das amostras coletadas em Setembro/2006. As letras após os valores indicam diferença estatística em relação ao controle (a letra "b" após o valor indica $p<0,05$. A letra "c" após o valor indica $\mathrm{p}<0,01)$. Análise estatística por ANOVA e pós-teste de Dunnet.

\begin{tabular}{lcccccccc}
\hline & \multicolumn{10}{c}{ Pontos de coleta } \\
\hline \multicolumn{1}{c}{ Parâmetros } & CONTROLE & $\mathbf{1}$ & $\mathbf{2}$ & $\mathbf{3}$ & $\mathbf{4}$ & $\mathbf{5}$ & $\mathbf{6}$ & $\mathbf{7}$ \\
\hline Idade da primípara (dias) & 4,0 & 4,4 & 4,3 & $6,0^{\mathrm{c}}$ & $7,8^{\mathrm{c}}$ & $5,0^{\mathrm{c}}$ & 4,1 & $6,8^{\mathrm{c}}$ \\
Longevidade média (dias) & 21,0 & 20,8 & 21,0 & 19,0 & 21,0 & 19,7 & 20,3 & 20,8 \\
$\mathrm{~N}^{\mathrm{o}}$ médio ovos/fêmea & 88,1 & $22,4^{\mathrm{c}}$ & $37,0^{\mathrm{c}}$ & $26,3^{\mathrm{c}}$ & $13,5^{\mathrm{c}}$ & $32,3^{\mathrm{c}}$ & 80,6 & $7,8^{\mathrm{c}}$ \\
$\mathrm{N}^{\mathrm{o}}$ médio neonatos/fêmea & 87,9 & $22,0^{\mathrm{c}}$ & $36,2^{\mathrm{c}}$ & $25,5^{\mathrm{c}}$ & $11,5^{\mathrm{c}}$ & $31,5^{\mathrm{c}}$ & 79,8 & $7,2^{\mathrm{c}}$ \\
Desenvolv. Embrionário (dias) & 2,5 & 3,0 & 2,7 & $3,0^{\mathrm{c}}$ & $3,0^{\mathrm{c}}$ & $2,8^{\mathrm{b}}$ & 2,7 & $3,1^{\mathrm{c}}$ \\
Intervalo produção ovos (dias) & 2,5 & $3,2^{\mathrm{c}}$ & 2,7 & 2,9 & 2,7 & 2,8 & 2,7 & $4,1^{\mathrm{c}}$ \\
$\mathrm{N}^{\mathrm{o}}$ médio de crias/fêmea & 6,5 & $3,7^{\mathrm{c}}$ & 5,2 & $4,1^{\mathrm{c}}$ & $2,3^{\mathrm{c}}$ & 4,6 & 5,7 & $2,9^{\mathrm{c}}$ \\
$\mathrm{N}$ & 10 & 10 & 10 & 10 & 10 & 10 & 10 & 10 \\
\hline
\end{tabular}




\subsection{Discussão}

\subsubsection{Teste LuminoTox}

Os resultados obtidos no teste LuminoTox com as amostras de água demonstraram, mais claramente que outros testes, a maior toxicidade dos Pontos de coleta a jusante das cidades, quando comparados com o ponto correspondente a montante, em ambas as coletas realizadas. Isso pôde ser observado quando se compara o resultado do Ponto 1 em relação ao Ponto 2, e do Ponto 3 em relação ao Ponto 4. No geral, o teste LuminoTox foi considerado bastante sensível às amostras ambientais testadas. Os testes com amostras de sedimento também indicaram um alto grau de toxicidade para as enzimas PEC do LuminoTox, sendo que a menor toxicidade registrada (excluindo a do Ponto 1, onde não houve indício de toxicidade) foi o $\mathrm{CI}_{25}$ (15 min.) de 4,92\% do Ponto 7. Mesmo assim, em valores absolutos pode-se considerar que este valor indica alta toxicidade. $\mathrm{O}$ teste LuminoTox foi originalmente projetado para se testar amostras líquidas, como por exemplo amostras ambientais de água. Porém, Dellamatrice et al. (2006) realizaram um estudo com diversos sedimentos, tanto naturais quanto artificiais (ou seja, sedimentos de referência certificados), tendo desenvolvido um novo protocolo para a utilização do LuminoTox com amostras de sedimentos. Este protocolo foi empregado no presente estudo, e considera-se que tenha produzido resultados válidos, já que corroboram os outros bioensaios realizados. Assim como nos outros bioensaios, as amostras de sedimento causaram maior toxicidade que as de água.

A Tabela 29 mostra a análise de correlação linear (Pearson) entre os resultados do teste LuminoTox e os resultados dos bioensaios principais. Houve correlação significativa apenas para alguns testes realizados com sedimento: D. magna $(\mathrm{r}=0,9269)$ e $P$. subcapitata $(\mathrm{r}=0,8404)$. Em todos os testes realizados, as amostras de sedimento sempre 
se mostraram mais tóxicas que as de água. A correlação positiva entre o LuminoTox e a alga $P$. subcapitata pode ser explicada pela semelhança entre os sistemas testados, já que se tratam de organismos com sistemas bioquímicos e enzimáticos semelhantes, e que sofreriam efeitos tóxicos pelos mesmos modos de ação. A ausência de correlação entre alguns testes não significa necessariamente um resultado ruim ou inválido, mas sim pode indicar que eles apresentam sensibilidade a diferentes agentes tóxicos, por diferentes rotas de exposição, que sofrem toxicidade por diferentes modos de ação, e, portanto, o mais recomendável é compor uma bateria de bioensaios bem selecionada, para contemplar os diferentes tipos de organismos que se pretende proteger em um dado ecossistema. Segundo os resultados obtidos, não seria necessário realizar ambos os testes com alga e com o LuminoTox para avaliar o sedimento, pois eles parecem produzir resultados redundantes. Mais estudos seriam necessários, entretanto, para validar esta interpretação. A correlação positiva com o teste com D. magna pode indicar uma boa validação para o LuminoTox, mas não uma redundância, já que se tratam de organismos e endpoints bastante diferentes entre si.

Tabela 29. Análise de correlação linear (Pearson) entre os valores obtidos no teste LuminoTox e os valores de toxicidade dos bioensaios principais realizados com amostras do rio Corumbataí.

\begin{tabular}{lcccc}
\hline & \multicolumn{3}{c}{ LuminoTox } \\
\cline { 2 - 3 } & \multicolumn{2}{c}{ ÁGUA } & & SEDIMENTO \\
\cline { 2 - 3 } D. magna & Março/2006 & Junho/2006 & & Março/2006 \\
\hline H. attenuata & $-0,2016$ & 0,5543 & & $\mathbf{0 , 9 2 6 9}$ \\
P. subcapitata & $-0,1308$ & $-0,5543$ & & $-0,7462$ \\
C. xanthus & - & - & & $\mathbf{0 , 8 4 0 4}$ \\
\hline
\end{tabular}




\subsubsection{Teste de genotoxicidade com Allium cepa}

Quanto aos testes de genotoxicidade conduzidos com A. cepa, apesar de não haver diferenças estatisticamente significativas entre o controle e alguns pontos de coleta, foi possível observar alguns aspectos: (1) de modo geral, as amostras de água dos pontos de coleta causaram uma redução no índice mitótico, enquanto que as amostras de sedimento causaram um aumento no índice mitótico das células; estes resultados podem ser explicados por uma maior concentração de nutrientes no sedimento, que fariam com que as radículas crescessem mais; (2) ambos os tipos de amostras causaram um aumento na ocorrência de micronúcleos nos pontos de coleta, quando comparados à ocorrência nos respectivos controles.

Em relação aos resultados que foram determinados como sendo estatisticamente diferentes, ressalta-se que os Pontos 5, 6 e 7 tiveram uma ocorrência maior de aberrações cromossômicas - como era de se esperar, levando em consideração os bioensaios principais. Os resultados produzidos neste bioensaio devem ser tomados como um alerta, pelo fato de o ponto de captação de água para Rio Claro estar localizado neste trecho do rio. Apesar de os valores indicarem um potencial genotóxico baixo no rio Corumbataí, eles indicam também que este potencial está presente. Na literatura, há vários estudos que utilizaram com sucesso este bioensaio para determinar a presença de agentes genotóxicos no ambiente. Uma revisão da literatura feita por Grant (1982) listou mais de uma centena de substâncias que causam efeitos genotóxicos em A. cepa. Leme e Marin-Morales (2008) encontraram uma correlação positiva entre a ocorrência de efeitos genotóxicos em A. cepa e a presença de hidrocarbonetos de petróleo e hidrocarbonetos policíclicos aromáticos em um rio contaminado por petróleo. Fernandes et al. (2007) provaram ser a trifluralina um herbicida altamente genotóxico. Cotelle et al. (1999) mostraram que A. cepa é bastante sensível a presença de metais, hidrocarbonetos policíclicos aromáticos, e PCBs. 
Finalmente, Smaka-Kincl et al. (1996), utilizando este mesmo bioensaio, mostraram que $A$. сера sofreu efeitos genotóxicos quando submetida a diversas amostras líquidas, como águas fluviais, efluentes industriais e domésticos, e esgotos tratados e não-tratados.

A Tabela 30 mostra a análise de correlação linear (Pearson) entre os resultados do bioensaio com A. cepa e os bioensaios principais. Neste caso, houve pouca correlação entre os bioensaios, provavelmente pelo tipo de parâmetro avaliado, já que os bioensaios principais levam em consideração parâmetros letais, e o teste com A. cepa avalia danos no material genético. Mesmo assim, houve algumas correlações significativas. Os resultados de correlação mostrados aqui não indicam nenhuma redundância de resultados, que permitam eliminar qualquer dos bioensaios realizados, no caso de uma seleção para compor uma bateria de testes, já que eles avaliam parâmetros muito diferentes entre si, e visam proteger diferentes aspectos da biota.

Tabela 30. Análise de correlação linear (Pearson) entre os valores obtidos no teste de genotoxicidade $\operatorname{com} A$. cepa e os valores de toxicidade dos bioensaios principais realizados com amostras do rio Corumbataí.

\begin{tabular}{lcclccc}
\hline & \multicolumn{2}{c}{ ÁGUA } & & \multicolumn{2}{c}{ SEDIMENTO } \\
\cline { 2 - 3 } \cline { 6 - 7 } & AC & MN & & AC & MN \\
\hline D. magna & 0 & 0 & & $-0,0534$ & 0,4100 \\
H. attenuata & 0,3997 & 0,2196 & & 0,5125 & 0,4815 \\
P. subcapitata & $\mathbf{0 , 8 9 7 5}$ & 0,4780 & & 0,4535 & 0,3514 \\
C. xanthus & - & - & & 0,5572 & $\mathbf{0 , 7 8 3 1}$ \\
\hline
\end{tabular}

\subsubsection{Teste crônico com Daphnia magna}

Os resultados obtidos no teste crônico com D. magna indicaram uma significativa redução da fecundidade das fêmeas expostas às amostras testadas, em todas as coletas (tanto na produção de ovos quanto na de neonatos, e no número médio de crias). As amostras dos Pontos 6 e 7 foram, mais uma vez, as que causaram mais efeitos deletérios 
nos organismos testados, segundo os parâmetros avaliados. Geralmente, isso se deve a necessidade de realocação de energia que as fêmeas enfrentam, para poderem sobreviver. Este é um mecanismo natural deste tipo de organismo aquático, que investe mais na desintoxicação para sobreviver, e ter como produzir neonatos em tempos futuros provavelmente mais favoráveis, do que na produção de filhotes que não terão condições de enfrentar um ambiente desfavorável desde o seu nascimento (LYNCH, 1980). Uma exceção à resposta de D. magna a estes pontos foram os resultados do Ponto 6 da coleta de Setembro/2006 (Tabela 28) em que se obtiveram respostas semelhantes às do controle para todos os parâmetros avaliados. Este foi considerado um resultado anormal, já que nos outros dois testes foi observado que o Ponto 6 exerceu grande efeito tóxico sobre as fêmeas testadas. Isso talvez possa ser explicado por uma presença maior de nutrientes do que de agentes tóxicos nesta amostra. Outros bioensaios, como o de $H$. attenuata não apresentou toxicidade para esta amostra, e $P$. subcapitata teve $\mathrm{CI}_{50}$ igual a $68,1 \%$.

Vários pontos de coleta causaram um atraso na produção da primeira cria (parâmetro idade primípara), das coletas de Março e Setembro de 2006 (Tabelas 27 e 28). Segundo Bridges et al. (1996), efeitos negativos neste parâmetro podem resultar em uma diminuição significativa da população a longo prazo. Os autores deste estudo aplicaram um modelo matemático de dinâmica de populações, e concluíram que um atraso de apenas dois dias no início da fase reprodutiva pode reduzir pela metade o número final de indivíduos em uma população após um período de 28 dias.

Sobre a longevidade, houve apenas alguns Pontos de coleta em Setembro/2005 que causaram uma redução neste parâmetro, mas mesmo assim nos Pontos 3, 5, 6, e 7 (Tabela 26). Lynch (1980) afirma que os organismos usam da estratégia de investir principalmente na sobrevivência, em detrimento da reprodução, e que, portanto, este parâmetro seria menos afetado que os reprodutivos. Mas se os efeitos tóxicos persistem, a longevidade e a 
sobrevivência são afetadas ao longo do tempo. Os parâmetros desenvolvimento embrionário e intervalo na produção de ovos não demonstraram efeitos negativos severos sobre os organismos testados. Entretanto, quando houve diferença significativa, na maioria dos casos, foram nos Pontos 6 e 7. As leituras destes endpoints foram feitas a cada 24 horas. Provavelmente, se tivessem sido feitas a cada 12 horas, teriam resultados mais precisos e sensíveis. Geralmente, estes parâmetros são mais influenciados pela temperatura do que por agentes tóxicos (Vijverberg, 1989). O número médio de crias por fêmea dos Pontos de coleta sempre se mostrou numericamente inferior aos valores do controle, e a maioria deles com diferença estatística. Inicialmente, pretendia-se analisar a porcentagem de eclosão dos ovos, já que é um parâmetro comumente utilizado em testes crônicos. Mas no presente estudo, a ocorrência de ovos abortados foi extremamente baixa.

Neste estudo, pôde-se dizer que o teste crônico indicou com maior sensibilidade a influência de efeitos tóxicos, quando este é comparado ao teste agudo com o mesmo organismo, se mostrando mais adequado que o teste agudo. Outros autores já utilizaram, também com sucesso, o teste crônico com $D$. magna para determinar a contaminação de sedimentos fluviais (NEBEKER et al., 1988). O teste crônico é uma ferramenta extra disponível a ser utilizada quando se deseja aumentar a sensibilidade (o "limite de detecção") de um organismo, como D. magna. Apesar de ser mais trabalhoso, é um teste que oferece mais informações sobre a amostra testada, e que pode garantir uma maior proteção à biota aquática, já que é capaz de determinar níveis mais sutis de contaminação ambiental. Nebeker et al. (1988) encontraram resultados similares, em relação à fecundidade e o intervalo na produção de ovos, quando utilizaram testes crônicos para avaliar a qualidade de sedimentos fluviais. Lahr et al. (2003) utilizaram uma grande bateria de bioensaios para avaliar o grau de toxicidade de diversas amostras de sedimentos naturais, e concluíram que o teste crônico com D. magna foi um dos mais sensíveis dentre 
os estudados por eles. Mas ressaltaram também que a utilização simultânea de diversos testes aumenta a chance de demonstrar efeitos tóxicos de sedimentos contaminados, e que o teste crônico com D. magna estando entre eles atinge este objetivo. Bridges et al. (1996) testaram uma grande quantidade de sedimentos naturais, e demonstraram, através dos testes crônicos com D. magna, que os contaminantes presentes no sedimento podem comprometer a dinâmica de populações de organismos que entram em contato com estes sedimentos. Martínez-Jerónimo et al. ${ }^{4}$ (no prelo), realizaram testes agudos e crônicos com D. magna para testar amostras de sedimentos contaminadas por metais e hidrocarbonetos, e também concluíram que os testes crônicos foram mais adequados na avaliação de toxicidade de suas amostras.

De acordo com os três bioensaios crônicos, não foi possível identificar uma sazonalidade nas respostas obtidas, nem em relação a estações do ano, nem quanto à pluviosidade. A qualidade do sedimento parece ser menos influenciada pelas estações do que a qualidade das águas. O sedimento parece retratar mais o histórico de poluição de seu corpo d'água, e o sedimento do rio Corumbataí parece indicar que o rio está contaminado e que sua qualidade não vem melhorando ao longo do tempo, a despeito dos esforços empreendidos neste sentido, por órgãos ambientais como a CESTESB, o comitê do PCJ, prefeituras, dentre outros. Não houve também diferenças significativas entre os Pontos de coleta, em relação aos parâmetros avaliados, mas apenas entre os Pontos e o controle.

A Tabela 31 mostra a análise de correlação linear (Pearson) entre os resultados do bioensaio crônico com Daphnia magna e os bioensaios principais. Houve apenas um resultado de correlação significativa, que parece ter sido ocasional, já que nas outras duas coletas houve correlação negativa. A ausência de correlação entre o teste agudo e o crônico

\footnotetext{
${ }^{4}$ MARTÍNEZ-JERÓNIMO, F.; CRUZ-CINEROS, J.L. e GARCÍA-HERNÁNDEZ, L. A comparison of the response of Simocephalus mixtus (Cladocera) and Daphnia magna to contaminated freshwater sediments. Ecotoxicology and Environmental Safety, New York, no prelo. 2008.
} 
de D. magna e os resultados destes testes sugerem que o teste crônico foi capaz de demonstrar efeitos deletérios mais sutis sobre este organismo, já que o teste agudo indicou menos toxicidade - e até mesmo ausência de toxicidade para alguns Pontos de coleta. Para as amostras de sedimento do rio Corumbataí, o teste crônico foi mais determinante na indicação de riscos para a proteção da biota aquática.

Tabela 31. Análise de correlação linear (Pearson) entre os valores obtidos de número médio de neonatos por fêmea no teste de toxicidade crônica com D. magna e os valores de toxicidade dos bioensaios principais realizados com amostras do rio Corumbataí.

\begin{tabular}{lccc}
\hline & \multicolumn{3}{c}{ Neonatos por fêmea } \\
\cline { 2 - 4 } & Setembro/2005 & Março/2006 & Setembro/2006 \\
\hline D. magna & $-0,0239$ & $-0,3271$ & $-0,0104$ \\
H. attenuata & $-0,6061$ & 0,426 & 0,5181 \\
P. subcapitata & $-0,6246$ & 0,2505 & 0,4752 \\
C. xanthus & $-0,5692$ & $\mathbf{0 , 6 8 6 3}$ & $-0,4511$ \\
\hline
\end{tabular}




\subsection{Conclusões}

- O LuminoTox forneceu resultados que contribuíram para a avaliação da qualidade do rio Corumbataí, pois indicou elevados graus de toxicidade, tanto da água quanto do sedimento. O LuminoTox, através de seus resultados, indicou com sucesso o impacto exercido pelas cidades, quando se compara os Pontos de coleta a montante e a jusante delas;

- O protocolo desenvolvido para o teste LuminoTox para amostras de sedimento se mostrou válido, permitindo a análise destas amostras;

- A correlação positiva entre os resultados do sedimento com o LuminoTox e o teste com a alga $P$. subcapitata sugerem que ambos os testes apresentam respostas semelhantes pelo fato de apresentarem sistemas bioquímicos e enzimáticos semelhantes, sofrendo efeitos tóxicos pelos mesmos modos de ação, e, que portanto, parecem ser redundantes em uma bateria de testes. Porém, estudos mais enfocados nesta questão precisariam ser realizados;

- A ausência de correlação entre testes pode indicar diferentes rotas de exposição, sensibilidade e modos de ação entre os organismos-teste. Esta ausência de correlação pode ajudar na composição de baterias de testes adequadas aos ambientes a serem testados;

- $\mathrm{O}$ teste de genotoxicidade com A. cepa forneceu importantes informações a respeito do potencial genotóxico das amostras do rio Corumbataí. Através dele, foi possível identificar que os últimos três Pontos de coleta exercem efeitos genotóxicos sobre A. cepa;

- Apesar de não haver diferença estatisticamente significativa, todos os pontos de coleta (água e sedimento) causaram um aumento na freqüência de aberrações cromossômicas; 
- Não houve diferença significativa na freqüência de micronúcleos nas células meristemáticas de A. серa, apesar de nos últimos três Pontos de coleta, estas freqüências terem sido numericamente mais altas;

- Foi observada ocorrência significativa de aberrações cromossômicas e de micronúcleos no local de captação de água de Rio Claro, assim como nos Pontos 6 e 7. Estes resultados devem ser tomados como um alerta, pois o potencial genotóxico, mesmo sendo baixo, está presente neste trecho do rio Corumbataí;

- O teste de genotoxicidade com A. cepa pode ser considerado um dos testes a compor uma bateria de bioensaios para avaliação de um ambiente aquático;

- Baseando-se nos testes crônicos com D. magna, pode-se concluir que os Pontos 6 e 7 foram os que mais exerceram efeitos tóxicos sobre os organismos expostos, segundo os parâmetros avaliados;

- Os testes crônicos com D. magna foram sensíveis na detecção de agentes tóxicos presentes no sedimento do rio Corumbataí;

- Os parâmetros de fecundidade (Produção de ovos, neonatos, e número médio de crias) foram os mais sensíveis, sofrendo reduções significativas na maioria dos Pontos de coleta;

- Não foi observada influência da sazonalidade ou regime de chuvas nos resultados do teste crônico; tampouco foi observada uma melhora na qualidade do sedimento dentro do período estudado;

- O teste crônico se mostrou mais adequado que o teste agudo para avaliar a qualidade do sedimento do rio Corumbataí, visando à proteção da biota aquática. 


\subsection{Referências Bibliográficas}

ALBERTINI，R.J.; ANDERSON，D.; DOUGLAS，G.R.; HAGMAR，L.; HEMMINK，K.; MERLO, F.; NATARAJAN, A.T.; NORPPA, H.; SHUKER, D.E.; TICE, R.; WATER, M.D.; AITIO, A. IPCS guideline for the monitoring of genotoxic effects of carcinogens in humans, International Programme on Chemical Safety. Mutation Research, Amsterdam, v. 463, p. 111$172,2000$.

BIESINGE, K.E.; ANDREW, R.W.; ARTHUR, J.W. Chronic toxicity of NTA (Nitrilotriacetate) and metal-NTA complexes to Daphnia magna. Journal of the Fisheries Research Board of Canada, Ottawa, v. 31, n. 4, p. 486-490, 1974.

BOUCHER, N.; LORRAIN, L.; ROUETTE, M.E.; PERRON, E.; DÉZIEL, N.; TESSIER, L.; BELLEMARE, F. Rapid testing of toxic chemicals. American Laboratory, Shelton, p. 34-37, mar. 2005. Disponível em: <http://www.environmentalexpert.com/files/19413/articles/4206/4206.pdf>. Acesso em 11 Abr. 2008.

BRIDGES, T.S.; WRIGHT, R.B.; GRAY, B.R.; GIBSON, A.B.; DILLON, T.M. Chronic toxicity of Great Lakes sediments to Daphnia magna: elutriate effects on survival, reproduction and population growth. Ecotoxicology, Berlin, v. 5, p. 83-102, 1996.

COTELLE, S.; MASFARAUD, J.F.; FÉRARD, J.F. Assessment of the genotoxicity of contaminated soil with the Allium/Vicia-micronucleus and the Tradescantia-micronucleus assays. Mutation Research, Amsterdam, v. 426, p. 167-171, 1999.

DELlAMATRICE, P.M.; MONTEIRO, R.T.R.; BLAISE, C.; SLABBERT, J.L.; GAGNÉ, F.; ALLEAU, S. Toxicity assessment of reference and natural sediments with the LuminoTox Assay. Environmental Toxicology, New York, v. 21, n. 4, p. 395-402, 2006.

FERNANDES, T.C.C.; MAZZEO, D.E.C.; MARIN-MORALES, M.A. Mechanism of micronuclei formation in polyploidizated cells of Allium cepa exposed to trifluralin herbicide. Pesticide Biochemistry and Physiology, New York, v. 88, p. 252-259, 2007.

FISKESJÖ, G. The Allium test as a standard in environmental monitoring. Hereditas, Lund, v. 102, p. 99-112, 1985.

GRANT, W.F. Chromosome aberration assays in Allium: A report of the U.S. Environmental Protection Agency Gene-Tox Program. Mutation Research, Amsterdam, v. 99, p. 273-291, 1982.

HUANG, X.D.; MCCONKEY, B.J.; BABU, T.S.; GREENBERG, B.M. Mechanisms of photoinduced toxicity of photomodified anthracene to plants: inhibition of photosynthesis in the aquatic higher plant Lemna gibba (Duckweed). Environmental Toxicology and Chemistry, New York, v. 16, p. 1707-1715, 1997.

JONCZYK, E.; GILRON, G. Acute and chronic toxicity testing with Daphnia sp. In: BLAISE, C.; FÉRARD, J.F. (Ed.). Small-scale freshwater toxicity investigations. v. 1. Toxicity test methods. Dordrecht: Springer Science, 2005.

LAHR, J.; MAAS-DIEPEVEEN, J.L.; STUIJFZAND, S.C.; LEONARDS, P.E.G.; DRÜKE, J.M.; LÜCKER, S.; ESPELDOORN, A.; KERKUM, L.C.M.; VAN STEE, L.L.P.; JAN HENDRIKS, A. Responses in sediment bioassays used in the Netherlands: can observed toxicity be explained by routinely monitored priority pollutants? Water Research, New York, v. 37, p. 1691-1710, 2003. 
LEME, D.M.; MARIN-MORALES, M.A. Chromosome aberration and micronucleus frequencies in Allium cepa cells exposed to petroleum polluted water - A case study. Mutation Research, Amsterdam, v. 650, p. 80-86, 2008.

LYNCH, M. The evolution of cladoceran life histories. The Quarterly Review of Biology, Baltimore, v. 55, p. 23-42, 1980.

MARTINEZ-JERÓNIMO, F.; VILLASEFIOR, R.; ESPINOSA, F.; RIOS, G. Use of life-tables and application factors for evaluating chronic toxicity of kraft mill wastes on Daphnia magna. Bulletin of Environmental Contamination and Toxicology, New York, v. 50, p. 377-384, 1993.

NEBEKER, A.V.; ONJUKKA, S.T.; CAIRNS, M.A. Chronic effects of contaminated sediment on Daphnia magna and Chironomus tentans. Bulletin of Environmental Contamination and Toxicology, New York, v. 41, p. 574-581, 1988.

ORGANISATION FOR ECONOMIC CO-OPERATION AND DEVELOPMENT. OECD Test Guidelines: Daphnia sp. Acute Immobilization test and reproductive test. Paris: OECD, 1987. 20 p. (Test 202).

RUSSEL, P.J. Chromosomal mutation. In: CUMMINGS B. (Ed.). Genetics. San Francisco: Pearson Education Inc, 2002. p. 595-621.

SHUGART, L.R. Structural damage to DNA in response to toxicant exposure. In: FORBES, V.E. (Ed.). Genetics and Ecotoxicology. London: Taylor \& Francis, 1998, p. 151-168.

SMAKA-KINCL, V.; STEGNAR, P.; LOVKA, M.; TOMAN, M.J. The evaluation of waste, surface and ground water quality using the Allium test procedure. Mutation Research, Amsterdam, v. 368, p. 171-179, 1996.

VIJVERBERG, J. Culture techniques for studies on the growth, development and reproduction of copepods and cladocerans under laboratory and in situ conditions: a review. Freshwater Biology, Oxford, v. 21, p. 317-373, 1989.

ZAR, J. H. Biostatistical analysis. New Jersey: Prentice Hall, 1999. 663 p. 


\section{Avaliação de amostras fluviais (Saint Lawrence River, Montreal, Canada), efluentes tratados e de nanomateriais utilizando o bioensaio MARA (Microbial Array for Risk} Assessment).

\section{Resumo}

Conhecimentos sobre os efeitos ecotoxicológicos dos nanomateriais - estruturas químicas com novas propriedades, dado seu pequeno tamanho (1-100nm) - são necessários atualmente e merecem ser melhor documentados. No presente estudo, testes com o bioensaio MARA (Microbial Array for Risk Assessment) foram realizados para determinar o potencial tóxico de quatro nanomateriais (NM) metálicos: óxido de cobre-zinco-ferro, óxido de samário, óxido de érbio, e óxido de hólmio. O bioensaio MARA é um teste de toxicidade que utiliza 11 linhagens microbianas, onde se tem como endpoint a inibição de crescimento de cada uma destas linhagens. Os valores de CTM (Concentração tóxica microbiana - equivalente ao $\mathrm{CL}_{50}$ ) obtidos indicaram uma gama de respostas que parecem ser específicas para cada nanomaterial. Os valores de CTM foram então submetidos ao método estatístico Cluster Analysis, e os resultados indicaram que o modo de ação destes NM sobre as linhagens microbianas pode ser diferente. Foram realizados testes com sedimento artificial, composto por proporções definidas de areia e argila, com e sem adição dos mesmos nanomateriais, separadamente, a fim de se determinar a influência da granulometria na toxicidade resultantes destes elutriatos. Os resultados com os nanomateriais indicaram que a toxicidade do elutriato é menor quando o sedimento apresenta uma maior proporção de partículas finas (e.g., argila), exceto para o óxido de $\mathrm{Cu}$ $\mathrm{Zn}-\mathrm{Fe}$, onde nenhuma influência da granulometria foi observada. Bioensaios foram então realizados com sedimentos naturais, coletados no rio Saint Lawrence (Montreal, Canadá), de diversas granulometrias, com e sem adição dos mesmos nanomateriais. Mais uma vez, resultados análogos aos dos sedimentos artificiais foram obtidos em relação à toxicidade dos elutriatos. Em geral, o bioensaio MARA indicou que a toxicidade dos nanomateriais pode ser influenciada pela granulometria do sedimento, e que efeitos adversos sobre a biota aquática podem depender parcialmente desta característica do sedimento. Amostras de água e sedimento provenientes da região de Montreal, Canadá, assim como amostras de efluentes de diversas estações de tratamento de esgoto também foram testadas quanto à sua toxicidade às linhagens do bioensaio MARA. Para cada amostra, foi obtido um perfil tóxico único, demonstrando os variados graus de susceptibilidade de cada linhagem microbiana.

Palavras-chave: MARA; Ecotoxicologia; rio Saint Lawrence; água; sedimento; efluente; nanomateriais. 


\begin{abstract}
Knowledge concerning the ecotoxic effects of nanomaterials, chemical structures with novel properties owing to their small sizes (1-100 nm), is necessary and deserves to be documented more fully. In this study, we conducted testing with the MARA (Microbial Array for Risk Assessment) assay, an 11 microbial species 96-well microplate toxicity test measuring growth inhibition, to determine the toxic potential of four metallic nanopowders (NPs), copper zinc iron oxide, samarium (III) oxide, erbium (III) oxide and holmium (III) oxide. MTC (Microbial Toxicity Concentration, equivalent to $\mathrm{CL}_{50}$ ) endpoint values showed a range of toxicity responses generated by individual strains that was NP-specific. Cluster analysis undertaken with the $(n=11)$ MTC values of the four NPs, reflecting a toxic fingerprint proper to each nano-chemical, indicated that their modes of action may be different. Experiments were also conducted with an artificial sediment, composed of varying concentrations of silica sand and kaolin (fine particles $<0.004 \mathrm{~mm}$ ), spiked with each NP to assess the contribution of fine particles on resulting elutriate toxicity. The latter was shown to increase as fines contents decreased, except for $\mathrm{CuZnFeO}$ where no particular trends were observed. Toxicity testing was then undertaken with each NP spiked into natural St-Lawrence River (Montreal, Canada) freshwater sediments displaying low, medium and high fines contents. Once again, analogous results to those obtained with the artificial sediment experiments were observed for NP elutriate toxicity. Overall, MARA bioassay data indicate that NP toxicity can be modulated by sediment grain size and that resulting adverse effects on aquatic biota will in part depend on such sediment characteristics. Water and sediment samples from rivers of Montreal, Canada, as well as wastewater treatment plant effluent samples were tested in order to assess their toxicity to MARA microbial strains. For each sample a unique toxic fingerprint was obtained, showing varying degrees of susceptibility for each strain.
\end{abstract}

Keywords: MARA; Ecotoxicology; Saint Lawrence River; water; sediment; effluent; nanomaterials. 


\subsection{Introdução}

Paralelamente aos estudos ecotoxicológicos realizados no rio Corumbataí, foram testados também bioensaios microbiológicos durante um estágio no exterior (Bolsa PDEE CAPES, Proc. 2209/07-1), no Saint Lawrence Centre, Environment Canada, Montreal, Canadá, durante um período de quatro meses (Setembro a Dezembro de 2007). O bioensaio denominado "MARA" (Microbial assay for risk assessment) foi utilizado na avaliação da toxicidade de amostras de água e sedimento fluviais, efluentes industriais/urbanos tratados, e nanomateriais.

O bioensaio MARA utiliza um sistema com diversas linhagens microbianas, e por isso tem a vantagem de produzir um perfil tóxico de uma dada amostra, ao invés dos bioensaios como Microtox ${ }^{\circledR}$, ToxAlert (LA FARRE et al., 2001) e Polytox (ARULGNANEDRAN e NIRMALAKHANDAN, 1998), que retornam apenas um valor para cada ensaio. Ele pode ser uma ferramenta alternativa poderosa na área da Ecotoxicologia, por testar diversas linhagens padronizadas de microorganismos simultaneamente, pela sua facilidade de uso, por sua rápida execução, e pela vasta diversidade genética dos microorganismos utilizados. Esta última característica produz uma alta diversidade de respostas às substâncias químicas testadas.

Este bioensaio consiste em expor um conjunto de 11 linhagens microbianas isoladamente em uma placa multi-escavada (96 cavidades) a diversas concentrações de um dado composto químico (ou a uma amostra ambiental) a ser avaliado quanto à sua toxicidade. O bioensaio MARA é baseado em medidas da inibição do crescimento microbiano, após estas linhagens terem sido expostas a uma amostra, por um período de 18 horas. A inibição de crescimento microbiano em cada cavidade da placa é avaliada pela precipitação de um corante presente no meio em forma de pellet (indicador de crescimento). A placa é lida por um scanner e o diâmetro e a densidade de cada pellet é 
determinado por um software próprio para isso. Um perfil tóxico é obtido, único para cada amostra testada, constituído dos valores de inibição de crescimento das 11 linhagens (parâmetro este semelhante ao $\mathrm{CL}_{50}$ ). Estes perfis podem, ainda, ser agrupados para produzir um dendrograma, que mostra as similaridades e diferenças entre os agentes químicos testados de uma dada bateria de ensaios.

O bioensaio MARA foi concebido e validado por Gabrielson et al. (2003) e atualmente vendido comercialmente pela NCIMB Ltd. (United Kingdom, www.ncimb.com).

No presente estudo, foram avaliadas quanto à sua toxicidade amostras de efluentes de estações de tratamento de esgotos, amostras de água e sedimento (elutriatos) fluviais, assim como nanomateriais isoladamente, e misturados a sedimentos.

A nanotecnologia é a área da ciência que conduz pesquisas e desenvolvimento de partículas de tamanho entre 0,1 e $100 \mathrm{~nm}$ (os chamados nanomateriais), sintetizando, modificando e manipulando estas partículas. Devido à sua composição, reduzido tamanho e forma, os nanomateriais apresentam novas propriedades que os permitem serem aplicados, por exemplo, nos campos da medicina, da eletrônica, da física, da química, e na engenharia de materiais (AITKEN et al., 2006). O óxido de érbio (ErO), por exemplo, é atualmente usado na indústria como material supercondutor e como corante de vidros e cerâmicas; na óptica na composição de fibras ópticas e como absorvente de raios ultravioleta. Ao mesmo tempo em que muitos benefícios são esperados dos produtos da nanotecnologia, há também bastante preocupação em relação ao risco que os nanomateriais podem oferecer à saúde humana e ao meio ambiente. De fato, estudos recentes mostraram que efeitos adversos podem ser causados pelos nanomateriais (LOVERN e KLAPER, 2006; HANDY e SHAW, 2007; ZURITA et al., 2007). 
A presença de nanomateriais no meio ambiente não foi ainda documentada, com exceção de poucos trabalhos (MOORE, 2006). Mesmo assim, espera-se que eventualmente estes nanomateriais sejam liberados por despejos de efluentes industriais, por exemplo, e encontrados no ambiente. A ecotoxicidade destes nanomateriais é esperada, devido às características deste tipo de material: tamanho, forma, alta relação superfície/volume, cargas de superfície, comportamento de colóides, que conferem alta reatividade com sistemas biológicos (GAGNÉ et al. ${ }^{5}$, no prelo). Por conta da existência destes novos materiais, surgiu a chamada nanotoxicologia, que investiga a toxicidade de nanomateriais sobre seres vivos - como animais, microorganismos e plantas - e inclusive seres humanos (WIKIPEDIA, 2008).

Em um estudo recente (BLAISE et al. ${ }^{6}$, no prelo), foi mostrado, dentre outros achados, que nanomateriais metálicos como o óxido de samário $(\mathrm{SmO})$, óxido de érbio (ErO), óxido de hólmio ( $\mathrm{HoO})$ e óxido de cobre-zinco-ferro $(\mathrm{CuZnFeO})$ misturados a sedimentos de referência aumentaram a toxicidade dos elutriatos preparados a partir destes sedimentos. É sabido que a granulometria dos sedimentos é capaz de modular a biodisponibilidade de diversos contaminantes (CHAPMAN e WANG, 2001), sendo que quanto maior a porcentagem de grãos menores (argila), maior a concentração de contaminantes adsorvidos no sedimento, e, conseqüentemente, menor a sua biodisponibilidade (WANG et al., 2007). No presente estudo, foi avaliada a influência deste fator sobre a toxicidade destes mesmos quatro nanomateriais metálicos, quando misturados a sedimentos com diferentes granulometrias.

\footnotetext{
${ }^{5}$ GAGNÉ, F.; GAGNON, C.; BLAISE, C. Aquatic nanotoxicology: a review. Research Trends-Current Topics in Toxicology (no prelo). 2008. ${ }^{6}$ BLAISE, C.; GAGNÉ, F.; FÉRARD, J.F.; EULLAFFROY, P. Ecotoxicity of selected nanomaterials to aquatic
organisms. Environmental Toxicology, New York, no prelo. 2008 .
} 


\subsubsection{Objetivos}

- Testar, quanto à sua toxicidade, utilizando o MARA Test, amostras de: água e sedimentos de rios, e efluentes tratados;

- Determinar a toxicidade de nanomateriais para as linhagens microbianas do MARA Test;

- Avaliar como nanomateriais se comportam em sedimentos de diferentes granulometrias, e se os sedimentos fluviais agem como um sumidouro (removendo da coluna d'água) ou como uma fonte (liberando para a coluna d'água) destes nanomateriais, acarretando implicações para os organismos bentônicos e/ou da coluna d'água. 


\subsection{Material e Métodos}

\subsubsection{Linhagens microbianas}

As onze linhagens microbianas presentes nas placas comercializadas pela NCIMB Ltd. foram as mesmas padronizadas por Gabrielson et al. (2003), provenientes de coleções de origem marinha e dulcícola (Tabela 32). A seleção das 11 linhagens pelos referidos autores levou em consideração, em uma pré-seleção de aproximadamente 150 linhagens bacterianas diferentes, os seguintes fatores: a sensibilidade a agentes tóxicos; a reprodutibilidade dos ensaios; e estabilidade durante o processo de liofilização; a reação adequada com o corante indicador de crescimento; e a variabilidade das respostas a diferentes substâncias químicas, devido a variabilidade genética entre as linhagens selecionadas. Por questões de patente e confidencialidade, não são reveladas quais linhagens estão em quais posições da placa comercializada pela NCIMB.

Tabela 32. Linhagens microbianas presentes nas placas do bioensaio "MARA".

\begin{tabular}{|c|c|c|}
\hline Linhagem & Designação & Origem \\
\hline Pseudomonas fluorescens & JG 11 & Roslagen \\
\hline Pseudomonas fluorescens & JG 59 & Blackan $^{(a)}$ \\
\hline Microbacterium trichothecenolyticum & JG 66 & Blackan $^{(a)}$ \\
\hline Pseudomonas fluorescens & JG 110 & Roslagen \\
\hline Stenotrophomonas maltophila-like, $\beta$-proteobacterium & & Skagerrak \\
\hline Aeromonas hydrophila & & Swedish drinking water \\
\hline Escherichia coli & MZ 480 & Mozambique \\
\hline Micrococcus sp. & Oban F & $\operatorname{Oban}^{(\mathrm{b})}$ \\
\hline Saccharomyces cerevisiae & Baking yeast & Sollentuna, Sweden \\
\hline Aeromonas caviae & BDE12 & Pond in Bangladesh \\
\hline Staphylococcus sp. & & Baby skin \\
\hline
\end{tabular}

(a) Swedish east coast, brackish water. (b) Scottish west coast. Adaptado de Gabrielson et al. (2003). 


\subsubsection{Placas multi-escavadas}

As placas multi-escavadas utilizadas nos ensaios são de poliestireno, compostas por 96 cavidades, e vendidas comercialmente (NCIMB Ltd., United Kingdom). Apesar de não serem esterilizadas, vêm embaladas a vácuo assepticamente antes do uso. As placas foram então armazenadas a $4^{\circ} \mathrm{C}$ até o momento do uso, assim como todos os reagentes e amostras utilizados nos ensaios. Nesta temperatura, as linhagens microbianas liofilizadas, com aproximadamente $10^{5}$ células cada, resistem sem mudanças em sua sensibilidade por até seis meses de armazenagem.

\subsubsection{Preparação das amostras}

As amostras testadas precisaram passar por um pré-tratamento antes de serem utilizadas nos bioensaios.

Para as amostras líquidas ambientais (águas fluviais e efluentes urbanos tratados), apenas procedeu-se com a filtração $(0,45 \mu \mathrm{m})$ para evitar contaminações externas.

Para as amostras de sedimento puro (rio Saint Lawrence e área de Mercier) foi preparado um elutriato na proporção 1:4 de sedimento:água destilada (exceto no experimento com nanomateriais - ver abaixo), que foi agitado por 1 hora a 12 RPM em agitador rotatório, centrifugado por 15 minutos a 3000 RPM, e o sobrenadante coletado por uma seringa esterilizada, e filtrado $(0,45 \mu \mathrm{m})$.

Para os experimentos com nanomateriais, as amostras passaram por um prétratamento diferente em alguns pontos: os elutriatos foram preparados na concentração de $13,75 \%(1,25 \mathrm{~g}$ de sedimento para $0,125 \mathrm{~g}$ de nanomaterial, com adição de $10 \mathrm{~mL}$ de água destilada), agitados por 1 hora a 12 RPM em agitador rotatório, centrifugados por 30 
minutos a 3000 RPM, o sobrenadante coletado por uma seringa esterilizada, e filtrado $(0,45 \mu \mathrm{m})$.

O preparo de todas as amostras (volume de 10mL) foi então finalizado adicionando-se $0,4 \mathrm{~g}$ de meio de cultivo (Reagente 1 ) e $200 \mu \mathrm{L}$ do indicador de crescimento cloreto de 2,3,5-trifeniltetrazólio (TTC, Reagente 4), segundo recomendações da NCIMB, fabricante do kit do teste MARA.

\subsubsection{Procedimento do ensaio}

No estágio de pré-incubação das placas usadas nos testes foram pipetados $150 \mu \mathrm{L}$ de meio de cultivo (Reagente 2) em cada cavidade contendo as 11 linhagens liofilizadas (Linha H, Figura 21). As placas então foram levadas à incubadora, em câmara úmida por 4 horas a $30^{\circ} \mathrm{C}$, para que as linhagens fossem ressuscitadas.

Após o estágio de pré-incubação, foram preparadas as diluições da amostra nas linhas B a G da placa, sendo o volume final em cada cavidade de $100 \mu \mathrm{L}$, contendo meio de cultivo e indicador de crescimento cloreto de 2,3,5-trifeniltetrazólio (TTC, Reagente 3) juntamente com a substância a ser testada em suas concentrações correspondentes. O corante indicador de crescimento (em inglês tetrazolium red) é reduzido pelos microorganismos, e precipita-se no fundo de cada cavidade, formando um pellet. $\mathrm{O}$ crescimento microbiano é estimado pelo diâmetro e densidade do pellet. Cada cavidade foi inoculada com $15 \mu \mathrm{L}$ da suspensão com os microorganismos, e as placas imediatamente levadas à incubação por 18 horas a $30^{\circ} \mathrm{C}$. Na linha A situa-se o controle negativo onde os microorganismos podem crescer sem a interferência da substância testada, e na coluna 12, 


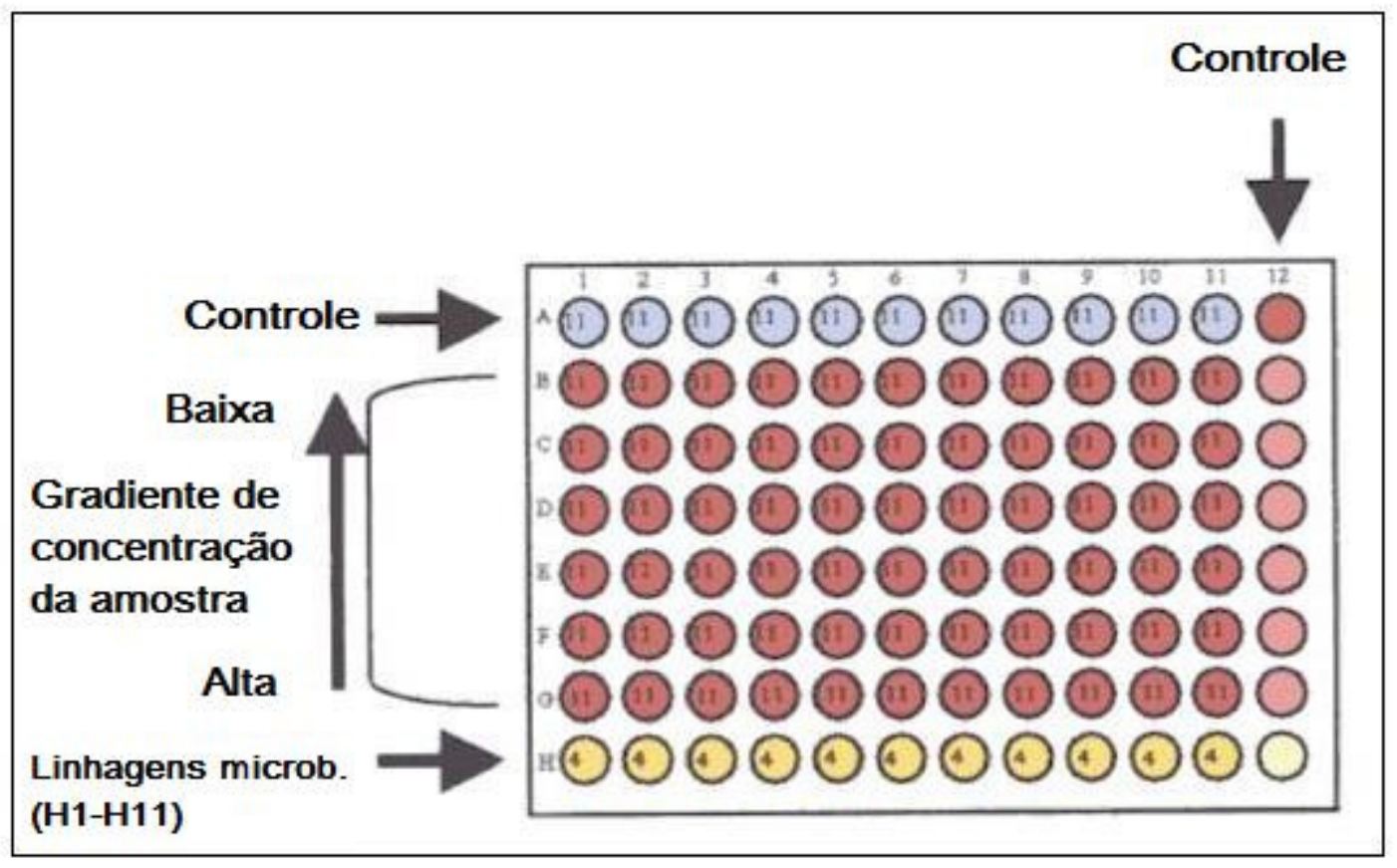

Figura 21. Desenho esquemático de uma placa multi-escavada "MARA". Onze linhagens microbianas diferentes são liofilizadas, cada uma em uma coluna (cavidades H1 a H11). A substância química (ou amostra ambiental) testada sofre uma diluição em série, onde a concentração mais alta fica na Linha $\mathrm{G}$, e a mais baixa na linha B. A linha A é o controle negativo, onde as bactérias podem crescer sem interferência da substância testada. $\mathrm{Na}$ coluna 12 localiza-se a amostra testada sem inoculação de nenhuma linhagem, para verificar se a própria amostra está contaminada ou foi contaminada durante a preparação do ensaio.

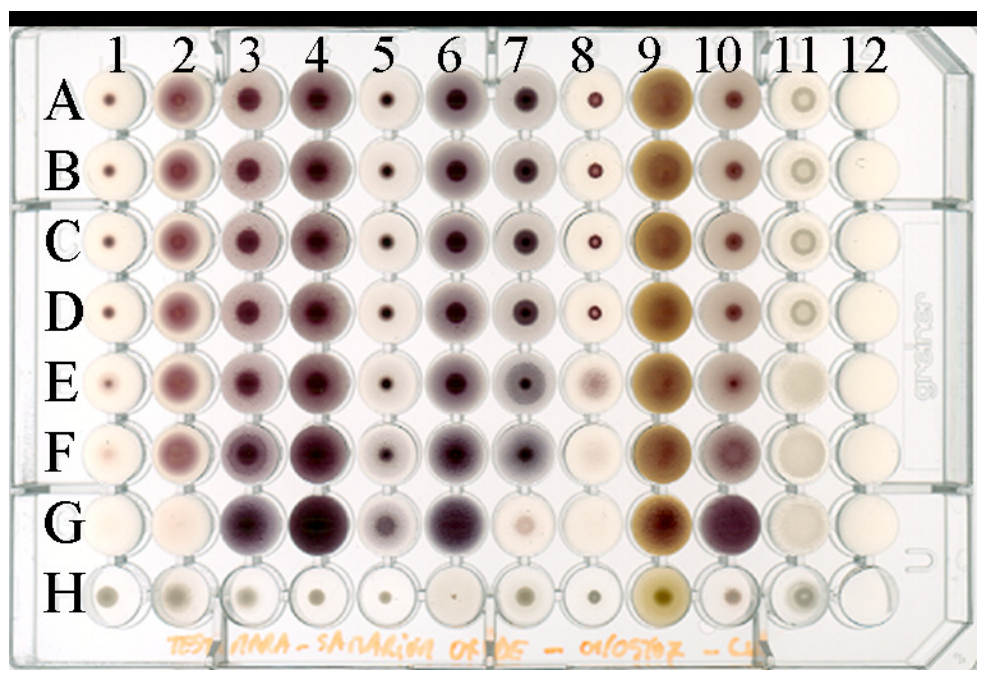

Figura 22. Imagem de uma placa do MARA Test após o período de incubação e exposição à uma amostra ambiental. 
o controle de contaminação da placa (Figura 21). Nesta coluna, há apenas o meio de cultivo, o indicador de crescimento e a amostra testada. Qualquer crescimento microbiano nesta coluna acusa a contaminação da placa, que deve ter seus resultados descartados. Para as amostras ambientais foram feitas 3 placas (3 réplicas) de cada amostra. No experimento com nanomateriais, foi feita apenas uma réplica de cada amostra.

As placas multi-escavadas são lidas por um scanner apropriado (Flatbed Scanner, Agfa 600, Agfa-Gevaert, Mortsel, Belgium), conectado em um micro-computador. As leituras são analisadas por um software (disponibilizado pela PhPlate Microplate Techniques, Estocolmo, Suécia, http://www.phplate.se), segundo Gabrielson et al. (2003), que processa a imagem, calcula e fornece os resultados do teste.

\subsubsection{Resultados esperados e tratamento dos dados}

Espera-se um padrão de resposta de crescimento para cada linhagem microbiana, devido às variadas suscetibilidades aos agentes químicos testados. Uma placa do MARA Test, após o período de incubação, e a leitura pelo scanner, tem em geral o aspecto mostrado na Figura 22.

O grau de inibição de crescimento de cada linhagem foi medido seguindo os seguintes métodos e cálculos:

\section{- Concentração tóxica microbiana (CTM)}

É a concentração que corresponde ao crescimento médio do tamanho dos pellets de cada linhagem das placas. Corresponde a um endpoint como o $\mathrm{CL}_{50}$. Como o 
formato dos pellets difere entre as linhagens, o tamanho do pellet no controle negativo é incluído na fórmula (3):

$$
C T M=c_{\min } \cdot d^{\left(\frac{P_{T o t}}{P_{0}}\right)-0,5}, \text {, onde }
$$

$\boldsymbol{c}_{\min }$ é a menor concentração utilizada, $\boldsymbol{P}_{\boldsymbol{0}}$ é o tamanho do pellet do controle de cada linhagem, $\boldsymbol{d}$ é o fator de diluição (e.g., 1/2 ou 1/3), e $\boldsymbol{P}_{\text {Tot }}$ é a soma dos tamanhos dos pellets expostos a série de diluições da amostra testada. Cada ensaio produz um conjunto de 11 valores de CTM (um para cada linhagem microbiana), que formam um gráfico, denominado "toxic fingerprint" (ou perfil tóxico). Os valores de CTM vão de 0 a $100 \%$ no caso de amostras ambientais, sendo que $0 \%$ representa a maior toxicidade possível (inibição total do crescimento), e 100\% representa a amostra testada como não sendo tóxica para a linhagem microbiana correspondente. No caso de substâncias químicas, os valores de CTM vão de zero à concentração máxima testada. No caso de elutriatos preparados a partir de sedimentos, os valores de CTM vão de zero à concentração de sedimento em relação à água adicionada para a preparação do elutriato. Os valores de CTM são calculados e fornecidos pelo software que processa a imagem da placa feita pelo scanner.

\section{- CTM médio}

É a média do conjunto dos 11 valores de CTM em um dado ensaio. 


\section{- CTM mínimo}

É o menor valor de CTM encontrado em uma placa, em um dado ensaio, dentro de suas réplicas.

Outra análise, além desta, também é possível: os perfis tóxicos podem ser comparados entre si e sua similaridade calculada através de um coeficiente de correlação. A matriz de similaridade resultante é então agrupada, através do (UPGMA)-method produzindo um dendrograma (SNEATH e SOKAL, 1973). Neste dendrograma, as substâncias são ligadas entre si por linhas verticais de acordo com a similaridade entre seus perfis tóxicos, que podem ser quantificados pelo eixo-x. Estes cálculos de similaridade e agrupamento no dendrograma foram feitos pelo software $\mathrm{PhP}$ da PhPlate Microplate Techniques.

\subsubsection{Monitoramento dos resultados do controle negativo}

Os resultados do controle negativo obtidos de cada linhagem e de cada ensaio realizado foram tabulados, com o objetivo de se realizar um monitoramento da resposta de cada linhagem ao longo da realização de todo o projeto, como em uma carta-controle. O monitoramento do crescimento microbiano em cada controle negativo de cada placa foi analisado através da comparação com a média, o desvio padrão e o coeficiente de variação dos resultados anteriores. Desta forma, pôde-se verificar se o crescimento das linhagens no controle negativo ocorreu dentro do intervalo esperado (média $\pm 2 \mathrm{x}$ desvio padrão). 


\subsubsection{Amostras testadas}

\subsubsection{Sedimentos do rio Saint Lawrence, Montreal, Canadá}

Sete pontos no rio Saint Lawrence, na região de Montreal, foram selecionados para o teste de amostras de sedimentos: Ile de Grace, Lac St-François, Port de Montréal, Iles Robinet, Ilet Vert, Amont-CUM e Ile Beauregard. As amostras de sedimento foram coletadas em Agosto de 2007, e mantidas a $-20^{\circ} \mathrm{C}$ até o momento dos testes.

\subsubsection{Usina de Mercier - Água e sedimento}

Oito amostras de água e sedimento do entorno da área de uma usina de processamento de óleo, que atualmente está sendo descontaminada, foram testadas quanto à sua toxicidade:

1. Água: Amont, Aval 1, Aval 2, Drain.

2. Sedimento: Amont, Aval 1, Aval 2, Drain.

Na Figura 23, há uma imagem ilustrativa desta área de estudo, e da localização dos pontos de amostragem. Há cerca de 20 anos atrás, foi instalada na área uma usina para processar diversos tipos de óleos, que eram depositados em lagoas, até o momento de serem processados e incinerados. Após algum tempo, foi constatada a contaminação da água subterrânea do local (e do lençol freático) por estas lagoas, fazendo com que a usina fosse fechada. Algumas destas lagoas foram cobertas com terra, e outras não. Desde então, a água subterrânea é bombeada para a superfície, onde recebe tratamento primário e secundário, e é posteriormente despejada no Little Brook Canal. Este, por sua vez, deságua no Esturgeon River depois de cerca 
de 300 metros (Bourchard, informação verbal) ${ }^{7}$. Os pontos escolhidos para coleta de amostras de água e sedimento são as já citadas, e indicadas na Figura 23: O Ponto Amont situa-se no Esturgeon River a montante da foz do Little Brook Canal. Os pontos Aval 1 e Aval 2 situam-se a jusante do Little Brook Canal. O ponto Drain situa-se no ponto de despejo da água subterrânea já tratada no canal supracitado. A determinação de dois pontos de coleta a jusante do canal foi causada pela existência de uma pluma de dispersão da água do Canal no Esturgeon River. Segundo Bourchard (informação verbal) ${ }^{7}$, o Ponto Aval 2 localiza-se fora da pluma, e teria, majoritariamente, água proveniente do Esturgeon River. Já o ponto Aval 1 teria, majoritariamente, água despejada pelo Little Brook Canal. As amostras de água e sedimento foram coletadas e testadas após 1 e 2 dias, respectivamente, permanecendo a $4^{\circ} \mathrm{C}$ até o momento dos testes.

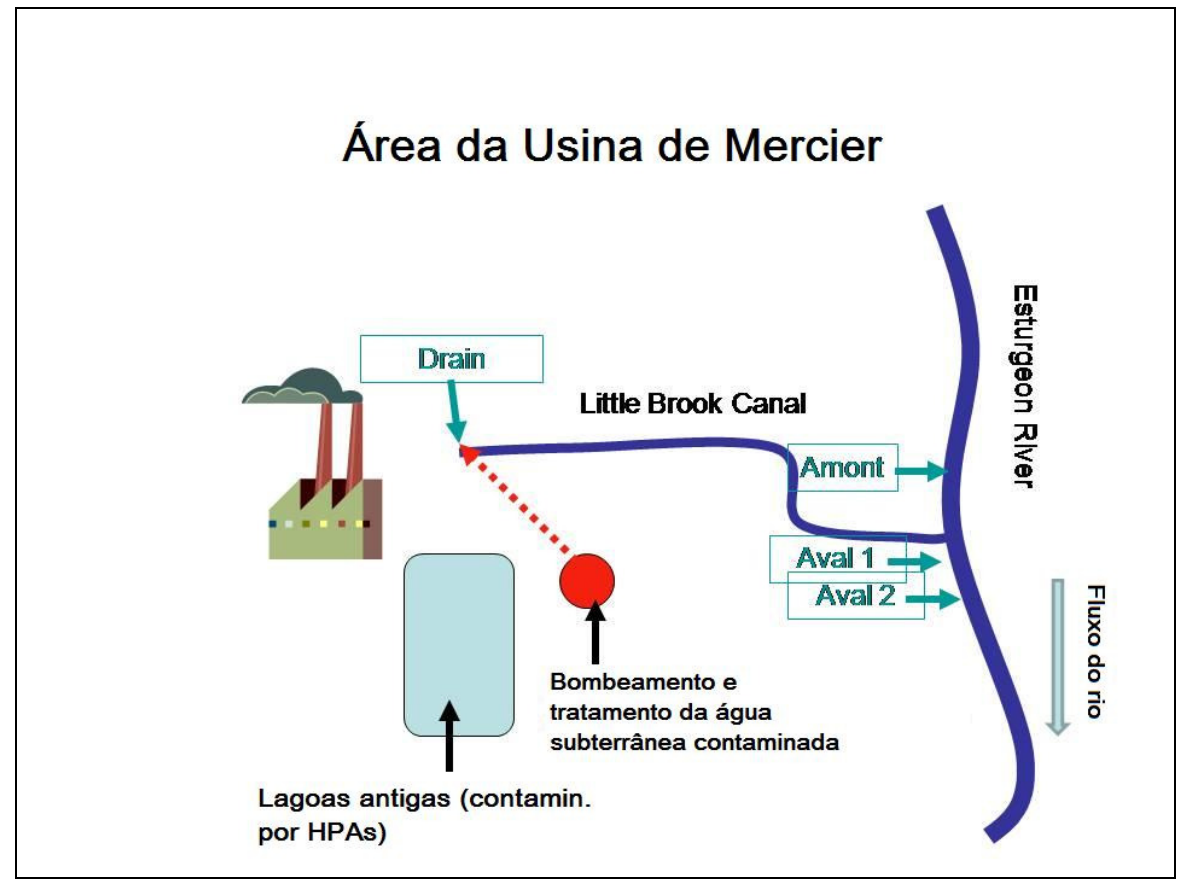

Figura 23. Esquema ilustrativo da área de estudo da Usina Mercier, em Montreal, Canadá, segundo Bourchard (informação verbal) ${ }^{7}$.

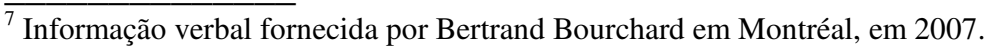




\subsubsection{Efluentes urbanos}

Cinco amostras de efluentes urbanos tratados foram testadas quanto à sua toxicidade:

1. Estação de tratamento de esgoto de Saint Basile (afluente de origem inteiramente doméstica);

2. Estação de tratamento de esgoto de Laschenaie-Mascouche (afluente de origem doméstica e hospitalar);

3. Estação de tratamento de esgoto de Montreal (afluente de origem doméstica e industrial), com três amostras: (1) efluente tratado não-desinfetado, (2) efluente tratado desinfetado pela técnica de injeção de ozônio "O $\mathrm{O}_{3}$ hydro-injection”, e (3) efluente tratado desinfetado pela técnica de injeção de ozônio " $\mathrm{O}_{3}$ colonne".

\subsubsection{Nanomateriais}

A toxicidade de quatro nanomateriais misturados a amostras de sedimento (cada nanomaterial tratado individualmente) foi testada, levando-se em conta a influência da granulometria destes sedimentos na toxicidade causada às linhagens microbianas presentes no MARA Test. Os nanomateriais testados foram:

1. Óxido de samário $\left(\mathrm{Sm}_{2} \mathrm{O}_{3}\right)$, Sigma-Aldrich, $99,9 \%$

2. Óxido de érbio $\left(\mathrm{Er}_{2} \mathrm{O}_{3}\right)$, Sigma-Aldrich, $99,9 \%$

3. Óxido de Hólmio $\left(\mathrm{Ho}_{2} \mathrm{O}_{3}\right)$, Sigma-Aldrich, 99,9\%

4. Óxido de $\mathrm{Cu}-\mathrm{Zn}-\mathrm{Fe}\left(\mathrm{CuZnFe}_{4} \mathrm{O}_{4}\right)$, Sigma-Aldrich, $98,5 \%$

Este experimento foi realizado em cinco etapas: na primeira, cada nanomaterial foi testado, puro, diluído em água bidestilada, na concentração máxima de $500 \mathrm{mg} \mathrm{L}^{-1}$. A 
solução preparada nesta concentração foi agitada por 1 hora a 12 RPM em agitador rotatório. Após a agitação, $100 \mathrm{~mL}$ da solução foram filtrados por um filtro de membrana de celulose $(0,45 \mu \mathrm{m})$ pré-pesado. A membrana foi então seca $\left(60^{\circ} \mathrm{C}\right.$ por $\left.24 \mathrm{~h}\right)$ e pesada novamente, para determinar, por diferença, a concentração inicial do nanomaterial testado.

Na segunda etapa, o "sedimento artificial", composto de diversas combinações de argila (Fisher Scientific, Cat. $\mathrm{N}^{\mathrm{o}}$ AC21174-0010) e areia (Fisher Scientific, Cat. N $\mathrm{N}^{\mathrm{o}}$ 29405107), foi testado isoladamente para verificar se o sedimento, per se, seria tóxico às linhagens microbianas do teste MARA. As combinações de argila e areia testadas nesta etapa foram: $0 \%$ de argila e $100 \%$ de areia; $40 \%$ de argila e $60 \%$ de areia; e $100 \%$ de argila e $0 \%$ de areia, na proporção de $1,25 \mathrm{~g}$ de sedimento para $10 \mathrm{~mL}$ de água destilada.

$\mathrm{Na}$ terceira etapa, cada nanomaterial foi misturado ao sedimento "artificial" composto de areia e argila, em diferentes proporções. A partir desta mistura, foi preparado um elutriato, na concentração de $13,75 \%$ (1,25 g de sedimento para $0,125 \mathrm{~g}$ de nanomaterial, com adição de $10 \mathrm{~mL}$ de água destilada), o qual foi avaliado quanto à sua toxicidade pelo teste MARA. As proporções de areia e argila para cada nanomaterial testado estão dispostos na Tabela 33.

Tabela 33. Proporções (\%) de areia e argila utilizadas na composição de um sedimento "artificial", para cada um dos quatro nanomateriais testados.

\begin{tabular}{cccccccc}
\hline \multicolumn{2}{c}{ SmO } & \multicolumn{2}{c}{ ErO } & \multicolumn{2}{c}{ HoO } & \multicolumn{2}{c}{ CuZnFeO } \\
Argila & Areia fina & Argila & Areia fina & Argila & Areia fina & Argila & Areia fina \\
\hline 0 & 100 & 0 & 100 & 0 & 100 & 0 & 100 \\
20 & 80 & 20 & 80 & 20 & 80 & 20 & 80 \\
40 & 60 & - & - & - & - & 40 & 60 \\
60 & 40 & 60 & 40 & 60 & 40 & - & - \\
80 & 20 & - & - & - & - & 80 & 20 \\
100 & 0 & 100 & 0 & 100 & 0 & 100 & 0 \\
\hline
\end{tabular}


Na quarta etapa, os sedimentos do rio Saint Lawrence foram testados isoladamente para verificar se o sedimento, per se, seria tóxico às linhagens microbianas do MARA Test. De maneira semelhante à segunda etapa, os elutriatos foram preparados na proporção de $1,25 \mathrm{~g}$ de sedimento para $10 \mathrm{~mL}$ de água destilada.

Na quinta etapa, os mesmos nanomateriais foram testados quanto à sua toxicidade, mas desta vez misturados a amostras de sedimentos coletados no rio Saint Lawrence, com granulometria conhecida, a fim de verificar a ocorrência de respostas semelhantes às obtidas com os sedimentos artificiais, pelo teste MARA. Elutriatos foram preparados com cada sedimento, e cada nanomaterial, individualmente, na concentração de $13,75 \%(1,25 \mathrm{~g}$ de sedimento para $0,125 \mathrm{~g}$ de nanomaterial, com adição de $10 \mathrm{~mL}$ de água destilada). As amostras de sedimento foram escolhidas baseando-se na granulometria, levando em consideração a fração de partículas finas de cada sedimento, ou seja, a fração cujas partículas sejam menores que 0,063 mm (Tabela 34). A classificação granulométrica segue padrões do Environment Canada (2002).

Tabela 34. Composição granulométrica das amostras de sedimento do rio Saint Lawrence testadas juntamente com nanomateriais. Classificação granulométrica segundo Environment Canada (2002).

\begin{tabular}{ccccc}
\hline Ponto de coleta & $\begin{array}{c}\mathbf{0 , 0 6 3} \text { mm ou menos } \\
\text { (areia fina) (\%) }\end{array}$ & $\begin{array}{c}\mathbf{0 , 0 3 3 1} \text { mm ou menos } \\
\text { (silte) (\%) }\end{array}$ & $\begin{array}{c}\mathbf{0 , 0 0 4} \text { mm ou menos } \\
\text { (argila) (\%) }\end{array}$ & $\begin{array}{c}\text { Partículas } \\
\text { Finas } \\
\text { Total (\%) }\end{array}$ \\
\hline Ile Robinet & 12,3 & 3,6 & 5 & 20,9 \\
Ile Beauregard & 30,9 & 7 & 9 & 46,9 \\
Islet Vert & 3,6 & 13,9 & 41,6 & 59,1 \\
Ile de Grâce & 2,8 & 81,6 & 15,2 & 99,6 \\
\hline
\end{tabular}




\subsection{Resultados}

\subsubsection{Monitoramento dos resultados do controle negativo}

O acompanhamento dos resultados do controle negativo das 11 linhagens microbianas mostrou que o teste MARA é um teste com bastante reprodutibilidade, em relação à resposta das linhagens. Os valores médios de crescimento das linhagens microbianas, assim como o desvio padrão e o coeficiente de variação podem ser consultados na Tabela 35. As médias correspondem ao tamanho do pellet dado pelo software, por isso diferem bastante entre si. Os valores obtidos de coeficiente de variação estiveram entre $5,8 \%$ a $35,2 \%$, considerados satisfatórios.

Tabela 35. Resultados do controle negativo das 11 linhagens microbianas presentes no teste MARA. Os valores médios correspondem ao tamanho do pellet ao final do período de incubação, dado pelo software que processou a imagem das placas.

\begin{tabular}{lccccccccccc}
\hline Linhagens & $\mathbf{1}$ & $\mathbf{2}$ & $\mathbf{3}$ & $\mathbf{4}$ & $\mathbf{5}$ & $\mathbf{6}$ & $\mathbf{7}$ & $\mathbf{8}$ & $\mathbf{9}$ & $\mathbf{1 0}$ & $\mathbf{1 1}$ \\
\hline Média & 49,2 & 149,6 & 114,1 & 299,8 & 34,4 & 248,5 & 135,4 & 38,6 & 249,6 & 143,0 & 29,9 \\
Desv. Padrão & 5,2 & 52,7 & 13,5 & 17,4 & 4,5 & 17,7 & 18,0 & 4,7 & 42,3 & 19,4 & 10,0 \\
C.V. (\%) & 10,5 & 35,2 & 11,9 & 5,8 & 13,1 & 7,1 & 13,3 & 12,1 & 17,0 & 13,6 & 33,4 \\
\hline
\end{tabular}

\subsubsection{Sedimentos do rio Saint Lawrence, Montreal, Canadá}

Os perfis tóxicos contendo os valores de CTM das amostras de sedimento coletadas no rio Saint Lawrence estão dispostos na Figura 24. Para estas amostras, o bioensaio MARA não indicou toxicidade significativa. Para a maioria das amostras, a linhagem 1 foi a mais sensível, sendo dela a maioria dos valores de CTM mínimo. Os valores de CTM médio e CTM mínimo para estes pontos de coleta estão dispostos na Tabela 36. 


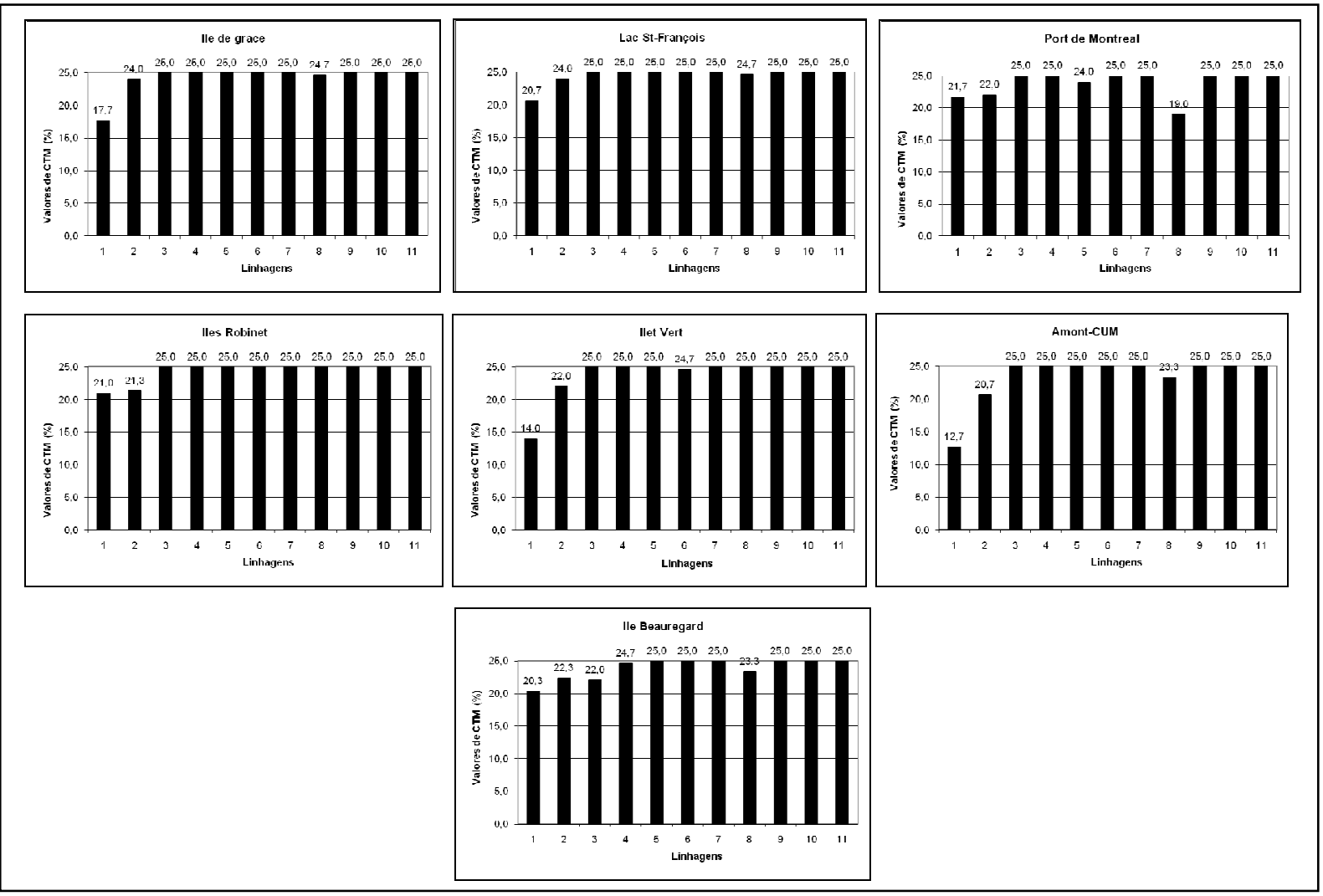

Figura 24. Perfis tóxicos das amostras de sedimento coletadas no rio Saint Lawrence, Montreal, Canadá.

Tabela 36. Valores de CTM Médio e CTM Mínimo (ambos em \%) obtidos nos testes com amostras de sedimento coletadas no rio Saint Lawrence, Montreal, Canadá. Para estas amostras, o valor máximo possível para o CTM (Concentração tóxica microbiana) é 25\%, sendo que este valor indica ausência de toxicidade.

\begin{tabular}{lcc}
\hline Pontos de coleta & CTM Médio & CTM Mínimo \\
\hline Ile de Grace & 25 & 14 \\
Lac St-François & 25 & 16 \\
Port de Montréal & 24,3 & 11 \\
Iles Robinet & 25 & 17 \\
Ilet Vert & 24,7 & 13 \\
Amont-CUM & 24,7 & 15 \\
Ile Beauregard & 25 & 16 \\
\hline
\end{tabular}




\subsubsection{Usina de Mercier}

Os perfis tóxicos contendo os valores de CTM das amostras de água coletadas no entorno da Usina de Mercier estão dispostos na Figura 25. Os valores de CTM médio e CTM mínimo para estas amostras estão dispostos na Tabela 37. As quatro amostras de água avaliadas aqui apresentaram diferentes perfis tóxicos, demonstrando o efeito dos agentes tóxicos sobre as linhagens e o efeito da mistura das águas subterrâneas tratadas, das águas do Little Brook Canal e as do Esturgeon River. Pelos resultados obtidos, pode-se dizer que a amostra mais tóxica foi a Amont, e a menos tóxica foi a Aval 1.
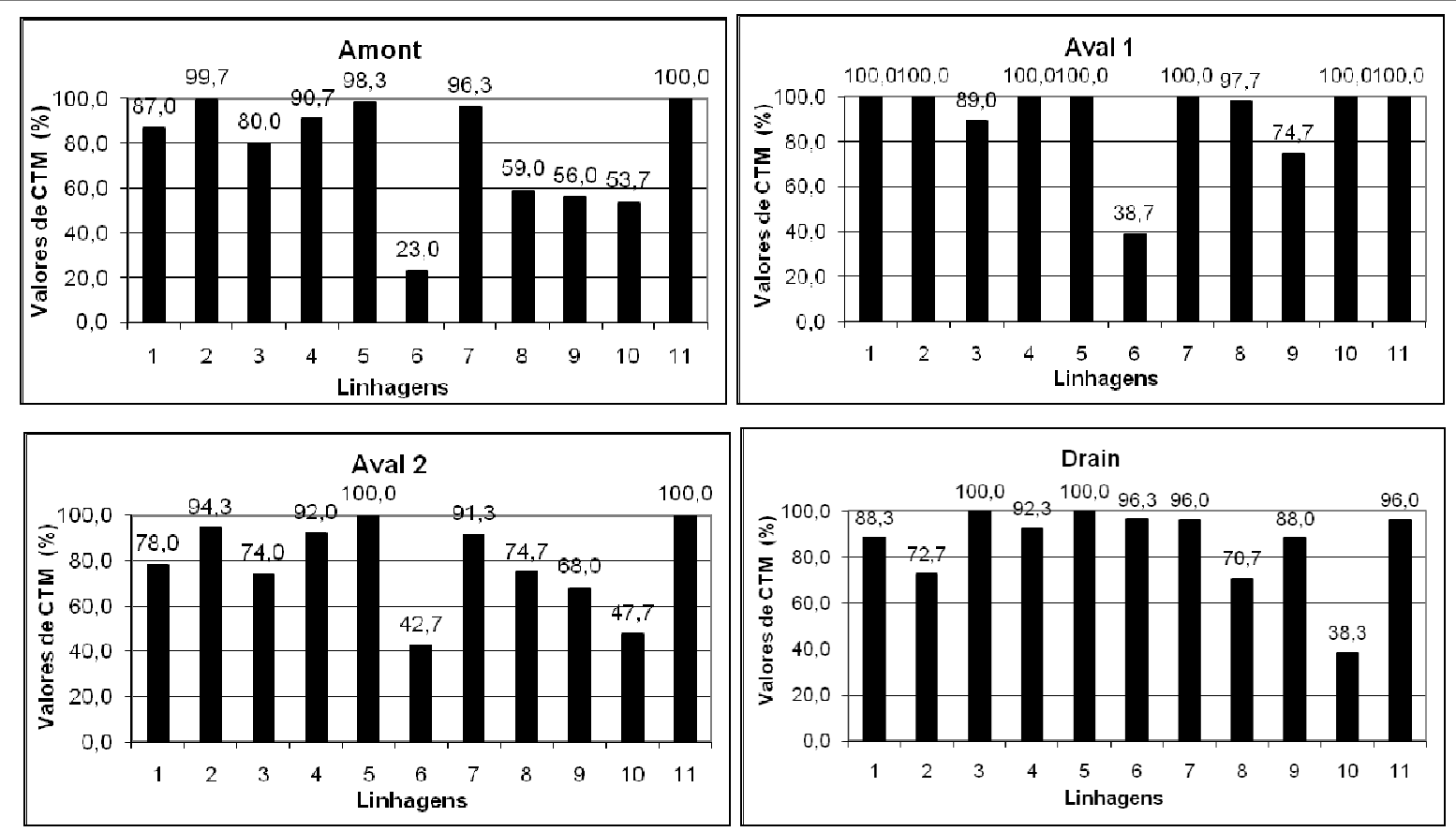

Figura 25. Perfis tóxicos das amostras de água coletadas no entorno da Usina de Mercier, em Montreal, Canadá.

Tabela 37. Valores de CTM Médio e CTM Mínimo (ambos em \%) obtidos nos testes com amostras de água coletadas no entorno da Usina Mercier, Montreal, Canadá. Para estas amostras, o valor máximo possível para o CTM (Concentração tóxica microbiana) é 100\%, sendo que este valor indica ausência de toxicidade.

\begin{tabular}{lcc}
\hline Pontos de coleta & CTM Médio & CTM Mínimo \\
\hline Amont & 71,3 & 11 \\
Aval 1 & 95 & 32 \\
Aval 2 & 77 & 21 \\
Drain & 85,3 & 32 \\
\hline
\end{tabular}


Os perfis tóxicos contendo os valores de CTM das amostras de sedimento coletadas no entorno da Usina de Mercier estão dispostos na Figura 26. Para estas amostras, o bioensaio MARA não indicou altos níveis de toxicidade. O ponto mais tóxico, em relação ao sedimento foi o Ponto Drain, e o menos tóxico foi o Ponto Aval 2. Os valores de CTM médio e CTM mínimo para estas amostras estão dispostos na Tabela 38.
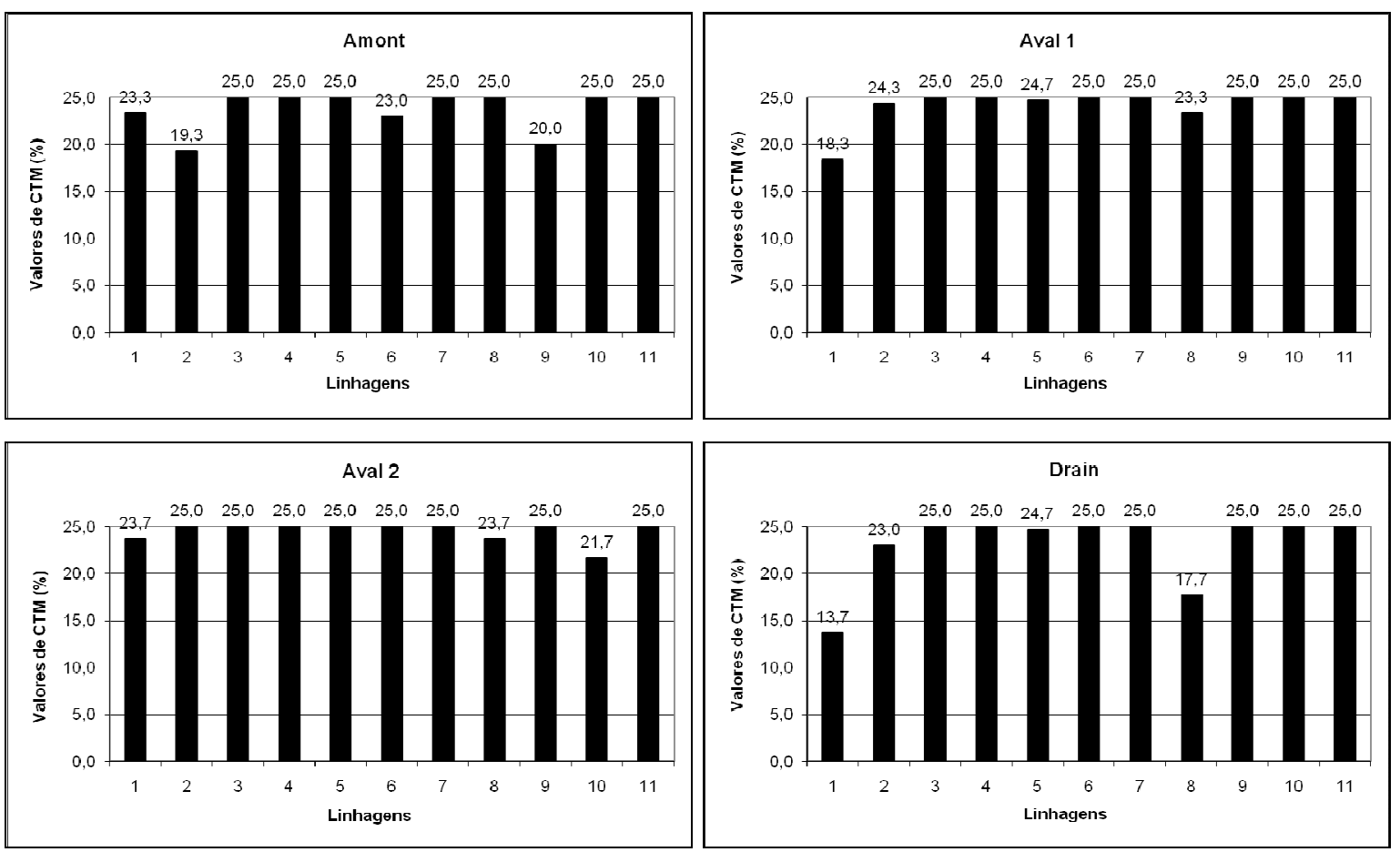

Figura 26. Perfis tóxicos das amostras de sedimento coletadas no entorno da Usina de Mercier, em Montreal, Canadá.

Tabela 38. Valores de CTM Médio e CTM Mínimo (ambos em \%) obtidos nos testes com amostras de sedimento coletadas no entorno da Usina de Mercier, Montreal, Canadá. Para estas amostras, o valor máximo possível para o CTM (Concentração tóxica microbiana) é $25 \%$, sendo que este valor indica ausência de toxicidade.

\begin{tabular}{lcc}
\hline Pontos de coleta & CTM Médio & CTM Mínimo \\
\hline Amont & 25 & 9,8 \\
Aval 1 & 25 & 11 \\
Aval 2 & 25 & 15 \\
Drain & 24,3 & 6,1 \\
\hline
\end{tabular}




\subsubsection{Efluentes urbanos}

Os perfis tóxicos contendo os valores de CTM das amostras de efluentes urbanos tratados estão dispostos nas Figuras 27 (Saint Basile e Laschenaie-Mascouche) e 28 (Montreal). Os valores de CTM Médio e CTM Mínimo de Saint Basile e LaschenaieMascouche estão dispostos na Tabela 39, e os mesmos valores da estação de Montreal estão dispostos na Tabela 40. As amostras de Saint Basile e Laschenaie-Mascouche avaliadas não causaram toxicidade significativa às linhagens do teste MARA, enquanto que a amostra de Montreal sem desinfecção causou significativa toxicidade, como mostra o perfil tóxico da Figura 28. As amostras que receberão tratamento de desinfecção tiveram a sua toxicidade às linhagens microbianas bastante reduzida.
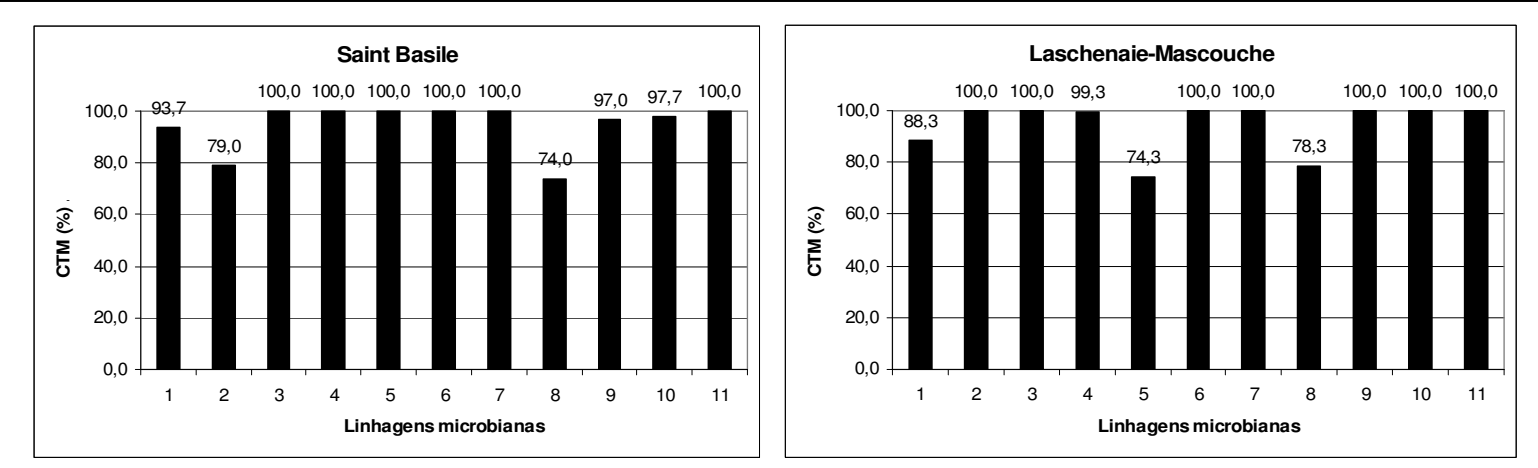

Figura 27. Perfis tóxicos das amostras de efluentes tratados das estações de tratamento de esgotos de Saint Basile e Laschenaie-Mascouche.

Tabela 39. Valores de CTM Médio e CTM Mínimo (ambos em \%) obtidos nos testes com amostras de efluente tratado coletadas nas estações de tratamento de esgotos de Saint Basile e Laschenaie-Mascouche, Canadá. Para estas amostras, o valor máximo possível para o CTM (Concentração tóxica microbiana) é 100\%, sendo que este valor indica ausência de toxicidade.

\begin{tabular}{lcc}
\hline Pontos de coleta & CTM Médio & CTM Mínimo \\
\hline Saint Basile & 92 & 37 \\
Laschenaie-Mascouche & 95,7 & 23 \\
\hline
\end{tabular}




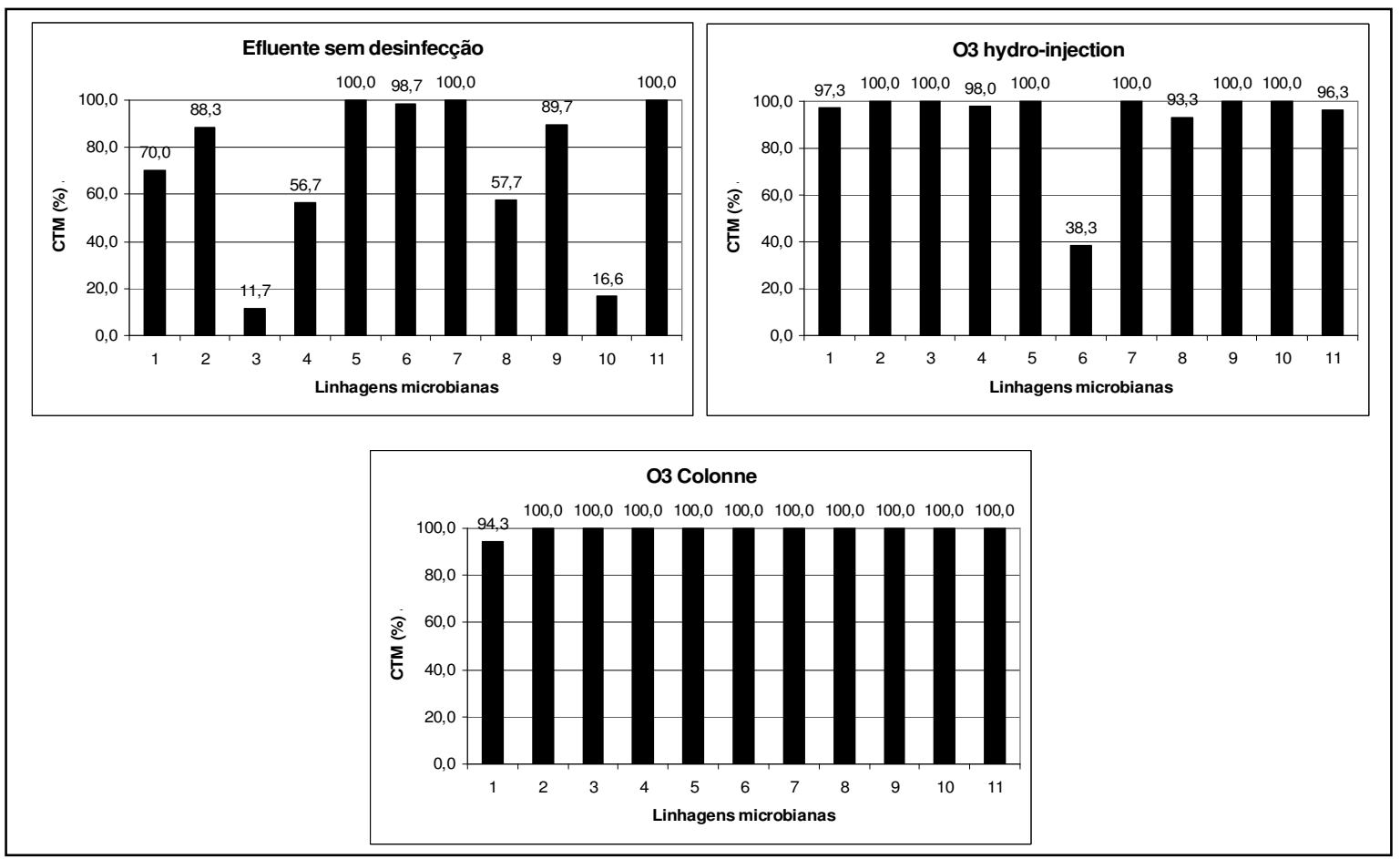

Figura 28. Perfis tóxicos das amostras de efluentes da estação de tratamento de esgotos de Montreal: efluente tratado, mas ainda sem desinfecção; desinfetado pela técnica " $\mathrm{O}_{3}$ hydroinjection", e pela técnica " $\mathrm{O}_{3}$ colonne".

Tabela 40. Valores de CTM Médio e CTM Mínimo (ambos em \%) obtidos nos testes com amostras de efluente tratado coletadas na estação de tratamento de esgotos de Montreal, Canadá. Para estas amostras, o valor máximo possível para o CTM (Concentração tóxica microbiana) é $100 \%$, sendo que este valor indica ausência de toxicidade.

\begin{tabular}{lcc}
\hline Pontos de coleta & CTM Médio & CTM Mínimo \\
\hline Não-desinfetado & 59 & 8 \\
O3 hydro-injection & 94 & 29 \\
O3 Colonne & 100 & 86 \\
\hline
\end{tabular}




\subsubsection{Nanomateriais}

\subsubsection{Primeira etapa}

Nesta primeira etapa, foi analisado se cada nanomaterial exercia algum efeito tóxico sobre as linhagens microbianas do teste MARA. Na Figura 22 é possível ver a imagem da placa onde se testou o óxido de samário, onde cada linhagem teve uma sensibilidade diferente a esta substância. Os perfis tóxicos (gráficos de barras) de cada nanomaterial estão mostrados na Figura 29, mostrando os valores de CTM de cada linhagem para cada um dos quatro nanomateriais testados. Por exemplo, a linhagem 1 se mostrou a mais sensível ao $\mathrm{SmO}\left(\mathrm{CTM}=7 \mathrm{mg} \mathrm{L}^{-1}\right)$, enquanto que as linhagens $3,4,6$, e 9 se mostraram menos sensíveis $\left(\mathrm{CTM}=243 \mathrm{mg} \mathrm{L}^{-1}\right)$. Os resultados brutos estão na Tabela 58/Apêndice A. A Figura 29 mostra também o resultado do método "Cluster analysis", que agrupou de acordo com os coeficientes de correlação, os nanomateriais com efeitos tóxicos semelhantes. É possível notar, mesmo visualmente, a semelhança entre os perfis tóxicos dos nanomateriais $\mathrm{ErO}$ e $\mathrm{CuZnFeO}$, que são os dois mais próximos segundo a análise de correlação. Esta semelhança na toxicidade parece indicar, segundo Gabrielson et al. (2003) que estas substâncias tem o mesmo modo de ação sobre os microorganismos do teste MARA. Apesar de os valores de CTM Médio dos quatro nanomateriais não serem muito diferentes entre si, variando entre 67 e $114 \mathrm{mg} \mathrm{L}^{-1}$, algumas linhagens microbianas apresentaram respostas bastante diferentes, como por exemplo as respostas das linhagens frente ao $\mathrm{SmO}$, que se distanciam por até duas ordens de magnitude (7 e $243 \mathrm{mg} \mathrm{L}^{-1}$ ). Os valores de CTM Médio e CTM Mínimo (ambos em $\mathrm{mg} \mathrm{L}^{-1}$ ) desta primeira etapa estão dispostos na Tabela 41. 


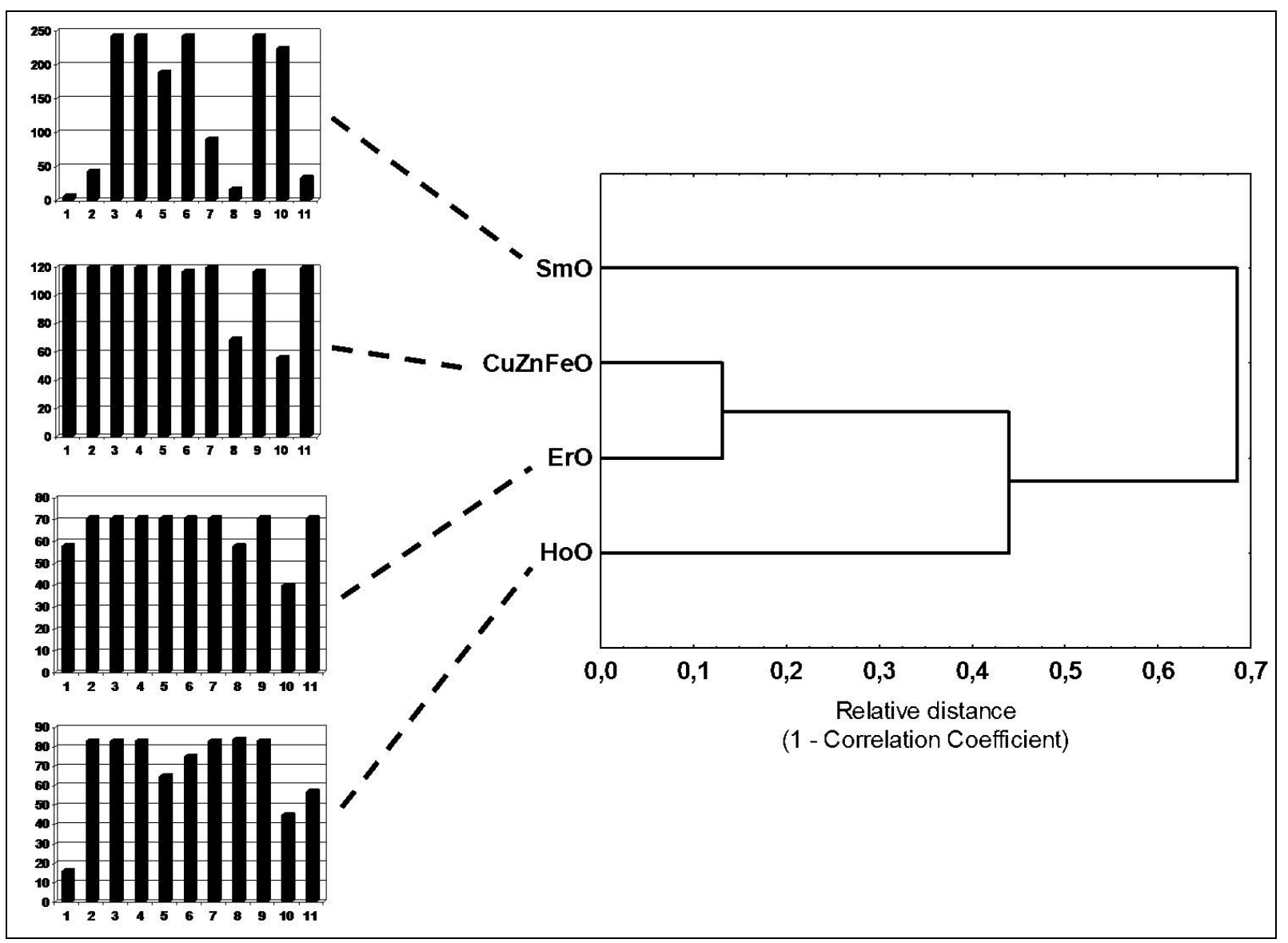

Figura 29. Resultados do método "Cluster analysis" dos quarto nanomateriais testados, baseado nos respectivos perfis tóxicos $(\mathrm{n}=11$ valores de CTM das linhagens microbianas geradas com o teste MARA para cada nanomaterial, em $\mathrm{mg} \mathrm{L}^{-1}$ ). Os quatro gráficos de barras mostram os perfis tóxicos dos quatro nanomateriais metálicos testados.

Tabela 41. Valores de CTM Médio e CTM Mínimo (ambos em $\mathrm{mg} \mathrm{L}^{-1}$ ) obtidos com o teste MARA para os quatro nanomateriais testados ( $\mathrm{SmO}, \mathrm{ErO}, \mathrm{HoO}$, e $\mathrm{CuZnFeO}$ ). Os valores máximos possíveis - que indicam ausência de toxicidade - para cada nanomaterial são, respectivamente, $243 ; 70,9 ; 83,2 ;$ e $120 \mathrm{mg} \mathrm{L}^{-1}$.

\begin{tabular}{lcc}
\hline Amostras & CTM Médio $\left(\mathbf{m g ~ L}^{\mathbf{- 1}}\right)$ & CTM Mínimo $\left(\mathbf{m g ~ L}^{-\mathbf{1}}\right)$ \\
\hline & & \\
Primeira etapa & & 7 \\
SmO & 90 & 40 \\
$\mathrm{ErO}$ & 69 & 16 \\
$\mathrm{HoO}$ & 67 & 56 \\
$\mathrm{CuZnFeO}$ & 114 & \\
\hline
\end{tabular}




\subsubsection{Segunda etapa}

$\mathrm{Na}$ segunda etapa, foi testada a toxicidade de diversas composições de um "sedimento artificial", feito a partir de areia e argila. Esta etapa foi realizada para se certificar de que o sedimento isoladamente não exerce efeitos tóxicos significativos sobre as linhagens microbianas. Todas as proporções testadas de misturas de areia e argila demonstraram ausência significativa de toxicidade para as linhagens microbianas do teste MARA, permitindo que se prosseguisse para a terceira etapa, onde os nanomateriais foram misturados aos sedimentos artificiais. Os resultados estão dispostos na Figura 30. Os valores de CTM Médio e CTM Mínimo (ambos em \%) desta etapa estão dispostos na Tabela 42.

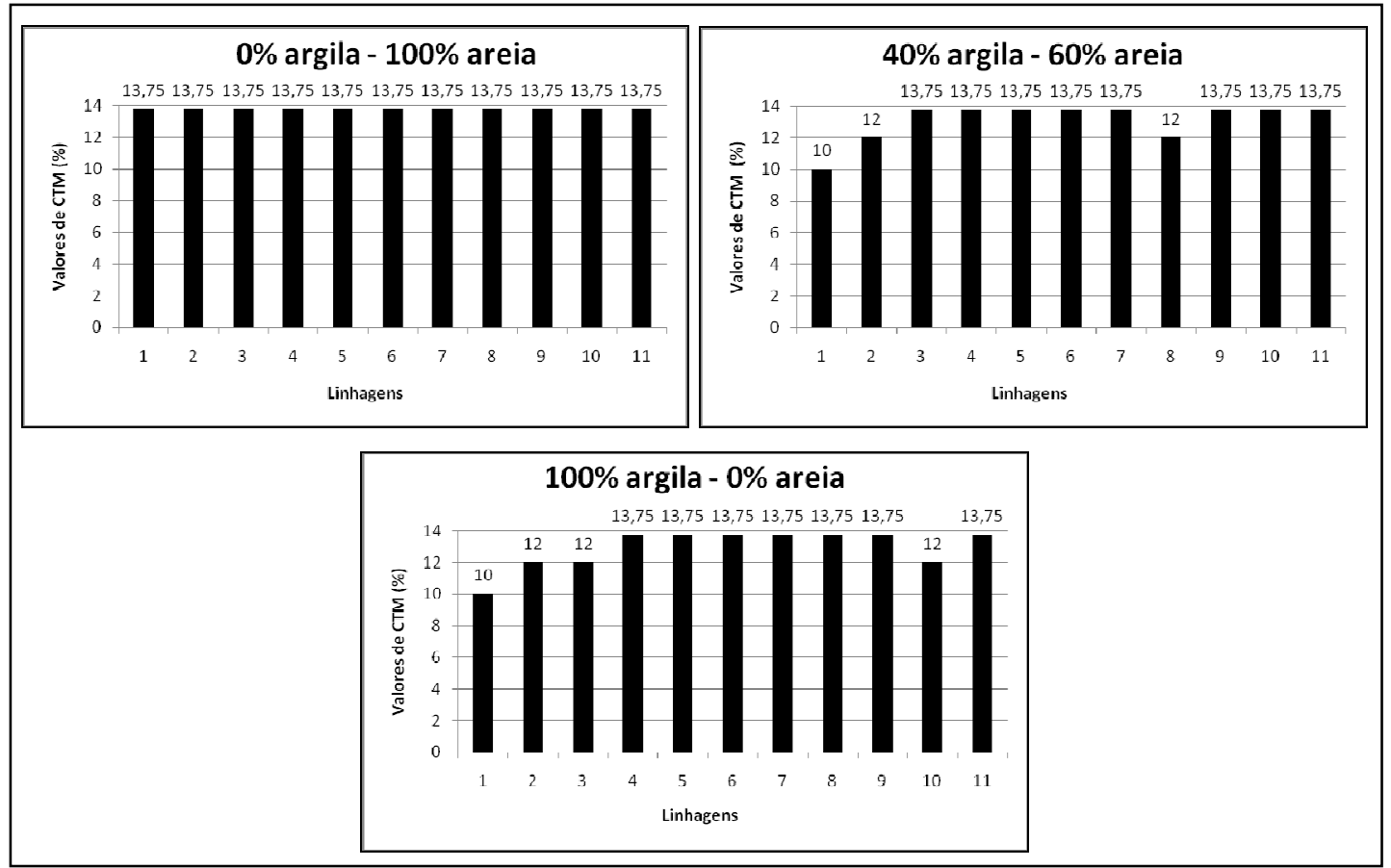

Figura 30. Perfis tóxicos das diversas combinações de argila e areia dos sedimentos artificiais testados. 
Tabela 42. Valores de CTM Médio e CTM Mínimo (ambos em \%) obtidos das diversas combinações de argila e areia dos sedimentos artificiais testados. Para estas amostras, o valor máximo possível para o CTM (Concentração tóxica microbiana) é 13,75\%, sendo que este valor indica ausência de toxicidade.

\begin{tabular}{lcc}
\hline Amostras & CTM Médio & CTM Mínimo \\
\hline & & \\
Segunda etapa & & \\
$0 \%$ argila - 100\% areia & 13,75 & 7 \\
$40 \%$ argila - 60\% areia & 13,75 & 10 \\
$100 \%$ argila - 0\% areia & 13,75 & 10 \\
\hline
\end{tabular}

\subsubsection{Terceira etapa}

Na terceira etapa, cada nanomaterial foi misturado separadamente aos sedimentos artificiais compostos de areia e argila, em diferentes proporções, segundo a Tabela 33. Os perfis tóxicos de cada nanomaterial dos testes desta etapa estão dispostos na Figura 31. Os valores de CTM Médio e CTM Mínimo (ambos em \%) desta etapa estão dispostos na Tabela 43. Para o SmO foi possível observar que quanto maior a proporção de argila na composição do sedimento, menor a toxicidade deste nanomaterial para as linhagens microbianas. A análise estatística por ANOVA (significância de 5\%) corrobora esta observação (Tabela 43). O agrupamento por cluster analysis também demonstra esta influência da granulometria, quando agrupa mais estreitamente os sedimentos com $60 \%$ ou mais de argila em sua composição (Figura 32). Para o ErO e para o $\mathrm{HoO}$, em geral foram observados efeitos semelhantes, entretanto a análise ANOVA não indicou diferença significativa entre os tratamentos. Entretanto, o agrupamento por cluster analysis sugere um gradiente de similaridade entre os tratamentos para o óxido de hólmio, de acordo com a proporção de argila (Figura 32). Não foi observada influência da granulometria sobre a toxicidade de $\mathrm{CuZnFeO}$ sobre os microorganismos do teste MARA, após o teste com diversas proporções de argila e areia, indicando que provavelmente a adsorção/dessorção deste nanomaterial não é influenciada pelo tamanho dos grãos do sedimento. 
Tabela 43. Valores de CTM Médio e CTM Mínimo (ambos em \%) obtidos das diversas combinações de argila e areia dos sedimentos artificiais testados, com a adição dos nanomateriais. Para estas amostras, o valor máximo possível para o CTM é 13,75\%, sendo que este valor indica ausência de toxicidade. As letras após os valores indicam diferença significativa segundo o teste ANOVA $(\mathrm{p}<0,05)$, em relação ao tratamento com $100 \%$ areia.

\begin{tabular}{|c|c|c|}
\hline Amostras & CTM Médio & CTM Mínimo \\
\hline \multicolumn{3}{|l|}{ Terceira etapa } \\
\hline \multicolumn{3}{|l|}{$\mathrm{SmO}$} \\
\hline $0 \%$ argila $-100 \%$ areia & 2,5 & 0,83 \\
\hline $20 \%$ argila $-80 \%$ areia & 2,8 & 0,85 \\
\hline $40 \%$ argila $-60 \%$ areia & $3,5^{\mathrm{a}}$ & 1,7 \\
\hline $60 \%$ argila $-40 \%$ areia & $4,1^{\mathrm{a}}$ & 1,3 \\
\hline $80 \%$ argila $-20 \%$ areia & $6,5^{\mathrm{a}}$ & 2,3 \\
\hline $100 \%$ argila $-0 \%$ areia & $4,7^{\mathrm{a}}$ & 1,8 \\
\hline \multicolumn{3}{|l|}{ ErO } \\
\hline $0 \%$ argila $-100 \%$ areia & 9,5 & 0,91 \\
\hline $20 \%$ argila $-80 \%$ areia & 11 & 6,2 \\
\hline $60 \%$ argila $-40 \%$ areia & 9,8 & 0,7 \\
\hline $100 \%$ argila $-0 \%$ areia & 11 & 6 \\
\hline \multicolumn{3}{|l|}{$\mathrm{HoO}$} \\
\hline $0 \%$ argila $-100 \%$ areia & 9,7 & 4,2 \\
\hline $20 \%$ argila $-80 \%$ areia & 7,9 & 1,9 \\
\hline $60 \%$ argila $-40 \%$ areia & 8,9 & 4,1 \\
\hline $100 \%$ argila $-0 \%$ areia & 9,2 & 3,5 \\
\hline \multicolumn{3}{|l|}{ CuZnFeO } \\
\hline $0 \%$ argila $-100 \%$ areia & 13,75 & 6 \\
\hline $20 \%$ argila $-80 \%$ areia & 12 & 6,1 \\
\hline $40 \%$ argila $-60 \%$ areia & 12 & 5,1 \\
\hline $80 \%$ argila $-20 \%$ areia & 13,75 & 8,5 \\
\hline $100 \%$ argila $-0 \%$ areia & 13,75 & 9,8 \\
\hline
\end{tabular}




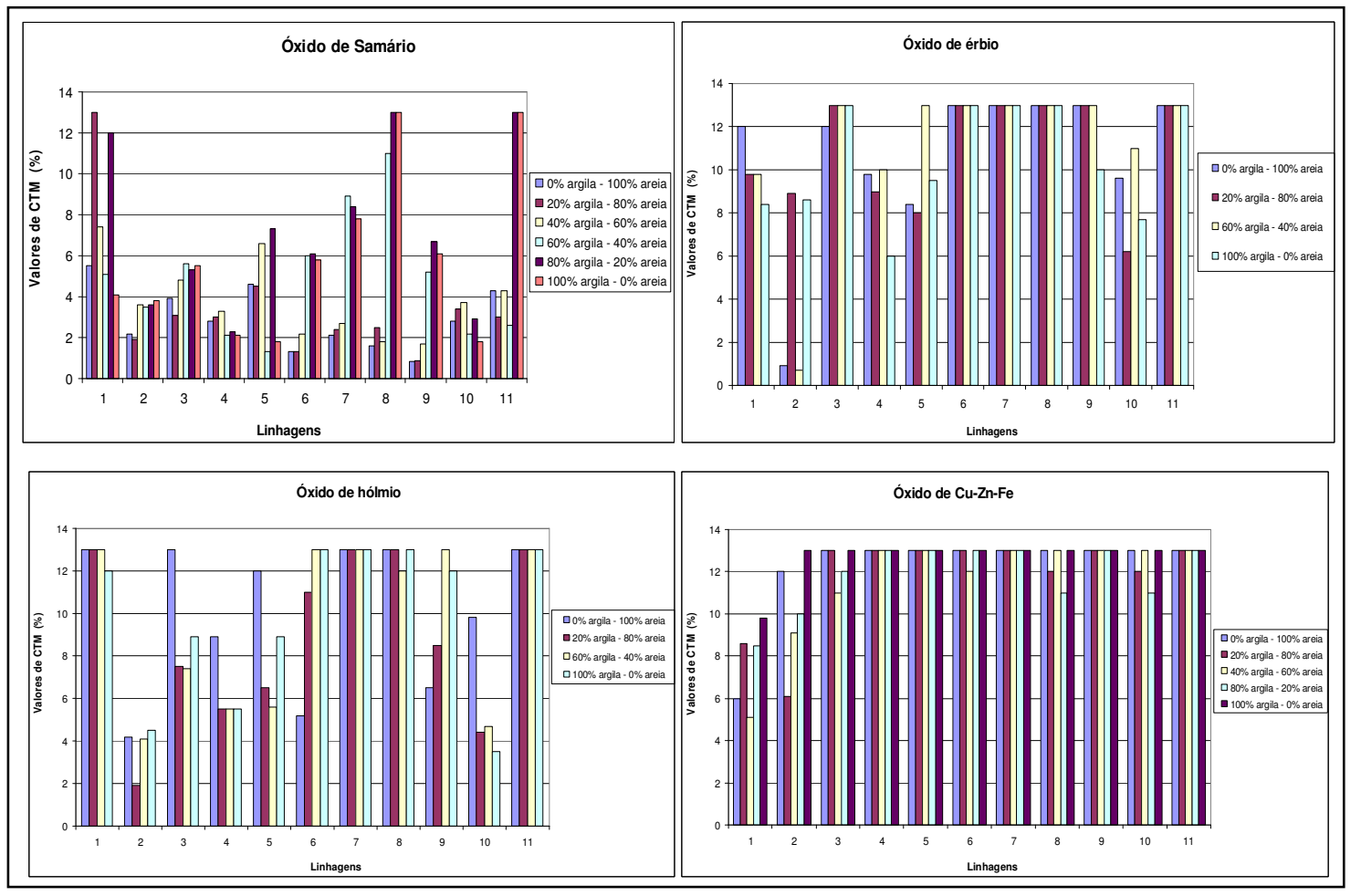

Figura 31. Perfis tóxicos das amostras de sedimento artificial com adição dos quatro nanomateriais testados, com diversas combinações de argila e areia.

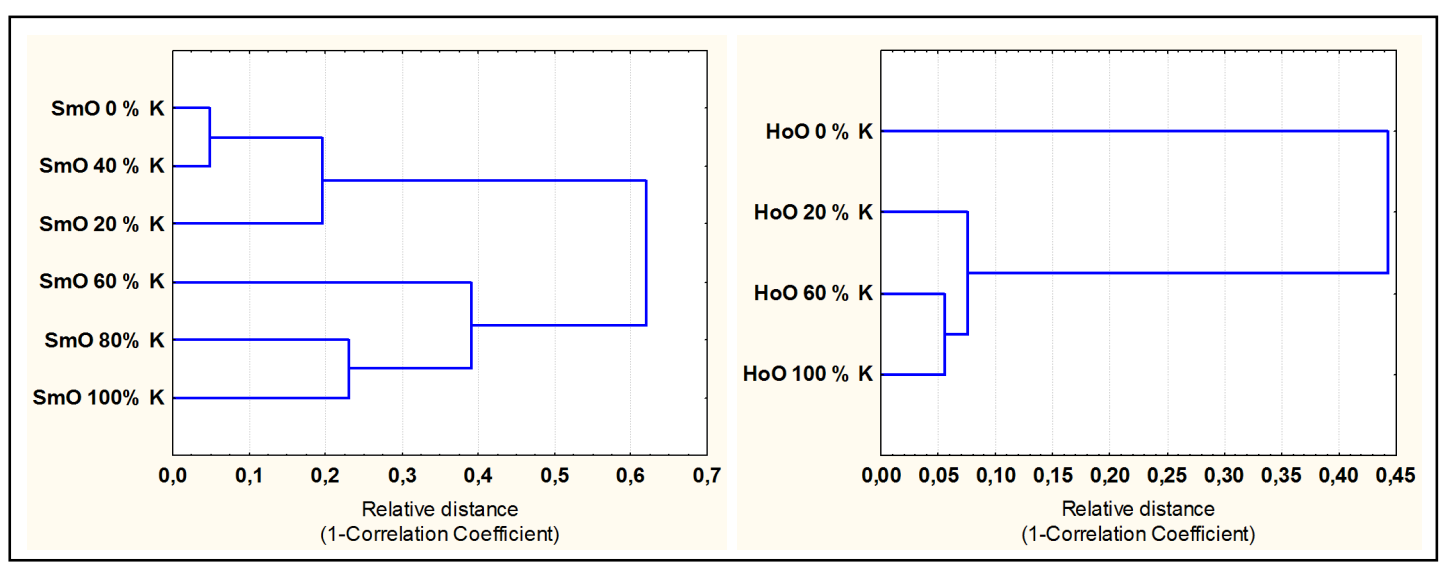

Figura 32. Cluster analysis dos testes com sedimentos artificiais versus $\mathrm{SmO}$ e HoO. (e.g. " $20 \%$ K" significa sedimento composto por $20 \%$ argila e $80 \%$ areia). 


\subsubsection{Quarta etapa}

$\mathrm{Na}$ quarta etapa, as quatro amostras de sedimento do rio Saint Lawrence escolhidas para se testar o comportamento dos nanomateriais em condições mais realistas foram testadas isoladamente para verificar se o sedimento, per se, seria tóxico às linhagens microbianas do teste MARA. Todas as amostras testadas demonstraram ausência de toxicidade significativa para as linhagens microbianas, permitindo que se prosseguisse para a quinta etapa, quando os nanomateriais foram misturados a estes sedimentos. Os resultados estão dispostos na Figura 33. Os valores de CTM Médio e CTM Mínimo (ambos em \%) desta etapa estão dispostos na Tabela 44.
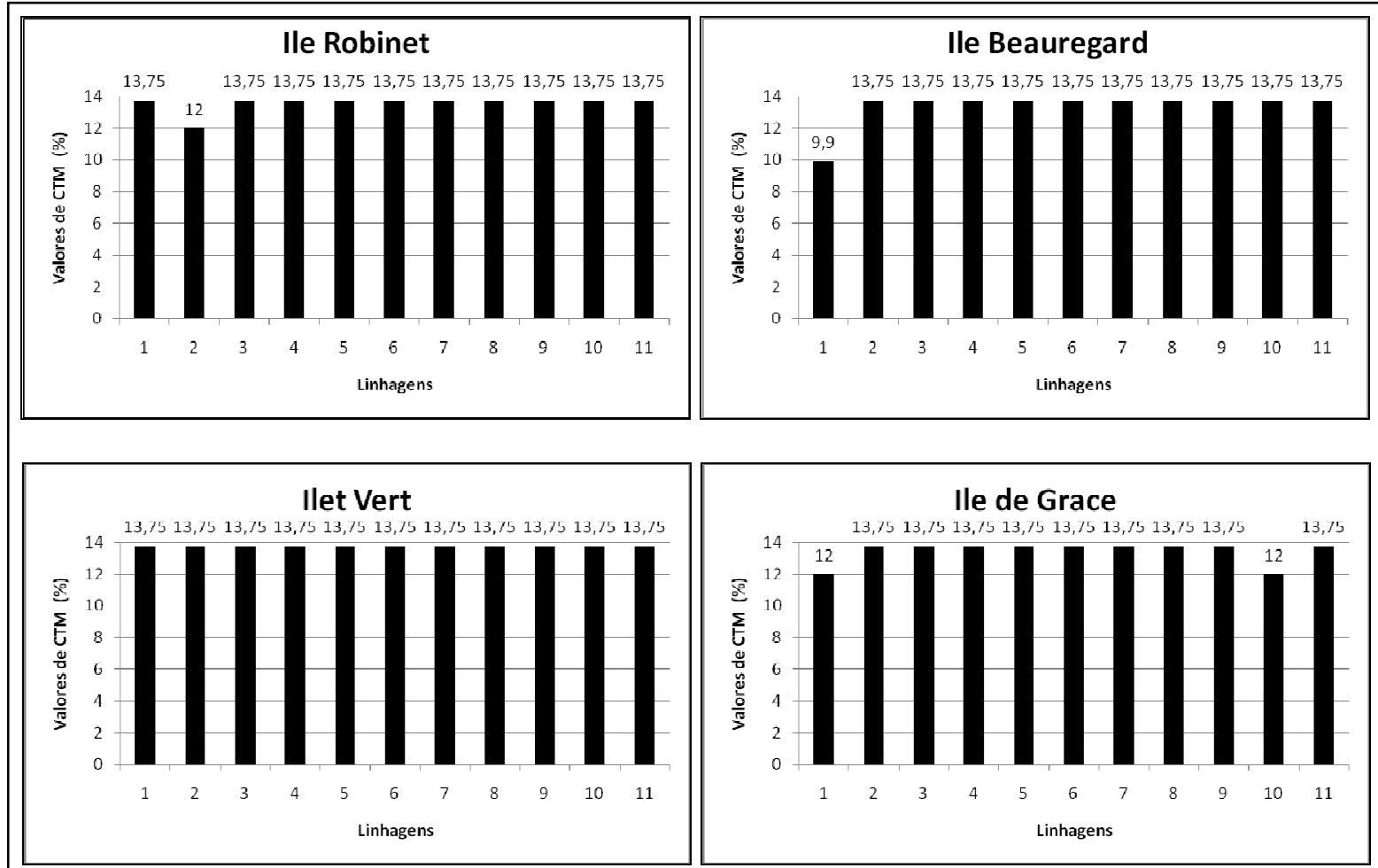

Figura 33. Perfis tóxicos das amostras de sedimento do rio Saint Lawrence. 
Tabela 44. Valores de CTM Médio e CTM Mínimo (ambos em \%) das amostras de sedimento coletadas no rio Saint Lawrence, Montreal, Canadá. Para estas amostras, o valor máximo possível para o CTM (Concentração tóxica microbiana) é 13,75\%, sendo que este valor indica ausência de toxicidade.

\begin{tabular}{lcc}
\hline Amostras & CTM Médio & CTM Mínimo \\
\hline Quarta etapa & & \\
& & \\
Ile Robinet & 13,75 & 12 \\
Ile Beauregard & 13,75 & 9,9 \\
Ilet Vert & 13,75 & 13 \\
Ile de Grace & 13,75 & 12 \\
\hline
\end{tabular}

\subsubsection{Quinta etapa}

Na quinta etapa, os mesmos nanomateriais foram testados quanto à sua toxicidade, mas desta vez misturados a amostras de sedimento coletados no rio Saint Lawrence, com granulometria conhecida (Tabela 34), a fim de verificar a ocorrência de respostas semelhantes às respostas da terceira etapa, mas em condições mais realistas. Do mesmo modo que na terceira etapa, porcentagens maiores de partículas finas contribuíram para a redução da toxicidade do SmO (Tabela 45). A Figura 34 com os agrupamentos por cluster analysis também demonstra esta influência da granulometria sobre a toxicidade do elutriato, tanto para $\mathrm{SmO}$ quanto para $\mathrm{HoO}$ (apesar de $\mathrm{HoO}$ não ter tido esta confirmação pelo teste ANOVA). Além disso, segundo a Tabela 34, o sedimento Ile Beauregard tem a maior proporção de partículas finas na categoria "areia fina", ou seja, 66\% $((30,9 / 46,9) * 100=66 \%)$, seguido pelo sedimento Ile Robinet $(59 \%)$, Ilet Vert $(6 \%)$, e por último Ile de Grace (2,8\%). Estas proporções podem explicar o agrupamento mais próximo entre "SmO 0\% K" e "IB 47\% F", mostrado na Figura 34, para SmO. Estes resultados sugerem também que as partículas de tamanho próximo do limite superior $(0,063 \mathrm{~mm})$ são menos capazes de reter os nanomateriais adsorvidos na matriz sólida do sedimento. Grãos maiores implicam menos superfície relativa e conseqüentemente menor interação com os 
nanomateriais. Os nanomateriais $\mathrm{ErO}$ e $\mathrm{CuZnFeO}$ misturados aos sedimentos naturais não causaram toxicidade significativa às linhagens do teste MARA, e pareceram não ser influenciados pela granulometria. Os valores de CTM Médio e CTM Mínimo (ambos em \%) desta etapa estão dispostos na Tabela 45.

Tabela 45. Valores de CTM Médio e CTM Mínimo (ambos em \%) das amostras de sedimento coletadas no rio Saint Lawrence, Montreal, Canadá, com a adição de nanomateriais (na proporção 10:1). Para estas amostras, o valor máximo possível para o CTM (Concentração tóxica microbiana) é $13,75 \%$, sendo que este valor indica ausência de toxicidade. As letras após os valores indicam diferença significativa segundo o teste ANOVA $(\mathrm{p}<0,05)$, em relação ao tratamento com $100 \%$ areia mais o respectivo nanomaterial.

\begin{tabular}{lcc}
\hline Amostras & CTM Médio & CTM Mínimo \\
\hline Quinta etapa & & \\
& & \\
SmO & & \\
Ile Robinet & $5,4^{\mathrm{a}}$ & $2,2^{\mathrm{a}}$ \\
Ile Beauregard & 2,7 & 0,54 \\
Ilet Vert & $7,0^{\mathrm{a}}$ & $1,8^{\mathrm{a}}$ \\
Ile de Grace & $4,8^{\mathrm{a}}$ & $1,3^{\mathrm{a}}$ \\
\hline & & \\
ErO & & \\
Ile Robinet & 13,75 & 5,9 \\
Ile Beauregard & 13,75 & 7,5 \\
Ilet Vert & 13,75 & 6,1 \\
Ile de Grace & 13,75 & 7,8 \\
\hline & & \\
HoO & & \\
Ile Robinet & 8,9 & 4,3 \\
Ile Beauregard & 9,6 & 4,7 \\
Ilet Vert & 11,0 & 4,2 \\
Ile de Grace & 11,0 & 3,9 \\
\hline & & \\
CuZnFeO & & \\
Ile Robinet & 13,75 & 13,75 \\
Ile Beauregard & 13,75 & 13,75 \\
Ilet Vert & 13,75 & 12,0 \\
Ile de Grace & 13,75 & 10,0 \\
\hline
\end{tabular}




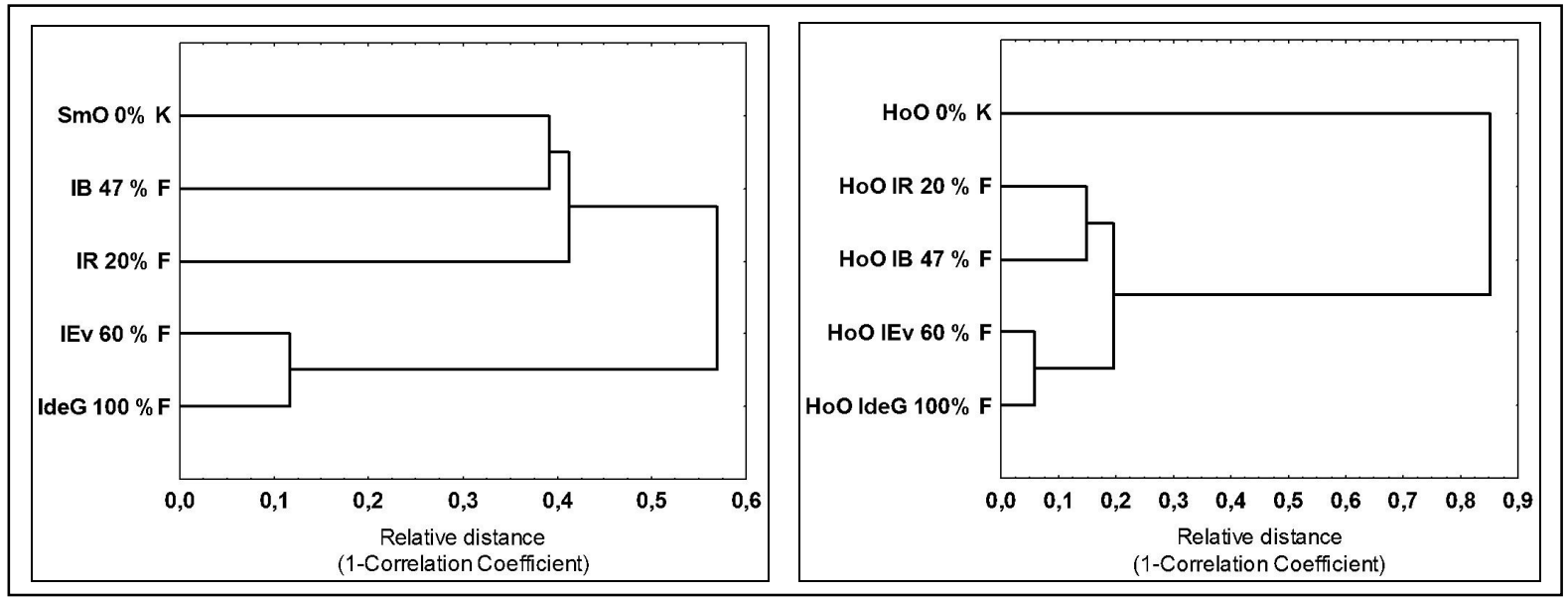

Figura 34. Cluster analysis dos testes com $\mathrm{SmO}$ e $\mathrm{HoO}$ versus sedimentos do rio Saint Lawrence, Canadá, comparados com o sedimento artificial (100\% areia $+0 \%$ argila) + nanomaterial. "IR" = Ile Robinet; "IB" = Ile Beauregard; "IEv" = Ilet Vert"; "IdeG" = Ile de Grace. (e.g. "20\% F" significa sedimento composto por $20 \%$ de partículas finas). 


\subsection{Discussão}

\subsubsection{Monitoramento dos resultados do controle negativo}

O monitoramento dos resultados do controle negativo mostrou-se útil, ao se tornar uma boa ferramenta na detecção da reprodutibilidade de cada placa utilizada durante cada um dos experimentos, assim como em uma carta-controle, permitindo a comparação com os resultados anteriores (Tabela 35). Através deste monitoramento, foi possível detectar quando uma (ou mais) linhagens apresentaram problemas de crescimento devido a algum fator externo ao experimento em si (como problemas de transporte, armazenagem ou contaminação), e por isso deveriam ser descartadas, e seus resultados desconsiderados. Outro fator importante que teve de ser levado em consideração foi o contato direto com o fabricante (técnicos responsáveis da NCIMB Ltd.), que nos informou de mudanças na fabricação das placas, que influenciassem neste monitoramento, e na comparação entre resultados dos experimentos.

\subsubsection{Sedimentos do rio Saint Lawrence, Montreal, Canadá}

Inicialmente, esperava-se encontrar uma toxicidade maior nas amostras de sedimento do rio Saint Lawrence, pelo menos em alguns dos pontos de coleta, como por exemplo, o "Port de Montréal", onde há bastante tráfego de barcos e navios, e conseqüente contaminação do rio por conta deste tráfego intenso. Apesar de os valores de CTM Médio não indicarem toxicidade (Tabela 36), os valores de CTM Mínimo indicam toxicidade para as linhagens mais sensíveis presentes no teste MARA - sendo que na maioria das amostras a linhagem 1 foi a mais sensível. Entretanto, segundo Blaise (informação verbal) ${ }^{3}$, por conta de legislação e fiscalização por conta do governo canadense, atualmente no Canadá 
não há nenhuma indústria cujo efluente tenha toxicidade aguda. Com certeza, este fator contribui para que não tenha sido detectada toxicidade significativa através do teste MARA. Esta informação pode explicar a ausência de toxicidade na maioria dos pontos amostrados. Outros bioensaios (Tabela 46) utilizados para avaliar a toxicidade das mesmas amostras de sedimento também indicaram ausência de toxicidade significativa na maioria destes pontos do rio Saint Lawrence (exceto o teste com H. attenuata - fase sólida), confirmando os resultados obtidos pelo teste MARA (Tabela 47).

Tabela 46. Bioensaios utilizados para avaliar a toxicidade das amostras de sedimento do rio Saint Lawrence, Montreal, Canadá. Blaise (Informação pessoal) ${ }^{8}$.

\begin{tabular}{|c|c|c|c|}
\hline Nível trófico & Bioensaio / Organismo & Endpoint & Referências \\
\hline \multicolumn{4}{|c|}{ Biensaios de fase sólida (Sedimento total) } \\
\hline Decompositor & Microtox & $\mathrm{CI}_{50}(20 \mathrm{~min})$. & Environment Canada (2002) \\
\hline Produtor primário & LuminoTox & $\mathrm{CI}_{50}(15$ min. $)$ & Dellamatrice et al. (2006) \\
\hline Consumidor secundário & Hvdra attenuata & $\mathrm{CL}_{50}(96 \mathrm{~h})$ & Trottier et al. (1997) \\
\hline Consumior secundario & пуага алтепиала & $\mathrm{CE}_{50}(96 \mathrm{~h})$ & oromer et al. (199/) \\
\hline Consumidor secundário & Hyalella azteca & Mortalidade & Borgmann e Norwood (2005) \\
\hline \multicolumn{4}{|c|}{ Bioensaios de fase líquida (Elutriato) } \\
\hline Decompositor & MARA & CTM (18 h) & Gabrielson et al. (2003) \\
\hline Consumidor secundário & Hydra attenuata & $\mathrm{CL}_{50}(96 \mathrm{~h})$ & Trottier et al. (1997) \\
\hline & & $\mathrm{CE}_{50}(96 \mathrm{~h})$ & \\
\hline Produtor primário & LuminoTox & $\mathrm{CI}_{50}(15$ min. $)$ & Dellamatrice et al. (2006) \\
\hline
\end{tabular}

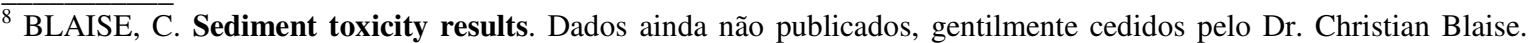
Mensagem recebida por masantos@ cena.usp.br, em 27 jun. 2008.
} 
Tabela 47. Resultados de outros bioensaios realizados com as amostras de sedimento do rio Saint Lawrence, Canadá. Blaise (Informação pessoal) ${ }^{8}$.

\begin{tabular}{|c|c|c|c|c|}
\hline Ponto de coleta & $\begin{array}{c}\text { LuminoTox } \\
\text { (Fase sól.) } \\
\text { CI }_{50} \text { (15 min.) }\end{array}$ & $\begin{array}{c}\text { Microtox } \\
\text { (Fase sól.) } \\
\text { CI }_{50} \text { (20 min.) }\end{array}$ & $\begin{array}{c}\text { H. attenuata } \\
\text { (Fase sól.) } \\
\mathrm{CL}_{50}(96 \text { h) }\end{array}$ & $\begin{array}{c}\text { H. attenuata } \\
\text { (Fase sól.) } \\
\mathrm{CE}_{50}(96 \text { h) }\end{array}$ \\
\hline \multirow{2}{*}{ Lac St-François } & 3,2 & 0,26 & $>25^{a}$ & $>11,1^{\mathrm{a}}$ \\
\hline & Não Tóxico ${ }^{b}$ & 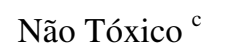 & Não tóxico & Não tóxico \\
\hline \multirow{2}{*}{ Port de Montréal } & $>10$ & 2,14 & $>25^{\mathrm{a}}$ & $<0,26$ \\
\hline & Não Tóxico b & Não Tóxico ${ }^{c}$ & Não tóxico & Muito tóxico \\
\hline \multirow{2}{*}{ Amont-CUM } & $>10$ & 1,50 & $>25^{\mathrm{a}}$ & 11,2 \\
\hline & Não Tóxico b & Não Tóxico ${ }^{c}$ & Não tóxico & Tóxico \\
\hline \multirow{2}{*}{ Ilet vert } & 1,4 & 0,29 & $>25^{\mathrm{a}}$ & $>15,8$ \\
\hline & Tóxico & Não Tóxico ${ }^{c}$ & Não tóxico & Não tóxico \\
\hline \multirow{2}{*}{ Ile Robinet } & $>10$ & 2,00 & $>25^{\mathrm{a}}$ & $>18,4$ \\
\hline & Não Tóxico b & Não Tóxico ${ }^{c}$ & Não tóxico & Não tóxico \\
\hline \multirow{2}{*}{ Ile Beauregard } & 4,7 & 0,48 & $>25^{\mathrm{a}}$ & $\mathbf{8 , 7 4}$ \\
\hline & Não Tóxico ${ }^{b}$ & Não Tóxico ${ }^{c}$ & Não tóxico & Tóxico \\
\hline \multirow{2}{*}{ Ile de Grâce } & 2,0 & 0,31 & $>25^{\mathrm{a}}$ & $>8,4$ \\
\hline & Não Tóxico b & Não Tóxico ${ }^{c}$ & Não tóxico & Não tóxico \\
\hline
\end{tabular}

(Continua...)

(Continuação)

\begin{tabular}{|c|c|c|c|c|}
\hline Ponto de coleta & $\begin{array}{c}\text { LuminoTox } \\
\text { (Elutriato) } \\
\text { CI }_{20} \text { (15 min.) } \\
\end{array}$ & $\begin{array}{c}\text { H. attenuata } \\
\text { (Elutriato) } \\
\mathrm{CL}_{50}(96 \mathrm{~h}) \\
\end{array}$ & $\begin{array}{c}\text { H. attenuata } \\
\text { (Elutriato) } \\
\mathrm{CE}_{50}(96 \mathrm{~h}) \\
\end{array}$ & $\begin{array}{l}\text { Hyallela azteca } \\
\text { (Fase sólida) } \\
\text { \% sobrevivência }\end{array}$ \\
\hline \multirow{2}{*}{ Lac St-François } & $>25^{a}$ & $>25^{\mathrm{a}}$ & $>25^{a}$ & 63,3 \\
\hline & Não tóxico & Não tóxico & Não tóxico & \\
\hline \multirow{2}{*}{ Port de Montréal } & $>25^{\mathrm{a}}$ & $>25^{\mathrm{a}}$ & 3,2 & 85,0 \\
\hline & Não tóxico & Não tóxico & & \\
\hline \multirow{2}{*}{ Amont-CUM } & $>25^{a}$ & $>25^{a}$ & 20,9 & 70,0 \\
\hline & Não tóxico & Não tóxico & & \\
\hline \multirow{2}{*}{ Ilet vert } & 12 & $>25^{a}$ & 11,9 & 86,7 \\
\hline & Tóxico & Não tóxico & & \\
\hline \multirow{2}{*}{ Ile Robinet } & $>25^{\mathrm{a}}$ & $>25^{\mathrm{a}}$ & 10 & 78,3 \\
\hline & Não tóxico & Não tóxico & & \\
\hline \multirow{2}{*}{ Ile Beauregard } & $>25^{\mathrm{a}}$ & 17,7 & 11,4 & 43,3 \\
\hline & Não tóxico & & & \\
\hline \multirow{2}{*}{ Ile de Grâce } & $>25^{a}$ & $>25^{\mathrm{a}}$ & $>25^{\mathrm{a}}$ & 83,3 \\
\hline & Não tóxico & Não tóxico & Não tóxico & \\
\hline
\end{tabular}

(a) Não tóxico na mais alta concentração testada. (b) Quando o sedimento tem mais de $20 \%$ de partículas finas, ele é considerado tóxico apenas se o valor de $\mathrm{CI}_{50}$ é menor que 2\% (Dellamatrice et al., 2006). (c) O sedimento é considerado tóxico apenas se o valor de $\mathrm{CI}_{50}$ é menor que $0,1 \%$ (Environment Canada, 2002). 
Por ainda se tratar de um teste novo, não há muita literatura científica sobre o teste MARA, e o potencial deste teste ainda precisa ser explorado. Entretanto, Wadhia et al. (2007) testaram com sucesso uma grande variedade de amostras como águas fluviais, metais, substâncias orgânicas e inorgânicas, efluentes, lodo de esgoto, obtendo bons resultados com o teste MARA. Estes autores compararam seus resultados com os de outros testes já consolidados, como Microtox, Daphnia magna, e Thamnocephalus platyurus e mostraram que a sensibilidade do teste MARA é equivalente ou até maior em alguns casos que os testes já consolidados na Ecotoxicologia.

\subsubsection{Usina de Mercier}

Os testes realizados com as amostras desta área produziram resultados bastante interessantes. Os resultados dos testes com as amostras de água permitiram a discussão de diversos mecanismos e interações que ocorrem na área estudada: baseando-se nos resultados do teste MARA, a água subterrânea que está sendo descontaminada (amostra Drain) ainda apresenta toxicidade, por causar inibição de crescimento na maioria das linhagens microbianas (Figura 25). Em discussão com outros colegas do Environment Canada, que realizam outros estudos nesta área, soube-se que o Esturgeon River é um rio bastante poluído e contaminado por outras atividades antrópicas; e o teste MARA indicou isso, sendo o ponto Amont o mais tóxico dentre os estudados na área da Usina de Mercier teve os menores valores de CTM Médio e CTM Mínimo (Tabela 37), e os menores valores de CTM para cada linhagem, isoladamente (Figura 25). A decisão de determinar dois pontos de coleta a jusante da foz do Little Brook Canal foi acertada, pois realmente foi detectada uma diferença de toxicidade por conta da pluma de dispersão da água do Little Brook Canal no Esturgeon River. É possível notar visualmente que os perfis tóxicos das 
amostras de água de Amont e Aval 2 são bastante semelhantes, e que o perfil tóxico da amostra Aval 1 (que contém majoritariamente água do Little Brook Canal é diferente. De acordo com os resultados obtidos, pelo fato de o Esturgeon River ser um rio bastante poluído, pode-se afirmar que as águas subterrâneas tratadas acabam por diluir a toxicidade deste rio, pelo fato de que o perfil tóxico da amostra Aval 1 demonstra menos toxicidade que o Ponto Amont. No perfil de Aval 1 sete das onze linhagens não sofreram toxicidade. Além disso, o ponto Aval 1 apresenta os valores mais altos de CTM Médio e CTM Mínimo, indicando redução da toxicidade em relação ao Ponto Amont (Tabela 37).

Apesar do fato de as amostras de sedimento não se mostrarem muito tóxicas, observou-se um valor bastante baixo (indicando alta toxicidade) no CTM Mínimo $(6,1 \%)$ do sedimento do Ponto Drain (Tabela 38). Este resultado sugere que por conta das atividades que ocorreram nesta área ao longo dos anos, o solo pode ainda estar contaminado.

\subsubsection{Efluentes urbanos}

Os resultados obtidos nos testes com efluentes urbanos foram semelhantes aos esperados. Como os efluentes testados de Saint Basile e Laschenaie-Mascouche são efluentes finais, já tratados, não eram esperados altos índices de toxicidade. Entretanto, os valores de CTM Mínimo (Tabela 39) indicaram graus de toxicidade que estão sendo causados por algum agente tóxico que mereceria uma investigação mais cuidadosa.

Com as amostras testadas provenientes da estação de tratamento de esgotos de Montreal, foi possível observar que o efluente tratado, mas ainda não desinfetado acusou alta toxicidade para a maioria das linhagens presentes no teste MARA (oito das onze linhagens). Seria necessária uma maior investigação para determinar a causa desta 
toxicidade: ou a presença de algum agente tóxico ou apenas a ocorrência de algum efeito causado pela presença de bactérias (e outros organismos) no efluente. É importante dizer que toda amostra líquida testada pelo MARA é previamente filtrada $(0,45 \mu \mathrm{m})$ para a retirada de outros microorganismos que possam contaminar e inviabilizar o próprio teste. Ambos os métodos de desinfecção mostraram-se bastante eficientes na redução da toxicidade apresentada pela amostra não desinfetada. Entretanto, o método " $\mathrm{O}_{3}$ hydroinjection" produziu algum efeito altamente tóxico sobre a linhagem 6 do teste MARA que não estava presente na amostra sem desinfecção (Figura 28). $\mathrm{O}$ método de desinfecção " $\mathrm{O}_{3}$ colonne" mostrou-se mais eficiente que o anteriormente citado, causando apenas uma leve toxicidade à linhagem 1. Tanto os perfis tóxicos (Figura 28) quanto os valores de CTM Médio e CTM Mínimo (Tabela 40) corroboram estas afirmações.

Foram feitas diversas tentativas de se obter informações a respeito das duas técnicas de desinfecção do efluente por aplicação de ozônio pela estação de tratamento de esgotos de Montreal, o que não foi possível, pelo fato de serem técnicas patenteadas e confidenciais.

\subsubsection{Nanomateriais}

Na primeira etapa foi possível observar uma grande variedade nas respostas dos microorganismos frente aos quatro nanomateriais testados, como, por exemplo, no caso do óxido de samário, onde foram observadas respostas com até duas ordens de magnitude de diferença. Os perfis tóxicos permitiram agrupar os nanomateriais testados, segundo efeito tóxico sobre os microorganismos, permitindo inferir, segundo Gabrielson et al. (2003), que substâncias estreitamente agrupadas segundo este método estatístico tem modos de ação semelhantes, como por exemplo, ErO e CuZnFeO (Figura 29). Todos os nanomateriais 
testados apresentaram alguma toxicidade para as linhagens do teste MARA, indicando que esta nova classe de substâncias pode ser nociva à biota aquática caso estas substâncias acabem sendo liberadas em ambientes aquáticos. Outros estudos também vêm corroborando esta discussão, demonstrando efeitos adversos de nanomateriais sobre diversos organismos aquáticos: $\mathrm{ZnO}, \mathrm{TiO}_{2}$, e $\mathrm{Al}_{2} \mathrm{O}_{3}$ sobre o peixe Danio rerio ( $\mathrm{ZHU}$ et al., 2008); $\mathrm{ZnO}, \mathrm{CuO}$, e $\mathrm{TiO}_{2}$ sobre Vibrio fischeri, D. magna e Thamnocephalus platyurus (HEINLAAN et al., 2008); e ZnO sobre a alga $P$. subcapitata (FRANKLIN et al., 2007).

$\mathrm{Na}$ segunda etapa pôde-se assegurar que o sedimento artificial composto de diversas proporções de areia e argila não exerceu toxicidade significativa para as linhagens microbianas do teste MARA. A comprovação da ausência de toxicidade pelo sedimento isoladamente foi fundamental para os testes da terceira etapa, onde se testou a toxicidade dos quatro nanomateriais misturados a este sedimento artificial. Seria importante evitar alguma toxicidade provocada pela matriz sólida que pudesse interferir na toxicidade observada quando da adição dos nanomateriais.

Na terceira etapa, o objetivo foi avaliar a influência da granulometria do sedimento na biodisponibilidade dos nanomateriais. Nesta etapa, foram utilizados sedimentos artificiais com granulometria conhecida e bem definida para avaliar o comportamento dos nanomateriais quanto à sua toxicidade. O nanomaterial óxido de samário foi o que apresentou os melhores resultados, quando se analisam os perfis tóxicos produzidos nesta etapa. Ou seja, observou-se uma diminuição da toxicidade relacionada com o aumento na proporção de argila (partículas menores que tem relativamente mais superfície que grãos maiores, e, portanto, tem maior interação com as moléculas testadas). A Figura 31 mostra este comportamento em 7 das 11 linhagens do teste MARA para o SmO. Para os nanomateriais $\mathrm{ErO}$ e $\mathrm{HoO}$ houve também uma tendência neste sentido, mas com a confirmação apenas pelo método cluster analysis para o óxido de hólmio. O óxido de 
samário também apresentou este comportamento em relação à granulometria quando se observa seus valores de CTM Médio e CTM Mínimo (Tabela 43). O óxido de Cu-Zn-Fe não apresentou diferenças entre os tratamentos, quando diversas proporções de areia e argila foram testadas, indicando que a dessorção deste nanomaterial para a coluna d'água parece não sofrer influência da composição granulométrica do sedimento.

$\mathrm{Na}$ quarta etapa pôde-se apenas confirmar os resultados já obtidos nos experimentos descritos no item 4.2.7.1. Esta etapa aparentemente é uma repetição deste experimento, mas na verdade como o procedimento de preparo das amostras é diferente, foi necessário realizar esta etapa para que fosse possível a comparação entre as cinco etapas dos experimentos com nanomateriais. Foi confirmado que os sedimentos do rio Saint Lawrence não exerceram toxicidade significativa para as linhagens microbianas do teste MARA. A comprovação da ausência de toxicidade pelos sedimentos naturais isoladamente foi fundamental para os testes da quinta etapa, onde se testou a toxicidade dos quatro nanomateriais misturados a estes sedimentos naturais. Outros bioensaios também comprovaram ausência significativa de toxicidade dos sedimentos do rio Saint Lawrence (Tabelas 46 e 47).

$\mathrm{Na}$ quinta etapa, foram testados os sedimentos naturais do rio Saint Lawrence misturados aos quatro nanomateriais para verificar se as respostas encontradas na terceira etapa poderiam ocorrer também em situações reais, no meio ambiente. Nesta etapa, assim como na terceira, foi possível observar uma resposta semelhante do óxido de samário quando misturado a sedimentos naturais, ou seja, maiores porcentagens de partículas finas no sedimento causaram uma diminuição da toxicidade às linhagens do teste MARA. Este comportamento do SmO foi confirmado tanto por ANOVA quanto por cluster analysis. Esta última análise também demonstrou esta resposta para o óxido de hólmio. 
Outra resposta encontrada nestes experimentos foi a influência de determinadas parcelas das partículas finas - como areia, silte e argila - na modulação da toxicidade. Sedimentos naturais com maior proporção de areia causaram maior toxicidade de seus elutriatos para as linhagens microbianas. Os valores de CTM Médio e CTM Mínimo também mostram este padrão de resposta (Tabela 45). Dentre os nanomateriais testados, ErO e $\mathrm{CuZnFeO} \mathrm{não} \mathrm{apresentaram} \mathrm{um} \mathrm{padrão} \mathrm{de} \mathrm{resposta} \mathrm{claro} \mathrm{como} \mathrm{o} \mathrm{óxido} \mathrm{de} \mathrm{samário,}$ parecendo não sofrer influência da granulometria em suas biodisponibilidades para as linhagens do teste MARA.

Pelo menos alguns dos nanomateriais testados parecem se comportar de maneira semelhante aos metais pesados, no que se refere à adsorção/dessorção no sedimento, de acordo com a sua composição granulométrica. Partículas de argila são mais capazes de reter estas substâncias, devido à sua superfície relativamente maior, e exemplos deste tipo de resposta estão largamente documentados na literatura (SOARES et al., 1999; ZHONG e WANG, 2008). Estes estudos demonstram que sedimentos com grande quantidade de partículas finas são mais capazes de reter metais, dificultando sua extração por água intersticial ou por elutriato. $\mathrm{O}$ presente estudo mostrou que os nanomateriais, exceto o $\mathrm{CuZnFeO}$, são seqüestrados de maneira semelhante pelas partículas finas do sedimento, e que isso é um fator importante na determinação do risco potencial que estes nanomateriais podem apresentar quando liberados em ambientes aquáticos. Dependendo dos eventos que ocorrerem com sedimentos contaminados com estes nanomateriais, podem decorrer situações prejudiciais à biota aquática, tanto a organismos bentônicos, quando aos da coluna d'água. 


\subsection{Conclusões}

- Após a utilização do bioensaio MARA na avaliação de diversas amostras, pôde-se concluir que se trata de uma boa ferramenta para análises ecotoxicológicas, e que pode contribuir muito no campo da Ecotoxicologia. O teste MARA apresenta boa reprodutibilidade, assim como sensibilidade dos organismos-teste, constituindo uma boa alternativa em avaliações ecotoxicológicas;

- Na avaliação de sedimentos do Rio Saint Lawrence, teve seus resultados de acordo com diversos outros bioensaios já consolidados realizados com as mesmas amostras;

- $\mathrm{Na}$ avaliação de amostras fluviais e efluentes urbanos, o teste MARA mostrou sensibilidade na detecção de agentes tóxicos presentes;

- Os quatro nanomateriais testados $(\mathrm{SmO}, \mathrm{HoO}, \mathrm{ErO}$, e $\mathrm{CuZnFeO})$ foram tóxicos às linhagens microbianas do teste MARA. Através do método Cluster Analysis é possível sugerir que alguns nanomateriais tem modos de ação semelhantes (ErO e $\mathrm{CuZnFeO})$ e outros bem diferentes $(\mathrm{SmO})$.

- Foi possível verificar que a toxicidade destes nanomateriais (exceto o $\mathrm{CuZnFeO}$ ) é modulada pela proporção de partículas finas no sedimento, assim como de suas subdivisões granulométricas, argila, silte e areia, tanto quando foram testados em sedimentos artificiais, compostos por areia e argila, quanto quando foram testados em sedimentos naturais;

- A contaminação de sedimentos por nanomateriais deve ser levada em conta, caso estas substâncias sejam liberadas em ambientes aquáticos. Os nanomateriais $\mathrm{SmO}$, ErO e HoO são mais prováveis de serem liberados para a coluna d'água em caso de sedimentos com baixa proporção de argila, e menos prováveis em sedimentos com 
alta proporção de argila. Este fator é determinante no risco potencial em relação ou a organismos bentônicos, ou a organismos da coluna d'água.

- O nanomaterial $\mathrm{CuZnFeO}$ parece ficar mais fortemente adsorvido ao sedimento, e esta característica pode prejudicar mais organismos bentônicos, que ingerem partículas do sedimento. 


\subsection{Referências Bibliográficas}

AITKEN, R.J.; CHAUDHRY, M.Q.; BOXALL, A.B.A.; HULL, M. Manufacture and use of nanomaterials: current status in the UK and global trends. Occupational Medicine, Chicago, v. 56, p. 300-306. 2006.

ARULGNANENDRAN, V.R.J.; NIRMALAKHANDAN, N. Microbial toxicity in soil medium. Ecotoxicology and Environmental Safety, New York, v. 39, n. 1, p. 48-56, 1998.

BORGMANN, U.; NORWOOD, W.P. Amphipod (Hyalella azteca) solid-phase toxicity test using high water-sediment ratios. In: BLAISE, C.; FÉRARD, J.F. (Ed.). Small-scale freshwater toxicity investigations. v. 1. Toxicity test methods. Dordrecht: Springer Science, 2005. P. 413-436.

CHAPMAN, P.M.; WANG, F. Assessing sediment contamination in estuaries. Environmental Toxicology and Chemistry, New York, v. 20, p. 3-22, 2001.

DELLAMATRICE, P.M.; MONTEIRO, R.T.R.; BLAISE, C.; SLABBERT, J.L.; GAGNÉ, F.; ALLEAU, S. Toxicity assessment of reference and natural sediments with the LuminoTox Assay. Environmental Toxicology, New York, v. 21, n. 4, p. 395-402, 2006.

ENVIRONMENT CANADA. Biological test method: Reference method for determining the toxicity of sediment using luminescent bacteria in a solid-phase test. Ottawa, 2002. (EPS 1/RM/42).

FRANKLIN, N.; ROGERS, N.; APTE, S.; BATLEY, G.; GADD, G.; CASEY, P. Comparative toxicity of nanoparticulate $\mathrm{ZnO}$, bulk $\mathrm{ZnO}$, and $\mathrm{ZnCl}_{2}$ to a freshwater microalgae (Pseudokirchneriella subcapitata): the importance of particle solubility. Environmental Science and Technology, Easton, v. 41, p. 8484-8490, 2007.

GABRIELSON, J.; KÜHN, I.; COLQUE-NAVARRO, P.; HART, M.; IVERSEN, A.; MCKENZIE, D.; MÖLLBY, R. Microplate-based microbial assay for risk assessment and (eco)toxic fingerprinting of chemicals. Analytica Chimica Acta, Amsterdam, v. 485, p. 121-130, 2003.

HANDY, R.D.; SHAW, B.J. Toxic effects of nanoparticles and nanomaterials: Implications for public health, risk assessment and the public perception of nanotechnology. Health, Risk \& Society, Oxford, v. 9, p. 125-144. 2007.

HEINLAAN, M.; IVASK, A.; BLINOVA, I.; DUBOURGUIER, H-C.; KAHRU, A. Toxicity of nanosized and bulk $\mathrm{ZnO}, \mathrm{CuO}$ and $\mathrm{TiO}_{2}$ to bacteria Vibrio fischeri and crustaceans Daphnia magna and Thamnocephalus platyurus. Chemosphere, Amsterdam, v. 71, n. 7, p. 1308-1316, 2008.

LA FARRE, M.; GARCIA, M.J.; TIRAPU, L.; GINEBREDA, A.; BARCELO, D. Wastewater toxicity screening of non-ionic surfactants by Toxalert ${ }^{\circledR}$ and Microtox ${ }^{\circledR}$ bioluminescence inhibition assays. Analytica Chimica Acta, Amsterdam, v. 427, p. 181-189, 2001.

LOVERN, S.B.; KLAPER, R. Daphnia magna mortality when exposed to titanium dioxide and fullerene (C60) nanoparticles. Environmental Toxicology and Chemistry, New York, v. 25, p. 1132-1137, 2006.

MOORE, M.N. Do nanoparticles present ecotoxicological risks for the health of the aquatic environment? Environmental International, Amsterdam, v. 32, p. 967-976, 2006. 
SNEATH, P.H.A.; SOKAL, R.R. Numerical Taxonomy: the principles and practice of numerical classification. San Francisco: Freeman, 1973. 573p.

SOARES, H.; BOAVENTURA, R.; MACHADO, A.; ESTEVES DA SILVA, J. Sediments as monitors of heavy metal contamination in the Ave river basin (Portugal): multivariate analysis of data. Environmental Pollution, London, v. 105, p. 311-323, 1999.

TROTTIER, S.; BLAISE, C.; KUSUI, T.; JOHNSON, E.M. Acute toxicity assessment of aqueous samples using a microplate-based Hydra attenuata assay. Environmental Toxicology and Water Quality, New York, v. 12, p. 265-271, 1997.

WADHIA, K.; DANDO, T.; THOMPSON, K.C. Intra-laboratory evaluation o Microbial Assay for Risk Assessment (MARA) for potential application in the implementation of the Water Framework Directive (WFD). Journal of Environmental Monitoring, London, v. 9, p. 953-958, 2007.

WANG, X-C.; FENG, H.; MA, H-Q. Assessment of metal contamination in surface sediments of Jiaozhou, Qingdao, China. Clean Journal, Weinhein, v. 35, p. 62-70, 2007.

WIKIPEDIA. Nanotoxicology. Disponível em: <http://en.wikipedia.org/wiki/Nanotoxicology>. Acesso em: 11 jun. 2008.

ZHONG, H.; WANG, W-X. Effects of sediment composition on inorganic mercury partitioning, speciation and bioavailability in toxic superficial sediments. Environmental Pollution, London, v. 151, p. 222-230, 2008.

ZHU, X.; ZHU, L.; DUAN, Z.; QI, R.; LI, Y.; LANG, Y. Comparative toxicity of several metal oxide nanoparticle aqueous suspensions to zebrafish (Danio rerio) early developmental stage. Journal of Environmental Science and Health. Part A, New York, v. 43, p. 278-284, 2008.

ZURITA, J.L.; JOS, A.; DEL PESO, A.; SALGUERO, M.; CAMEAN, A.M.; LOPEZARTIGUEZ, M.; REPETTO, G. Toxicological assessment of indium nitrate on aquatic organisms and investigation of effects in the PLHC-1 fish cell line. Science of the Total Environment, Amsterdam, v. 387, p. 155-165, 2007. 


\section{Conclusões Gerais}

- Testes ecotoxicológicos são boas ferramentas na avaliação da qualidade de corpos hídricos, fornecendo informações adicionais, em complemento às análises tradicionais;

- A utilização de baterias de testes ecotoxicológicos foi fundamental no resultado final da avaliação da qualidade da água e do sedimento do rio Corumbataí;

- É altamente recomendável a utilização de organismos-teste de diferentes níveis tróficos, e de testes ecotoxicológicos com diferentes endpoints na composição de uma bateria de bioensaios. Testes diferentes se complementam, aumentam a faixa de sensibilidade a agentes tóxicos presentes nas amostras testadas, e dão indicações das respostas de cada nível trófico frente a poluentes;

- O bioensaio MARA (Microbial Array for Risk Assessment) constitui uma ferramenta boa e prática na avaliação de toxicidade de diversos tipos de amostras e de substâncias, que apresenta boa reprodutibilidade e sensibilidade, podendo ser adotado em avaliações ecotoxicológicas de ambientes aquáticos. 


\section{Apêndice A - Tabelas de dados}

Tabela 48. Medidas de parâmetros físicos e químicos coletados em campo, no rio Corumbataí: Valores de pH, temperatura da água $\left({ }^{\circ} \mathrm{C}\right)$, oxigênio dissolvido $\left(\mathrm{mg} \mathrm{L}^{-1}\right)$, e condutividade $\left(\mu \mathrm{S} \mathrm{cm}^{-1}\right)$.

\begin{tabular}{|c|c|c|c|c|c|c|c|c|c|c|c|c|c|c|c|c|}
\hline \multirow{2}{*}{$\begin{array}{c}\text { Pontos de } \\
\text { coleta } \\
\end{array}$} & \multicolumn{4}{|c|}{ Novembro / 2004} & \multicolumn{4}{|c|}{ Fevereiro / 2005} & \multicolumn{4}{|c|}{ Maio / 2005} & \multicolumn{4}{|c|}{ Setembro / 2005} \\
\hline & pH & Temp. & O.D. & Cond. & pH & Temp. & O.D. & Cond. & pH & Temp. & O.D. & Cond. & pH & Temp. & O.D. & Cond. \\
\hline 1 & 6,86 & 21,4 & 9,50 & 21,1 & 6,87 & 20,9 & 8,36 & 33,5 & 6,60 & 18,1 & 8,17 & 21,4 & 6,68 & 18,8 & 8,65 & 31,3 \\
\hline 2 & 7,05 & 21,7 & 8,00 & 25,1 & 7,13 & 21,2 & 8,35 & 38,9 & 6,95 & 18,8 & 8,20 & 26,6 & 7,64 & 18,9 & 8,98 & 36,7 \\
\hline 3 & 6,97 & 23,3 & 5,40 & 27,2 & 6,96 & 22,0 & 8,20 & 35,0 & 6,98 & 19,0 & 8,20 & 30,4 & 7,22 & 19,1 & 8,70 & 39,8 \\
\hline 4 & 7,00 & 24,2 & 5,19 & 35,1 & 6,96 & 22,9 & 7,63 & 41,8 & 7,10 & 20,1 & 8,16 & 32,3 & 7,20 & 20,4 & 8,97 & 45,9 \\
\hline 5 & 7,02 & 23,9 & 5,47 & 39,5 & 6,92 & 23,7 & 7,26 & 49,3 & 7,09 & 19,6 & 7,80 & 39,4 & 7,53 & 20,6 & 9,00 & 51,4 \\
\hline 6 & 7,03 & 25,1 & 4,80 & 136,9 & 7,05 & 24,5 & 7,10 & 330,0 & 7,10 & 21,1 & 6,78 & 144,8 & 7,25 & 22,7 & 5,86 & 228,0 \\
\hline 7 & 7,00 & 24,9 & 4,06 & 118,1 & 7,28 & 26,1 & 7,01 & 148,0 & 7,01 & 20,9 & 7,04 & 155,6 & 6,76 & 23,4 & 4,62 & 217,0 \\
\hline
\end{tabular}

\begin{tabular}{|c|c|c|c|c|c|c|c|c|c|c|c|c|c|c|c|c|}
\hline \multicolumn{17}{|c|}{ (Continuação) } \\
\hline \multirow{2}{*}{$\begin{array}{c}\text { Pontos de } \\
\text { coleta } \\
\end{array}$} & \multicolumn{4}{|c|}{ Dezembro / 2005} & \multicolumn{4}{|c|}{ Março / 2006} & \multicolumn{4}{|c|}{ Junho / 2006} & \multicolumn{4}{|c|}{ Setembro / 2006} \\
\hline & pH & Temp. & O.D. & Cond. & pH & Temp. & O.D. & Cond. & pH & Temp. & O.D. & Cond. & $\mathbf{p H}$ & Temp. & O.D. & Cond. \\
\hline 1 & 6,06 & 21,5 & 9,00 & 23,8 & 6,45 & 23,5 & 8,02 & 39,2 & 6,33 & 14,7 & 9,50 & 25,3 & 6,46 & 19,0 & 9,24 & 27,1 \\
\hline 2 & 4,35 & 21,6 & 8,90 & 34,6 & 6,60 & 23,9 & 8,46 & 44,8 & 7,21 & 17,8 & 9,25 & 37,5 & 6,20 & 19,2 & 8,96 & 31,8 \\
\hline 3 & 5,25 & 22,5 & 8,97 & 29,2 & 5,95 & 25,0 & 7,54 & 46,8 & 6,41 & 16,5 & 10,02 & 29,4 & 6,25 & 20,2 & 8,90 & 36,0 \\
\hline 4 & 6,27 & 23,3 & 8,65 & 34,1 & 6,18 & 26,3 & 7,56 & 53,0 & 6,34 & 16,8 & 9,80 & 34,5 & 6,32 & 20,6 & 8,73 & 37,0 \\
\hline 5 & 6,30 & 23,7 & 8,20 & 39,9 & 7,32 & 25,8 & 7,40 & 83,0 & 6,52 & 17,8 & 9,20 & 39,5 & 6,46 & 21,5 & 8,44 & 38,8 \\
\hline 6 & 6,78 & 24,1 & 5,55 & 216,0 & 7,41 & 26,6 & 6,14 & 164,6 & 6,80 & 19,0 & 7,09 & 240,0 & 6,48 & 20,9 & 3,77 & 186,0 \\
\hline 7 & 6,43 & 24,5 & 4,90 & 130,0 & 6,98 & 27,2 & 6,53 & 190,4 & 6,71 & 19,0 & 7,40 & 179,1 & 6,36 & 22,8 & 3,90 & 180,9 \\
\hline
\end{tabular}


Tabela 49. Valores de DBO $\left(\mathrm{mg} \mathrm{L}^{-1}\right)$ das amostras de água coletadas no rio Corumbataí.

\begin{tabular}{ccccccccc}
\hline $\begin{array}{c}\text { Pontos de } \\
\text { coleta }\end{array}$ & Nov/ 2004 & Fev / 2005 & Mai / 2005 & Set / 2005 & Dez/ 2005 & Mar/2006 & Jun / 2006 & Set/2006 \\
\hline $\mathbf{1}$ & 2,45 & 9,51 & 8,83 & 1,70 & - & 6,30 & 1,85 & 1,52 \\
$\mathbf{2}$ & 3,07 & 5,87 & 9,16 & 1,95 & - & 7,08 & 4,07 & 3,15 \\
$\mathbf{3}$ & 1,75 & 6,09 & 9,67 & 1,50 & - & 3,50 & 2,80 & 5,54 \\
$\mathbf{4}$ & 3,64 & 7,10 & 9,98 & 1,85 & - & 4,11 & 1,47 & 3,49 \\
$\mathbf{5}$ & 2,42 & 5,23 & 9,70 & 1,69 & - & 6,74 & 1,46 & 2,40 \\
$\mathbf{6}$ & 14,18 & 8,51 & 6,51 & 7,69 & - & 12,26 & 9,33 & 18,05 \\
$\mathbf{7}$ & 4,69 & 9,32 & 6,67 & 5,90 & - & 8,70 & 8,53 & 18,66 \\
\hline
\end{tabular}


Tabela 50. Valores de nitrogênio (N-total, Amônia e nitrato, em $\mathrm{mg} \mathrm{L}^{-1}$ ) determinados nas amostras de água coletadas no rio Corumbataí.

\begin{tabular}{|c|c|c|c|c|c|c|c|c|c|c|c|c|c|c|c|c|}
\hline \multirow{2}{*}{$\begin{array}{c}\text { Pontos de } \\
\text { coleta }\end{array}$} & \multicolumn{8}{|c|}{ N-total $\left(\mathrm{em} \mathrm{mg} \mathrm{^{-1 } )}\right.$} & \multicolumn{8}{|c|}{ Amônia $\left(\mathrm{NH}_{3}, \mathrm{em} \mathrm{mg} \mathrm{L}^{-1}\right)$} \\
\hline & Nov/04 & Fev/05 & Mai/05 & Set/05 & Dez/05 & Mar/06 & Jun/06 & Set/06 & Nov/04 & Fev/05 & Mai/05 & Set/05 & Dez/05 & Mar/06 & Jun/06 & Set/06 \\
\hline 1 & 0,98 & 1,08 & 0,72 & 0,89 & 0,97 & 1,16 & 0,86 & 1,26 & 0,26 & 0,35 & 0,33 & 0,55 & 0,46 & 0,62 & 0,31 & 0,64 \\
\hline 2 & 0,81 & 1,13 & 0,95 & 0,87 & 0,79 & 0,97 & 0,95 & 1,35 & 0,17 & 0,46 & 0,27 & 0,30 & 0,27 & 0,27 & 0,43 & 0,55 \\
\hline 3 & 1,15 & 1,16 & 0,98 & 0,73 & 0,85 & 1,38 & 1,10 & 1,68 & 0,46 & 0,50 & 0,28 & 0,28 & 0,31 & 0,54 & 0,39 & 0,61 \\
\hline 4 & 1,06 & 1,53 & 0,97 & 1,02 & 0,86 & 1,21 & 0,96 & 1,87 & 0,30 & 0,53 & 0,25 & 0,37 & 0,25 & 0,47 & 0,22 & 0,61 \\
\hline 5 & 0,91 & 1,36 & 0,91 & 0,78 & 0,88 & 1,52 & 1,25 & 1,67 & 0,19 & 0,54 & 0,19 & 0,24 & 0,37 & 0,64 & 0,32 & 0,43 \\
\hline 6 & 1,44 & 1,41 & 2,03 & 4,38 & 2,55 & 1,50 & 3,43 & 6,64 & 0,60 & 0,60 & 0,95 & 2,55 & 1,72 & 0,41 & 2,20 & 3,41 \\
\hline 7 & 1,42 & 1,39 & 1,63 & 2,24 & 1,64 & 1,38 & 2,57 & 3,06 & 0,36 & 0,58 & 0,61 & 1,08 & 0,44 & 0,64 & 0,56 & 1,27 \\
\hline
\end{tabular}

\begin{tabular}{|c|c|c|c|c|c|c|c|c|}
\hline \multicolumn{9}{|c|}{ (Continuação) } \\
\hline \multirow{2}{*}{$\begin{array}{l}\text { Pontos de } \\
\text { coleta }\end{array}$} & \multicolumn{8}{|c|}{ Nitrato $\left(\mathrm{em} \mathrm{mg} \mathrm{L}^{-1}\right)$} \\
\hline & Nov/04 & Fev/05 & Mai/05 & Set/05 & Dez/05 & Mar/06 & Jun/06 & Set/06 \\
\hline 1 & 0,42 & 0,48 & 0,42 & 0,64 & 0,49 & 0,54 & 0,53 & 0,56 \\
\hline 2 & 0,56 & 0,57 & 0,75 & 0,53 & 0,47 & 0,67 & 0,48 & 0,78 \\
\hline 3 & 0,57 & 0,52 & 0,76 & 0,38 & 0,56 & 0,68 & 0,52 & 1,07 \\
\hline 4 & 0,71 & 0,55 & 0,71 & 0,58 & 0,53 & 0,6 & 0,74 & 1,21 \\
\hline 5 & 0,62 & 0,54 & 0,66 & 0,59 & 0,49 & 0,54 & 1,09 & 1,29 \\
\hline 6 & 0,64 & 0,58 & 0,84 & 0,63 & 0,73 & 0,64 & 0,68 & 0,84 \\
\hline 7 & 0,82 & 0,53 & 0,89 & 1,10 & 1,10 & 0,67 & 1,42 & 1,77 \\
\hline
\end{tabular}


Tabela 51. Valores de fósforo ( $\mathrm{P}-$ total, $\mathrm{P}$-solúvel e $\mathrm{PO}_{4}{ }^{3-}$, em $\mathrm{mg} \mathrm{L}^{-1}$ ) determinados nas amostras de água coletadas no rio Corumbataí.

\begin{tabular}{|c|c|c|c|c|c|c|c|c|c|c|c|c|c|c|c|c|}
\hline \multirow{2}{*}{$\begin{array}{c}\text { Pontos } \\
\text { de } \\
\text { coleta }\end{array}$} & \multicolumn{8}{|c|}{ P-total (em mg L ${ }^{-1}$ ) } & \multicolumn{8}{|c|}{ P-solúvel (em mg L ${ }^{-1}$ ) } \\
\hline & Nov/04 & Fev/05 & Mai/05 & Set/05 & Dez/05 & Mar/06 & Jun/06 & Set/06 & Nov/04 & Fev/05 & Mai/05 & Set/05 & Dez/05 & Mar/06 & Jun/06 & Set/06 \\
\hline 1 & 0,018 & 0,015 & 0,014 & 0,018 & 0,034 & 0,011 & 0,074 & 0,120 & 0,003 & 0,008 & 0,004 & 0,010 & 0,020 & 0,006 & 0,036 & 0,020 \\
\hline 2 & 0,007 & 0,017 & 0,008 & 0,260 & 0,068 & 0,016 & 0,075 & 0,180 & 0,002 & 0,007 & 0,004 & 0,024 & 0,012 & 0,005 & 0,012 & 0,040 \\
\hline 3 & 0,018 & 0,017 & 0,027 & 0,031 & 0,040 & 0,031 & 0,086 & 0,180 & 0,006 & 0,009 & 0,014 & 0,031 & 0,016 & 0,006 & 0,009 & 0,030 \\
\hline 4 & 0,018 & 0,019 & 0,061 & 0,043 & 0,097 & 0,069 & 0,089 & 0,180 & 0,010 & 0,015 & 0,008 & 0,041 & 0,034 & 0,012 & 0,019 & 0,040 \\
\hline 5 & 0,026 & 0,019 & 0,030 & 0,048 & 0,075 & 0,081 & 0,102 & 0,240 & 0,007 & 0,012 & 0,009 & 0,044 & 0,027 & 0,014 & 0,016 & 0,120 \\
\hline 6 & 0,062 & 0,035 & 0,068 & 0,164 & 0,260 & 0,201 & 0,485 & 0,640 & 0,036 & 0,027 & 0,058 & 0,140 & 0,118 & 0,101 & 0,282 & 0,130 \\
\hline 7 & 0,072 & 0,040 & 0,055 & 0,092 & 0,228 & 0,202 & 0,285 & 0,480 & 0,024 & 0,021 & 0,035 & 0,070 & 0,119 & 0,094 & 0,105 & 0,120 \\
\hline
\end{tabular}

(Continua...)

\begin{tabular}{cccccccccc}
\hline \begin{tabular}{c} 
(Continuação) \\
\hline $\begin{array}{c}\text { Pontos } \\
\text { de } \\
\text { coleta }\end{array}$
\end{tabular} & Nov/04 & Fev/05 & Mai/05 & Set/05 & Dez/05 & Mar/06 & Jun/06 & Set/06 \\
\hline $\mathbf{1}$ & 0,009 & 0,025 & 0,012 & 0,031 & 0,061 & 0,018 & 0,110 & 0,060 \\
$\mathbf{2}$ & 0,006 & 0,021 & 0,012 & 0,074 & 0,037 & 0,015 & 0,036 & 0,120 \\
$\mathbf{3}$ & 0,018 & 0,028 & 0,043 & 0,095 & 0,049 & 0,018 & 0,027 & 0,090 \\
$\mathbf{4}$ & 0,031 & 0,046 & 0,025 & 0,126 & 0,104 & 0,037 & 0,058 & 0,120 \\
$\mathbf{5}$ & 0,021 & 0,037 & 0,028 & 0,135 & 0,083 & 0,043 & 0,048 & 0,360 \\
$\mathbf{6}$ & 0,110 & 0,083 & 0,178 & 0,429 & 0,362 & 0,309 & 0,862 & 0,390 \\
$\mathbf{7}$ & 0,074 & 0,064 & 0,107 & 0,215 & 0,365 & 0,288 & 0,321 & 0,360 \\
\hline
\end{tabular}


Tabela 52. Valores de sólidos totais (em $\mathrm{mg} \mathrm{L}^{-1}$ ), turbidez (em NTU), e fluoretos (em $\mathrm{mg} \mathrm{L}^{-1}$ ), das amostras de água coletadas no rio Corumbataí.

\begin{tabular}{|c|c|c|c|c|c|c|c|c|c|c|c|c|c|c|c|c|}
\hline \multirow{2}{*}{$\begin{array}{c}\text { Pontos } \\
\text { de } \\
\text { coleta }\end{array}$} & \multicolumn{8}{|c|}{ Sólidos Totais (em $\mathrm{mg} \mathrm{L}^{-1}$ ) } & \multicolumn{8}{|c|}{ Turbidez (NTU) } \\
\hline & Nov/04 & Fev/05 & Mai/05 & Set/05 & Dez/05 & Mar/06 & Jun/06 & Set/06 & Nov/04 & Fev/05 & Mai/05 & Set/05 & Dez/05 & Mar/06 & Jun/06 & Set/06 \\
\hline 1 & 54 & 152 & 68 & 28 & 40 & 17 & 16 & 128 & 27,2 & 18,1 & 29,1 & 15,1 & 8,5 & 15,8 & 8,1 & 9,5 \\
\hline 2 & 101 & 223 & 36 & 14 & 41 & 17 & 26 & 142 & 11,9 & 11,9 & 9,4 & 7,0 & 10,6 & 16,9 & 2,3 & 12,0 \\
\hline 3 & 46 & 206 & 70 & 28 & 43 & 23 & 33 & 142 & 26,4 & 27,7 & 22,4 & 8,0 & 14,1 & 25,1 & 1,6 & 12,0 \\
\hline 4 & 44 & 196 & 57 & 15 & 63 & 42 & 23 & 193 & 27,4 & 37,4 & 24,7 & 33,5 & 44,0 & 45,1 & 1,9 & 20,0 \\
\hline 5 & 39 & 146 & 87 & 35 & 54 & 72 & 32 & 134 & 24,5 & 38,1 & 28,0 & 14,4 & 20,9 & 53,2 & 3,1 & 10,0 \\
\hline 6 & 47 & 312 & 147 & 207 & 96 & 175 & 128 & 466 & 52,1 & 37,4 & 33,0 & 17,4 & 43,7 & 135,0 & 1,8 & 110,0 \\
\hline 7 & 260 & 230 & 148 & 21 & 62 & 185 & 112 & 192 & 114,0 & 42,9 & 34,3 & 16,9 & 50,8 & 166,0 & 4,2 & 8,0 \\
\hline
\end{tabular}

(Continua...)

(Continuação)

\begin{tabular}{ccccccccc}
\hline \multirow{2}{*}{$\begin{array}{c}\text { Pontos de } \\
\text { coleta }\end{array}$} & \multicolumn{7}{c}{ Fluoretos $\left(\mathbf{e m ~} \mathbf{m g ~ L}^{\mathbf{- 1}}\right)$} \\
\cline { 2 - 9 } & Nov/04 & Fev/05 & Mai/05 & Set/05 & Dez/05 & Mar/06 & Jun/06 & Set/06 \\
\hline $\mathbf{1}$ & - & - & 0,06 & 0,15 & 0,08 & 0,14 & 0,13 & 0,38 \\
$\mathbf{2}$ & - & - & 0,05 & 0,14 & 0,08 & 0,11 & 0,12 & 0,37 \\
$\mathbf{3}$ & - & - & 0,05 & 0,14 & 0,08 & 0,10 & 0,13 & 0,40 \\
$\mathbf{4}$ & - & - & 0,05 & 0,15 & 0,08 & 0,10 & 0,12 & 0,43 \\
$\mathbf{5}$ & - & - & 0,05 & 0,15 & 0,08 & 0,10 & 0,12 & 0,36 \\
$\mathbf{6}$ & - & - & 0,11 & 0,25 & 0,15 & 0,15 & 0,16 & 0,47 \\
$\mathbf{7}$ & - & - & 0,12 & 0,26 & 0,14 & 0,17 & 0,17 & 0,45 \\
\hline
\end{tabular}

(-) Determinações não realizadas. 
Tabela 53. Valores de clorofila-a (em $\mu \mathrm{g} \mathrm{L}^{-1}$ ) das amostras de água coletadas no rio Corumbataí.

\begin{tabular}{ccccccccc}
\hline $\begin{array}{c}\text { Pontos de } \\
\text { coleta }\end{array}$ & Nov / 2004 & Fev / 2005 & Mai / 2005 & Set / 2005 & Dez / 2005 & Mar / 2006 & Jun / 2006 & Set / 2006 \\
\hline $\mathbf{1}$ & 3,12 & 1,79 & 4,02 & 11,16 & 1,34 & 3,57 & 7,14 & 2,68 \\
$\mathbf{2}$ & 1,34 & 0,89 & 2,23 & 6,24 & 5,36 & 3,60 & 1,79 & 4,46 \\
$\mathbf{3}$ & 2,68 & 0,45 & 1,79 & 6,69 & 3,57 & 5,00 & 4,46 & 4,02 \\
$\mathbf{4}$ & 5,36 & 1,34 & 3,12 & 12,94 & 7,59 & 3,12 & 6,25 & 6,70 \\
$\mathbf{5}$ & 4,02 & 1,79 & 4,02 & 11,60 & 4,02 & 5,35 & 4,91 & 5,80 \\
$\mathbf{6}$ & 7,14 & 1,67 & 2,68 & 2,67 & 3,57 & 4,46 & 1,34 & 42,41 \\
$\mathbf{7}$ & 3,35 & 1,12 & 6,70 & 10,26 & 2,23 & 5,58 & 0,45 & 7,59 \\
\hline
\end{tabular}


Tabela 54. Dados brutos dos testes de sensibilidade com os quatro organismos-teste utilizados no presente estudo.

\begin{tabular}{|c|c|c|c|c|c|c|}
\hline \multirow{2}{*}{ Ano } & \multirow{2}{*}{ Mês } & \multirow{2}{*}{$\begin{array}{l}\text { C. xanthus } \\
\text { CL }_{50}\end{array}$} & \multirow{2}{*}{$\begin{array}{l}\text { D. magna } \\
\mathrm{CL}_{50}\end{array}$} & \multicolumn{2}{|c|}{ H. attenuata } & \multirow{2}{*}{$\begin{array}{c}P . \text { subcapitata } \\
C_{50}\end{array}$} \\
\hline & & & & $\mathbf{C L}_{50}$ & $\mathrm{CE}_{50}$ & \\
\hline \multirow[t]{9}{*}{2005} & abr & 7,26 & 4,25 & 2,4 & 1,54 & 0,91 \\
\hline & mai & 6,98 & 5,22 & 2,5 & 1,7 & 0,75 \\
\hline & jun & 6,15 & 4,68 & 2,32 & 1,52 & 0,72 \\
\hline & jul & 5,69 & 5,43 & 2,21 & 1,4 & 0,97 \\
\hline & ago & 5,52 & 6,21 & 2,11 & 1,37 & 0,69 \\
\hline & set & 5,3 & 7,21 & 2,13 & 1,44 & 0,84 \\
\hline & out & 4,31 & 6,33 & 2,44 & 1,22 & 0,95 \\
\hline & nov & 5,61 & 5,76 & 2,59 & 1,41 & 0,68 \\
\hline & dez & 6,2 & 5,33 & 1,81 & 1,1 & 0,96 \\
\hline \multirow[t]{12}{*}{2006} & jan & 4,94 & 4,5 & 2,15 & 1,25 & 0,77 \\
\hline & fev & 5,78 & 4,49 & 2,74 & 1,69 & 1,3 \\
\hline & mar & 7,37 & 5,06 & 2,77 & 1,04 & 0,8 \\
\hline & $\mathbf{a b r}$ & 6,97 & 5,3 & 3,06 & 1,4 & 0,69 \\
\hline & mai & 7,79 & 6,33 & 2,98 & 1,58 & 0,81 \\
\hline & jun & 6,91 & 6,33 & 2,58 & 1,37 & 1,35 \\
\hline & jul & 5,81 & 5,1 & 3,06 & 1,59 & 0,8 \\
\hline & ago & 5,95 & 5,61 & 2,31 & 1,01 & 0,9 \\
\hline & set & 4,45 & 6,97 & 2,73 & 1,63 & 0,83 \\
\hline & out & 5,57 & 5,23 & 3,29 & 1,9 & 0,94 \\
\hline & nov & 5,4 & 6,47 & 2,94 & 1,51 & 0,95 \\
\hline & $\operatorname{dez}$ & 4,26 & 5,14 & 2,59 & 1,53 & 0,87 \\
\hline \multirow[t]{6}{*}{2007} & jan & 6,1 & 4,33 & 3,05 & 1,2 & 0,6 \\
\hline & fev & 5,3 & 5,8 & 2,85 & 1,65 & 0,9 \\
\hline & mar & 4,45 & 6,01 & 2,15 & 1,47 & 0,8 \\
\hline & Média: & 5,84 & 5,55 & 2,57 & 1,44 & 0,87 \\
\hline & D.P.: & 0,99 & 0,83 & 0,38 & 0,22 & 0,17 \\
\hline & C.V.(\%): & 17,03 & 15,02 & 14,84 & 15,28 & 20,09 \\
\hline \multicolumn{2}{|c|}{ Média - D.P.: } & 4,84 & 4,72 & 2,19 & 1,22 & 0,69 \\
\hline \multicolumn{2}{|c|}{ Média + D.P.: } & 6,83 & 6,39 & 2,96 & 1,66 & 1,04 \\
\hline \multicolumn{2}{|c|}{ Média - 2.D.P.: } & 3,86 & 3,89 & 1,81 & 1,00 & 0,53 \\
\hline \multicolumn{2}{|c|}{ Média + 2.D.P.: } & 7,82 & 7,21 & 3,33 & 1,88 & 1,21 \\
\hline
\end{tabular}


Tabela 55. Dados utilizados para análise estatística, juntamente com resultados de toxicidade de amostras de água. Dados de herbicidas $\left(\mu \mathrm{g} \mathrm{L}^{-1}\right)$ de Monteiro et al. (2008). Não foram determinados herbicidas nos Pontos 2 e 3 do presente estudo.

\begin{tabular}{|c|c|c|c|c|c|c|c|c|c|c|c|c|}
\hline \multirow[b]{2}{*}{$\begin{array}{c}\text { Pontos de } \\
\text { coleta }\end{array}$} & \multicolumn{12}{|c|}{ NOVEMBRO / 2004} \\
\hline & Glifosato & AMPA & Ametrina & Atrazina & Simazina & Metribuzin & Tebuthiuron & Clomazona & Picloram & Propanil & Hexazinona & Sulfentrazona \\
\hline 1 & 0,00 & 0,000 & 2,900 & 2,700 & 0,600 & 0,000 & 0,000 & 0,400 & 0,000 & 0,000 & 0,000 & 0,000 \\
\hline 4 & 0,00 & 0,000 & 1,900 & 2,200 & 0,500 & 0,000 & 0,000 & 0,400 & 0,000 & 0,000 & 0,000 & 0,000 \\
\hline 5 & 0,02 & 0,000 & 0,004 & 0,002 & 0,000 & 0,000 & 0,000 & 0,000 & 0,000 & 0,000 & 0,000 & 0,000 \\
\hline 6 & 0,02 & 0,000 & 0,700 & 0,600 & 0,005 & 0,000 & 0,000 & 0,015 & 0,000 & 0,000 & 0,000 & 0,000 \\
\hline \multirow[t]{2}{*}{7} & 0,02 & 0,000 & 0,800 & 0,700 & 0,005 & 0,000 & 0,000 & 0,015 & 0,000 & 0,000 & 0,000 & 0,000 \\
\hline & \multicolumn{12}{|c|}{ MAIO / 2005} \\
\hline $\begin{array}{l}\text { Pontos de } \\
\text { coleta }\end{array}$ & Glifosato & AMPA & Ametrina & Atrazina & Simazina & Metribuzin & Tebuthiuron & Clomazona & Picloram & Propanil & Hexazinona & Sulfentrazona \\
\hline 1 & 0,020 & 0,000 & 5,400 & 2,800 & 0,400 & 0,100 & 0,020 & 0,600 & 0,060 & 0,015 & 0,010 & 0,000 \\
\hline 4 & 0,000 & 0,000 & 4,300 & 2,100 & 0,300 & 0,045 & 0,005 & 0,400 & 0,100 & 0,015 & 0,000 & 0,000 \\
\hline 5 & 0,000 & 0,000 & 15,400 & 2,400 & 0,200 & 0,100 & 0,000 & 0,700 & 0,600 & 0,015 & 0,000 & 0,000 \\
\hline 6 & 0,080 & 0,100 & 4,300 & 1,900 & 2,100 & 0,100 & 0,005 & 0,500 & 0,000 & 0,015 & 0,010 & 0,000 \\
\hline 7 & \multicolumn{12}{|c|}{ SETEMBRO / 2005} \\
\hline $\begin{array}{c}\text { Pontos de } \\
\text { coleta }\end{array}$ & Glifosato & AMPA & Ametrina & Atrazina & Simazina & Metribuzin & Tebuthiuron & Clomazona & Picloram & Propanil & Hexazinona & Sulfentrazona \\
\hline 1 & 0,020 & 0,000 & 3,900 & 1,600 & 0,200 & 0,000 & 0,005 & 0,200 & 0,000 & 0,050 & 0,000 & 0,000 \\
\hline 4 & 0,000 & 0,000 & 6,900 & 1,400 & 0,200 & 0,000 & 0,060 & 0,300 & 0,000 & 0,000 & 0,000 & 0,000 \\
\hline 5 & 0,000 & 0,000 & 4,700 & 0,900 & 0,100 & 0,000 & 0,010 & 0,200 & 0,020 & 0,015 & 0,000 & 0,000 \\
\hline 6 & 0,050 & 0,160 & 16,000 & 3,600 & 0,400 & 0,200 & 0,320 & 0,500 & 0,700 & 0,200 & 0,000 & 0,000 \\
\hline 7 & 0,020 & 0,100 & 22,200 & 2,700 & 0,300 & 0,000 & 0,040 & 0,400 & 1,100 & 0,100 & 0,000 & 0,000 \\
\hline
\end{tabular}

(Continua...) 


\section{DEZEMBRO / 2005}

\begin{tabular}{|c|c|c|c|c|c|c|c|c|c|c|c|c|}
\hline $\begin{array}{l}\text { Pontos de } \\
\text { coleta }\end{array}$ & Glifosato & AMPA & Ametrina & Atrazina & Simazina & Metribuzin & Tebuthiuron & Clomazona & Picloram & Propanil & Hexazinona & Sulfentrazona \\
\hline 1 & 0,020 & 0,000 & 6,900 & 3,200 & 0,300 & 0,000 & 0,000 & 0,500 & 0,200 & 0,070 & 0,000 & 0,000 \\
\hline 4 & 0,020 & 0,000 & 5,300 & 1,700 & 0,300 & 0,000 & 0,020 & 0,400 & 0,100 & 0,060 & 0,000 & 0,000 \\
\hline 5 & 0,020 & 0,020 & 5,100 & 2,200 & 0,200 & 0,000 & 0,020 & 0,300 & 0,200 & 0,050 & 0,000 & 0,000 \\
\hline 6 & 0,070 & 0,090 & 6,000 & 1,700 & 0,200 & 0,000 & 0,040 & 0,200 & 1,300 & 0,015 & 0,050 & 0,000 \\
\hline 7 & 0,020 & 0,070 & 12,600 & 3,900 & 0,500 & 0,000 & 0,040 & 0,500 & 1,400 & 0,100 & 0,010 & 0,100 \\
\hline
\end{tabular}

Tabela 56. Dados utilizados para análise estatística, juntamente com resultados de toxicidade, do sedimento, coleta de Novembro/2004. Dados de herbicidas de Armas (2006) e metais de Zambetta (2006).

\begin{tabular}{|c|c|c|c|c|c|c|c|c|c|c|c|c|c|c|}
\hline \multirow{2}{*}{ Pontos de coleta } & \multirow{2}{*}{$\begin{array}{l}\text { Glifosato } \\
\left(\mathrm{mg} \mathrm{Kg}^{-1}\right) \\
\end{array}$} & \multirow{2}{*}{$\begin{array}{l}\text { Ametrina } \\
\left(\mathrm{mg} \mathrm{Kg}^{-1}\right)\end{array}$} & \multicolumn{9}{|c|}{ Metais (mg Kg ${ }^{-1}$ ) } & \multicolumn{3}{|c|}{ Variáveis físico-químicas } \\
\hline & & & Al & Cd & $\mathrm{Cr}$ & $\mathbf{C u}$ & $\mathbf{F e}$ & Mn & $\mathrm{Ni}$ & $\mathbf{P b}$ & $\mathbf{S r}$ & pH & O.D. & Cond. \\
\hline 1 & $0,025^{*}$ & 0,00 & 142,5 & 0,122 & 0,276 & 0,236 & 1810,933 & 40,813 & 0,016 & 1,487 & 0,504 & 6,86 & 9,50 & 21,1 \\
\hline 2 & n.d. & n.d. & 263,7 & 0,069 & 0,340 & 0,399 & 855,210 & 21,139 & 0,097 & 1,330 & 0,931 & 7,05 & 8,00 & 25,1 \\
\hline 3 & n.d. & n.d. & 153,4 & 0,057 & 0,272 & 0,200 & 824,610 & 33,014 & 0,016 & 0,947 & 0,619 & 6,97 & 5,40 & 27,2 \\
\hline 4 & 0,00 & 0,00 & 259,2 & 0,077 & 0,298 & 0,325 & 940,737 & 26,119 & 0,046 & 1,801 & 1,003 & 7,00 & 5,19 & 35,1 \\
\hline 5 & 0,00 & 0,00 & 257,5 & 0,060 & 0,282 & 0,355 & 980,480 & 48,278 & 0,054 & 1,072 & 1,075 & 7,02 & 5,47 & 39,5 \\
\hline 6 & $0,025^{*}$ & 0,00 & 252,7 & 0,059 & 1,256 & 0,697 & 968,567 & 15,829 & 0,160 & 1,493 & 1,048 & 7,03 & 4,80 & 136,9 \\
\hline 7 & $0,025^{*}$ & 0,01 & 3492,2 & 0,778 & 5,171 & 25,019 & 12943 & 681,150 & 6,509 & 13,441 & 6,255 & 7,00 & 4,06 & 118,1 \\
\hline
\end{tabular}

* Metade do limite de quantificação; (n.d.): valores não determinados. 
Tabela 57. Dados utilizados para análise estatística, juntamente com resultados de toxicidade, do sedimento, coleta de Fevereiro/2005. Dados de herbicidas de Armas (2006) e metais de Zambetta (2006).

\begin{tabular}{|c|c|c|c|c|c|c|c|c|c|c|c|c|c|c|}
\hline \multirow{2}{*}{ Pontos de coleta } & \multirow{2}{*}{$\begin{array}{l}\text { Glifosato } \\
\left(\mathrm{mg} \mathrm{Kg}^{-1}\right) \\
\end{array}$} & \multirow{2}{*}{$\begin{array}{l}\text { Ametrina } \\
\left(\mathrm{mg} \mathrm{Kg}^{-1}\right)\end{array}$} & \multicolumn{9}{|c|}{ Metais (mg Kg ${ }^{-1}$ ) } & \multicolumn{3}{|c|}{ Variáveis físico-químicas } \\
\hline & & & Al & Cd & $\mathrm{Cr}$ & $\mathrm{Cu}$ & $\mathbf{F e}$ & Mn & $\mathrm{Ni}$ & $\mathbf{P b}$ & $\mathbf{S r}$ & pH & O.D. & Cond. \\
\hline 1 & 0,00 & 0,00 & 118,571 & 0,089 & 0,295 & 0,139 & 1597,97 & 23,569 & 0,048 & 0,455 & 0,656 & 6,87 & 8,36 & 33,5 \\
\hline 2 & n.d. & n.d. & 188,063 & 0,040 & 0,252 & 0,283 & 796,803 & 24,699 & 0,022 & 0,663 & 0,717 & 7,13 & 8,35 & 38,9 \\
\hline 3 & n.d. & n.d. & 170,770 & 0,030 & 0,231 & 0,353 & 570,323 & 26,24 & 0,011 & 0,398 & 0,762 & 6,96 & 8,20 & 35,0 \\
\hline 4 & 0,00 & 0,00 & 140,040 & 0,027 & 0,186 & 0,182 & 517,750 & 30,923 & 0,008 & 0,396 & 0,761 & 6,96 & 7,63 & 41,8 \\
\hline 5 & 0,00 & 0,00 & 155,610 & 0,036 & 0,175 & 0,174 & 657,813 & 74,751 & 0,031 & 0,436 & 0,874 & 6,92 & 7,26 & 49,3 \\
\hline 6 & 0,00 & 0,00 & 370,150 & 0,054 & 0,834 & 1,066 & 1010,600 & 29,291 & 0,191 & 1,792 & 1,484 & 7,05 & 7,10 & 330,0 \\
\hline 7 & 0,00 & 0,00 & 398,677 & 0,058 & 0,526 & 1,780 & 932,760 & 34,432 & 0,181 & 1,766 & 2,033 & 7,28 & 7,01 & 148,0 \\
\hline
\end{tabular}

(n.d.): valores não determinados. 
Tabela 58. Valores de CTM (Concentração Tóxica Microbiana) dos quatro nanomateriais testados com o MARA Test.

\begin{tabular}{|c|c|c|c|c|c|c|c|c|c|c|c|c|}
\hline \multirow{2}{*}{ Nanomateriais } & \multicolumn{11}{|c|}{ CTM $\left(\mathrm{mg} \mathrm{L}^{-1}\right)$ para cada linhagem (1-11) do MARA Test } & \multirow{2}{*}{ CTM Médio } \\
\hline & 1 & 2 & 3 & 4 & 5 & 6 & 7 & 8 & 9 & 10 & 11 & \\
\hline $\mathrm{SmO}$ & 7 & 43 & 243 & 243 & 189 & 243 & 91 & 17 & 243 & 225 & 34 & 90 \\
\hline $\mathrm{CuZnFeO}$ & 120 & 120 & 120 & 120 & 120 & 117 & 120 & 69 & 117 & 56 & 120 & 114 \\
\hline ErO & 58 & 70,9 & 70,9 & 70,9 & 70,9 & 70,9 & 70,9 & 58 & 70,9 & 40 & 70,9 & 69 \\
\hline $\mathrm{HoO}$ & 16 & 83,2 & 83,2 & 83,2 & 65 & 75 & 83,2 & 84 & 83,2 & 45 & 57 & 67 \\
\hline
\end{tabular}

(a) CTM Médio das onze linhagens calculado pelo software MARA. 